Ecstatic Encounters 


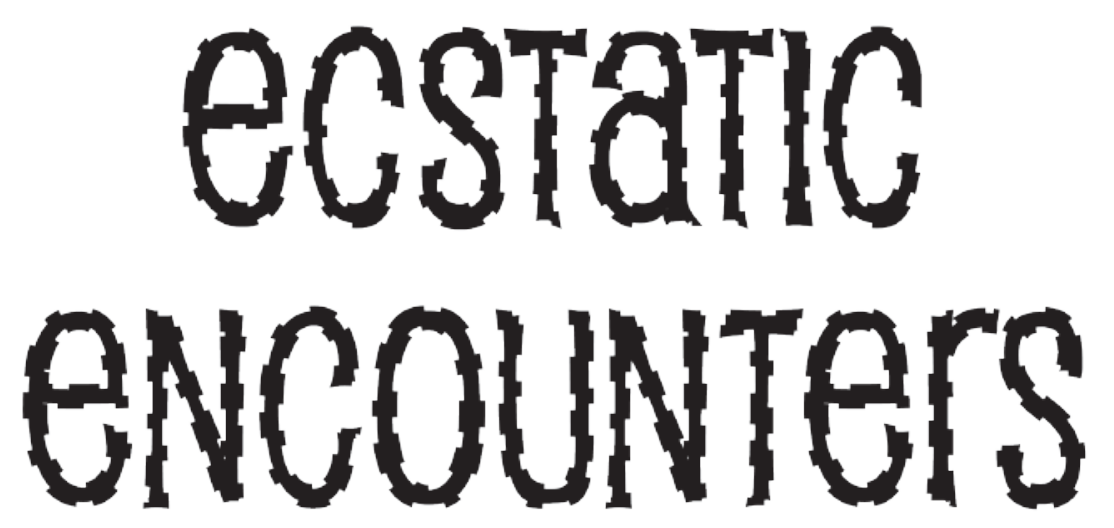

\title{
Bahian Candomblé and the Quest for the Really Real
}

\author{
Mattijs van de Port
}

AMSTERDAM UNIVERSITY PRESS 
Layout: Maedium, Utrecht

ISBN $\quad 978908964298$ I

e-ISBN 97890485 I 3963

NUR 761

(C) Mattijs van de Port / Amsterdam University Press, Amsterdam 20II

All rights reserved. Without limiting the rights under copyright reserved above, no part of this book may be reproduced, stored in or introduced into a retrieval system, or transmitted, in any form or by any means (electronic, mechanical, photocopying, recording or otherwise) without the written permission of both the copyright owner and the author of the book. 


\section{Contents}

PREFACE / 7

INTROduction: Avenida Oceânica / 11

Candomblé, mystery and the-rest-of-what-is in processes of world-making

1 On Immersion / 47

Academics and the seductions of a baroque society

2 Mysteries are Invisible / 69

Understanding images in the Bahia of

Dr Raimundo Nina Rodrigues

3 Re-encoding the Primitive / 99

Surrealist appreciations of Candomblé in

a violence-ridden world

4 Abstracting Candomblé / 127

Defining the 'public' and the 'particular' dimensions

of a spirit possession cult

5 Allegorical Worlds / 159

Baroque aesthetics and the notion of an 'absent truth'

6 Bafflement Politics / 183

Possessions, apparitions and the really real of

Candomblés miracle productions 
7 The Permeable Boundary / 215

Media imaginaries in Candomblés public

performance of authenticity

CONCLUSIONS Cracks in the Wall / 249

Invocations of the-rest-of-what-is in the anthropological study of world-making

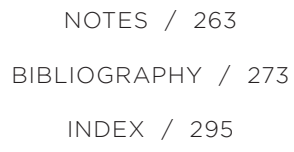




\section{Preface}

Oh! Bahia da magia, dos feitiços e da fé. Bahia que tem tantas igrejas,

e tanto Candomblé.

Vem, vem, vem, em busca da Bahia!

Cidade da tentação,

onde meu feitiço impera.

Vem, se me trazes o teu coração!

Vem, a Bahia te espera, Bahia, Bahia!
Oh! Bahia of magic, fetishes and faith.

Bahia that has so many churches, and so much Candomblé.

Come, come, come, in search of Bahia! City of temptation, where my magic spell reigns.

Come, if you bring me your heart!

Come, Bahia awaits you, Bahia, Bahia! ${ }^{1}$

This study will take you to Salvador da Bahia, Brazil, a palm-fringed place that likes to tell the world that it is the next best thing to paradise - and puts on a rather convincing performance of the paradisiacal (until, of course, it starts to rain). The roots of this project, however, stretch back to another time and place: the war-ridden Serbia of the early I990s, where I conducted my first long-term anthropological fieldwork, and where I had to face the fact that people are not only shocked by the horrific spectacle of an all-out war, but seduced by it as well. In the book that I wrote about those dark and turbulent times, I found myself struggling with what I now recognize to be the great themes of Lacanian thought: the Serbian townsmen that figure in Gypsies, Wars and Other Instances of the Wild (van de Port I998) had sought refuge from their traumatic experiences in World War In in 'the symbolic order' of Titoist Yugoslavia, which had provided them with a master-narrative to make sense of their past, present and future. This symbolic order, however, proved incapable to stand up to the forces of the Real. Faced with their world falling apart, my Serbian interlocutors resorted to fantasy: the kind of daydreaming that screens off the rents and fissures in one's narration of the world and is thus capable to restore 
the symbolic order. Yet they also gave themselves over to the debauchery of their Gypsy bars and to the ecstasies of war, in a desperate attempt to access a 'really real' beyond all narration and daydreaming.

I have never been back to Serbia - but I still listen to the music and hum those deeply melancholic songs. Moreover, the research themes that Serbia held in store for me have remained at the top of my research agenda. The confrontation with people being 'chased out of the stories they lived by' was such a powerful, painful and overwhelming experience that two decades later I still find most of my research questions 'Serbianized'. Wherever my research activities have taken me - to the Dutch underworld (van de Port 200I), to the Lisbon fado (van de Port 1999) or to the Candomblé temples in Brazil - I ended up studying the same issue over and over again: what happens when people have to face up to the fact that their understandings of what is 'real' are dependent on a particular, and ultimately contingent narration of what life is like? And how do they, once they are lucid about the contingency of their reality definitions, produce a sense of the really real?

So if my decision to accept the invitation, in 200I, to study Bahian Candomblé, in the framework of Birgit Meyer's PIONEer project 'Modern Mass Media, Religion and the Imagination of Communities' felt like a radical switch in my career; was indeed grabbed as an opportunity to make a radical switch; and in many ways was a radical switch: it also turned out to be a continuation of the same questions about people's quest for the 'really real'.

This quest could not have been realized, had it not been for the generous support of two organizations: the Netherlands Foundation of Scientific Research (NWO) and the Amsterdam School for Social Science Research (ASSR, today: AISSR) of the University of Amsterdam. I would also like to thank the vu Institute for the Study of Religion, Culture and Society (VISOR) for having made possible the full-color photographs in this book.

In Brazil, I would like to thank all the people who have been such loving and hospitable company, and who - in one way or the other - have made Brazil, more in particular Bahia, a veritable 'second home'. In alphabetical order: Maria Paula Adinolfi; Susana Barbosa; Patrícia Birman; Marcelo Sousa Brito; Liza Earl Castillo; Dona Ceci; Edson Dalmonte; Marcos Dias; Luciana Duccini; Ana Dumas; Xandra Dumas; Ariana Dumas; Augusto Fernandes; Deise Cabral Guex; Ana Jaleco; Fabio Lima; Pai Luís; Carly Machado; Edward MacGray; Gil Maciel; Stéphane Malysse; William Marques; Adilson de Melo; Eloisa Brantes Mendes; Pai Milton; Eliane 
Pinha Moura; Mario Cravo Neto; Marcos Nogueira; Zé Carlos Oliveira; Luís Nicolau Parés; Paulinha Prado; Robério Sampaio; Lucas Sanper; Roger Sansi-Roca; Djalma Santana; Jocélio Teles dos Santos; André Werneck d'Andrade Bakker; Vagner Gonçalves da Silva; Jerome Souty; Eledir Victor Sobrinho; Mario Vieira; Carlo Wallnöfer; Jean Wyllys and Silvia de Zordo. On every arrival in Salvador, I am sadly aware that some of my friends are no longer around - Raimundo Nonato da Silva Fonseca, Cravina Cravo and most of all, Joel Santos Lobo. May you have found peace on the other side.

My special thanks go to Victor Silva Souza and his family: Rilza, Ana Leia, João, Relane, Gisele, and my afiliada Eliana. Without Victor this book would not have been what it turned out to be: his impatience with starryeyed paradise seekers, his wry comments on the ways of his country and countrymen (and their anthropologists), his resilience in the face of life's adversities and his unobtrusive wisdom have been - and continue to be a source of inspiration.

Beyond Brazil, I am indebted to many people who generously shared their thoughts (and doubts) about this project; who inspired me to pursue my writing; or had the good sense to drag me away from my office desk from time to time: Zé d'Abreu, Stanley Arnhem, Koštana Banović, Niko Besnier, Maarten Boekelo, David Chidester, Freek Colombijn, Jill CrosbyFlanders, André Droogers, Yolanda van Ede, Alex Edmonds, Patrick Eisenlohr, my family, João Paulo Firmino, Peter Geschiere, Francio Guadeloupe, Thomas Blom Hansen, Charles Hirschkind, Lotte Hoek, Jan Hooiveld, Stephan Hughes, José Koomen, Suzanne Kuik, Erle de Lanooi, Brian Larkin, Birgit Meyer, Annemarie Mol, Pál Nyiri, Martijn Oosterbaan, Marijke Pfeiffer, Paul van der Plaat, Joost van de Port, Pepijn van de Port, Graeme Reid, Johan Roeland, Joost Roth, Rafael Sanchez, Willem Schinkel, Alexandra Schüssler, Irene Stengs, Alex Strating, Jeremy Stolow, my students, Marjo de Theije, Bonno Thoden van Velzen, Thomas Vandamme, Milena Veenis, Oskar Verkaaik, Jojada Verrips, Nico Vink, David Weissman, Marleen de Witte, Jarret Zigon.

I thank my parents, Walter van de Port and Corine Houx-Smeets, for having taught me to be open to the beauty of the world. There is no greater gift. I dedicate this book to them. 


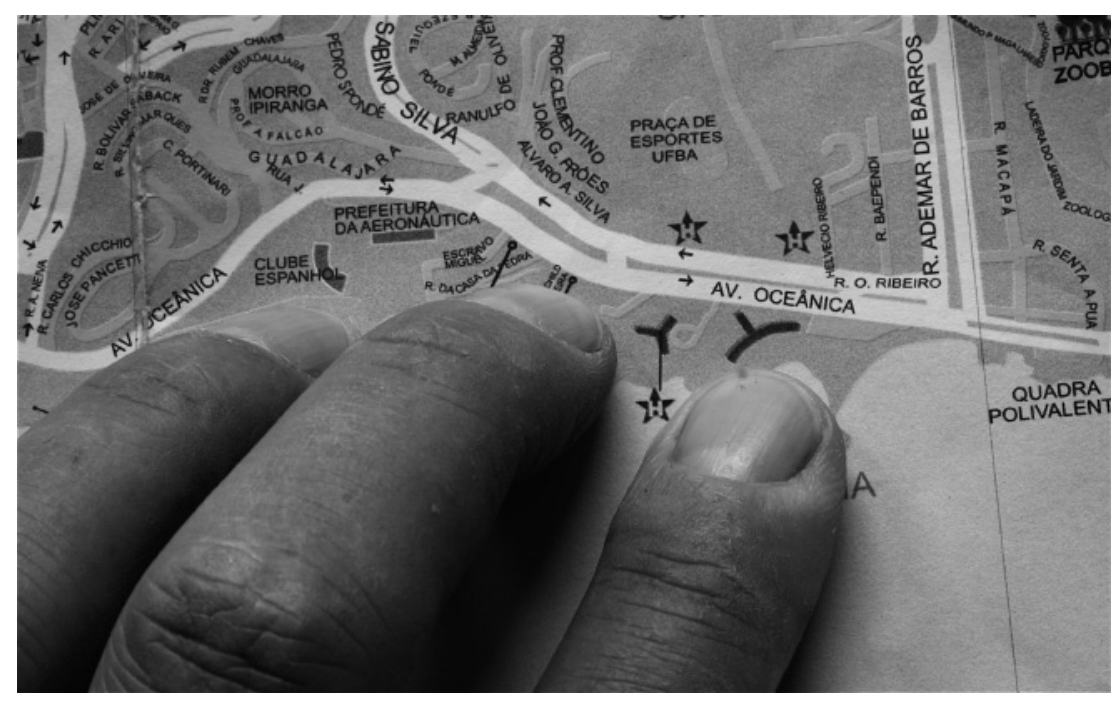

Figure 1 Salvador da Bahia de Todos os Santos 


\title{
Introduction
}

\section{aveNIDa oceânICa}

\author{
Candomblé, mystery and the-rest-of-what-is \\ in processes of world-making
}

The field notes I made on 4 February 2008, were brief. 'Insist on the thought,' it says (underlined like that), 'that this is what it is all about'.

This energy on the street. This sparking electricity. This ecstatic frenzy of thousands of scantily clad bodies, packed together on the Avenida Oceânica, jumping to the rhythm of Daniela Mercury, sweating from top to bottom, stretching their arms towards the goddess of Axé Music, stretching, stretching, jumping, jumping, singing their heads off in massive unison - Zum-zum-zumzumbaba. Zumbaba. Zumbaba. Really, that's all there is to say.

Bahian carnival is hardly a time to write extensive field notes. Yet I vividly recall the urge I had felt that night to write these few lines. Three o'clock in the morning or thereabouts. Slightly tipsy from a beer too many. Yet not so much as to refrain from waking my laptop from its slumber and sending this commandment to a future 'me': the sober 'me' that sits behind a desk, caught up in writing and theorizing, and that is no longer satiated with a magic just experienced. The 'me' who would probably no longer be willing to take that moment as wholeheartedly, as totalizing and 
world-engulfing as it had been then and there, on the Avenida Oceânica. The 'me' who would allow himself to be a traitor to the revelation of a moment that had shown 'what it is all about'.

The nocturnal memo from 4 February leaves me with two questions. The first one asks what had been so perfectly summarized in that ecstatic moment. What was the 'it' in the exclamation that 'this is what it is all about'? Candomblé, the spirit possession cult that $\mathrm{I}$ had been studying for years? Bahia? The secret of life itself? God? An expanded 'me', encompassing the world? The second question concerns this instruction to my sober me: why this concern that the revelation on Avenida Oceânica would not make it through the night? What sudden comprehension of the conventional practices of anthropological text-making - the unspoken rules as to what is of first, second and third interest in our attempts to make sense of social and cultural worlds - had bubbled up at three o'clock in the morning?

In a way, these two issues are at the heart of the essays that make up this book. They are about the revelations that come to you, engulf you, unsolicited, unpredictable, as an immediate, fully embodied knowing. And they discuss (as well as exemplify) what happens to these revelations when they come to be expressed in one or another form of mediation.

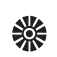

I am not sure that members of the Candomble community would nod their heads in appreciation about a study of their religion starting like this. But then again, many people from Candomblé are not going to like this study no matter how it would start. Salvador, capital of the state of Bahia, is full of anthropologists studying Candomblé, and has been a popular anthropology destination for a long time. These anthropologists are but the most stubborn and pushy forefront of a much larger contingent of curious outsiders knocking on the doors of the terreiros (temple-compounds) wanting to know more: writers, journalists, artists, historians, New Age travelers, poets, filmmakers, philosophers, composers. To different extents, they have all studied and absorbed the stories of the orixás, the ancient African divinities worshipped in Candomblé; they have all sat through the lengthy night-time ceremonies during which the orixás take possession of the bodies of their mediums so as to dance away the night in splendid baroque costumes; and they have all processed such information and experiences in one form or another - books, articles, films, photographs, sound recordings, artworks, musical compositions, choreogra- 
phies, theatrical performances. After the more than hundred years that Candomblé has been an object of public interest, it would take a bulky archive to store all the texts, images and recordings that have appeared on the cult.

The Candomblé community appears to be deeply ambivalent about all the attention bestowed upon them. Bearing a long history of persecution and humiliations in mind, they revel in all the positive interest, the prestige that it brings, and the politics that it enables. Yet they are also deeply worried about the possible consequences of being on so many different agendas. For it is due to the overwhelming interest in Candomble that the cult has become the object of ongoing literary interpretation, artistic elaboration, philosophical speculation, New Age meditation and anthropological explanation (not to mention commercial and political exploitation). In other words, ever more people are involved in defining Candomblé, producing statements as to what it is, what it could be, or should be, or was and might become again. In the perception of the priesthood, these new voices, many of them authoritative in their own way, pose a serious threat to what the people from Candomblé call the cult's 'deep knowledge': the secrets and mysteries that are at the heart of the cult.

In a booklet called Meu Tempo é Agora ('My Time is Now') a famous Candomblé priestess called Mãe Stella wrote:

Our religion is so strong and so mysterious that it raises the curiosity of those who are outside. They seem to think that a host of curious questions, sometimes even impertinent ones, is synonymous with knowledge. But I tell you; those ways are dangerous, leading into veritable labyrinths, and with dire results. I therefore advise visitors and friends of the Axé: don't ask questions, just observe! (Santos I993: 88)²

I will return to Mãe Stella and her instructions to outsiders further on in this book. Here it suffices to note that the polite request to 'please, shut up!' is expressive of a general reluctance among the Candomblé priesthood to accommodate the outsiders' search for information. When priests discuss their conception of religious learning, they are prone to insist that words and images will never capture the 'deep knowledge' that is at the heart of their ancient traditions and mysteries. To reach a true understanding of their religion, so they keep saying, there is no other way than the lengthy process of initiation. And in the understandings of the Candomble community, initiation implies that knowledge is not to be sought. Knowledge - 'deep knowledge', that is - cannot be extracted from the world in the 
scholarly fashion: through cleverly designed conquest and the relentless battles, which earn one the judicium 'he has mastered the field'. 'Knowledge comes to you with time,' is how one initiate phrased it succinctly: by submitting yourself to the long yearly cycles of rituals; by performing your obligations towards the orixás; by obeying the authoritative voice of the elders, the guardians of the tradition; by observing the many do's \& don'ts of terreiro life; by opening up the body for divine possession; and last but not least, by not asking questions.

'Of course. I'm not going to deny it,' an initiate confessed during a conversation. 'I have gone to the library to read the ethnography on the rituals. My mãe-de-santo (priestess) didn't want me to do it, but I did it anyway. And you know what? She was right. What I read was irrelevant. There is no way to queimar etapas (skip stages, i.e. to know things before you are ready to know them).'

The centrality of time and performative bodily action in Candomblé conceptions of religious learning makes 'inarticulability' the very essence of Candomblés deep knowledge. Candomblé priests maintain that there is an unbridgeable gap between the anthropologist saying 'the initiation cycle lasts seven long years' (a phrase of seven words, which produce their meaning in a split second) and the initiates' experience of living those seven long years of energies given and energies received. What is more, they want the world to know that this gap marks a watershed between two ways of acquiring knowledge: the way of the words, leading into 'veritable labyrinths', and the way of initiation, leading to 'true knowledge'. To push that point in the public sphere, the priests are engaged in a public (and at times rather noisy) performance of not-speaking and secrecy, punctuated with demonstrations of extraordinary phenomena such as possession, clairvoyance and healing. ${ }^{3}$

The conceptualization of 'deep knowledge' as being 'beyond words' and thus incompatible with learning-by-asking-questions sits uneasily with the great majority of curious outsiders 'wanting to know about Candomblé. They do not have seven years at their disposal to be initiated. They have deadlines to meet, projects to finish, careers to pursue, and they therefore do not easily take the priests' No! for an answer. In addition, these outsiders also do not want to be left thinking that all they can access is the surface: that their inquiries will never lead them beyond 'the superficial things' (as pai-de-santo Luis indicated when, at the beginning of an interview, I told him that my research focused on the encounters between people from Candomblé and outsiders to the cult: 'Ah, I see! You study the superficial things!'). Few researchers are willing to accept $a$ priori that the 
heart of the matter under inquiry is not available. And so they continue trying to capture 'the real of Candomble' in their work - with or without the participation of Candomblé priests.

The announcement of an article on Candomble on the cover of a popular Brazilian magazine for inquisitive teenagers called Superinteressante! is a fine example of what the cult's performance of not-speaking and secrecy induces in the minds of curious outsiders. It reads 'CANDOMBLÉ. AN X-RAY PHOTOGRAPH OF A RELIGION'. This incantation of the power of modern technology to disclose instantaneously (one click of the camera!) all that there is to know about what lies hidden in the muted, shadowy realm of the terreiro - or indeed: in the interior of the cultist's body where 'deep knowledge' has been stored away - perfectly signals what Candomblés performance of secrecy provokes: an ever more zealous desire to penetrate those realms of the occult with all possible means (cf. Bellman I984; Johnson 2002). Hence, the hyperproduction of texts on Candomblé. And hence the enormous proliferation of Candomblé imagery.

Clearly, this study too is driven by the desire to capture the 'real of Candomblé in a text. I have, however, instructed myself to remain loyal to that epiphany on Avenida Oceânica. I will not blind myself for that unspeakable revelation that came after seven long years of energies given and energies received - unsought and unexpected; a knowing incarcerated in the experience itself, unavailable for explanation or representation; a fleeting moment where 'it' was all perfectly clear, fully grasped in the meaninglessness of those syllables - zum-zum-zum-zum-zumbaba.

\section{滵}

It is exactly because of its unavailability to full scientific explanation that Candomblé is such an intriguing object for investigation. Indeed, if I were to answer the legitimate question "why should anyone want to read a book about Candomblé?' I would point out Candomblés insistence that it offers a different road to knowledge, one that is incommensurable with the discursive practices that rein the social sciences. For Candomblés insistence that the mysteries of the world will not give in to our relentless questioning makes total sense to me. What is more, statements like those of Mãe Stella, saying that 'asking questions should not be equated with acquiring knowledge', strongly resonate with my increasing discontent about an academy of science where logocentrism reins unchallenged, and where all forces work together to keep up the fiction that a scientific discourse offers the privileged forms to represent and come to know reality. 
Candomblé, as I will show in this book, has a powerful repertoire of performances to bring home to us - social scientists, academic researchers, heirs to the Age of Reason, subscribers to a secular worldview - that the world is not, and will never be, transparent to us. Intellectual reasoning does not provide us with all the answers. We, too, are subject to forces beyond our own comprehension. And sometimes, on some Avenida Oceânica or other, it may happen that we end up with answers - true answers, satisfactory answers, fulfilling answers - that we do not understand (even though they 'say it all'), for the simple reason that these answers refuse to come out of the here-and-now in which they occurred, and defy all further abstraction.

Of course, I can (and will) make the argument that Candomblés stubborn insistence that the ways of the scholar do not lead to 'deep knowledge' is part of the cult's politics of authentication. When priests stress the inarticulability of 'deep knowledge', or somewhat haughtily classify all anthropology (and other interpretative frameworks within which their creed has been cast) as belonging to the realm of 'superficial things', they seek to assert the authority of the priestly voice in Bahia's public sphere. When priests proclaim that 'only initiation will do to understand the mysteries', they are making public their claim that they, and they alone, are the 'true voice' of Candomblé. Yet I will also argue that the validity of this argument cannot undo the challenge that the notion of 'deep knowledge' presents to the conventions of academic world-making.

The particular understanding in Candomblé circles as to how 'deep knowledge' is acquired shows a lack in our academic attempts to understand the-ways-of-the-world: the reluctance (or stubborn refusal) to grant the infinity of our not-knowing a role in our portrayals of the world. Let me put it this way: academic research practices instruct you to access the world by being its author. You do not just go out into the world to meet up with whatever comes. You first study the debates in your field, explore the various theoretical positions concerning your subject, and formulate an idea as to what the urgent questions are. It is only then that you make your moves. In other words, you first make a picture of the world and then you step inside its frame. This particular form of world-making produces all kinds of pleasurable experiences: it gives a structure to hold on to, a sensation of being in control, a guideline of what to look for, a fixed and manageable horizon. Yet these advantages come at a cost, for within this mode of approaching the world it is hard to avoid the sensation that all you will ever be is a spectator to a world of your own making. The real 
world - or rather, that which, following William James, might be called the 'plenum of existence' - remains somehow out of reach.

Candomblé proposes a radically different mode of world-making. Priests prohibit initiates to 'design' the world they are about to enter beforehand (by studying the anthropological corpus on Candomblé, for instance). They instruct initiates to submit themselves to ill-understood and unexplained rules and procedures without asking questions. They thus seek to 'block' the very forms of world-making that rein academia. If the academy spurs you on to act on the world in search of knowledge, Candomblé aims at 'setting the world in motion' so as to make it act on you. In other words, in Candomble the idea is not to be the author of the world, but to let yourself be 'written' by the world. Spirit possession, I would say, is a clear example of this mode: allowing the body to be invaded by an Other is allowing the self to be 'written' by an agent that comes from beyond the world of one's own making. The great significance attributed to dreams and visions, or the attribution of sacred qualities to objects or events that crossed one's path 'spontaneously' and 'unpremeditated', are other examples of how the people from Candomble script the world as an agent that brings them knowledge (cf. van de Port 2005b; Sansi-Roca 2005).

Candomble's disregard for the human capacity to 'design the world', and its search for ways to block conventional modes of meaning-production can be found in the many religious practices that have been grouped under the label 'mysticism'. Bringing the body to a state of exhaustion; working the body up to a state of frenzy; subjecting the body to repetitive movements or repetitive chanting; gazing into a flame so as to block out all further stimuli; inflicting pain on oneself so as to 'unmake the world of meaning' (Scarry 1985); all these 'mystical' techniques seek to call to a halt the authoring-of-the-world in the expectation that it is only then that the 'totality of the world' might come to speak (and not the pre-selection made in the cultural design). As Katherine Pratt Ewing argued in her study on Sufism,

Access to truth requires an irruption, a disruption of the imaginary, of the ideologies, including the ideology of the 'self' that place a screen or 'veil' between truth and us. Without such an irruption, we are caught in a historically contingent discursive formation (Ewing I997: 259).

For me, the paradigmatic case of these attempts to 'checkmate' discursive forms of meaning-production, thus to open roads to other modes of 
knowing, is glossolalia, the 'speaking in tongues' of various charismatic religions - the lapsing of language into a meaningless gibberish (which has its profane pendants as well, as the zum-zum-zum-zumbaba on Avenida Oceânica showed). The charismatic Catholics studied by Thomas Csordas considered glossolalia 'a pure act of expression' because it will never be 'subject to codification' (I990: 27). He states that '... glossolalia ruptures the world of human meaning, like a wedge forcing an opening in discourse and creating the possibility of creative cultural change, dissolving structures in order to facilitate the emergence of new ones' (I990: 24). Specifying this thought Csordas continues,

... the stripping away of the semantic dimension in glossolalia is not an absence, but rather the drawing back of a discursive curtain to reveal the grounding of language in natural life, as a bodily act. Glossolalia reveals language as incarnate, and this existential fact is homologous with the religious significance of the Word made Flesh, the unity of human and divine. [...] Glossolalia facilitates and is the embodiment of non-verbal thought - in glossolalia the physical experience of utterance (parole) comes into balance with the intellectual experience of language (langue) ... (I990: 25-26).

Attempts to give up on being the author of the world and let oneself be 'written-by-the-world' are also found beyond the realm of mysticism. Obstructions to authorship are at the heart of the Surrealist's admiration of the flâneur, who would wander the city to provoke chance encounters, or the beatnik's faith in serendipity, or even the practitioners of such mindblowing activities as bungee jumping, pipeline surfing, and parachuting. This is what a practitioner of the free fall had to say on the matter:

When we are in the plane climbing to the altitude for the jump, I always feel frightened and surprised that $\mathrm{I}$ am undertaking such a peculiar activity - jumping from a plane. But as soon as l've left the plane, it's like being in another dimension. Suddenly everything seems so real. Free fall is much more real than everyday life (Breton 2000: 3).

All these examples, I would say, hint at a continuous search for what I will call 'the-rest-of-what-is': the 'surplus' of our reality definitions, the 'beyond' of our horizons of meaning, that which needs to be excluded as 'impossible', 'unknown', 'mere fantasy' or 'absurd' for our worldview to make sense. Mystics and bungee jumpers meet in their attempts to open 
the gates to this great unknown. Their effort is to give up mind control, to obstruct language and to keep their not-knowing center stage.

Academia has long kept its doors locked for such forms of inquiry. In fact, in his genealogical study of mysticism, Michel de Certeau (I992) argued that mystical forms of apprehending the world had to be set apart as 'a special case' for scientific modes of research to come into being.

... since the sixteenth or seventeenth century, one no longer designated as mystical that form of 'wisdom' elevated by a full recognition of the mystery already lived and announced in common beliefs, but rather an experimental knowledge that slowly detached itself from traditional theology or church institutions, characterized by the consciousness, received or acquired, of a fulfilling passivity in which the self loses itself in God (I992: 13).

From this time on, 'the mystical' became a category of its own. 'Mysticism' was now identified with a certain number of phenomena (extraordinary events, lived experiences, a 'language' of the body). 'The mystic' was the persona who lived those events and bodily experiences, and would report on them to the society-at-large. And 'the mystical road to knowledge' was now assigned a place that stressed the out-of-the-ordinary status of this type of inquiry: at the margins of society, and excluded from a secular form of knowing that 'defines its own scientific objects' (ibid.) in the act of authoring the world. It was because of that separation of different roads to knowledge, says de Certeau, that the scientific study of human life could develop the way it did: scientists studied the world within the pre-established parameters of their disciplines, and could do so relatively unhampered because the-rest-of-what-is - the plenum of existence that has the power to reveal the contingency of our language games - was now for the mystics to deal with.

This division of labor is kept in place up until this day. The phrase 'we do not practice theology here' was, until very recently, something of a mantra with which my colleagues in the anthropology of religion section at the University of Amsterdam discouraged questions about the transcendent. Religion was to be understood in terms of its being a social and cultural formation. Period. I remember how, having returned from fieldwork, and having reported my experience of being 'baffled' and awestruck in the face of some inexplicable phenomena that I had encountered in 
Candomblé, these experiences were immediately dismissed with a reference to what one colleague called 'technologies of the occult'. Of course, in itself this term did not answer what it was that I had encountered, but it did suggest that there had been a 'technology' at work that - with sufficient energy and scientific rigor - could be broken down to its constitutive parts (instruments, procedures, skills etc.) and thus be shown for what it really is. ${ }^{5}$

Interestingly, however, more and more thinkers in academia have expressed their dissatisfaction with being locked up in the rigid, conventional schemes of the scientific text. Sociologists and anthropologists are tuning in with philosophical inquiries and re-examining the methodological and epistemological dimensions of academic world-making, 'adding realism to science', as Bruno Latour provocatively called it (1999: 3). Given my decision to remain loyal to that epiphany on Avenida Oceânica - and treat it as an incentive to consider the wisdom that lies hidden in Candomblés alternative routes to knowledge - I line up behind these critical reconsiderations of the academic regimes of truth telling.

Within the social sciences, anthropology has probably gone farthest to overcome the limitations of conventional, academic forms of report. The discipline has opened up a space for critical reflections on the role of rhetoric and authorship in ethnography; for pondering the subjective dimension of all truth telling; for literary experimentation and poetics; and for a re-evaluation of the expressive power of other media of report such as photography and film. It is striking that many of these attempts to find new ways of 'writing culture' seem to be informed by the wish to open up the academic text for 'the-rest-of-what-is'. Given the nature of anthropological research, this is hardly surprising. Anthropologists have been submerged for extended periods of time in the social lives of the people they study; they have experienced 'the field' in all of its sensory and sensuous dimensions; they have faced academically inadmissible yet locally unquestioned truths such as witchcraft, sorcery, shamanism and spirit possession; and they have studied, theorized and probably experienced the mind- and sense-expanding possibilities of 'anti-structure' as encountered in native ritual practices. For all of these reasons, many anthropologists are acutely aware of the deep rift between the immediate, active, ambiguous "plenum of existence" in which all ideas and intellectual constructions are grounded' (Jackson I983:3) and the expressive limits of the academic language that should somehow bring this totality into resonance. Johannes Fabian commented on this issue when confronted with the unmentioned and unmentionable dimensions of igth century 
explorations of Africa. 'Human beings communicate by means of language, signs, and symbols,' he wrote, 'but also by their ways with space and time, with things and events: by sensory perceptions of sound, touch, and smell; by habits of gaze and bodily movement - all of which vary greatly as regards the extent to which they can be made subject to conscious control and methodical scientific investigation' (2000: I03). In his admirable attempt to design a 'sociology of mess', John Law stated that

... parts of the world are caught in our ethnographies, our histories and statistics, but other parts are not, or if they are, they are distorted into clarity ... if much of the world is vague, diffuse or unspecific, slippery, emotional, ephemeral, elusive or indistinct, changes like a kaleidoscope, or doesn't have much of a pattern at all, then where does this leave social science? How might we catch some of the realities we are currently missing? (Law 2004: 2)

Clearly then, academic instructions as to how one should go about carving a meaningful, sensible, explicable world out of the grand-totality-of-being are here evaluated as doing violence to the fullness of life as we know it from experience.

In what is now called 'the literary turn in anthropology', attempts are being made to bring back dimensions of being that hover beyond the horizon of the academic imagination. Michael Taussig, for instance, rejects the mere 'explanation' of the magical and surreal realities that he encountered in Latin America. Unsatisfied that in the academy 'explanation' usually boils down to the 'explaining away' of that which is at stake in the experiential worlds of the people under study, Taussig introduces Surrealist literary techniques such as the collage, which seek to derail the expectations of the academic reader. The confusion of the reader may open a space in which the forms of knowing that are relevant to the local situation may occur. 'Penetrating the veil while retaining its hallucinatory quality', is the epistemological guideline that Taussig brings to the ethnography he envisions (I987: I0). Michael Jackson, another major voice in the 'writing culture' debate, speaks of his awareness that 'time', the 'body' and the 'unconscious' continuously destabilize fixed categories of thought and he urges anthropologists to develop a 'radical empiricism' that seeks to incorporate, rather than neutralize, these unsettling forces (I983: 3). A similar point is made by Fabian, who stated that

... much of our ethnographic research is carried out best when we are 'out of our minds,' that is, while we relax inner controls, forget our purposes, let 
ourselves go. In short, there is an ecstatic side to fieldwork which should be counted among the conditions of knowledge production, hence objectivity (200I: 3I).

The romantic tinge of these anthropological calls to bring the fullness of 'real life' back to the academic text is hard to miss (cf. Gouldner I974). Yet this qualification ought not - as is too often the case - be taken as a disqualification of anthropological critiques on academic forms of worldmaking. Quite to the contrary. Romantics have a point when stating that there is a fundamental failure to a text that tries to pass for a truthful portrayal of another people's life world, but only manages to evoke the dull scent of the chalkboard; the bleak, Formica aesthetics of the university class room; the quibbling of the science committee over methodological procedures; or the institutional incentives to display sophistication, erudition and expertise. If we want to maintain that our wordings are capable of bringing our readers closer to the real of power, the real of violence, the real of the body, the real of the sacred, the real of sexuality or the real of beauty, we cannot do without literary strategies that are capable to evoke the unspeakable dimensions of such phenomena.

Important as literary and poetic experimentation may be, it is necessary to realize that new ways of writing will not suffice to respond to the challenge posed by Candomblés insistence that their 'deep knowledge' is not available for discursive analysis. As I will discuss at various points in this book, I frequently stumbled upon a fundamental incapacity to grasp the 'otherness' of Candomblé (and broader, the life world that is Bahia). I was constantly aware of my middle-class, suburban biography, and the horizon of the possible that comes with it. For instance, after so many years of studying Candomblé, it still takes conscious effort to remind myself that for the people I study, spirits are as real a presence in their lives as their relatives, friends, employers and visiting anthropologists. I was even more aware of the extent to which I am marked by a particular habitus and its ingrained sense for what is (for want of a better word) 'experiensable'. In other words, it was not as if I had free access to the experiences that mystical techniques provoke, and only struggled to find adequate forms of report. As I have discussed elsewhere (van de Port 1999), the 'otherness' that we study can be very obstinate, closed off for explorative incursions from the outside. Therefore, our reports on other people's life worlds should accept - and make explicit - the limitations of cultural translation and acknowledge the reality of our not-knowing. 
What this means is that I seek to open up my writings to the-rest-ofwhat-is. I will keep the limits of our representational practices and expressive forms in sight, and place the extent of our not-knowing center stage. I will, to use Richard Kearney's (2010) felicitous phrasing, show 'hospitality' to that which is other - the genuine hospitality, which is unconditional, and welcoming to otherness as such. Living in Bahia and studying Candomblé, I have come to question the academic impulse to pass the-rest-ofwhat-is onto the plate of the mystic (or theologian). The challenge before us is not to answer to the unanswerable. It is to understand its presence and its effects in all world-making.

\section{䜪}

This brings me to a number of philosophers - Slavoj Žižek, Yannis Stavrakakis, Terry Eagleton, Alain Badiou - who have been important to the perspective that will be developed in this book. Their sophisticated discussions of the limits of human sense-making, strongly influenced by the thinking of Jacques Lacan, helped me to articulate and theorize the notion of 'the-rest-of-what-is'. In addition, these philosophers provided me with an academic laissez-passer which enables me to present my findings within the walls of academia. After all, if my intrigue with mystical roads to knowledge were to catapult this project to the realm of theology, New Age spirituality or the literary salon, it would be all too easy to qualify my considerations as 'irrelevant to the social sciences'.

The way these Lacanian thinkers apprehend reality is in many ways reminiscent of the mystics' attempts to 'checkmate' language. This is particularly noticeable in their musings on that 'radical negativity' that in Lacanian thinking is called 'the Real': the dimension of being that brings home to us that all symbolic structures fail to capture lived experience in its entirety. The Real is a complicated concept, and full of contradictions, but central to the arguments developed in this book. It therefore merits a brief discussion.

In a Lacanian perspective, the structures of meaning that allow us to come to terms with the world - the 'symbolic order' - violate the subjective experience of being. A newborn human being enters the symbolic order by being socialized into the roles and structures of its life world, and by learning to speak a language. This process equals subjugation to 'a supervening, deeply impersonal law which applies indifferently to all' (Eagleton 2009: 86). Difference, alterity and discrimination rein this symbolic order, for in the symbolic order a phenomenon can only be some- 
thing by not being something else. 'You' cannot be 'the world', just as 'the world' cannot be 'you'. Being a 'boy' you cannot be a 'girl', and being a 'girl' you are hooked up with the color 'pink', not 'blue'. Your 'mother' cannot be your 'wife', and your 'wife' should not be mistaken for 'a hat'. The fact that you are 'a man', 'a child', 'an academic' allows you certain actions and comportments but not others. In brief, social identities acquire their stability from the taboo; the prohibition to have certain awarenesses, think certain thoughts, feel certain feelings, act out certain actions.

Yet the ways of the world - and our experiences of them - are always more complex than the schemes allow for. There was, for instance, this man who mistook his wife for a hat, as Oliver Sacks reminds us in one of his famous 'clinical tales'. There are boys who opt for pink. And there are moments such as the one on Avenida Oceânica, which 'say it all' but defy any further verbalization. These 'impossible' phenomena - the surplus that the symbolic order produces - foster an awareness that the symbolic constructions we have at our disposal are lacking, and alert us to the fact that at the bottom of all meaning lies a residue of non-sense.

It is this awareness of a rest-of-what-is that Lacanians describe as 'the Real'. They stress that the Real ought to be conceptualized as a 'radical negativity' because of the elusive character of this awareness: Slavoj Žižek describes the Real as 'something that persists only as failed, missed, in a shadow, and dissolves itself as soon as we try to grasp it in its positive nature' (Žižek 1989: I69). Terry Eagleton also discusses the Real as a dimension of being that is exterior to all symbolization, yet highlights that its presence can be detected through its effects, through the ways it intrudes upon our lives. As Eagleton puts it, we only know the Real 'from the way it acts as a drag on our discourse', reminding us that the system cannot be totalized (Eagleton 2009: I44).

As the Symbolic's point of inner fracture, the Real is what resists being symbolized, a kind of surplus or leftover, which remains when reality has been thoroughly formalized. It is the point at which our sign-making trails off into incoherence and our meanings begin to unravel at the edges; and as such it registers itself not directly, but as the outer limit of our discourse or the silence inscribed within it. It represents a hard kernel or gaping void at the core of our symbolic schemata... which in preventing them from ever being quite at one with themselves is the ruin of all totality and the sabotaging of all sensemaking (ibid.). 
Jacques Lacan himself liked to compare the intrusions of the Real with a tile falling on the head of a passerby, or a knock on the door that interrupts a dream. When things like that happen, he said, we all of a sudden become aware that '... the network of signifiers in which we have our being is not all that there is, and the rest of what is may chance to break in upon us at any moment' (in Bowie I991: I03, italics mine).

The notion of the Real is also at the heart of philosopher Alain Badiou's discussion of the importance of what he calls 'the event' in grounding systems of meaning:

Knowledge as such only gives us repetition; it is concerned only with what already is. For truth to affirm its newness, there must be a supplement. This supplement is committed to chance - it is unpredictable, incalculable, it is beyond what is. I call it an event. A truth appears in its newness because an eventful supplement interrupts repetition (Badiou 2005: 46).

There are, of course, many more philosophers that might be quoted here in their attempts to call into existence the 'beyond' of language and symbolization: Roland Barthes, for instance, with his elaborations of the notion of jouissance, the 'obtuse meanings' of representational forms (I977) and the punctum, the one detail in the photographic image that 'hits' the viewer without his knowing quite why or how (Barthes 2000; cf. Schüssler 2006); or George Bataille, who studied transgression as a way that enables people to lift the discontinuities that all world-making implies (Bataille I989). As an anthropologist, however, I will steer clear of attempting a systematic comparison or overall treatise of these thinkers and their different articulations of the-rest-of-what-is. I will limit myself to the task of bringing these philosophical insights about the Real to my fieldwork findings, and my fieldwork findings to these philosophical insights.

On that note, I venture to say that the aforementioned authors offer examples of academic world-making that might provoke some appreciative nodding in Candomblé circles. For there is an elective affinity between their pondering of the Real and the mystic's understanding that conventional ways of world-making lock you up in the theater of your own imagination, and do not give access to a transcendent 'All'. Of course, these thinkers do not propose to embrace mysticism as an alternative to science. ${ }^{6}$ Yet what makes them so interesting is that they do not simply blind themselves to the-rest-of-what-is so as to return to the language games of old. Their work invites us to reconsider the alleged incompatibility of scientific and mystical roads to knowledge. Indeed, as I will show in this 
book, these thinkers allow us to see that keeping science and mysticism rigidly separated is to miss out on an opportunity: for just as academic modes of world-making help us to grasp what is peculiar to the 'mystical', mystical modes of world-making help us to grasp what is peculiar to our own 'academic' modes of world-making.

\section{鳃}

Keeping the-rest-of-what-is center stage in our reports on other places, times and peoples may be a vital project for anthropology. Over the last decades, anthropology has found itself under the influence of what Yannis Stavrakakis called 'the increasing hegemony of constructionist argumentation' (1999: 66). We have shown the work of culture and the social to be present in pretty much everything: in disease and charisma, in taste and dreams, in sex and the sacred, in race and gender. As Charles Lindholm put it, 'floating above local claims for transcendence or truth' anthropologists have made it their main business to 'demonstrate again and again that these claims are political and ideological representations supplied by self-interested parties pursuing domination' (Lindholm 2002: 334). In other words, in much of anthropological world-making, the people under study believe, and the anthropologist shows what these beliefs are really all about. The people 'out there' have a Sacred, and we will show how that sacred comes into being. They are in possession of authentic lives, and we will unravel how that authenticity is made up. They live in an enchanted garden; we are up to the tricks. The question to be asked, however, is: are we ... really?

In philosophy, Stavrakakis has convincingly sketched the limits of a constructionist argumentation. In attacking all essentialisms, he says, constructivism has itself taken up a 'meta-linguistic or essentialist position outside construction', and fails to answer (or even address) the question of how its own truths ought to be deconstructed (Stavrakakis i999: 66). A similar point is made by Bernard Williams in his Truth and Truthfulness. An Essay in Genealogy (2002). Williams discusses constructivist practices in history, and gives due credit to historians who have shown just how much power relations determine the way that histories are told and remembered. Nonetheless, he raises some difficult issues. "Those who say that all historical accounts are ideological constructs ... rely on some story which must itself claim historical truth' (Williams 2002: 2). But rarely - if ever - do we read what story that is. Indeed, 'it is remarkable how compla- 
cent some "deconstructive" historians are about the status of the history that they deploy themselves' (ibid.).

Such thorny questions should certainly not be taken as an incentive to do away with constructivist argumentations altogether. Showing the made-up in the taken-for-granted should remain one of the major tasks of anthropologists. For in a world where the demand for essentializing and totalizing discourses seems to be on the rise (both within the walls of academia and beyond), it still makes sense to infuse some doubts here and there by revealing how such discourses are stitched together. The problem, however, is that constructivism has declared itself to be the answer to the phenomena we study, rather than an invitation to explore new inroads into studying the workings of culture.

In anthropology, Michael Taussig is one of the leading voices in the search for ways to overcome the deadlock in constructivist argumentations. In his sketch of what has become of constructivism in academia, he wrote: 'With good reason postmodernism has instructed us that reality is artifice yet, so it seems to me, not enough surprise has been expressed as to how we nevertheless get on with living, pretending (...) that we live facts, not fictions' (Taussig I993: xv). It is certainly no coincidence that Taussig uses the inclusive pronoun 'we' in this call to investigate how the facticity of facts comes into being. For it is when we begin to deconstruct our own lives - in and beyond anthropology - that we soon become aware just how incomplete a constructivist approach to reality is. Just try it out for yourself: try to deconstruct the world of meaning that you inhabit. And do not make it easy on yourself. Take the things that really matter to you. I predict that you will be able to come up with some narrative or other about the love you feel for your loved ones; about your infatuations and crushes; about the ideas you hold sacred; about the missing of the people you have lost; about your existential despair; about your aesthetic likes and dislikes. Yet I am pretty sure that you would not want those loves, infatuations, sacred ideas and despairs to be reduced to that narrative. Quite likely, you will find yourself saying something like: 'well, yes, all of that can be said about it... but there is so much more to it'.

This nagging awareness that 'there is so much more to life than we can say' is at the root of the discontent with the 'increasing hegemony of the constructionist argumentation'. We cannot sit back and rest contented after having exposed the made-upness of the things people take 'for fact'. Deconstruction is only the first step. It ought to be followed by an account as to how people manage to produce the sensation that those so-called facts are 'for real'. What we need is what might be called a theory of 'cul- 
tural enchantment': an account of the magic that produces an authentically felt grounding to the man-made worlds of meaning that we inhabit.

Taussig sought a way out of the impasse of constructivist argumentation by turning to the sensuous body (Taussig I993). Many other anthropologists have made the same move: time and again, they have introduced the body into their texts as the ontological anchorage for the cultural construct, as the nature that transforms culture into 'second nature' (Bourdieu I990). I will elaborate this point in the chapters to come. Here I merely wish to express my dissatisfaction with the observation that this body that has now entered the anthropological text does not move us beyond the constructivist deadlock. To the contrary, all too often this body is merely a new object on which the constructivist project can feed itself and display its prowess.

A more radical theoretical move would be to conceptualize the sensuous body as a mystery; a given that is always in excess of our intellectual apprehensions, that indicates the limits of all sense-making, and always forces us to say 'well, yes, all of that can be said about it... but there is so much more to it'. This body that is a portal to the-rest-of-what-is might well be what the priests from Candomblé sought to bring home to me when insisting that 'deep knowledge' bypasses the signifying capacities of the word. Or in the Lacanian vocabulary, we might say that this body that cannot be fully known is a constant reminder of the Real. As it craves, suffers, exhilarates, hurts, sleeps, makes love, develops illnesses and ultimately dies, the body keeps invoking experiential domains that, to a greater or lesser extent, resist our discursive practices.

What could the-body-that-cannot-be-told - and other givens that do not lend themselves for discursive colonization - contribute to an understanding of the magic that 'makes the real real and the normal normal' and produces the facticity of the fact? In this book I will propose that the theorizing of cultural enchantment must start with a simple realization: the awareness of the lack in our narratives (we can never say enough about our loves, infatuations, sacred ideas, despairs and bodily experiences) is always also the awareness that 'there is so much more than we can say' about these things. In the chapters to come, I will show that processes of cultural enchantment exploit this notion of an excess to our narratives, an ungraspable beyond to our knowing: they mobilize the sense of relief that comes with the realization that our 'I love yous' are never as banal as we phrase them; they draw upon the infinite layers of meaning that lay hidden in the fact that we cannot put into words the depth of our despair; 
they play the body that escapes our 'being up to the tricks'; they ground themselves in William James' understanding that

... Man is not the measure of [God's] creation. The world is immense, constructed on no plan or theory which the intellect of man can grasp. It is transcendent everywhere. This is the burden of every verse, and is the secret if there be one, of the poem (2008: 62).

In a Lacanian vocabulary, the mumbled '... but there is so much more to it' might be translated as 'the impossibility to reach symbolic closure'. As stated above, Lacanians take this failure to reach symbolic closure to be characteristic of all world-making - constructivist or otherwise. What this radical position allows us to think is that constructivism, essentialism, mysticism, positivism and all the other '-isms' are nothing but different modes in that impossible project to uphold the truth of a vision against the constant intrusions of the Real; different designs to provide a particular world view with a sense of the real; different attempts to keep the-rest-of-what-is at bay to thus safeguard a particular reality definition - or invoke it to upgrade the persuasiveness, depth, credibility of that particular world view with a sense of a sacred 'beyond'.

Taking the impossibility to reach symbolic closure as a starting point in the chapters to come, I will scrutinize the modes of enchantment as I encountered them in Bahia: the mobilization of such registers as fantasy, bodies and experiences in the formation of the real Candomblé. I will also, in an equally scrutinous manner, reflect on the 'magic' underlying our own academic modes of fact-making. I will challenge the boundaries within which academic knowledge production takes place, develop an art of writing that tears the language games of anthropology out of joint, thus to show how these games have been designed to keep the impossibility of their totalizing pretenses out of sight. I will draw into the field of investigation all the excess of the homo academicus: his doubts and his notknowing, his being baffled and left without words, his being lost and given over to forces beyond his control and comprehension, his having a body attached to his head, his being without answers in the face of death, his losing his heart to a Bahian beauty - all of this to keep the reader focused on the fact that the anthropologist is not in full control, that he too is written-by-the-world.

So, let us say this book has a double agenda. I will do the deconstructionist thing, because I can no longer (nor would I want to) blind myself to the work of culture in world-making. Yet I will proceed with my analysis 
in awe of the-rest-of-what-is: the mysteries in which all cultural formations are grounded, the mysteries that animate the constructions people live by. Only an awareness of the-rest-of-what-is may rob the constructivist's arguments of their sense and open up avenues towards an ethnography that 'penetrates the veil while retaining its hallucinatory quality'. In this book I will keep going back to moments of shock, of bafflement, of enchantment, of being at a loss. Moments like the one on Avenida Oceânica. Or moments like that evening at a celebration in honor of the orixá called Oxóssi, when all of a sudden a young man that had been standing next to me outside of the ceremonial hall became possessed by the ancient spirit Oxalá, and transformed instantaneously into an old man, bent over forward, as if warped by rheumatism, trembling all over his body as if suffering from Parkinson's disease. Invented tradition? Possibly. Culturally informed performance? Sure. But then and there, watching old, shaking Oxalá shuffling towards the entrance of the temple, supported by two burly women so as to keep him from falling, such comments meant next to nothing.

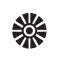

If this study seeks to re-sensitize anthropology to the dynamics of cultural enchantment - and to the methodological and epistemological challenges implied therein - then the encounters between people from Candomblé and curious outsiders are to be the focal point. For these encounters with others - or more generally: otherness - are the very moments when people become aware that 'the network of signifiers in which they have their being' is not all there is and that the-rest-of-what-is may intrude on established worldviews. It is therefore that this study will keep returning to the threshold of the Candomble temple: the stage where curious outsiders and believers have gathered to evoke this great unknown, to play its baffling mysteries, to exploit its horrors, to appropriate its transformative powers, to open up the body and mind to its unsettling energies. It is there, at the meeting ground, that one may witness the attempts to connect cultural form to a sacred beyond. It is there that one may try to find out how people seek to infuse their beliefs with a truth that transcends all cultural formulation.

The encounters on the temple's threshold will be discussed in seven essays. They are essays in the sense that every one of them addresses a particular dimension of the attempts to apprehend (define, appropriate, dismiss) the real of Candomblé and can therefore be read independently. 
Yet the essays are also organized chronologically, and taken together they tell a history of encounters. As I will document, this is a history of drastic change which concerns the social and political circumstances under which outsiders and people from Candomblé came to meet each other. Where it concerns the underlying motives for these meetings to take place, however, history seems to be repeating itself, over and over again.

Thus, the first essay is a thorough reflection on my own encounters with Candomble - and more broadly, Bahia. It introduces the research setting, and the work of my countless predecessors in the field of Candomblé studies, and it ponders the particularities of doing anthropological fieldwork in Bahia by juxtaposing academic and Bahian modalities of being-in-the-world. As against the academic dictum that aloofness and levelheadedness are the privileged mode to 'get the picture', the preferred mode by which Bahians seek to relate themselves to each other, their world, and their Gods is 'immersion'. This preference is traced in music and dance, in carnival, in Bahia's famous baroque art and architecture, in the ecstatic dimension of many Bahian religions, as well as in the Great Narratives of the Brazilian nation, which privilege tropes of mixture over those of categorical purity, and the 'cannibalization' of foreign elements over the mere 'copying' of them. In a place so geared towards immersion, academics soon find themselves invited to immerse themselves in the life world they had come to observe. I discuss how a long line of researchers (including myself) gave in to that invitation, in a desirous - but not necessarily successful - attempt to give up on the injunction of the academic habitus to 'keep one's distance'.

Chapter two discusses the 'semiotic ideologies' (Keane 2003) in Igth century Bahia that underlie the work of Candomblés first ethnographer, Dr Raimundo Nina Rodrigues. Dr Nina's interest in Candomblé has often been linked to public debates in post-abolition Brazil as to how the Brazilian nation, given its 'unfavorable' racial make-up, could be moved towards the 'order and progress' of modernity. This essay, however, focuses on a much neglected dimension of his work: the attempt to introduce the 'ocularcentered' perspective of late igth century positivist science (which sought to redefine reality as that which meets the observing eye) in a world dominated by the perceptual regimes of the baroque - with their appeal to all the senses and their assumption that 'what one sees is but a part of what is out there'. I will show that Dr Nina's attempts at demystification not only concerned Candomblé as such, but were directed at all Bahian classes and races. If only Bahians would accept the eye to be the prime arbiter of truth, so he assumed, their straying from the road to progress 
could be prevented. Far from subscribing to Dr Nina's ocularcentrism, the essay seeks to highlight that Dr Nina's faith in the truth of vision depends on its own mystifications.

In chapter three, I discuss the celebratory re-encodings of the primitive that are at the root of the contemporary extolment of Candomble as the quintessential Bahian cultural heritage. The discussion takes me back to the I920s and I930s, when the Brazilian avant-garde 'discovered' Candomblé. Like Dr Nina, these Modernistas were convinced that the cult was expressive of a 'primitive' mentality. Unlike Dr Nina, however, they extolled the 'primitive' character of Candomblé, depicting the cult as a source of vital forces and revolutionary energies, capable of breaking the chains that tied Brazil to Europe, and thus restore Brazil to its 'true' being: a nation of mixed races. The main focus of the chapter, however, is on the fact that, in a place like Bahia, artistic re-encodings of the primitive as 'beauty' also always speak to the grim realities of a destitute and deeply violent society. Candomblé-as-public-culture is a deeply ambiguous phenomenon. An analysis of the clashing views on Candomblé by some of my informants, and a discussion of the many urban legends and rumors in which Candomblé is depicted as evil and ugly, lead me to conclude that too many Bahian lives are marked by poverty, ignorance, violence and abuse - as well as fear for the powers of the occult - for Candomblé to be locked up in the picturesque of museums, galleries, postcards or academic debates on 'tradition' and 'culture'. What is more, the continuing vitality of Candomblé aesthetics is grounded in its dangerous dimensions, its unsettling, disruptive and fear-inducing powers.

Chapter four is an essay on the processes of abstraction that are constitutive of the apprehension of Candomblé as a 'public' phenomenon. Following Michael Warner's understanding that apprehending something as 'public' always implies a negation of those dimensions which purportedly bear no weight beyond the horizon of particular groups or individuals (Warner 2002a; Warner 2002b), the central question in this chapter is: what dimensions of Candomblé were deemed publicly relevant, and what dimensions were declared to be 'in excess' to the cult's public worth? As such discriminations are always contested, the chapter brings into view the ways in which such diverse agents as the Bahian state, the culture- and tourist industry, and various social movements engaged themselves with Candomblé, and (re)defined its public worth. Concretely, the chapter follows those historical developments from the I930s up to the present day that were most relevant in enabling and stimulating Candomblés public life. Starting with the Vargas era (I930-1954), the discussion focuses on the 
new role of folklore and popular culture in the process of nation building; for the I960s, the focus will be on the emergence of rebellious youth- and counter cultures which criticized existing social and political structures, and opted for a cultural and spiritual revival; from the i97os onwards, the booming of tourism in Bahia made itself felt ever more strongly in arenas relevant to the divulgation of Candomble imagery in the public sphere, requiring a discussion as to how the tourist industry sought to foreground 'the exotic' and 'the mysterious' dimensions of Candomblé in the marketing of Bahia, and how 'the black body' was promoted as a sign of a desirable Baianidade; the growing importance of alternative identity-based politics since the I980s, attempting to reframe Candomblé as a site of subaltern resistance to dominant social values, will be discussed in an analysis of the appropriation of Candomblé imagery by the gay and black movements. Underneath this long history of appropriations emerges an intriguing pattern: Candomblé elements that were declared to be 'in excess' of the cult's public worth in one period, made up that public worth in another period, a pattern that bears witness to the fact that the vitality of cultural form feeds on that which that very form excludes.

The fifth essay seeks to unearth what is specific to the baroque aesthetics that is so prominently present in the cultures of Bahia, and contemplates the aptness of this particular mode of world-making for the Bahian life world. The chapter is organized around Walter Benjamin's discussion of baroque allegory (Benjamin 2003; Cowan I98I; Wolin I994). Benjamin contrasts allegory with the symbolic mode of representation that came into being in the Romantic era. The latter is founded on the promise that its expressive forms enable men to access the transcendent realm of the divine, and thus partake in a united whole that comprises God, men and the world. Allegory's expressive mission in the world is to declare such promises to be false and illusionary. In allegory, the breaks, cleavages, and rifts in the symbolic order are highlighted. Its forms of world-making seek to express the 'unavailability' of stable meaning, and are akin to all those other representational forms of the anti-art that was the baroque empty emblems, evidently artificial, 'mannerist' and 'kitschy' forms, shallow surfaces, labyrinths, trompe l'oeuil effects, riddles, and mysteries. I will argue how the baroque obsession with the failure of mortals to produce a convincing, totalizing metaphysical account of the state of things in the world, speaks to the experiences of a people caught betwixt-and-between irreconcilable paradigms. I will also point out how allegorical modes of world-making thus nurture a mindset that has been aptly described as 'desperate faith': a yearning for signs of the Divine Power that might bring 
coherence to the world of meaning, a desirous waiting for a miracle, a 'fulfilling event' that might bring forth wholeness, and in the wake of such cravings: the willingness to recognize such intrusions of the sacred in the world.

Chapter six is an attempt to connect the thinking of the French philosopher Alain Badiou (Badiou 2003) about the notion of the 'truth event' with the possessions, apparitions and other miracle production that are constitutive of Candomble's boundary politics. The focus is on what I call a 'politics of bafflement': the way Candomblé presents its mystical secrets and miracles in public. With so many different voices being involved in defining Candomblé, many cultists feel pressed to publicly assert their voice as the one and only 'true voice of Candomblé. The basic form of a 'politics of bafflement' is reminiscent of what Badiou called a 'truth event': it is the evocation of an intruding force, an agent from beyond the horizons of what is known, inexplicable as to what it is, yet undeniable as to its powers. In terms of the allegorical imagination, it is the calling forth of the workings of an absent truth that brings the world to order. The Candomble priesthood uses this intruding force as an agent that is capable to reduce all discursive forms of meaning production in the public sphere to 'mere opinionating'. Due to its capacity to highlight the limits of human understandings, and its promise to give access to more all-encompassing truths, this force-from-beyond is put on a throne to reign supreme in the kingdom of the real. Spirit possession is the most visible and most spectacular instance of this force-from-beyond, yet I make clear that its manifestations can also be discerned in other expressive forms and practices in Candomblé.

Chapter seven is an essay that takes a closer look at practices of mediation within the Candomblé community to reveal that the religious imagination of the people of Candomble is permeated by the aesthetics, formats and styles that dominate the public sphere of the media saturated society that is Brazil. The first case concerns the production of video registrations of important celebrations of Candomblé by cultists. Employing a televisual language and style - that speaks to the tastes and aesthetic ideals of Brazilian media consumers - these commemorative documents counter both sacerdotal and anthropological portrayals of the cult as a sovereign universe that is somehow immune to the world in which it operates. They unmistakably speak to a desire on the part of cultists to bring their religious activities into consonance with their daily life worlds (rather than locate these activities in an imagined 'traditional Africa') and signal the cultists' wish to make their enthusiasm for, faith in, dedication to, and 
love of Candomblé known and understood to an imagined public that is located beyond the strict confines of the temple. The second case concerns the construction of priestly authority in the public sphere. Given that the religious criteria for priestly authority do not carry much weight beyond the temple walls, co-opting famous media figures becomes a way for the Candomblé priesthood to communicate the import and power of their religion in the public sphere. They thus find their religious leadership authorized in terms that are well understood by the consumers of modern mass media. In this case too, the conclusion must be that the new significance of Candomble in the public sphere and the aspirations of the Candomblé priesthood to be recognized as the authentic and authoritative voice of their cult have triggered a complex reconfiguration of power relations: priestly authority is no longer solely made in the interior of the temples. Increasingly, that authority comes to depend on - and needs to adapt itself to - the authoritative voices of the media.

魚

If these essays address different dimensions of the enchantments and disenchantments at the temple's threshold, they have been organized chronologically so that, taken together, they tell a history of encounters between outsiders and people from Candomblé. What makes this history of encounters so interesting is the fact that it is also the history of the meeting up of two antagonistic ways of getting to know the world, two different modalities of world-making. I will label these modalities as 'classic' and 'baroque. The relevance and adequacy of these particular terms for the project I have just introduced will have to become clear throughout this book (and will be discussed extensively in chapter five). All I want to do here, in the introduction, is to give a preliminary idea of how I have come to understand these terms, and point out why they are particularly well geared to theorize an anthropology that refrains from totalizing accounts by keeping life's mysteries center stage.

The classic, as I define it, is the preferred register of academic knowledge production. It is a style that foregrounds a morphology of - and concomitant preference for - fixed forms, delineation, clarity, order, categorical purity, etc. which it invests with the promise that 'to name is to know'. I do not know a better example to illustrate the specifics of its world-making than a photograph of a Candomblé altar that appeared in a Brazilian weekly called O Cruzeiro from I95I. 


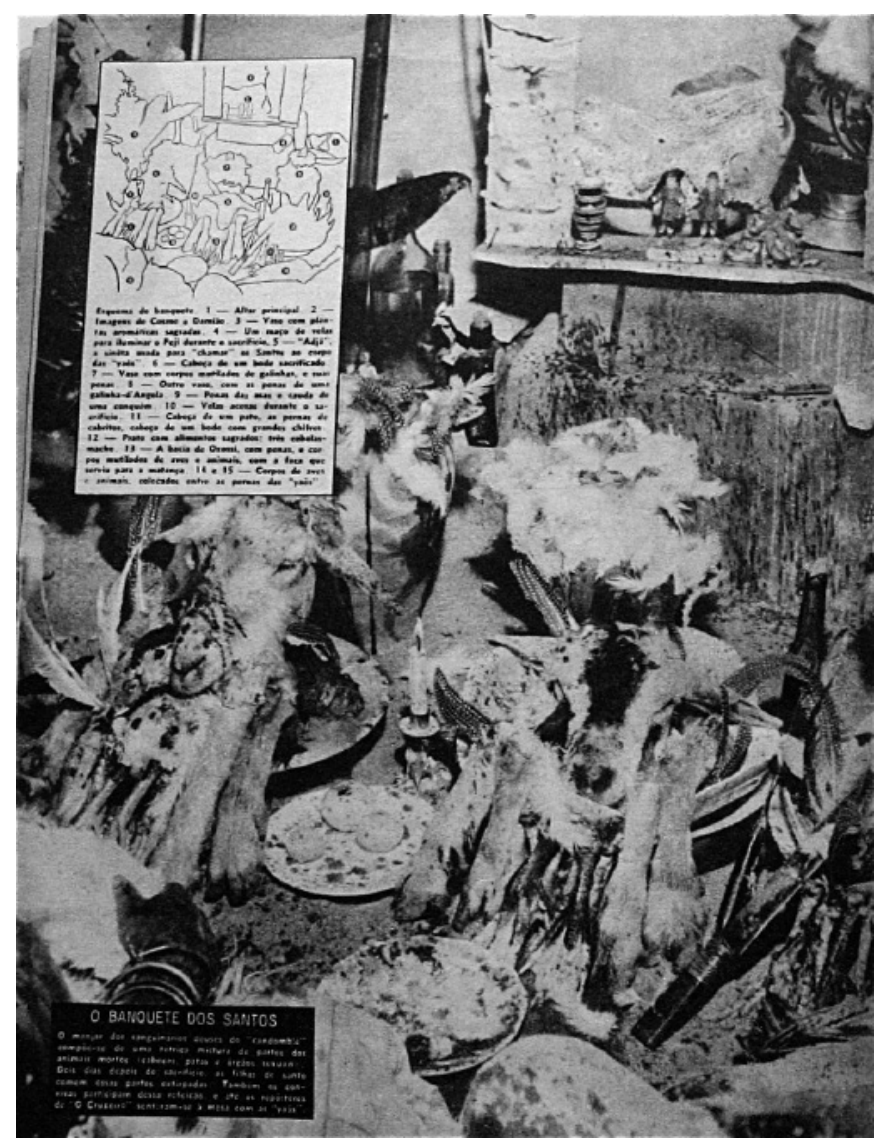

Figure 2 Representing a Candomblé altar in the spirit of

the classic. Photograph from a reportage on Candomblé in the Brazilian weekly O Cruzeiro, 1951

The photograph itself shows a mess, a jumble of the remains of sacrificial animals, foodstuffs, candles and statues. Inserted in the photograph is a text box that helps the reader to distinguish what is what. In clear lines, the jumble is reduced to its neatly numbered constitutive parts: number three is 'a vase with plants', number six 'a goat's head', number nine 'chicken feathers', number ten 'candles'. There is, of course, nothing 'untrue' about this representation. Everything is there. Nothing has escaped the attention of the observer. And yet, 'something' has gone missing in this schematic representation of the altar - something that might well be crucial to what this altar is, or does in the lives of the cultists (cf. van de Port I998). 
Baroque, by contrast, is a style that seeks to make you aware of the impossibility to capture the jumbles of the world in such neatly organized schemes and structures. In a recent historical overview of the use of the term baroque in art history and philosophy, Helen Hills concludes that the term 'readily lends itself to extension such that it becomes meaningless' (2007: 67), yet she nonetheless urges researchers to investigate its hermeneutic potentialities and possibilities 'outside the standard usages by art historians' (ibid.). ${ }^{7}$ The dimension that I would like to highlight in a baroque aesthetics - a dimension that undoubtedly struck me because of my readings of the Lacanian thinkers discussed above - is that its expressive forms constantly draw attention to the failures of representation; the lack that is at the heart of all totalizing narratives; the limits of control; the shadowy zones, the interstices and the areas-in-between that every order produces. Compared to the classic proposition that 'to name is to know', its sensibilities are much closer to the kind of anthropology this book proposes.

To evoke the particularities of a baroque modality of world-making, I might start with the observation that the baroque is permeated with the notion of an 'absent truth' (Benjamin 2003; cf. Cowan I98I; Reijnders I99I; Wolin I994). Being the art of the Counter-Reformation, as well as the art of the conquest of the New World, the baroque sought to impose a reinvigorated Roman orthodoxy on the wavering believers in a Europe ridden with religious conflict, as well as on the pagan peoples of the New World. Stressing the unfathomable nature of divine power, while at the same time making that power felt in the sensual pompousness of its arts and ceremonies was very much part of this attempt. 'You don't have to understand it, you have to accept it for real' was at the heart of what Birgit Meyer would have called its 'aesthetics of persuasion' (Meyer 2009; cf. Valle 2002: Hills 2007).

One of the expressive missions of the baroque was thus to draw attention to its premise that the world is brought to order by an 'absent truth'. To accomplish this task, baroque artists developed a whole set of forms geared to produce the double effect of, on the one hand, highlighting the fact that people live in man-made, and therefore imperfect worlds, and on the other hand, highlighting the glory of Divine Power as the sole force that is capable of bringing these imperfect worlds to harmony. The imperfections of man-made worlds found expression in such forms as the celebration of the artificial and the 'mannerist'; a fascination with the incongruent, the disharmonious, the monstrous; a tendency to indulge in excess, heterogeneity, fragmentation; a preference for deceptive forms 
such as the labyrinth, the metamorphosis, the fold, the curve, the trompe l'oeuil; as well as in the preference for 'shallowness' (as in the opaque surfaces of the façade) and 'emptiness' (as in the ample use of the emblem). All these stylistic devices and strategies helped to convey an image of the world as a place that finds itself in a state of loss, a place that is lacking meaning and finds itself at the brink of all out fragmentation, and as such, a place in constant need of the splendor of the divine so as to be kept together. Baroque altars are probably most illustrative as to how the baroque sought to express the cohering force of the absent divine: for it is only in the grand total of the architectural structure that the jumble and wild profusion of ornaments is - mysteriously - brought to coherence.

Clearly, this cosmovision, which puts an absent God at the center, plays on people's desire to establish a relationship with that God. Another set of expressive forms typical of the baroque sought to accommodate (and stimulate) this desire: the cult of the visionary saints; the mystics and their ecstatic and erotic bodily languages of immersion and transgression; the transubstantiations; the miracle, the 'impossible becoming possible' through which God affirms his power over the world ('I define the possible!'), but not his presence in the world (as the miracle always evokes an elsewhere beyond human comprehension).

This historical baroque survived the specific circumstances that gave birth to its expressive forms, or, as some would argue, this historical 'baroque' is but a particular manifestation of an aesthetic impulse that can be found in many epochs and places (the Hellenistic period in antiquity being the well-known example). ${ }^{8}$ As Omar Calabrese and others have argued, the baroque might be understood as a trans-historical 'category of the spirit', which sets itself up against the spirit of the classic. The Dutch art historian Frank Reijnders, in a wonderful little book called Metamorphose van de Barok (199I), has for instance shown how the spirit of the baroque lived on in the realm of fine arts as the anti-art, whose impulses kept (and keep) undermining romantic notions of art's totalizing visions of the sublime. Time and again, the baroque impulse sets out to show the falsity of the promise that the artwork enables the beholder to partake in the mysteries of the world. In cultural studies and the social sciences, the baroque is now regularly invoked as John Law recently phrased it, 'as a set of procedures and sensibilities that refuse representation and seeks to know, appreciate, trouble, and/or redeem the world allegorically through the fractured and endlessly recombined play of separating and joining.' The continued relevance of baroque forms of world-making is also evidenced in the many postmodernist thinkers who have discussed and/or 
picked up the style, the ethos and the sensibilities it expresses (Chiampi I998; Day I999; Ndalianis 2004).

My intention to study the history of encounters between outsiders and people from Candomblé - and the public renditions of the cult to which these encounters gave rise - as (in)formed by the tensions between 'classical' and 'baroque' forms of world-making is grounded in historical, political and epistemological considerations.

To start with the former, the historical relevance of the baroque for a place like Bahia is evident. The old colonial capital of Salvador is rightly famed for its baroque heritage, and as I will document in the chapters to come, I found the spirit of the baroque to be omnipresent in Bahia: in its architectural legacy of colonial churches, convents and palaces; in the endless folds of the saints' robes in the Museum of Religious Art; but also in the endless folds and curves of Bahian feasting, decorating, talking, dressing, posing, and flirting. ${ }^{10}$

Baroque came to Bahia with the Jesuits - the intellectual mentors and guardians of the spirit of the Counter-Reformation - and had all the characteristics of an 'aesthetic of conquest', seeking to impress on its subjects the truth, but not necessarily the understanding, of the new(ly invigorated) faith. With the eviction of the Jesuits from the Brazilian colony in I755, lay brotherhoods, the so-called irmandades, became the backbone of colonial Catholicism in Brazil, and an important institution in the public life of the colony. As the principal performers of Brazilian Catholicism, the brotherhoods were the prime transmitters of a baroque aesthetics and the ethos implied therein. Their organization followed racial lines, as there were separate brotherhoods for whites, mulatos, crioulos (Brazilian-born blacks) and the African slave population. The black brotherhoods

... formed a space of relative black autonomy in which its members - through the organization of festivities, meetings, elections, funerals, masses and mutual assistance - could construct socially significant identities in a universe that was oftentimes suffocating and always shot through with uncertainty. The brotherhood was a kind of ritual family, in which Africans, cut loose from their native lands, lived and died together. Idealized by the whites as a mechanism to domesticate the African spirit ... they constituted an instrument for the production of identities and collective solidarity (Reis i996: 9). 
Within the larger picture, however, for slaves 'to enter a brotherhood was the most evident form of being socially inserted in Portuguese America' (Souza 2006: I86).

Some brotherhoods were extremely rich, others poor. Yet given such differences, they were all organized in the same way: they had the same hierarchical structure; they were engaged in the same kind of activities (the organization of the worship of their patron saints through celebrations, processions and the building of altars, chapels and churches); and they all assumed the same responsibilities for their members (looking after the religious and spiritual well-being of the brothers, and guaranteeing them a decent funeral). With time, says João José Reis (2003) in his discussion of the brotherhoods, they became the prime institution for Bahians to organize and celebrate their sense of belonging.

Due to the fact that Bahians from all levels of society participated in these highly comparable organizational units, the brotherhoods became the most important vehicle through which social groups sought to express their social ambitions and actual ascendency in the public sphere. The black brotherhoods were no exception. As Mariza de Carvalho Soares (2000) and other historians have shown, the black brotherhoods were fully engaged in the fierce competition between the different brotherhoods, who sought to outdo each other in the lavish decorations of their altars and the pomp and splendor of their processions and ceremonies. Even the poorest of the brotherhoods tried to copy the forms of the most prestigious ones (Soares 2000: 165-166). The churches and altars of the black brotherhoods - often dedicated to black saints such as São Benedito - were fully designed and executed along the lines of the baroque, a clear indication that Bahian blacks sought to express themselves through (and thus sought to be publicly included in) the cultural forms of the colony. Public competition between the brotherhoods united them in employing the same aesthetic repertoires, and it was thus that they dispersed baroque aesthetics and imaginaries to all groups and classes in colonial society. So much so that today, every single person in Bahia whom I offered the thought immediately confirmed: Bahia is 'muito barroco' (very baroque).

Particularly relevant to this study is the fact that the formation of Candomblé took place within - and drew upon - these brotherhoods. Many of the ritual and aesthetic practices that are found in contemporary Candomble have their exact equivalent in what historians have documented and described for the brotherhoods - from the use of fictive kinship terms by brotherhood members to the ample use of fireworks during religious celebrations; from the communal meals to the 'profane' dances that closed 
religious ceremonies; and from the attempts to co-opt people of standing into one's ranks so as to be able to exert influence in the public arena to the mimicking of courtly dress.

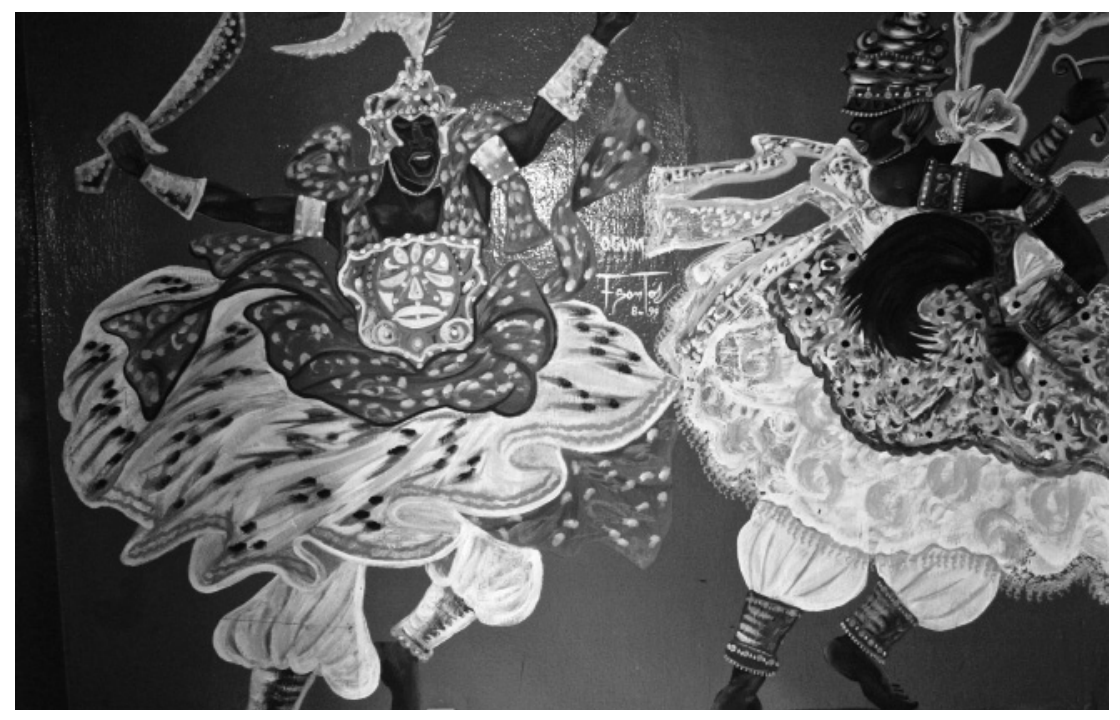

Figure 3 Orixás, mural in Salvador 2007

My argument that the modalities of world-making that one finds to be operative in Candomblé are thoroughly baroque brings me to the politics of the choice for the terms 'classic' and 'baroque', and by implication, the politics of this book. The great majority of anthropological studies on Candomblé tell you to study the cult as an Afro-Brazilian formation. Candomble's cosmology, rituals and aesthetics are to be seen through the prism of their 'Africanness'. Clearly, there is by no means a unified understanding as to what this 'Africanness' means, and whether it ought to be understood as 'root', 'origin', 'survival', 'resistance', 'invention', 'continuation', 'core', 'display', or 'memory'. Yet virtually all studies position Candomblé in this particular framework.

This tendency to study the cult as an 'African' formation is reinforced due to the fact that in the research arena that is Salvador, anthropologists and people from Candomblé are engaged in a lively and ongoing dialogue. Many of the latter have embraced the so called 're-Africanization' of the cult, an ideological project that, I will argue, is informed by the 'spirit of the classic' as it denounces syncretistic forms and practices such as the doubling of orixás with Catholic saints, or the celebration of mass before 
or after Candomblé rituals. Such practices are increasingly seen as 'degenerations' of an authentic, purely African religious form. The search for African purity on the part of cultists, and its 'discovery' in the so-called 'Nagô' (Yorubá) tradition (Capone I999; Dantas I988; Matory 2005; Parés 2006), is increasingly intertwined with the identity politics of the Movimento Negro, the black movement (cf. Santos 2005). As one commentator put it, priests, activists and many scholars found each other in the pretension to "homologize the "Nagô" traditions on both sides of the Atlantic, molding them into an undifferentiated unity' (Brumana 2007). In contemporary Salvador, subscribing to this particular perspective is very much the 'politically correct' thing to do, and academic scholars are not always impervious to such pressures.

It goes without saying that the call to study the history and formation of Candomble in the context of a Black Atlantic, as Paul Gilroy (1993) dubbed it, makes sense: there are obviously many African contributions to this religious imaginary, its forms and practices. There are also, most certainly, deeply felt, nostalgic sentiments for a lost homeland that inspire the foregrounding of these African elements. In the course of my research I came to realize, however, that Candomble is as much heir to the baroque ethos and the aesthetics of colonial society. Not only the colonial society that came into being in Bahia and the New World, but also the baroque aesthetics that had already rooted in African kingdoms (cf. Souza 2006: 2I7 ff.). It might be argued that next to a Black Atlantic there was a Baroque Atlantic. The garments in which the spirit mediums are dressed when possessed by the orixás - silver crowns, golden helmets, lavishly decorated staffs and scepters, lace blouses, hoop skirts and crinolines are but the outward signs of what is a far deeper merging of the religious imagination in Candomblé with baroque forms of world-making.

I find it astonishing that the baroque dimensions of Bahian Candomblé are almost absent from the anthropological canon of Candomble studies. Baroque aesthetics are everywhere in Candomblé, and yet, one is supposed not to notice it. ${ }^{11}$ If the baroque heritage of other Afro-American religions such as Santeria and Vodoun has been recognized and discussed (Brown 2003; Middelanis 2005), Candomblé studies tend to turn a blind eye to this prominent feature of the cult. Roger Bastide's early Imagens do Nordeste Místico em Branco e Prêto (I945), is the noticeable exception here. Sitting in one of the many baroque churches in the historical center of Salvador, the French anthropologist contemplates the striking correspondences between churches and candomblés: 
When one visits churches and candomblés, an analogy imposes itself, even against one's will, between two modes of ecstasy. Down there, in that intensely green valley, between the palm trees, the banana trees, and the thick undergrowth of plants that carry the names of saints and orixás - Bush-of-Ogum, Saints-wood, Carpet-of-Oxalá, Wounds-of-Saint-Sebastian - the tam-tam of the Negroes penetrates one's being through the ears, through the nose, through the mouth, hitting one in the stomach, imposing its rhythms on one's body and mind. Here [in the baroque churches of the upper city] it is the tamtam of the gold and the ornaments that penetrates us, not through our ears but through our eyes. As with the other tam-tam, that of the sanctuary of the spirits, it is inescapable. Attempts to escape from the golden profusion by closing one's eyes are in vain. It is as when one has been looking into the sun for too long: luminous stains, a whirling of reds and yellows going through one's brain. Opening one's eyes again, there is no way to put one's spirit to rest. The light plays over the low columns, it nestles in a black vine, in a green leaf, a sacred bird, an angel's smile, and then leads us to yet another glittering spot, with the effect that everything seems to be dancing and whirling, a spinning sensation that soon captures our own heads. Here, all that is profane in us has left us. Here, it is impossible to link two ideas, or to coordinate a thought: we find ourselves turned over to the most terrible of adventures (Bastide I945: 27-28).

In his later work, however, Bastide would never again be so explicit about the elective affinities between the spirit of the baroque and the spirit of the Afro-Brazilian religions.

How this curious blind spot in Candomblé studies came into being may be related to a critique voiced by Marina Mello de Souza in her study of the Congado, the annual rituals in colonial Brazil whereby slaves crowned their African king. The study of Afro-Brazilian cultural forms and practices, says de Souza, tends to frame everything in terms of either 'repression' or 'resistance', thus reducing Afro-Brazilian history to either a tragic or a heroic tale. What gets excluded in this perspective is the cultural encounter, the mixture and hybridization that comes into being when people try to make it in the New World, holding on to 'things African', but also finding themselves seduced by the aesthetics of the dominant class in colonial society, an aesthetics they actively sought to appropriate and incorporate (Souza 2006). Fully endorsing de Souza's critique, the politics of this book is to show the permeability of all cultural boundaries - the way they are constantly transgressed, and the way they are constantly reinstalled, in a doomed attempt to bring the 'plenum of existence' to order. If we accept 
that all boundaries are ideological constructs, imposed on a world that defies their absoluteness, our task as anthropologists is to study the work of culture in the light of its constant failing.

This brings me to the epistemological reasons to opt for the baroque as the prism through which I will look at my Bahian findings. I found the spirit of the baroque far more capable of expressing the failures of cultural forms than the spirit of the classic that reins the academy. You will thus not only be reading about the classic and baroque impulses through which public forms of Candomblé come into being; you will also be reading a text that is itself a result - and example - of the way these impulses impinge on the process of world-making. In many ways, this is a baroque text. It looks at Candomblé from an oblique angle, and attempts to de-center prescribed, 'natural' perspectives on the cult. It is also baroque in its attempt to 'de-naturalize' the ethnographic text by highlighting the 'mannerisms' that go into the conventional modes of anthropological world-making. It is baroque in the acknowledgement that my voice is plural, the articulator of contradictory feelings and desires, rather than a solid, unified narrator. This text is baroque in its recognition that all anthropology is deeply allegorical, as it confiscates local knowledge to invest it with the privileged meaning of anthropological theory. And last but not least, it is baroque in showing that the anthropologist is subject to powers beyond his control.

Having said all that, I want to stress that the challenge is to understand baroque and classic modalities of world-making not as mutually exclusive, but as dialectical - generating a constant tension from which the dynamics of world-making follow (Ndalianis 2004). I can therefore reassure you that you will not find yourself lost in endless curves and folds; or stuck in mystical utterings akin to that meaningless yet deeply significant 'zumzum-zum-zumbaba' on Avenida Oceânica. Having been brought up in the spirit of the classic, and having been honed to work its power of articulation, impulses of the classic are at work in every baroque move I allow myself to make. 



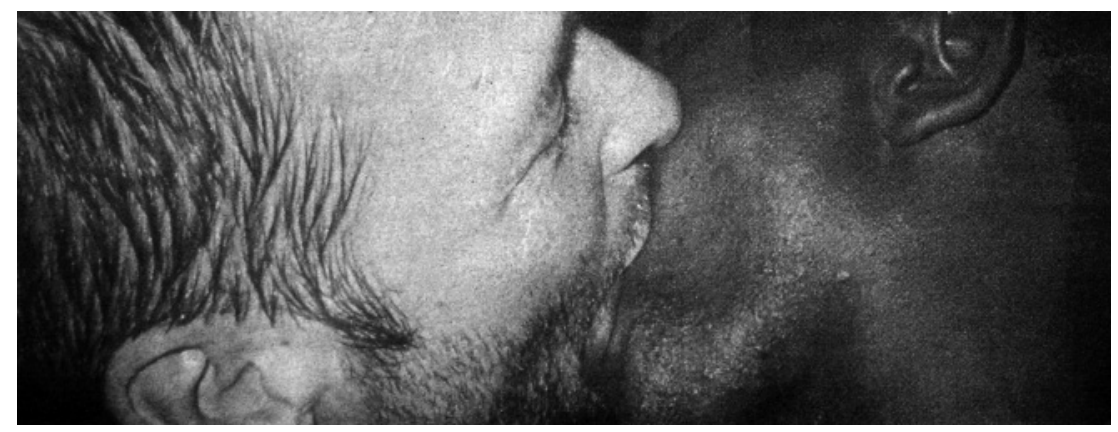

Figure 4 Tout le monde comprendra que je préfère un gros Saint-Bernard à une Mlle Franfreluche qui peut exécuter des pas de gavotte, et de toute façon un jaunt à un blanc, un nègre à un jaunt, et un nègre boxeur à un nègre étudiant. - Arthur Cravan (1887-1918) 


\section{1 \\ ON IMME'SION}

Academics and the seductions of a baroque society

Everyone will understand that I prefer a big Saint-Bernard to a Mademoiselle Franfreluche who knows to perform the steps of the gavotte, and certainly a yellow man to a white man, a black man to a yellow man, and a black boxer to a black student.

When I came across these words by the Dadaist artist Arthur Cravan (in Shelton 1984: 323) they were instantly recognizable, their content and tenor effortlessly graspable, commonsensical to the point of simply being true. Who would not understand this set of preferences? Who would not opt for the possibility to trade the world of Mademoiselle Franfreluche and her well rehearsed steps for a place where experience has the immediacy of clean punches, left jabs and right uppercuts? Let me be dragged along over snow-covered mountains. Let me court ever-darker shades of black, with all the moving out of control, and all the risk-taking this courting might imply.

There is no denying that the promise of Saint-Bernard dogs and nègres boxeurs is what makes me end up in places like Bahia - hot, exuberant, ever-dripping Bahia, where a gringo such as myself is subjected to a 24-hours invitation to drop the studious attitude, to part from scholarly 
ways of getting to know the world, and enter into more immediate modes of being.

You would not want to be deceived, however, into picturing me as a kindred being to the pugilist, poet, traveler, crook, loudmouth, provocateur and troublemaker that was Arthur Cravan. ${ }^{12}$ I was raised under the sign of the gavotte: once a stamping peasant dance from the Dauphinée that had allowed 'for the lord to kiss all the other ladies, and for the lady to kiss all the other lords', but destined to become a baroque affair of elegant nodding and courteous bowing, "intricately choreographed both in terms of step execution and floor pattern. ${ }^{13}$ From desirous kissing to courteous bowing: that pretty much characterizes all that I was made to be when growing up in a middle-class suburb in the Catholic deep south of the Netherlands. Here, the derivatives of the cultural and sexual revolutions of the late I960s and early I970s had arrived in such forms as homespun, hand-knitted sweaters, Bulgarian folk dancing, macrobiotic recipes, feminist inspired relational experimentation and indeed, the playing of distinctly pre-modern baroque music. I vividly recall the long evenings that were passed behind a music stand when the family consort had sat down to play gavottes and sarabandes and gigues: images of my father noisily sucking the accumulated saliva out of the mouthpiece of his ebony alto recorder in-between two cadenzas while his then girlfriend Alice danced around the living room in burgundy velvet knickerbockers, trimmed with colored ribbons and lace. Her very own, vaguely feminist reading of I8th century elegance.

The disconcerting part of such recollections is that I cannot claim to have been embarrassed by such unbecoming spectacles. Then and there, these were genuinely pleasurable moments. So better think of me as a close relative of Mlle Franfreluche. We are always mindful of step execution and floor pattern. We go after the yellow man and the black man by studying them. We let the Cravans of this world say the provocative things, and then we quote them. Diligently copying Dadaist effronteries is about as close as we come to the fancy of being something of a pugilist ourselves.

\section{䜪}

A newcomer in the global market for passionate encounters with exotic others, Bahia seduces its visitors to enter into more immediate modes of being, to immerse themselves in its glorious here-and-now. Insistently and with great verve it plays out its trumps in this flirtatious game. It holds 
out to you perfectly muscled black men that hang out on the balustrades at Porto da Barra Beach. It adorns these bodies with flowered Bermudas, just to soften their gangster-look - pink hibiscuses, gay camellias, frivolous palm leaves, jungle-book lianas in shocking blue, all of this to prompt you to take at face value offerings of instant friendship. 'Hey, amigo!' 'Oba, gostoso!' It produces soft sea breezes that tempt you to stray from research itineraries and simply drift out onto the ramshackle streets of old Salvador on a cloud of bittersweet caipirinha. It sends around distant rhythms of samba and pagode that help you to ignore all too sensible warnings about all too real violence. It summons up carnival mobs thumping down the Avenida Oceânica, that seek to draw you in, to make you submit yourself to their whirling choreography, to lose yourself in the larger body of a crowd that expands and shrinks, swells and contracts. It directs you towards the gigantic catedral da fé, where the church leader, deep down on his altar, begs you to join the thousands as they cry their heart out in search of Pentecostal salvation. 'Jesus!' And then it sings to you on the radio waves that 'there is no such thing as sin, south of the equator', or Elis Regina's famous

Hoje cedo, na Rua do Ouvidor

Quantos brancos horríveis eu vi

Eu quero um homem de cor

Um deus negro do Congo ou daqui

Que se integre no meu sangue europeu

Black is beautiful, black is beautiful

Black beauty, so peaceful

I wanna a black I wanna a beautiful

Hoje a noite amante negro eu vou

Vou enfeitar o meu corpo no seu

Eu quero este homem de cor

Um deus negro do Congo ou daqui

Que se integre no meu sangue europeu
Early today, on Ouvidor Street

How many horrible whites I saw

I want a man of color

A black god from Congo, or from here

Who will merge with my European blood

Black is beautiful, black is beautiful

Black beauty, so peaceful

I wanna a black, I wanna a beautiful [sic]

Tonight, black lover, I will

Adorn my body with yours

I want this man of color

A black god from Congo, or from here

Who will merge with my European blood

This Bahia leaves you at the doorstep of greasy eateries in rundown neighborhoods, where you give in to the temptation and order a spicy stew like dobradinha or sarapatel, just for the sake of it containing tripe and other, rather undefined giblets, which somehow help you to imagine that you are entering the inner state of things.

For that is where you want to be in Bahia: on the inside of things. To be able to sit as wide-legged, to caress your crotch as thoughtless, to drink 
your beer as gluttonously, to sweat as worry-free as that fat, middle-aged Baiano that I once observed during a late afternoon concert on Terreiro de Jesus: just to be able to live so fully immersed in those sunlit rolls of fat and then to sing along as wholeheartedly, as if that were all there is to say: Bahia, terra da felicidade ... (Bahia, land of happiness...).

\section{衡}

I know. I should not be writing like this. I should be moving into a more dispassionate register and explain how this place was made into a fetish - not how I came under its spell. Especially in Bahia, where Candomblé has been made into an icon of Bahianess, and where the combined forces of the Bahian state, the tourist industry, the art scene and the market see to it that all visitors, from the moment of their arrival, are emphatically informed that they are entering ' $a$ Terra da Magia' (the Land of Magic), 'O Capital do Feitiço' (the Capital of Fetishism), or 'A Velha Feitiçeira' (The Old Sorceress). As I will document in the chapters to come, to be 'enchanted' by 'mysteries' is the experience to be looking for in Bahia.

But then again, the anthropological prescript to deconstruct Bahia's magic straight away - to highlight its being a cliché, a sham, a tourist trap - produces its own mystifications. For it needs to be pointed out (and I can hear Mlle F. prompting me here ...) that I was certainly not the first foreign anthropologist who came to do research in Bahia, more in particular its terreiros de Candomblé, to find himself carried away by a desire to merge with the objects, practices and people under study. You only have to move to the margins of the ethnographic canon on Bahia to find the indications that many of my predecessors had been probing the alternative routes that might lead towards getting to know this place: trading an inspecting gaze from the sidelines for the more sentient and experiential understandings that come with closeness, proximity, intimacy, fusion, or immersion. ${ }^{14}$ Roger Bastide stated that writing about the cult always left him 'hesitating between science and poetry' (I945: 9) and he urged anthropologists not to live alongside the experiences of the group under study, but to share those experiences to the full:

We need to transform ourselves into that which we study .... It is necessary, as in an act of love, to transcend our personality [...] I became convinced that, the moment I would enter the temple, I would have to let myself be penetrated by a culture other than my own. Scientific research required of me to take the first steps towards initiation (Bastide, in Silva 2000: 96). 
Pierre Verger, a French ethnographer and photographer, rightly famed for his elegant black-and-white travel photography, including many (undeclared, but rather unmistakably) homo-erotic portrayals of men from the Bahian popular classes, moved to Bahia in 1946 to live there until his death in 1996. Verger stated that Bahia was the one place where he could be 'one with the Africans' and escape from Europe's stifling academic surroundings, ${ }^{15}$ and although he declared himself to be 'too French' to receive the spirits from Candomblé, he too was (partially) initiated and adorned himself with the African name 'Fatumbi'. In the introduction of one of Verger's books on Candomblé, Bastide comments

He belongs to the world of the candomblés; he was accepted by the Negroes of Bahia as one of them, as a true brother, a white brother [...] Pierre Verger is more than a participating observer, because the word 'observer' draws, in a certain way, a barrier, and splits the ethnographer - in a most unpleasant manner - in 'outsider' and 'insider'. Whereas the knowledge of Pierre Verger is the fruit of love and communion (in Silva 2000: 99).

Love and communion. Acts of penetration. Ruth Landes, the American anthropologist who studied Candomblé in Bahia in the late I930s, was scorned by her colleagues for having entertained love affairs with Bahian men of color (Cole 2003). Juana Elbein dos Santos, the Argentinean anthropologist and author of the classic Candomblé monograph Os Nagô e a Morte (1998), considered full initiation into the cult a prerequisite for any researcher and ended up marrying the son of one of Salvador's most prestigious priestesses. Giselle Cossard, the French anthropologist who came to study Candomblé became a priestess and opened up a temple in Rio de Janeiro (Dion 1998). And then there was Hubert Fichte, a self-made 'poetic ethnographer' from Germany who lived in Bahia in the I97os and who, after having visited priestess Olga de Alaketu, observed things like 'Ihr sohn, hübsch, sexy, arrogant, I9, hat schon einen Bauch' (her son, handsome, sexy, arrogant, I9, has already a protruding belly) and 'Die Mädchen sticken sich beim Tanzen auf eine obszöne Art die Zunge heraus' (when dancing, the girls stick out their tongues in a most obscene manner, 1987: 25). And then me, of course. 'Ah. Yet another anthropologist!', is what Jesualdo - a lily-white Baiano - said when he heard about my profession. He sighed ostentatiously. Then added: 'You know, if you ask me, they all come here to get laid by some negão (big black man).'

Moving towards intimacy and fusion, many anthropologists working in Bahia found their customary hierarchical ordering of the 'higher' and the 
'lower' senses reshuffled, so that touch came to precede vision; taste got primacy over spoken words; and the body had shivered before the mind knew why. In one of the great Candomblé ethnographies, entitled The Taste of Blood. Spirit Possession in Brazilian Candomblé, author Jim Wafer described how he ended up kissing the lips of a spirit medium possessed by the lascivious pomba gira spirit (and tells us she had a prickly moustache). He wrote highly evocative prose about his initiation into Candomblé:

After Marinalvo decapitated the bird, Dona Laura applied the bleeding stump of its neck to various parts of my body: to the same five places on my head, to the back of my neck, the palms and backs of my hands, and the tops of my feet. She then removed bunches of feathers and stuck them on the smears of blood. I think I had expected to get a mild thrill of moral indignation or disgust from this experience. What shocked me instead was that I found it so sensuous. The contact with the warm downy body of the little bird evoked memories of nuzzling the intimate parts of a lover, or of my mother; images of Leda and the swan, of the eagle and Ganymede; perhaps traces of my long forgotten experience of being born. It violated all the boundaries that made me separate from the rest of creation, and, like creation, it was beautiful in its profligacy (Wafer I99Ib: I50).

In Beneath the Equator. Cultures of Desire, Male Homosexuality and Emerging Gay Communities in Brazil, Richard Parker reports to have found his 'relatively abstract intellectual curiosity in the construction of sexual meanings in Brazil [...] quickly transformed into an intensely personal affair' when he met his partner to be (Parker 1999: I2); Don Kulick's book on Bahian transvestites was marketed with a back-cover text saying

wow, wow, wow! Take a walk on the really wild side, where you get to be ultra-intimate with some remarkable human beings, whose lives are not only extremely dangerous, physically brutal and emotionally tragic, but at the same time joyous, sexy, proud and free! (Kulick I998, back cover)

So let us say that anthropologists were not at all times carefully minding step execution and floor pattern as they moved about in the field. Let us say anthropologists were not at all times insusceptible to the fetish's charms; not at all times aware of the tricks that Bahia played out in front of them; or indeed, quite willing to suspend their disbelief. We may have smirked over Surrealist Benjamin Péret who, having visited Candomblé 
temples in the I92os, claimed to have found the 'marvelous' in the AfroBrazilian religions where "the religious and the erotic occurred in the same moment' and where 'Josephine Baker was a pale shadow when compared with the dancers of the Candomblé' (Péret I992). We may have mocked Gilberto Freyre a bit, calling him 'o supreme exponente da lusotropsicologia' (Fry 200r: 43) for having dwelled a bit too long on the thought that the Brazilian nation 'foi feita na cama' (was made in bed), and for having depicted Brazilian race relations as taking place in an ever sultry atmosphere. But what about all these more or less hidden fieldwork scripts promising a very similar 'ultra-intimacy' in erotic encounters, in initiation, in possession, in conversion, in consumption, in the ecstasies of music, dance and carnival?

Clearly, revelatory memories of 'nuzzling the intimate parts of a lover' sit somewhat uneasily with the habitual academic modes of knowledge production. Apparently it is one thing to discuss the fact that our informants are sentient beings, who embody their culture; or to seek to undo the Cartesian mind/body divide in our explanations of other people's doings; but it is quite another thing to acknowledge that the anthropological enterprise is itself an embodied practice; that it is not just our minds, but also our bodies that travel to far away places; and that this bodily presence may be relevant for the ways we come to understand the cultures we study ${ }^{16}$ In that respect, Wafer's confidences are extraordinarily candid. Slippages into immersion rarely make it into our texts. They come to be defined as belonging to the 'after hours' of research activity. They are relegated to 'the private sphere' and hence need not be mentioned, or may be subtly and eruditely evoked by quoting Bataille or Nietzsche (or Arthur Cravan). It is through such procedures that we continue to present ourselves as dispassionate observers, cool analysts, levelheaded academics who never get carried away. Tellingly, the university press that published Don Kulick's book made sure to inform the readers that the lustful wow, wow, wow on the back cover was uttered by a transvestite, not an academic. Tellingly, when Hubert Fichte 'outed' Pierre Verger as a homosexual in his ethnography, 'mentioning the name of the German writer in Verger's presence was taboo'. ${ }^{17}$ Tellingly, I have still not made up my mind as to whether or not I should mention Victor in this text.

\section{擦}

Look, I really would not be discussing all of this (says Mlle F.) if it were not for two facts relevant to this study: the fact that Bahians insistently 
tell visiting anthropologists that level-headedness and staying aloof is not the way to go about getting to know their world - and the fact that I soon became susceptible to such insinuations.

To start with the 'natives' point of view', I found that most Bahians are not inclined to put a premium on the cerebral rationality that underlies academic injunctions to maintain one's distance so as to be able 'to see things better.' Of course, with its long colonial history, Bahia has a feel for hierarchy, and in their own way Bahians accord respect to academic posturing and bookishness. They say 'Yes, Doutor! Sure, meu Xefe! Valeu, meu Patrão! All right, meu Rei!' But they do so with twinkling eyes and a big, big smile. And then they go on persuading you that this, of course, is not the way to move around their world. Now come here, they say. Realmente. Sit down. Put away that book. Join us for a beer.

Initially I figured their joyous laughter over having unmasked yet another doutor as a-carnal-being-after-all was all part of the leisurely reposing in the company of friends. With time, however, it began to dawn on me that there was more to these incentives to drop the studious attitude. The cervejinha na rua - which is all about the consumption of the moment, an immersion in the here-and-now as it passes from one beer bottle to the next - is in fact a variation on a theme that I found to be omnipresent in this society. In all kinds of arenas, Bahians tend to foreground the immediacy of the experiencing body as the privileged mode to be in the world, and thus to come to know it. Or to be more cautious, that is what outsider observers find them to be doing. Take for instance the way in which J. Lowell Lewis, who did a study on Bahian capoeira, introduces his readership to this martial art:

... the players had achieved a state of exhaustion that bordered on trance. Yet it was precisely this bone weariness which the men had sought, as a kind of liberation, freeing them from social obligations and personal worries, relaxing bodies to an elastic flexibility and focusing their attention on the game and the game alone. Most of these men and boys had known each other before the festival [...] But now they were beginning to understand each other deeply, in a way that had nothing to do with kinship, occupation, wealth, status, or previous history. These men had no use for such extraneous information now, they were immersed in a fundamental communication of bodies and wills, of slashing feet and twisting torsos: they were seeing into each other, trying to discern physical habits, emotional weaknesses and rational resources which could be brought to bear in the ring (Lewis I992: xvii). 
In music and dancing it is no different. Time and again it has been noticed how talented Bahian dancers become the music. Sometimes boisterous, with exhilarating energy, as in samba, pagode, or arrocha; sometimes seriously devoted to their dancing partner, as in the pair dancing that is forró; sometimes deeply concentrated as in the spectacularly beautiful modern dance performances that I witnessed in the city's theaters. But at all times, says Barbara Browning, the dancers 'throw themselves headlong into the pleasure of having a body' (I995: 88). Such outsiders' perceptions have been confirmed and reinforced in dialogues with Bahians. One of my students, studying Afro-Bahian rhythms in Salvador, was told to 'dance while drumming' in order to get the right swingue. As his drumming teacher put it: 'You must imagine the Baiana moving her sensual body to your rhythms. She shakes her ass, swings her hips! Like that! You have to see her when you play. You have to feel her! You have to be her!'(Vinkenoog 2003: 83).

It is exactly this instruction to move from 'seeing' to 'feeling' to 'being' that exemplifies the Bahian intuition that immersion is what it takes to come to knowledge that matters. Carnival magnifies this intuition, as is beautifully expressed in Chico Buarque's samba Quando o carnaval chegar (When carnival comes):

Whoever should see me, always quiet and remote

Would guarantee that I don't know how to samba

I'm just waiting for carnival

I'm only watching, learning, feeling, listening

I can't speak

I'm just waiting for carnival

I watch the porcelain legs of the girl who walks by

And I can't catch hold of her

I'm just waiting for carnival

It's been so long that l've wanted your kiss

Moistened with passion fruit

I'm just waiting for carnival

And whoever offends me, humiliating me, stepping on me

Thinking that l'll put up with it

I'm just waiting for carnival

And whoever sees me taking life's blows

Doubting that l'll fight back

I'm just waiting for carnival

I've got so much joy that's been put off and held in

If only I could cry out 
I'm just waiting for carnival

I'm just waiting for carnival

I'm just waiting for carnival $^{18}$

Here too, connecting oneself to the world by 'watching', 'learning', 'fantasizing', 'putting off and holding in' is clearly deemed inferior to the ultimate being-in-the-world that a mode of immersion allows to happen.

As indicated in the introduction, in a deeply religious place like Brazil, the call to immerse oneself easily slips into one or another form of spirit possession: where the believer's body becomes an empty vessel, animated by the spirit of his or her religious imagination. Rilza, a domestic worker in her late thirties told me (all giggles and embarrassed looks) a story that beautifully illustrates the porous and permeable nature of the boundaries that divide the religious from the popular, and how these domains are connected by an underlying cultural dictum that says: immerse! In the pre-Carnival period of 2003, when all the Bahian radio stations played that year's hits-to-be, she told me that she was 'a bit worried' to listen to the radio because a song called Dandalunda - by the popular singer Margareth Menezes - came on all the time, and at one point, the spirit called Dandalunda (to which the song refers) had possessed her. 'I was mopping the floor, when Margareth came on the radio, and the spirit just took me!'

Possession may be disturbing (as Rilza clearly communicated), yet the prevalence of such 'ecstatic' and embodied forms of religiosity in Brazil is hard to miss. So much so that some have argued that, in religious terms, Brazil is first and foremost a 'spiritist nation' (Carvalho I994: 70). In AfroBrazilian religions - Candomblé, Xangô, Macumba, Batuque, Tambor de Minas, Vodoun - 'intimacy with the divine has been a hallmark of religious experience' (Harding 2000: I54). Restyled so as to make this intimacy accessible for the Brazilian middle classes, divine possession is central to Umbanda and Kardecist spiritism (Ortiz I999; Hess I99I). It is also the sine qua non of 'receiving the Holy Spirit' in the Pentecostal churches that are mushrooming all over Brazil, just as it informs the techniques of embodiment practiced in the charismatic movement of the Brazilian Catholic church. All these religious traditions and inventions promise experiences of an immediate, embodied encounter with the divine. The confession of a friend about her teenage bedroom fantasies is a beautiful illustration of this desire: she would aim the portable electric fan in her bedroom at the crucifix on the wall, imagining how it might blow away the loincloth of Jesus and reveal his manliness. 
On the rapidly expanding Brazilian market for experiencing-the-divine, a proliferation of New Age-like religiosities offers ever-new techniques to make divine encounters happen. The hallucinatory Ayahuasca-drug of the Santo Daime cult, that 'opens everything' and thus 'reconnects you with God'19, or the promise that 'meditation is the way':

... in order to achieve peace of mind, calmness, firmness and happiness in one's inner life, it is absolutely necessary to move from belief to experience. This is the only thing that matters: to have certainty by the direct experience of God. ... In the midst of our suffering [...] we do not long for a vague and distant belief. We yearn for the immediate and direct experience of God! ${ }^{20}$

In all of these instances - from the cervejinha na rua to the various forms of divine possession - immersion is seen as the prerequisite to come to knowledge, or rather: the 'deep knowledge' that matters. A premium is placed on overcoming (or warding off) the body/mind divide, so much so that even one of Brazil's former presidents, Fernando Henrique Cardoso, publicly declared himself to be a "Cartesian with a pinch of Vodoun and Candomblé. ${ }^{21}$

And yet, we should probably not go along with the former president to trace a very noticeable inclination towards immersion and embodied forms of knowledge back to the African legacy in Brazil. Surely, African notions of permeable selves may have made their inroads into Bahian cultures, just as slavery and racism may have forced Africans and Afro-descendentes to make their bodies the prime site of worship for their forbidden and persecuted religions, as was suggested by Rachel Harding (2000) and others. ${ }^{22}$ But Brazil is heir to other traditions, equally inclined to foreground embodiment and immersion as the privileged mode of being in - and acquiring knowledge of - the world.

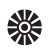

As pointed out in the introduction, immersing believers in the splendor of the divine by playing on their bodies was very much at the heart of the baroque 'aesthetics of persuasion'. Maria Lucia Montes states in her essay on the religious ethos in Brazil that baroque is the immersive aesthetic par excellence. $^{23}$

From the earliest times of the Jesuits onwards, theatre, music, song, dance and poetry had been part and parcel of the catechistic arsenal. Simple souls had to 
be conquered by stunning them; they had to be elevated to the ineffable greatness of the Sacred through the work of the imagination and the senses. Later, the form in which the churches were constructed, the decorative profusion of their ceilings, the perfection of the woodcarvings that incarnated the Saints, the splendor of the gold, sparkling in the ornaments and connecting itself with the silver so as to give liturgical objects a light of their own, the singing and the oratory of the sermon: all of this contributed to the production of that magical atmosphere in which the truths of the Faith - floating on perfumed clouds of incense - impregnated the soul through the five senses (Montes I998: I04).

Interestingly, if the African religions conceptualize the boundaries between the Self and the cosmos to be porous, allowing spirits to 'seize' human bodies (cf. Johnson 2002), so does Bahian baroque. Wherever it encounters closed boundaries, its impulse is to break these down, so as to access yonder realms. The trompe l'oeuil ceilings of baroque churches - with their breaking skies and flying angels, inviting the eye higher and higher up to the Light - are the clearest example of the Baroque preference for 'permeable frames': a pure negation of a closed structure, these ceilings promise a freedom of movement and flow between sacred and mundane domains. The attack on rigid boundaries can also be found in the baroque indulgence in ornamentation, which leads to an 'encrustation' of all clear lines, blurring all sharp divisions, and leaving all forms amorphous like a shipwreck on the bottom of the ocean. Thus, in the baroque churches of the historical center of Salvador, all you see is one golden orgy of vines, tied bows, roses, caryatides, seashells, acanthus leaves, hearts, ropes, grapes, birds, garlands, blazons, dragons, stylized torches aflame, bells and angels. Angels. Thousands of them. Cherubs and Seraphims. With and without wings. Offering their nakedness to the congregation like ever so many flashers. Punctuating the golden shimmer with their baby-colored skin and marzipan-pink nipples. Boasting silly smiles and other rather idiotic facial expressions, so stupid that you cannot help thinking that the slaves who did the woodcarving must have had a good laugh mocking the facial expressions of their Portuguese masters. Time and again, these flying creatures are positioned at the margins of architectural spaces, lending their ephemeral nature to the boundary - negating the absoluteness of the division, connecting separate domains, inviting the spectator to cross the line.

Such aesthetics might be better termed 'aesthesis' (Verrips 2006) or 'corpothetics' (Pinney 2004) to underscore that they play on the body and the senses. For the baroque interiors of Salvador's churches do not want 
you to maintain your distance in order 'to get the picture', to the contrary, they give your eyes little to hold on to, and in that way produce a sensation of being pushed off track. Curves, spirals, folds and labyrinthical patterns leave you dazzled. Indeed, dizziness is the sensation these interiors seek to produce.

In the Quarto de Santos, the saints help to frame this dizziness as being of divine origin. Life-size statues of saints occupy a long row of alcoves, proffering ecstasy as the privileged register of religious experience: São lvo Doutor, Santa Roza de Viterbo, São Elzeario, São Vivaldo, São Conrado, and other such long forgotten saints who now only live on to show us their being entranced with feverish, ecstatic facial expressions.
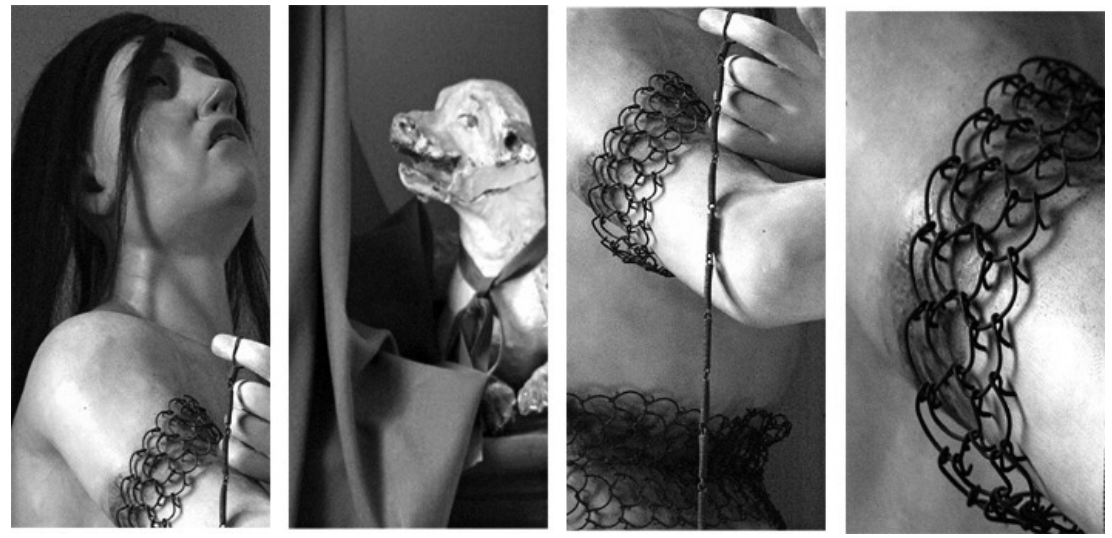

Figure 5 Santa Margarida de Cortona, Igreja da Ordem Terceira Secular de São Francisco, Salvador da Bahia

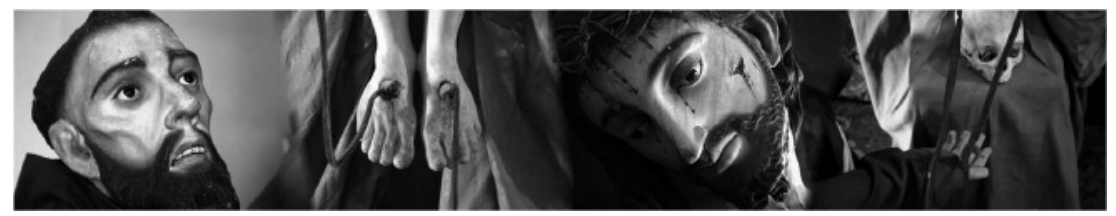

Figure 6 São Francisco receiving the stigmata, Igreja da Ordem Terceira

Secular de São Francisco, Salvador da Bahia

Looking at the statue of Santa Margarida de Cortona, half naked to show her torturous iron belts and bleeding wounds, or São Francisco receiving the stigmata, one can only agree that this is a baroque where the 'religious devotion to the statues of the saints is almost carnal and obscene' (Gonçalves 2005: 29). In Bahia, one suspects, the I6th century mystical nun Teresa of Ávila would have been understood when she reported to have been 'left afire with a great love of God' when an angel - holding 'a long 
golden spear' in his hands, with at the end of the iron tip 'a point of fire' penetrated her body, afflicting a pain

... so sharp that it made me utter several moans; and so excessive was the sweetness caused me by the intense pain that one can never wish to lose it, nor will one's soul be content with anything less than God (in Cangas, Sass \&

Pérez-Âlvarez 2008: 248).

'Brazilian Baroque,' says Mlle F., insisting I add her favorite quote, 'delighted in the tumescence of carnal forms, in the provocative swelling of the flesh' (Underwood 2002: 524).

Later attempts, often led by European clergy, to discourage popular forms of devotion and curb popular religious celebrations for being 'empty, superficial expressions of faith', signaling 'popular ignorance', or even 'perversion and bad intentions' (Montes I998: II2) - failed exactly because they made no effort to 'impregnate the soul through the five senses'. For similar reasons, says Montes, the un-ritualizing efforts of liberation theology never had any great lasting impact. As the priest turned himself around to face his congregation and devotional songs were replaced by militant songs calling upon believers to contribute to the struggle for a realization of God's Kingdom on earth, Catholicism lost its old magic, its capacity to capture believers in the pomp and splendor of its celebrations (I998: II7). Instead, the success of the booming neo-Pentecostal churches is in no small measure due to the fact that this is a Protestantism that successfully inscribes the baroque ethos of festivity and multisensorial ritual into its liturgical forms (ibid.).

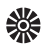

The preference for immersion and immediacy as the mode to connect oneself to the world finds yet another powerful expression in the nationalist imaginary that comes to dominate the Brazilian nation from the I920s and I930s onwards (as will be discussed in more detail in chapter four). Brazilian modernismo, a literary-artistic movement that sought to redefine the unique character of the Brazilian nation and was to gain support from the nationalist Vargas regime, celebrated cannibalism (antropofagia) as the quintessential Brazilian mode of culture-making. Oswald d'Andrade, the poet who introduced and elaborated the notion of antropofagia in the late I920s, proposed that the day that the Indians devoured the Portuguese bishop Sardinha (who was shipwrecked on the Brazilian coast in I554), 
should be 'the great date' to commemorate. Instead of copying Europe's ways and thoughts, said d'Andrade, Brazil should return to the cannibal's way of dealing with foreign things: incorporate them through that most intimate process of eating, digesting and defecating. 'Destroying so as to construct on top of it. Swallowing, in order to appropriate the enemy's powers, and thus be able to fight and conquer him. Swallowing the old knowledge, transforming it in primal material again' (Maltz, Teixeira, \& Ferreira 1993: II). Or as d'Andrade put it:

In the bulge of yesterday's freighters and slave ships, and on the decks of today's transatlantic cruisers, we imported all the mistaken sciences and art forms that European civilization created. The whole incoherent production of their printing presses was imported from overseas. They came to misguide us, with their Anchietas escolásticos [Anchieta was one of the first Jesuit missionaries to come to Brazil], with their cassocks and their dog-Latin (latinório); with their boring and false books. And what did we do? What should we have done? Eat them all. Yes. For as long as those missionaries talked, proclaiming the civilized beliefs of their tired and sad life-world, we should have eaten them and continued to be happy. We should have assimilated all those dead-born aesthetic tendencies from Europe, elaborate them in our subconscious, then to make something new, something that is truly ours (d'Andrade I990: 44).

The fact that subsequent generations of the Brazilian avant-garde explored the expressive power of the notion of antropofagia testifies to the apparently unrelenting appeal of this idea, and the provocation and scandal it brings about. The counter culture in the ig6os that came to be known as Tropicália sought to 'cannibalize' in their musical productions both local and foreign styles and technologies in what Christopher Dunn called 'a process of ironic appropriation and recycling' (Dunn 200I: II8). 'The Tropicalistas,' says Dunn 'digested large helpings of the North American counter culture of the I96os, from the hippie movement and acid rock to black power and soul music' (ibid., cf. Veloso \& Dunn 1996). But they also introduced popular music from Brazil - considered to be 'kitsch' by the establishment - as well as Afro-Bahian rhythms, in their recreations.

In contemporary Brazil, the tremendously popular songwriter Adriana Calcanhotto in turn proposes to 'cannibalize' one of the principal proponents of the Tropicalista movement, Caetano Veloso, as in her song Vamos Comer Caetano she sings to the thunderous drumming of a black Bahian drum band about how she is licking her lips at the very thought of eating, chewing, swallowing and devouring the singer raw in a 'super bacchanal'. 
What we find then, is that Bahia's constant invitation to drop the studious attitude and move one's body up close to the point of immersion is congruent with a strong, overall tendency towards the dissolution of boundaries, the transgression of frames, and the intimacy, closeness, proximity and stickiness implied therein. Of course, all of this takes place in the eye - and the body - of the beholder. Clearly, Bahia cannot be reduced to this mode of world-making, and in chapters to come instances of the spirit of the classic will pass. Yet it is equally true that the longing eye and body of the beholder meets with a dominant cultural script. In art, in social life, in religion, in festivals and celebrations as well as in basic understandings of the self, the body, and the group, the inclination is to move towards the fusion and mingling of opposites, towards connectivity, towards an elasticity and fluidity that allows for absorption and encompassment. Bahia wants you to be dazzled, rather than sharp-eyed. It seeks to open you up, in all kinds of corporeal ways. These propensities - which, as Omar Calabrese points out in his study of the Neo Baroque, really are preferences for certain kinds of forms, certain kinds of relations and certain kinds of movements, and are therefore probably to be called 'morphological' (Calabrese I992) - produce the distinct character of the life world that is Bahia, and more broadly speaking, Brazil. Gilberto Gil and Torquato Neto, two artists from the Tropicália movement, sought to grasp this specific quality by dubbing the world of Brazilians a Geléia Geral. Which translates as 'General Jelly'. 'Overall Jelly'. The frequency with which that notion is taken up and cited speaks of the aptness of the characterization (although Victor, who grew up in poverty, told me to inform my readers that oftentimes 'merda', shit, would be equally appropriate).

\section{鰏}

In a world that is heir to the ethos of the baroque, that seeks to dazzle and stun you, that forces you into its labyrinthical ways, where straight lines and traceable tracks are soon lost in curves, distractions and 'provocative swellings of the flesh', academics - embodying the classic like no one else - are bound to run into trouble. As Susan Harding stated, it is when previous voices begin to appear alien and when one's mind becomes a contested terrain that one comes 'under conviction' (Harding 2000: 34). And thus it was. I became susceptible to the opinion that academics, as heirs to Classicism and the Enlightenment, are ill-equipped to learn about Bahia. I felt interpellated by anthropologist Jan van Baal's remark that 'thinking, and in particular analytic thinking is not an act of participation but of detach- 
ment and dissociation, a process of affirming the distance between the subject and his world, between the self and the other' (van Baal I97I: 22I). I began to feel irritated by such unquestioned research directives never to confuse participant observation with immersion, never to 'go native', never to budge into 'the embarrassing possibility' of believing the local's belief (Ewing I994: 57I). I began to feel like a wallflower, the figure with whom Marta Savagliano compared the ethnographers' position so aptly: the girl who turns up at the great ball night after night, who knows all the steps and swirls and moves from so many hours of desirous observing the dancing couples, but who never makes it out of the shadow onto the dance floor to find out what the dancing really is all about (Savigliano I997).

Of course, there is no way of knowing whether my responsiveness to Bahia's call was due to romantic yearnings, libidinal undercurrents, silly but irresistible midlife fantasies of reinventing-oneself-wholly-anew, vague worries over the prospect of an academic career gone bureaucratic, echoes of my earlier work on 'the cult of unreason' in war-ridden Serbia (van de Port 1998; 1999), or indeed a growing understanding that a baroque disposition of the kind I encountered in Bahia calls for alternative ways of knowing and reporting. Yet I do know - and this I know for a fact - that I increasingly found myself questioning prerogatives to stay on the sideline 'from where you can see best' and 'get the picture'. As stated, troughout my fieldwork I found myself inventing fantasy scripts that might bring about the happy immersion in Bahia's here-and-now. I bought pretty much all the Candomblé statues at Feira de São Joaquim to set up a home altar. I struggled to learn to play the little four-stringed guitar that is called cavaquinho. I returned the flirtatious winks coming my way. I sought to master Bahian slang up to the last idiomatic expression. I dug out a cactus from Canudos, deep in the Bahian interior, and saw to it that it would root and grow on my windowsill. I kept cooking the fish stew moqueca-de-peixe until it came out just like the one served at Dadá's restaurant. I introduced Victor to my life. I stretched my arms to the goddess of Axé music, stretching, stretching, jumping, jumping, singing my head off. I was, in other words, working hard to transform looking into action, thinking into experiencing, dialoguing into touching, listening into eating and smelling - thus to be in Bahia's here-and-now.

Looking back, I am struck just how much these attempts to produce immersion were scripts of consumption, of appropriation, of moving in, of taking control, and most of all: how much they were imbued with the idea that immersion required active agency on my part. Salman Rushdie once described very aptly what I found myself doing in Bahia: 
... waking as well as sleeping, our response to the world is essentially imaginative; that is, picture making. We live in our pictures, our ideas. I mean this literally. We first construct pictures of the world and then we step inside the frames. We come to equate the picture with the world (Rushdie I991: 378).

What I failed to see then and there is that through such scripting, framing, narrating and envisioning you will always end up being a spectator to a world of your own making. Being-in-the-here-and-now - the most alluring promise of immersion - does not happen as long as you claim authorship over the world you inhabit. Clinging to your authorship-of-the-world is what keeps you locked up in the theater of your own imagination.

\section{彭}

'Yes, you are son of Oxóssi'; is what Pai Luis told me, confirming what many others had said before him - that the orixá governing my head is the hunter spirit of the woodlands called Oxóssi. 'You are. Most definitely!'

I must admit I had given him a lead, wearing green colors, which are Oxóssi's colors. I had already grown attached to the idea of Oxóssi being the master of my head, and given that I esteemed Pai Luis opinion in spiritual matters, I did not want him to declare me to be a son of Obaluaê (who is the spirit of pestilences), for example, or a son of lansá (the flamboyant female warrior spirit who is the favorite of all the gays). Pai Luis had something more to say, though.

'But your Oxóssi is a kingly figure, a proud ruler. He remains seated on his throne. Your Oxóssi will not descend from the skies.'

He brought it to me gently, sotto voce, this estimation that I would never be possessed. The way one tells a student that, all the hard work notwithstanding, he failed his exam. The way one would tell a patient that life in a wheelchair also has its moments. With pitying eyes he reassured me: 'There are various ways to honor your orixá.'

And indeed, for as much as I 'came under conviction' that I should step out onto the dance floor, I found the forces of the habitus to be utterly prohibiting. 'Too French', as Pierre Verger had put it. Possessed by Mlle F., who seemed adamant not to give up on her medium.

No clearer illustration of her enduring presence as that one night when full immersion in Bahia's here-and-now was about to happen. It was during one of the first spirit possession ceremonies that I witnessed in a small neighborhood temple (terreiro), packed with locals rubbing shoulders. After the introductory round dance had been danced, the drums started 
calling on the orixás. They seemed to arrive in large numbers. The daughters-of-saints who had been dancing for hours, circling round and round the central pillar, started bending forward and backward, quivering their shoulders and 'grunting like a Vitrola needle at the end of a record' - as Ruth Landes once described it in the metaphor of her time (Landes I947: 50). Many of the locals who had been watching the scene became possessed as well: a plump lady on high heels, a middle-aged man, a somewhat grayish looking woman wearing an apron, they all started to stagger on their feet and turned up their eyeballs. Contrary to the initiates, they took off silently, as if sneaking out of their bodies. Soon, two of the three adolescent boys who had been busy displaying a 'cool' and unaffected posture amidst the general effervescence, became possessed. I clearly remember the nervous expression on the face of the third one after the 'departure' of his mates. A young girl, who had been chatting and giggling with a friend as if this was a schoolyard rather than a place of worship, all of a sudden fell into a rigorous spasm, and rolled over the dance floor, stiff as a broomstick. She was covered with a white sheet and for over an hour lay motionless on the floor.

The drums were beaten ever more frantically. Each time someone would fall into a trance there was a lot of cheering and applause. I felt nervous. I was overwhelmed by the sight of behavior I could only interpret as a complete lack of self-control. And I was scared that I too would fall to the floor, but with no narrative other than 'hysteria' to make sense of it. I panicked; it was only a sense of professionalism that kept me from wrestling my way back to the exit. I recall that I crossed my arms over my chest. I tried to dissociate myself from the scene by rummaging in my rucksack to look for nothing in particular. I urged myself to breath deeply and calmly. I told myself that I do not believe in spirits. I forced myself to think of what anthropologists have been saying about possession trance, invoking the spirits of science to protect me from whatever it was that was creeping toward me that rowdy night. What calmed me down, in the end, was the sight of a dog. Not a Saint Bernard dog, to be sure, but a breed akin to a German shepherd. The animal had been walking around freely over the dance floor, pursuing its own canine pursuits. Undisturbed by the interactions of people and spirits, the dog offered a reassuring image of normalcy to hold on to. 
So much for wanting to be on the inside of things, for immersing oneself in the here-and-now of the situation. Coming under conviction is one thing, being able to hand over one's authorship of the world to forces beyond one's control - to let oneself be 'authored' by the world - is quite another. Which attests once more to the fact that doing anthropology can never be reduced to the imposition of one's paradigmatic preferences (whatever they are) onto the realities that we live and encounter. We are not in full control. Not even where it concerns the attempt to live up to that very insight.

And yet, this book cannot only be a report on the impotence and failure of the writer. We do not desire things we do not know. Desire - for nègres boxeurs, for the action taking place on the dance floor, for the happiness of that middle-aged Baiano on Terreiro de Jesus, feeling fully at home in his fat, sun-warmed body - is grounded in the moments (however fleeting) of desire's realization and fulfillment. Sometimes even Mlle F. found herself authored by the world: at night, for instance, when immersion is total in the picture-worlds of dreams (and nightmares); in the moments of being enraptured by music or being taken in by the words of the novelist; in the moments when the writing seems to flow and the hours pass without noticing; in drunkenness, when alcohol turns the world into a Geléia Geral; in that - rather traumatic - experience of being 'annihilated' by a fairground attraction called the Octopus, when tons and tons of merrily painted steel subjected her to a thousand-fold car crash, merciless and indifferent in the face of her panic; by the touch of faceless strangers in pitch-dark darkrooms; and most of all, in the happy moments that João Guimarães Rosa called 'as horinhas de descuido', the 'little hours of disregard' that can only be known in retrospect, after the fact, in the sweet memory that in the company of friends, or all by herself, the world had absorbed her.

Such moments may serve as a reminder that the challenge is to question the absoluteness with which first impressions - they immerse, we stand on the side, they are subjects of a baroque ethos, we are heirs to the classic - impose themselves. As stated in the introduction, we ought to unthink the 'classic' and the 'baroque' as fixed categories so as to be able to appreciate them as 'impulses', always at work in processes of world-making. In the next chapter, these impulses will be revealed in a discussion of the work of Dr Raimundo Nina Rodrigues, a professor of forensic medicine at the Faculdade de Medicina in Salvador who studied the Candomblé universe in the late igth century. Widely considered to be the first ethnographer of the cult, Dr Nina's explorations were driven by exactly the 
opposite desire as the one discussed in this chapter: far from wanting to immerse himself, his dream was the introduction of the 'ocularcentered' perspective of late igth century positivist science (which sought to redefine reality as that which meets the observing eye) in the mystery-laden world of Candomblé. Clearly, Nina Rodrigues exemplifies the spirit of the classic, as he subscribes to the dictum that 'to name is to know' and puts himself on the sideline, so as 'to get the picture'. Yet to understand this 'classic' in the work of Nina Rodrigues as an impulse is to remind oneself that the Bahian professor can never be reduced to that category. As Fernando Pessoa wrote in his Book of Disquiet:

... there exist contemplative souls who have lived more intensely, more widely, more tumultuously than others who have lived their lives purely externally. The end result is what matters. What one felt was what one experienced ... The person standing apart in the corner of the room dances with all the dancers. He sees everything and because he sees, he experiences everything. When it comes down to it, it is just another feeling, and seeing or even remembering someone's body is just as good as any actual contact. Thus when I see others dance, I dance too. I agree with the English poet who, describing how he lay far off in the grass watching three reapers at work, wrote: 'A fourth man is there reaping too, and that fourth man is me' (Pessoa 2002: 74). 


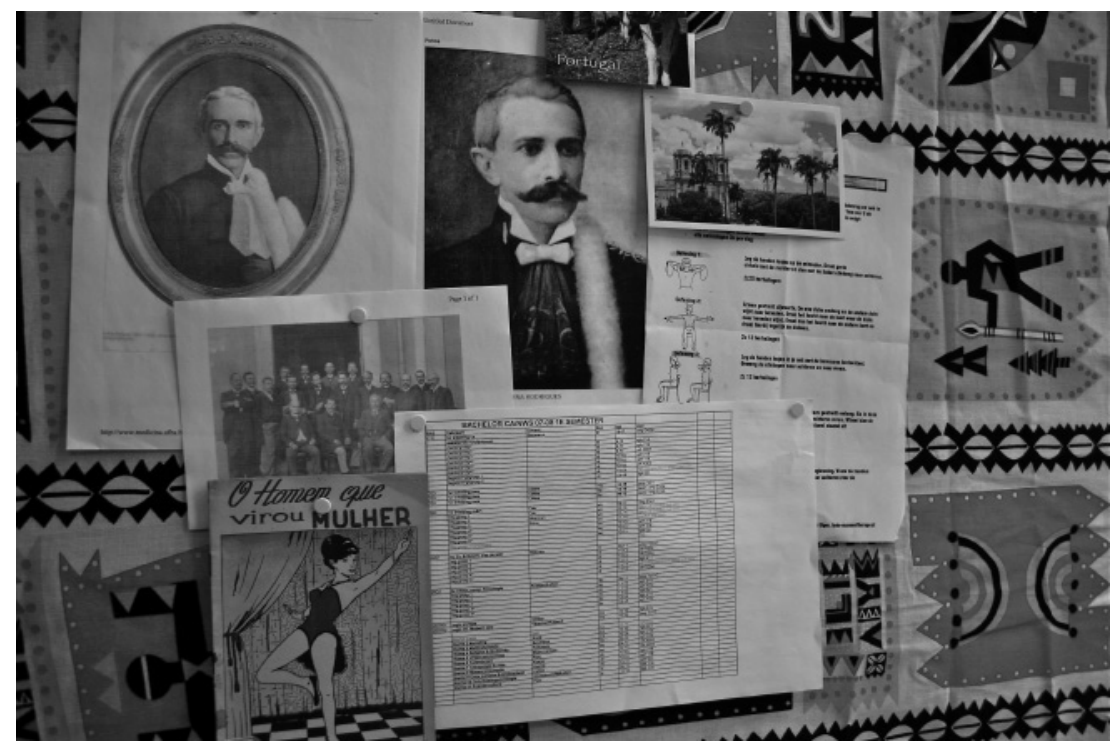

Figure 7 Dr Nina 


\title{
a \\ MYSTEIIES are INVISIBLE
}

\author{
Understanding images in the Bahia of Dr \\ Raimundo Nina Rodrigues
}

I have pushpinned two photocopied portraits of Dr Raimundo Nina Rodrigues (I862-I906) on the wall of my office in Amsterdam. They have been sitting there for months now, stuck somewhat unceremoniously between postcards from a summer's trip to the baroque churches of southern Spain, a printout with several how-to-avoid-RSI-exercises from my physiotherapist and teaching schedules for the next semester.

One of the portraits depicts Dr Nina as a young man. It seems to follow the conventions of portraiture in the Brazil of the second half of the igth century, when - as Ana Maria Mauad tells us - Brazilians were in the grip of a genuine estatuamania ('statue-mania') and wanted their portraits to recall the statues of powerful great men on public squares (I997: 228). If that indeed is what the painter has tried to accomplish, the result is not entirely convincing. The portrait shows him to be a pale, skinny doutor, hiding behind an immense moustache and with a look in his eyes that expresses something midway between worry and desperation. The black coat over a spotless white shirt with starched collar, and the fur-trimmed cassock that indicates academic stature hardly produce the desired effect; 
other than a certain stiffness, there is little in this portrait that recalls the potency and might of a statue towering over a public square.

The other portrait, in an oval frame, was painted not too long before Dr Nina's death. Here he is portrayed full frontal, and made to look like the eminence grise of the Institute for Legal Medicine in Bahia where he was positioned as a professor of forensic medicine. The fur-trimmed cassock is still there, and the moustache - now pointing downwards - is even bigger. The frivolous, embroidered neck scarf of the earlier painting has been replaced by an austere-looking white one. His hair has gone almost as white. It is hard to believe that the man on this painting was only in his late thirties, early forties.

I had read the work of Dr Nina before I had even started my fieldwork in Bahia. His O animismo fetichista dos negros baianos (The Fetishist Animism of the Bahian Negroes) is a Candomblé classic. Not so much because of the long disquisitions about possession, hysteria and the 'primitive mind' with which he sought to intervene in discussions on the 'Racial Question' in post-abolition Brazil (cf. Schwarcz 1993), but because the book contains detailed observations of religious life in the terreiros de Candomblé of late Igth century Bahia. Moreover, the study is one of the very first examples of Candomblé becoming an object of public interest. ${ }^{24}$ It was first published in 1897 as a feuilleton in a Brazilian journal under the title "The Illusions of Catechism' ${ }^{25}$, a title that refers to Dr Nina's idea that the Bahian Blacks were simply not high enough on the evolutionary ladder to become anything more than nominal Catholics. The articles were then translated into French and published as a book and finally brought back onto the Brazilian market in a Portuguese version in 1935. Given this history, O animismo fetichistsa was particularly relevant to the history of encounters between people from Candomblé and curious outsiders that I was about to study.

To Dr Nina's portraits, however, I had never paid much attention. From where I am trying to make sense of the world it is a man's thoughts we are supposed to contemplate, not his looks. In addition, these are not exactly portraits that, as the Dutch expression goes, "burn themselves on your retina'. They are every bit what you would expect a portrait of a I9th century scholar to look like: an emblem-like picture of a hairy face that aborts every urge to give it a second, curious look.

It was only when much later I returned to $O$ animismo fetichista that I gave those portraits a second, more attentive look. This man, I came to realize, had been visiting some of the same temples and had run into some of the very same research issues that Candomblé had given me to ponder. I could thus identify with the Bahian scholar in a way that had 
hitherto been blocked by the somewhat pedantic tone of his writings, his racist theories and his unbecoming moustache. I became curious. What - given his history, mindset and worldview - had this man made out of the Candomblé temples and the people living and worshipping in them? What had he been like behind the carefully groomed self-image to which the learned and scholarly words of his writings give access? Had he been susceptible to the call for immersion that seduced so many researchers of Afro-Bahia? Had he too been driven towards the proximity and intimacy that was discussed in the previous chapter?

With such questions in mind I started looking for biographical information on this man. ${ }^{26} \mathrm{I}$ began to read more about his world and times. Somewhere around that moment, I must have printed out his portraits and stuck them to the wall in my office.

Since then, the images of Dr Nina have been accompanying my readings, and the writing of this chapter. Many times, my gaze would move from the text towards that pale face on my wall. And although it would never change its expression, it would never be the same. Depending on what I had been reading, the portraits proffered thoughts like: 'so this was what became of the querulous child that grew up in the northern state of Maranhão, the son of a wealthy, slave-owning planter, considered ugly by all and suffering a weak health. 'So this was the man who was probably breastfed by an African ama-de-leite (wet-nurse) and then ended up arguing the inferiority of the black races.' 'So this was the man who came to be known as 'Dr Farinha Seca' ('Dr Dry Flour') for having attributed many of the slaves' diseases to malnutrition, and for having blamed the local doctors in Maranhão not to acknowledge such facts.' 'So this was the man of whom a colleague at the Faculdade de Medicina had said "Nina is crazy! Frequents candomblés, sleeps with iao's [initiates] and eats the food of the orixás!' 'So this was the man who, back in his native Maranhão, was remembered for having been meio místico (somewhat mystically inclined), but not so much as to give up on love affairs.' Or: 'So this was the man who spent his days in an office at the faculty, surrounded by glass jars containing human remains in formaldehyde and a great number of human skulls, neatly piled up, not unlike the pineapples and mangos at the Feira de São Joaquim. With every new finding the portraits seemed to change. The fact that his father died in his arms during a boat trip; that one of his seven siblings was insane, one a leper, and two were killed in fights; that his family was of Sephardic descent; that his gestures were reported brandos mas firmes (soft but firm) and his words escandida e escorreita (studious and well chosen); that he had the habit of constantly looking at his watch 
to see what time it was ('as if aware that he would die young, one of his biographers suggests): every newfound fact highlighted an expression in Dr Nina's face that up to that point had been obscured.

For all of those months that he has been hanging there, Dr Nina has been evading my gaze. Ostentatiously so. Where I had discerned 'a window onto the soul', he kept trying to be a 'mask' - as Michael Taussig once characterized the two notions that always coexist in the human face (Taussig I999: 225).

I cannot blame him. For my gaze, I must confess, was an impertinent one, indiscrete at times, blatantly ignoring the painter's invitation to see on the canvas a man of stature, a scholar of repute. Indeed, my gaze sought to foreground how the idealized image of the scholar failed to absorb all of Dr Nina. I kept seeing that there was more to this man; and that this 'larger being' kept spilling over the borders of the narrow emblem in which it had been cast. Thus, in this pale, bony face; in that worrisome expression; in that ridiculous moustache with those vainly turned-up tips, I discerned the excess to what these portraits sought to make out of Raimundo Nina Rodrigues.

It was exactly this 'remainder' of the portrait that helped me to keep in mind that Dr Nina can never be reduced to his scholarly words. It alerted me to the fact that underneath all those layers of clothes and academic regalia was a body, scraggy and milky white, as I imagined it; suffering continuous illnesses and fevers, as his biographers tell us; a body that sweated in the oppressive heat of a nightly ceremony of Candomblé, and who knows, found in the temples an opportunity to strip itself of neck scarfs and starched collars; a body that responded to the temple's sounds, smells, sights, and tastes; that - as he admits at one point in his study - admired the poesia selvagem (uncouth poetry) of the ceremonies (Rodrigues 2005: 45); a body that gave in to - or sought to ward off - the erotic possibilities of the terreiros, places he himself once described as 'available for anyone who wants to use them for all kinds of entertainment, orgiastic practices and lecherousness' (in Braga i995: 28).

Through such imaginings these portraits came to life. I think I came close to talking to the printouts on my wall. Mumbling things like 'That's a good morning to you too, Dr Nina!' Or: 'You could of course try to be a bit more helpful in sorting out what you're all about!' I also recall that once, when the writing of this chapter seemed to go nowhere, I felt like ripping them off the wall, giving up on this attempt to bring Dr Raimundo Nina Rodrigues to life - only to find out that the portraits, and the little collage 
of which they are a part, had already acquired altar-like qualities, inducing respectful behavior.

\section{镍}

It has often been said that in our treatment of images we reveal that we never stopped being animists. We may know perfectly well that portraits are mere images, oil on canvas, chemicals on photographic paper, printer ink on an A4 sized sheet, yet as W.T.J. Mitchell stated in his theory of the image,

Pictures are things that have been marked with all the stigmata of personhood: they exhibit both physical and virtual bodies; they speak to us, sometimes literally, sometimes figuratively. They present not just a surface, but a face that faces the beholder [...] In short, we are stuck with our magical, pre-modern attitudes towards objects, especially pictures, and our task is not to overcome these attitudes but to understand them (Mitchell 2005: 72).

The fact that, at the beginning of the 2Ist century, leading image theorists are willing to consider the animated life of images would probably have been Dr Nina's worst nightmare. His discussion of animism was inextricably linked to igth century evolutionist theories of the development of the human races. Following Auguste Comte's famous 'law of the three stages', animism - the African thing - was positioned squarely at the bottom of human evolution. Positivist science - the European thing, and ever since the young republic had embroidered 'order and progress' on its national flag, Brazil's hope and destination - was placed on top. ${ }^{27}$ The animists' failure to make a sound distinction between animate and inanimate matter; their treatment of mere objects as if they had a life of their own; their fear that objects were powerful agents, capable of producing real effects in the real world; all of this was a clear sign of the 'primitive' mindset of the Africans and their descendents in Bahia. Science was to enlighten this 'deeply superstitious race', certainly not - as Mitchell invites us to do - to think along with them.

As my involvement with Dr Nina's portrait already sought to indicate, I tend to agree with Mitchell that animism is here to stay with us. Once you set your mind on it, the list with examples of our contemporary animist involvement with images is endless. Take a recent incident when I found a photograph of an unknown girl in a drawer of my desk. I had been trying to create some order in my household administration, sorting out all 
the ill-classifiable papers that I had been collecting in that drawer, when all of a sudden there it was: a smiling, happy face of a girl that must have been somewhere around the age of nine or ten. The picture had probably been left there by someone I had sub-let my apartment to while being on fieldwork. There was something vaguely familiar about this girl, but I really could not figure out who she was, or to whom this picture belonged. As there was no reason to keep what was in all objectivity a meaningless piece of photographic paper, I figured I might as well throw it away. Yet the act of dropping that picture into the trashcan, to see it being soiled by leftovers of cooked-spaghetti-gone-sour, squeezed-out oranges and coffee grounds, produced a profound sensation of having done something utterly improper. Undeniably, the picture refused being reduced to its being a mere object.

And thus it is with tearing up a portrait (a deeply violent gesture in a breakup); removing a portrait because it no longer fits the new design of the living room (in which case some apologetic mumbling seems to be appropriate); deciding where it will be hung (my guess would be that few people would hang a portrait of their mother in their bedroom); burning candles for it, or putting flowers in front of it (so the portrait can appreciate their beauty, and comes to be included in the socially binding act of gift giving); or selling the portrait of your grandparents at an auction to the highest bidder (a highly improper form of commoditization, I would say). In all of these practices, we make something more out of images than their mere materiality. We act against our own cultural order, which purports that the separation of things and animated beings is absolute.

In Dr Nina's days it was no different. The term animismo (animism) may have been reserved for the 'primitive races', but animist practices and attitudes could be found from the humble quarters of the African population in Bahia all the way up to the homes of the rich and mighty. In a certain sense, Dr Nina himself was well aware of this.

The number of whites, mulatos, and individuals of all colors and backgrounds who, in their misery and unhappiness, go to consult the black fetish priests and publicly state their belief in the supernatural powers of talismans and fetishes is enormous; and even greater is the number of people who publicly denounce such beliefs, but then secretly do listen to the fetishists, and visit them to ask their advice; in fact, this is a number that is so vast that one might as well say that we are talking about the entire population, with the sole exception of a tiny minority of superior, enlightened spirits who have a true understanding of the exact value of these psychological manifestations (Rodrigues 2005: 130). ${ }^{28}$ 
I would like to point out, however, that we ought to refrain from simply ascribing animism to some groups and not others. Exoticizing animism, making it the belief of 'the others', prohibits the understanding that, in a rather more fundamental way, animism is the magical formula of all representational practices. Just think of the examples immediately relevant to the days and times of Dr Nina: the then all-powerful Catholic church had in fact canonized animism in its dogma of transubstantiation, which holds that the Eucharist becomes the body of Christ, and which by implication recognizes the permeability of the boundary between objects and animated beings. Moreover, through incarnation the Catholic God made himself corporeally available in rosaries, holy water, scapulars, medals, sacraments and other objects; just as the recognition of images performing miracles allowed for a Catholic notion of objects being animated matter with an agency of their own (Morgan I998: 66). In the 'fine arts', animistic attitudes abounded as well. Clearly, the blurring of the animate and the inanimate was all that a good portrait sought to provoke. At all times, a portrait ought to transcend its mere materiality by getting the beholder to say 'this painting really is Dr Nina! This painting really caught his true spirit!' Indeed, the whole idea that a good portrait 'speaks' to its beholder reintroduced a deeply animist terminology in the salon.

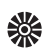

In my discussion of how the portraits on the wall of my office in Amsterdam came to life, I have sought to illustrate that the capacity of a portrait to transcend its materiality is not intrinsic to the image itself. Animation is an effect that is produced in what goes on between the image and its observer. What the image may contribute to this interplay are its formal elements (its colors, composition, material, style), its conventional meanings ('art' or 'kitsch'; 'figurative' or 'abstract'; 'modern' or 'primitive'), its ascribed powers (as in religious discourses that attribute power to icons; or marketing discourses that ascribe far-reaching effects to the image in advertising; or art discourses that promise encounters with the sublime). As my account above already illustrated, the image may even contribute its failure to make a convincing impression on its beholder. Yet in and of themselves, such elements cannot account for the image's representational power. They are probably best conceptualized as potentialities that need to be 'played' in a certain way in order to take effect.

The playing of the potentialities of an image is always bound to the visual practices and aesthetic regimes of particular times and places, and 
as Clifford Geertz argued, such practices and regimes 'are never wholly intra-aesthetic' (Geertz I983: 97)

\begin{abstract}
Whatever the innate capacities for response to sculptile delicacy or chromatic drama, these responses are caught up in wider concerns, less generic and more contentful, and it is this encounter with the locally real that reveals their constructive power. [...] If there is to be a semiotic science of art it is that [encounter] it will have to explain. And to do so it will have to give more attention to talk, and to other sorts of talk but the recognizably aesthetic, than it has usually been inclined to give (ibid.: I02).
\end{abstract}

My own 'playing' of the portraits pushpinned on the wall of my office may serve to illustrate what 'aesthetics being caught up in wider concerns' and 'other sorts of talk' might denote. Highlighting the failure of these portraits to produce a statue-like image of Nina Rodrigues - and taking this failure to be their truth - is a way of looking that closely follows contemporary understandings of what makes a pictorial representation 'convincing. In our image-laden societies, it is generally understood that the perfect beauty of photo models might well be the result of Photoshop interventions; that the compromising photograph in the tabloids which shows the politician visiting his mistress may turn out to be a forgery; that the picture of that beautiful landscape someone brought back from his travels abroad was probably framed in such a way as to leave out the row of electrical masts polluting the horizon; that the flattering picture sent in for a dating site was a genuine lucky shot, not a representation of the way this person looks at seven in the morning; or that the happy snapshots in the family photo album may not cover all there is to that family. In other words, our contemporary, 'postmodern' understanding of the representational power of images comes with a nagging awareness of their deceitfulness; their ability to play tricks on us; their manipulative qualities. This awareness does not undo what Jacques Derrida called the 'quasi-hallucinatory quality of the image', and we are certainly not at all times able to say when we are fooled, or how (in Stolow 2005: 126). Yet an overall suspicion towards images bars the possibility to take the truth of pictorial representations at face value.

Just as this suspicion guided my reading of Dr Nina's portraits ('I can see what the painter wanted me to see, but l'm not buying it!') my subsequent attempts to unearth the real Dr Nina from under brushstroked layers of paint followed an equally 'postmodern' procedure. Credibility - so our world tells us - is to be sought in that which escapes the pre-described 
model, the convention, the social role, the explicit intention, the programmatic. The authentically real is to be found behind the façades, on the 'backstage' of people's lives, away from the stage acting and make-believe. In a way, we are ever more susceptible to the tabloids-mode-of-truthtelling, which tells us that the real of the politician is his extramarital affair with a seventeen-year-old, or that the real of the pop star is that she has a drugs problem. Following this tabloids-mode-of-truth-telling was all I sought to do when peeling off poor Dr. Nina's cassock and clothes; when imagining the whiteness of his body, his movements, his moods and desires, his having been breast-fed by a black wet-nurse, his having wept in that boat with his dead father in his arms: all I was doing here was guiding myself to the access points of the 'backstage' of Dr Nina's public performance. Moving towards those points (the anthropologist as paparazzo), posthumously worming out of Dr Nina confessions he never confessed (the anthropologist as Oprah Winfrey) helped me to authenticate the scholar as a man of flesh and blood.

I am fully aware that what such imagining gets me is a figure out of a telenovela da época (a subgenre of the Brazilian soap opera that is set in a historical epoch): quite likely, my 'live and true' Dr Nina resembles an actor from the $O$ Globo television network, with an oily and melodious Rio de Janeiro accent, carefully pancaked to whiten his Copacabana suntan, and matching a $\mathrm{I} 9^{\text {th }}$-century outfit with a contemporary psychological profile. The accuracy of my imaginations, however, is not the point to be discussed here. The point is that my playing of these portraits' potentialities followed socially and culturally constituted guidelines as to what is (and what is not) real about people, and consequently what the 'real' of Dr Nina was like.

Needless to say, in Nina Rodrigues' days these portraits would have been played differently. Both he and his contemporaries would have highlighted other potentialities, thus making real and true another Dr Nina. This playing certainly did not follow uniform guidelines. We cannot simply set out to explain 'the power of images in Igth century Bahia' by exploring 'Bahia's visual culture', thereby lumping together recently liberated slaves and their descendents, the white and mulatto citizens of Salvador in all of their religious bigotry and small town notions of propriety, and the intellectual elite to which Dr Nina belonged, which sought to mobilize positivist science to figure out where the young Brazilian republic was heading in the course of nations. Yet two generalizations can be made.

First, all of these groups were witnesses to the revolution in pictorial representation that had been triggered by the invention of photography. 
In many ways, photography came to redefine the representational power of the image in terms of truthfulness and all the aforementioned groups in Bahian society were busy playing - to different effects - the specific potentialities of photographic representations of reality.

The second generalization is that this revolution in image-making took place in a world where, to adopt Michel de Certeau's felicitous expression, 'the contract between the seen and the real' had not yet been sealed (Certeau I984: I86). Invisible beings and forces lurking in the realm of the occult were as much part of people's reality as that which could be made out in the realm of the visible. As will be elaborated below, a powerful baroque organization of vision sustained this conviction that 'what one sees is but a fragment of what is out there' (Martins 2002: 230).

What all of this implies for this study is that we have to take notice of the fact that the first public representations of Candomblé came to light in a period when old ways of seeing where challenged by new understandings of vision. Indeed, in the remainder of this chapter I will argue that $\mathrm{Dr}$ Nina's writings on Candomblé were first and foremost motivated by his wish to replace the dominant baroque Weltanschauung of his life world which held mysteries and the occult in great awe - by an 'ocularcentered' and disenchanting perspective on the world. To refer to the terms introduced in the previous chapter: the birth of a public image of Candomble took place in the spirit of the classic - a classic that sought to assert itself by stressing 'looking' as a truth-producing practice; by bringing the obscure to light; by dispelling the all pervading, obfuscating mist of baroque aesthetics; by dissolving the sticky geléia geral so that categories would come apart and boundaries could be erected to keep them that way. With sight being classified as the highest of all the senses, 'a genuine arbiter of truth', it became possible to make categorical distinctions absolute. Or at least, that is how Dr Nina wanted to see it.

\section{稳}

The 'wonders' of daguerreotype photography had made it to Brazil with the arrival of Louis Compte, a Frenchman who had set out to travel around the world and use the new technology to make 'observations and studies in exotic countries' (Sampaio 2006: 13). After the first demonstration of 'Daguerre's instrument' in Rio de Janeiro in 1840, reports in journals exclaimed that one had to see 'with one's own eyes' the capacity of this new technology to immediately represent objects: 
... in less than nine minutes the fountain of Largo do Paço, the Praça de Peixe, the monastery of São Bento, and all the other objects in the vicinity were reproduced with such fidelity, precision and minituousness that it was as if the thing was made by nature's hand itself, and almost without intervention of the artist (in Mauad I997: I89).

These words - every single one buttressed by exclamation marks, so it seems - express the excitement that the world can be represented without human intervention, and the choices and subjectivities implied therein. As such, they are a beautiful early example of the insights Roland Barthes and others would articulate much later of the truth-producing magic of photography that held so many people in awe at the dawning of the media age.

Comparing photography with painting, Barthes argued that the latter is never free of the introduction of 'second meanings'. Through style and its conventions (schemes, colors, graphics, gestures, expressions, arrangements of elements, and the prioritizations implied therein) the represented object is always already imbued with a notion as to what society thinks of that object. In photography, however, the move from the object to its image never implies a transformation. Surely, says Barthes, the photograph is a reduction of reality - in proportion, perspective, color - but unlike all the other mimetic arts:

... there is no necessity to set up a relay, that is to say, a code, between the object and its image. Certainly the image is not the reality but at least it is its perfect analogon and it is exactly this analogical perfection, which, to common sense, defines the photograph (Barthes I977: 17).

The 'perfection and plenitude' of the photographic analogy has often been commented upon. Susan Sonntag, for instance, speaks of the photograph as 'able to usurp reality because first of all a photograph is not only an image (as a painting is an image), an interpretation of the real; it is also a trace, something directly stenciled off the real, like a footprint or a death mask' (2002: I54). Or as David Morgan puts it: 'unlike the word, which has no necessary relation to its referent, the photograph possesses its referent within itself. It 'bears an ontological relation to its referent' (I998: II).

The immediacy of the photograph; its indexical qualities and assumed objectivity; its belonging to the world of science and discovery; its being understood by one igth century scholar as 'a thoroughly scientific witness' which cannot be deceived, which has no preconceived opinions and cannot register 'subjective impressions' (Wallace, in Pels 2003: 263); all of this 
greatly boosted the 'ocularcentrism' of the igth-century Weltanschauung. Vision became 'the royal road to fact' (ibid.). Or, as de Certeau stated, the gaze of igth-century scientific positivism sought to transform 'seeing into believing and fabricate realities out of appearances' (Certeau I984: I86).

One has to be very cautious, however, to relocate such general understandings as to what the invention of photography was - and did - to a place like igth-century Bahia. For here, the introduction of photographic verisimilitude took place in a world steeped in baroque aesthetics, which offered its own particular guidelines as to how seeing and believing ought to be connected, and which organized its visual culture according to its own understandings of the relation between realities and appearances. So whatever the introduction of photographic verisimilitude did to the power of images in Bahia, and however this got 'played' to animate those images, it must be considered in the framework of an existing baroque aesthetics.

Doing so, one immediately runs into incongruities. As previously argued, baroque aesthetics do not grant vision a superior position above the other senses: it seeks to impregnate the soul through the five senses'. Moreover, the clarity of the photographic image is not at all what a baroque organization of vision is after: on the contrary, the baroque provokes a restless eye, lost in curves and curls and folds, and it indulges in the deceptions of vision (baroque trompe l'oeuil ceilings being a good example). As Martin Jay pointed out: 'If the eye is so deceptive and the visual scene so replete with dazzling flashes of brilliance casting light only on opaque, impenetrable surfaces, recourse to another sense for security may appear an obvious antidote to its dizzying effects' (Jay I988: 318).

Another incongruity that one runs into is that baroque aesthetics do not seek to mimic the 'natural' or strive for the kind of 'realism' that photography made possible (a point I will elaborate in chapter five). Artifice is what characterizes baroque representational practices; a deliberate highlighting of the failure of representation to capture the world in its entirety so as to leave the mysteries of the world for what they are: mysteries (Cowan I98I). Classic representational forms - I am thinking of Michelangelo's David, the English landscape garden, or a building by Frank Lloyd Wright - pretend to manifest the idea they represent within their own form and being. The David is beauty and perfection. Baroque representational forms, by contrast, make a point of highlighting the 'split' between form and meaning. They ostentatiously point out that they are man-made; and they do not shy way from the false and the disharmonious. As such, they 
evoke the desire for a cohering, harmonizing force: a force that is not to be found in the here and now, but pertains to another, transcendent plane.

Allegory (to which we will return in chapter five) is probably the clearest example of the baroque mode of representation and its mode of truth telling. Nothing in the allegorical still life tells you that the pomegranate stands for lust or fertility. The painting has to refer to a reality outside of its frames - the allegorist who knows what the symbols stand for to disclose its meaning. Similarly, nothing in the allegorical morality play explains what it is that makes the character Good Deeds the embodiment of 'good deeds', or the character Vice the personification of 'vice'. That knowledge - while crucial to make sense of the allegory - is absent in the form itself. As Benjamin understood it

resorting to a fictional mode literally of 'other-discourse' (allegoria), a mode that conceals its relation to its true objects, allegory shows a conviction that the truth resides elsewhere and is not detachable in relations between sign and signified (Cowan I98I: II3).

Allegory has often been dismissed as overly formulaic and artificial; empty emblems cut off from true experience; up to nothing more than a mere 'manipulation of its repertoire of signs'. Walter Benjamin, however, vehemently opposed such critiques. He considered allegory to be 'experience par excellence': the experience that the gap between sign and signified cannot be closed, and that the wholeness of classical forms is false. The truth expressed in allegory is therefore deeply melancholic:

... the affirmation of the existence of truth, then, is the first precondition for allegory; the second is the recognition of its absence. Allegory could not exist if truth were accessible: as a mode of expression it arises in perpetual response to the human condition of being exiled from the truth that it would embrace (Cowan I98I: II4).

Allegory is but one mode through which the baroque sought to situate an existing truth on an inaccessible plane. The visual overload of the church interiors in Salvador, discussed in the previous chapter, may well have been informed by a similar attempt. 'Piling up fragments ceaselessly, without any strict idea of a goal' is how Benjamin described such baroque ornamentations (Benjamin 2003: 178); or paraphrasing Martin Jay, one might say that this bewildering surplus of images is resistant to any panoptic God's eye view: these interiors offer opaque surfaces to explore, rath- 
er than an invitation to penetrate depth (Jay 1988). And yet, these church interiors have their own mode of playing the senses to articulate profound truths: the truth that the world of men is lacking intrinsic order and direction, as well as the sensation that to be restored to harmony, the world is in need of a higher, transcendent Almighty.

A last example how baroque aesthetics constantly sought to affirm the existence of truth while simultaneously recognizing its absence are the gazes of the Saints in the Quarto de Santos in the Igreja da Ordem Terceira Secular de São Francisco, in the historic center of Salvador. Just take a good look at them, these faces staring into nothingness (for that is what the situation is like in the Quarto de Santos: there is nothing there to look at).

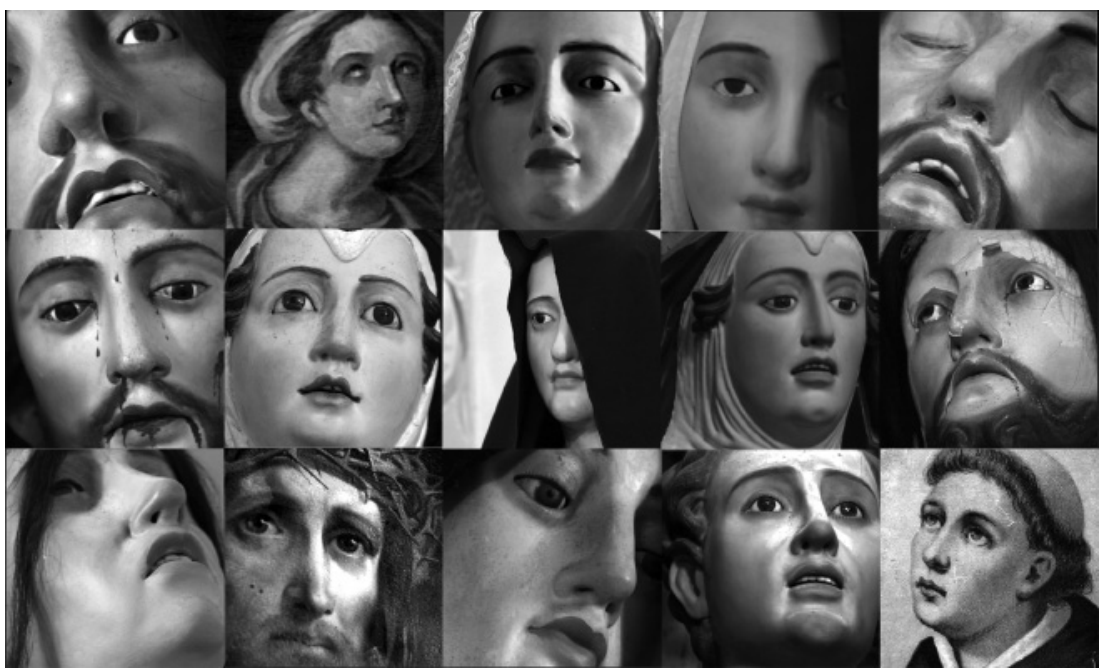

Figure 8 Saintly and divine gazes. Statues and images in the Igreja da Ordem Terceira Secular de São Francisco, Salvador da Bahia

This gazing only makes sense when one takes into account that Bahians lived (and to a great extent still live) in the firm conviction that, as José de Souza Martins puts it, 'what one sees is only a fragment of what is out there' (Martins 2002: 230). The visible only covered part of reality, which also included an invisible spirit world, a realm of demons and angels, Indian spirits, African orixás, saintly figures and the wandering souls of the dead, as well as of the dream-beings of the popular imagination, such as the fiery snake Boitatá, the forest Indian with its reversed feet called Curupirá, the one-legged black child Saci-pererê, the mermaid Mãe d'Agua, the werewolves called lobisomem, the half-goat-half-man known as bicho Papão, and the mule-without-a-head, mula-sem-cabeça. ('Well, people say 
they exist,' Victor told me diplomatically when I checked his knowledge of these colorful beings and his estimation of their ontological status). Moreover, the boundaries between these visible and invisible realms were considered to be highly permeable, with constant border crossings: signs of the active interference of such beings in people's lives were pointed out in spirit possession, miraculous apparitions, stigmata, strange illnesses, and various other ill-understood occurrences.
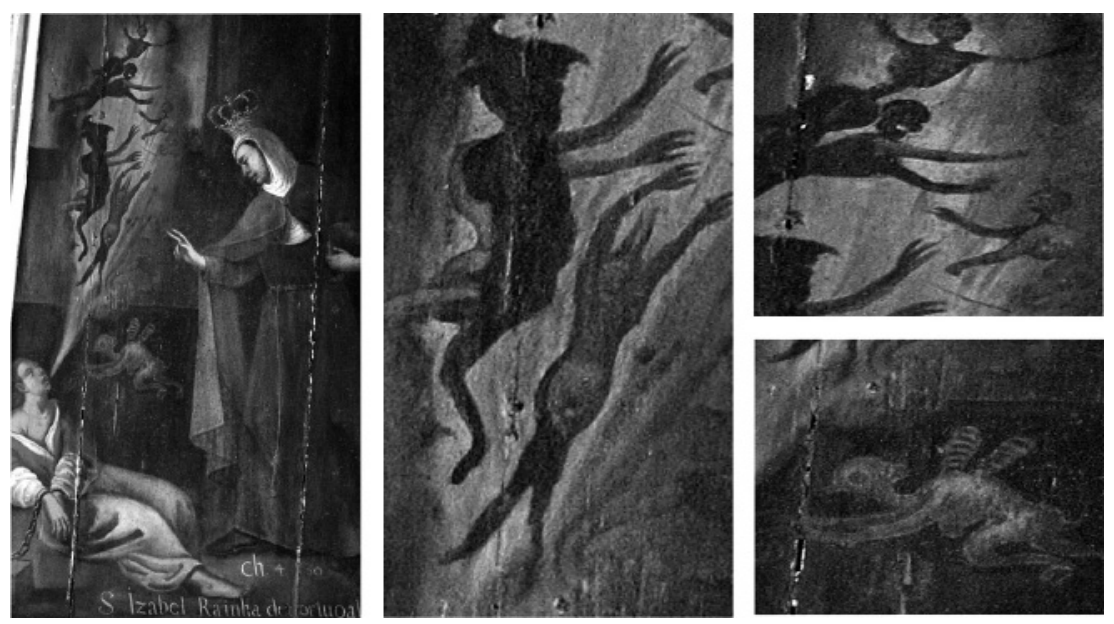

Figure 9 Making visible the invisible: Santa Isabel, Rainha de Portugal, exorcising demons

Painted ceiling panel, Igreja da Ordem Terceira Secular de São Francisco,

Bahia, 18th century

Fear of these invisible forces and beings, many of them engaged in an eternal struggle over the control of the souls of mortals, necessitated 'to see far beyond the visible of the everyday' (Martins 2002: 23I): a sense of urgency that certainly helps to explain why popular forms of Brazilian religions gave (and continue to give) such prominence to divination practices and sign reading; attributed such importance to dream-messages; and put such faith in prophets, visionaries, seers, clairvoyants and oracles. Yet again, the fact that this knowledge had to be sought by intermediaries signals that it was considered to be off-limits for ordinary human beings. Their condition remained to be 'exiled from the truth they would embrace'. Which is exactly what the saintly gazes impress so forcefully on the visitors of the Quarto de Santos: as much as these gazes suggest that there is something to be seen beyond the visible, they also keep the mystery intact. The saints can see. We can only see that they can see. 
The question to be asked then is: what could the invention of photography, with its perfect verisimilitude, its capacity to 'show things the way they are', and its promise to 'fabricate realities out of appearances' have meant in this particular, baroque organization of vision, with its studied disinterest in realism and 'the natural', and its insistence to keep the world's mysteries intact? The answer that presents itself is: 'not much'.

The historical record, however, prohibits such facile conclusions. There is ample empirical evidence to show that, in Bahia, as elsewhere in the world, there was an instant fascination with the unprecedented perfection and 'likeness' of photographs, just as there are signs that the indexicality of the photographic image - its being a trace of what is being depicted, rather than a representation - was indeed 'played' in Igth century Bahia.

Mauad, looking at the way the new medium was advertised and marketed (by I870 photographs had become so cheap as to be accessible for middle-class families), noticed it was above all the capacity of photography to produce superior parecença (likeness) and verossimilhança (verisimilitude) that was highlighted to draw potential customers in front of the camera. As stated in one ad of a photographer: '... all persons who are interested are invited to have a portrait made of themselves or their beloved ones, thus to see the perfection, the beauty and fidelity with which their forms are pressed on glass by pure rays of light ...' (in Mauad I997: I95). ${ }^{29}$

Not only did photography offer perfect 'likeness' for an affordable price as an alternative to painted portraits; it also set new standards for portrait painters, who began to incorporate photography's realism in the painted portrait. The so-called fotopintura, an invention made in I863, whereby a photograph of the person to be portrayed was projected onto a canvas in low contrast, after which the artist would paint it over in oil colors, became a popular technique in the second half of the igth century as it ensured a far greater verisimilitude in a portrait, and required far less skills of the painter.

Next to an obvious fascination with photography's verisimilitude, photographs were soon used in practices that reveal that Igth-century Bahians sought to play the indexicality of the photographic image, its reality 'trace', so to speak. Thus, photographs, and the hybrids to which they gave birth, were being used in various early forms of 'virtual presence.' Portraits of the heads of the household, framed and hung on the wall of the sala de visita (parlor), would never be taken down again for as long as a family would live in that house. As Alberto Cipiniuk (2003) argued, they were thus allowed 
to impregnate the space with their presence. Photographed portraits were printed on a cartão de visita (visiting card), to be offered to friends and family members, usually with a handwritten dedication in verse, as a proof of friendship, to say farewell, pay tribute or simply mark a rendezvous (Sampaio 2006: 23). They were also arranged in photo albums, or worn on the body in medallions and brooches. All these practices indicate that a sense of presence of the depicted person was both detected and 'played'.

In religious and magical practices photographs came to substitute exvotos, the wooden or waxen body parts left in the so called 'miracle rooms' of churches to testify miraculous healings (Martins 2002: 230). Discussing the use of photographs in the Afro-Brazilian universe, Lisa Earl Castillo tells us that photographic images also came to replace hair or fingernails in the preparation of the feitiços with which persons were bewitched (Castillo 2008: $85 \mathrm{ff}$.). All these practices suggest that, up to a point, people equated the photograph with the original body, rather than taking it to be a representation of that body.

In commemorative practices, the notion that photographs 'uncannily double the object they seek to represent' played up when photographic images were used to render present the deceased (Hanssen I999: 992). The most dramatic example from Bahia is the widespread igth-century custom to photograph dead infants. Luiz Lima Vailati's discussion of the photographs of these so called anjinhos - 'little angels', a name referring to the belief that these young children, having not yet sinned, would go straight to heaven - is particularly interesting (Vailati 2006). First, photographs of the anjinhos came to replace an existing tradition of carrying the corpses of deceased infants, dressed as little angels or infantile saints, in joyful procession through the streets (the joy following from the belief that these little cadavers radiated divine blessings). These early photographs show the corpses stuffed in little coffins, dressed in baroque outfits, with paper flowers, little crowns and saintly robes. The photographs clearly sought to highlight that these children were dead: after all, the fact that they had passed the boundary between life and death, and thus had access to the realm of the saintly gazes, was these dead infant's greatest 'asset'. In this case, one could argue, photography seems to have taken up a role similar to the aforementioned religio-magical practices, where the photograph became a 'double' of the real thing. Gradually, however, a new trend emerged in the photographic representation of anjinhos, whereby photography took up a role that was clearly 'commemorative'. In these later photographs, great care was taken to 'hide, or at least soften the indications ... that the portrayed was a dead child' (2006: 153). Dressed in 
normal clothes, sometimes sitting on the mother's lap, the photographic trace - the only record of the infant having had an earthly existence - was being played in such a way as to give the infant the life it had never had. ${ }^{30}$

It thus seems justified to suggest that the potentialities that photography brought to images - verisimilitude, realism and an almost 'material' objectivity - were fully 'played' in Igth-century Brazil. The one thing that does not happen in portraiture, however, is an all-out move towards the 'realism' of relaxation, spontaneity and naturalness. In concordance with the baroque aesthetics discussed before, people kept opting for the artificiality of 'the pose' and 'the emblem. ${ }^{31}$ In photo studios, Bahians had themselves photographed in fake décors. In Sampaio's book we see them posing in rowing boats, with bicycles, or in front of elegant flower arrangements, clinging to what can only be called an emblematic presentation of self. 'Me as a fine citizen who spends his Sundays peddling around the pond.' 'Me as a person with an interest in new ways of moving around.' 'Me as Mlle F..' Formal portraits such as those of Dr Nina - almost certainly fotopinturas ${ }^{32}$ - also remained deeply emblematic. These portraits show no discernable attempt to give access to the depths of the interior life of the depicted person (or indeed, to give access to the interiority of the artist, who expresses himself in the way he depicts another human being, as was the European answer to photographed portraits). Portraits were a summary of the person's public virtues: an assemblage of what, in the public eye, 'mattered' about this person. Hence, the continuous use of recognizable decorative elements that should indicate the status and reputation of the depicted person such as feathered hats and helmets, medals, swords, gold embroideries, and lavish decorations, and later in the century, symbols such as hats, walking sticks, cigars and jewelry.

Bespeaking the visual culture of the baroque of which they were part, portraits cultivated artifice and remained 'emblematical' through and through. All that verisimilitude did in the practices of pictorial representation of the Bahian bourgeoisie was to produce what Christopher Pinney called 'a moral physiognomy' (Pinney 1997: I06); the portrait sought to connect the recognizable individual traces of the figure portrayed with the public virtues that were expressed emblematically in the painting. Thus, in her discussion of Bahian portraiture in the Igth century, Viviana Rummler da Silva points out how the aesthetic exploration of the face - showing the 'marks of time', the 'traces of a laboriously and difficult life' - bestowed the depicted figure with dignity and honor (2006). The verism of igthcentury portraiture in Bahia, one could say, sought not to oppose idealism (as art historians usually put it), but infused these poses with 'likeness', 
thus making fully real the relation between a particular individual and his emblematic depiction.

If my 'postmodern' reading of the portraits of Dr Nina's on the wall of my office detected the absence of a merging of Dr Nina with the emblem of the academic scholar; we may now suggest that in Dr Nina's days this fusion was not sought. The artificial, idealized, emblematic pose remained the preferred form for a representation of self. It might be concluded, then, that the potentialities of the photographic image came to play their role within a baroque understanding of vision, not in opposition to that understanding. The igth-century idea of vision as 'the royal road to fact' that has been noted elsewhere (cf. Pels 2003) had little impact in a place where vision was organized in such a way as to keep the world's mysteries in place. The 'photographic real' was picked up in religious-magical practices, where it came to substitute the body. In commemorative practices it became a means to bridge the realm of the visible and invisible, not a means to define the invisible as 'not being there'. In portraiture, the 'photographic real' helped to link persons to emblems, not to fuse them: allegory and artifice remained the preferred mode of representation.

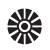

As he explicitly expressed in his writings, Dr Nina felt himself to be part of what he proudly called 'a tiny minority of superior, enlightened spirits'. He was, indeed, one of the very few people in Bahia who wholeheartedly embraced the ocularcentrism of positivist science. Although $O$ animismo fetichista dos negros baianos contains no photographs, the posthumously published 'Africans in Brazil' (Rodrigues I988) contained some pictures of material objects found in the Candomble temples.

It is not known who made these photographs. Maybe people from the photo studio that had opened in 1902 in the very Escola de Medicina where Dr Nina worked, whose explicit aim it was to use photography for scientific analysis (Sampaio 2006: 54). Or maybe it was Dr Nina himself. Sampaio tells us the first indications of amateur photography in Bahia are from around that same time (ibid.). Yet even without images, Dr Nina's ocularcentric approach to Candomblé clearly comes to the fore in the way he describes his explorations of the terreiros do Candomblé. Unmistakably, the narrative of $O$ animismo fetichista shows him to be a scientist eager to unveil the mysteries his contemporaries held in such awe. And unmistakably, his eyes were going to accomplish that mission. 
In the chapter called A liturgia fetichista (the fetishist liturgy), Dr Nina invites his readers to follow him along to the old Terreiro do Gantois, situated on what was then a muddy hill on the outskirts of town. While struggling to make it uphill, he recalls similar trips to similar temples, equally inaccessible:

I once had the opportunity to visit with some friends a candomblé situated on top of a hill, a spot that proved inaccessible on horseback, and was even difficult to reach on foot with the riding boots we were wearing. Down in the valley, where the sugar mill was situated, only a muffled sound of drumming had reached our ears. Yet when at midnight we set off in the clear light of the moon, and we had climbed over a first row of hills, the sound became loud and clear. The place we had reached was a desolate site, yet the combination of the nightly hour, the solemn and sad monotony of the primitive music, the African chanting, and the extravagant and strange character of the religious dances was not without a certain poetry: wild and mysterious, and deeply expressive of the bashful and primitive spirit of an extremely superstitious race (Rodrigues 2005: 44).

Back on the road to the temple of Gantois, and having reached the top of the hill ('no place is inaccessible' is an evident subtext in this chapter), Dr Nina takes his readers into a 'labyrinth' of 'ill-lit corridors', 'um verdadeiro ziguezague' (a true zigzag, ibid.: 46) at the end of which he finds an obscure space that is the shrine. In the semi-darkness of this place, food offerings to the gods can be made out. The offerings are randomly placed in the room, 'sem ordem, na mais indescritível promiscuidade' (without order, in an indescribable promiscuous way, ibid.). In fact, Dr Nina reports how the overall mess spreads to all the adjacent rooms. What he wants us to see is one big jumble of jars filled with palm oil, earthenware pots and porcelain dishes, bottles of wine, glasses and cups, plates containing the remains of food, containers filled with water, and in-between all kinds of accessories used in the rituals to the gods. He describes how this bustle of forms and shapes gradually merges with an equally messy background: all around on the walls, hung on rusty nails, he discerns the ceremonial clothes in which the mediums would be dressed after being possessed by the gods - in an enormous variation of colors and forms, from silk and expensive velvet, more or less used, to the cheapest of chita-cloth (printed cotton)' (ibid.).

The description evokes a sense of having entered a jungle, the habitat of primitive peoples, an obscure shadow world, where indecipherable patterns of lines and forms and colors meet an eye that is soon dazed, adrift in 
the 'oscillation of form and formlessness' (Jay I988). The description also evokes the golden mess of the Igreja de São Francisco, with its 'bewildering surplus of images', and its 'resistance to any panoptic God's eye view'. He does not say as much, but in Dr Nina's description Candomblé and Bahian baroque come eerily close.

One suspects that Dr Nina paints his readers this thoroughly baroque image to aggrandize the triumph of the classic gaze that will bring this world to order. For that is what he has come to do here. He is not here just because Candomblé, in and of itself, is an interesting object of study. He is not even here just to prove the black race inferior. He is here to break the mysteries that kept his contemporaries - of all colors - in such awe. To undo baroque instructions on vision. To show that if only you are prepared to look, there are no mysteries to be discerned.

Working under the contract that was signed between the seen and the real, we find him, page after page, enumerating what he observed: naming every single detail that came to meet his eye in the temples. This gaze is a true 'scanning' of Afro-Brazilian spaces and events: a clinical observation of what is there to see, taking - as so many social critics in the Brazil of his day - the 'stance of doctors diagnosing a sick body' (Borges I995: 60) or indeed, redirecting the detached gaze of the craniometrical inspections he had performed on so many skulls of criminals, mental patients and 'religious fanatics' to the Candomblé universe. The qualifying adjectives that were used so abundantly in earlier Igth-century reports on Afro-Brazilian religious practices - coarse, primitive, grotesque, stupid, rude, sickening, horrible, obscene, words that sought to disqualify these practices as not belonging to civilized order, but at the same time were deeply expressive of the excitement and awe with which such events had been witnessed (Sampaio 2000) - are absent in the narrative. There are just 'waistbands embroidered with cowry shells, colossal necklaces of beads and other glittering bits, diverse embellishments'. And when among these endless listings an altar is spotted, it is described equally as a matter of fact: 'steps, a small wall, some thirty centimeters high and with some depth, on which the fetiches or ídolos have been placed' (Rodrigues 2005: 46). No dramatization here. We have entered the heart of darkness only to find just other objects offering themselves to sight.

Dr Nina's eyes will reveal to his readers what in fact the occult is. These awe inspiring fetishes are just stones, water, sea shells, meteorites, pieces of iron, wood, fruits and other such unpolished forms of nature, 'chosen for no other reason than the singularity of their form, or another pure- 
ly accidental characteristic' (ibid.: 37 ). He will show you exactly how the uncanny obscurity of a sacred room comes about:

During the day, the space is caught in a dubious light which seems to come from some glass roofing tile, covered by a large stretch of white cloth, of the vulgar kind that is not woven too tightly, which serves as a canopy for all of the room. At night, the room is lit by a kerosene lamp, and sometimes by some candles (ibid.).

This then, is not the gazing of the saints in the quarto de santos, suggestive of invisible powers out of reach for ordinary humans. This is opening up the dark for sight. No one needs to feel 'exiled' from an inaccessible truth here. There are just rusty nails in doorposts, on which the priests have hung their ceremonial dresses. There is just a conjugal bed, right next to the altar, of which the old priestess had said that it was no problem to sleep there, as she had no husband or lover ...

The same rhetorical style - which really strikes me as the literary equivalent of photography's capacity to show it all, '... the Largo do Paço, the Praça de Peixe, the monastery of São Bento, and all the other objects in the vicinity, reproduced with fidelity, precision and minituousness' - is found throughout the book. Even when Dr Nina's writings move into the ideational sphere, metaphors of vision abound. Typically, he first reports what the people have been telling him, but then points out what in fact is going on, often with the backup of some French professor who had reported similar phenomena elsewhere, in Africa, or in the psychiatric consultancy room of some European capital. It has been seen before. It has been reported. There is nothing mysterious out there among the shadows.

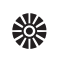

Clifford Geertz could not be more right in stating that visual practices and aesthetic regimes 'are caught up in wider concerns, less generic and more contentful' and that it is 'this encounter with the locally real' that reveals the constructive power of the aesthetic (I983: I02). Dr Nina saw himself as the buster of the mysteries and menaces of the occult. The dictum that 'seeing is believing' helped him to impose a new, 'progressive' order on his life world. The 'truth of vision' was to produce a clear boundary between the world of scientific facts and the world of superstitions.

The sense of urgency underlying this project in the days of Dr Nina is not to be underestimated. After the abolition of slavery in I888 and with 
the installment of the first republic (1889-I930) 'order and progress' had been declared the motto of the Brazilian nation. The modernization of Brazil continued to be imagined along the lines of a European model of 'civilization'. Within this model, the country's racial makeup was a major preoccupation and concern. In debates over the destiny of the Brazilian nation in the modern era, scientists and intellectuals were eager to apply the anthropological theories of Gustave le Bon (arguing the inferiority of the black races) and Darwinist racial theories to better understand what progress and civilization might mean for Brazil. Yet their conclusions were troubling. As Thomas Skidmore remarked, 'the harder Brazilian intellectuals tried to inform themselves about the latest ideas from Europe - for them the citadel of culture and progress - the more they heard about the inherent inferiority of the black' (I990: Io). The inevitable fact that mestiçagem was the prime characteristic of their nation was no less disconcerting. Darwinist thought stated that the mixing of heterogeneous species could only lead to the degeneration of both individual and collectivity. Lilia Schwarcz concluded,

These groups of intellectuals found themselves in an uneasy situation, oscillating between the adoption of deterministic models and reflecting upon their implications; between the exaltation over a 'national modernity' and the assessment that the country, the way it was, did not fit that modernity [...] What we find, then, is that the moment that the nation was discovered, indigenous peoples, Africans and mestiços came to be understood as obstacles on the way to the splendor of civilization, a barrier to the formation of a true national identity (Schwarcz I993: 240).

This issue was most urgently felt to be a problem in Bahia. With its overwhelming majority of black and mixed-race inhabitants the state was often described as 'a part of Africa' transplanted to the Americas. Moreover, Bahia's reputation elsewhere in Brazil was that of a decaying provincial backwater and a remnant of 'colonial times'. If the Brazilian nation had set out to march forwards towards progress and modernity, Bahian elites felt that in their state things were moving in the opposite direction. The constant allusions in $O$ animismo fetichista to the fear of Bahian whites 'slipping back' into primitive forms of belief are a clear example:

The fetishistic animism of the African, diluted with all the superstitions of the white race, and strengthened by the incipient animism of the American aboriginal, constituted the fertile underground on which all the occult mani- 
festations and religions of our people proliferated. Catholic beliefs, spiritist practices, card reading, etc., all receive and reflect in the same way the influx of fetishism and fetishist idolatry of the negro (Rodrigues 2005: II7).

Bahian intellectuals hoped that the branquemento ('whitening') of Bahian society would be a remedy for the 'disastrous consequences' of the African presence in Bahia. As elsewhere in Brazil, they figured that an intensification of white migration to the state would lead to miscegenation, which in turn would gradually and inexorably 'whiten' and thereby 'upgrade' the Bahian population (Skidmore I990: 9).

'Whitening' was also understood culturally. 'Desafricanizar as ruas' ('to un-Africanize the streets') became the battle cry of attempts to position Salvador squarely in the civilized part of the world: the presence of black women selling African foods on the streets and wearing African-style garments on the streets and squares was to be curbed, just as Afro-Brazilian entertainments such as capoeira and samba were to be forbidden. ${ }^{33}$ In Bahian newspapers one finds a steady call for a greater involvement of the city authorities in the preparations of Carnival, as the increasing presence of Afro-Brazilian carnival groups threatened to 'degrade the name of Bahia, with their tasteless and appalling performances'. Thus - next to the daily advertisements announcing the arrival of Swiss clocks and 'canned condensed milk', French wines and 'novidades de Paris', Italian straw hats, American pianos, suitcases and carpets, as well as Russian leather and tarot-players (cartmomantes) - letters-to-the-editor testify just how much civilization was thought to be at stake:

The festivities of Carnival are drawing close, and the African drums are preparing already to once again tell the world about our low level of civilization, turning celebrations as this one, so pleasant in other cities, in true candomblés (Rodrigues I988: 275).

If a foreigner were to judge Bahia by its carnival, he could not but put us in a par with Africa. We have noted that, to our great embarrassment, a commission of Austrian wise men is now visiting the city who - their pens undoubtedly poised - will communicate these facts to the rest of civilized Europe in their travel impressions (ibid.).

This year's carnival, notwithstanding requests to work towards the accomplishment of a more patriotic and civilized tone of the festivities, was still a public exhibition of candomblé, not counting the very few exceptions (ibid.). 
All these elements - the 'contagious' nature of primitive beliefs; the 'degeneration' that comes with racial mixture; and the supremacy of a European perspective on things - are played out in a particularly revealing passage in O animismo fetichista. It discusses the case of a young woman, who was about to get married, but then found herself to be the victim of black magic performed by the black mistress of the spouse-to-be. The anecdote merits extensive quotation:

The mother of the girl, who is a hysteric and degenerate [in Dr Nina's perspective meaning that she was of mixed blood] and lives surrounded by Negroes with influential positions in Candomblés, deemed [the plight that her daughter was in] the result of feitiços sent by the ex-mistress of her son-in-law. An African tio ('uncle') was called who then confirmed the mother's suspicions, declaring that the girl must have stepped on a feitiço, after which the demon had entered her body through her foot. The African, a fetish priest, set out to exorcise the girl and release her of the evil spirit. During eight long days, the poor lady, under the influence of the fetish priest and his exorcist practices, entered into a genuine state of grave hysteria. It was thus that a brother-inlaw, revolting against the procedures that the family had chosen to resolve the problem, came to me, asking me to intervene in time so as to save the girl's life. I came to the home of the patient in the evening, at the time that the fetish priest was supposed to be there, and they allowed me to see his actions. The effect of the voice of the fetish priest was evident. As soon as the lady heard his voice, she jumped up on her feet, as in defense, and - secured by her husband - sought for something with which to injure the fetish priest. The mixed-up prayers uttered by the priest, ordering all the cited demons to leave the victim, had a remarkable effect. With every name, the poor hysteric changed her movements and voice to respond to him. It was thus that the fetish priest was able to name the various demons that had possessed the lady. After that, he announced to be back the next day to continue his treatment. I made the family, and in particular the husband, see how sad the scene had been, and what kind of responsibilities were theirs to take.

With the first suggestive injunctions that I made to show that this was merely a case of hysteria, the lady, still contorting from the attack, calmed down como por encanto (as if she had been charmed). She slept a bit, and then woke up calmly and tranquil, albeit extremely tired. With some more hypnotic sessions, the attacks disappeared, and up until today, more than two years after this major crisis, she is relatively well and strong, having given birth to a daughter, and without further complications. Here then, a simple verbal suggestion was sufficient to call to a halt a state of possession (Rodrigues 2005: 86-87). 
I am struck how Dr Nina stages his meeting with the fetish priest as a battle between classic and baroque visions of the world. The fetish priest, in confused baroque fashion (he did not even get his prayers straight), seems only capable of pointing out the presence of the demons, but has no access to their realm (and thus, for the ninth day in a row, announces 'to come back tomorrow'). Dr Nina, triumphant and in full possession of the real truth of the case, simply explains the problem away by observing the scene and then giving it a European name: hysteria.

The more important point to make, however - and Dr Nina's little flirt with the thought of being a fetish priest himself might function as a reminder here - is that this spirit of the classic depended on its own animistic operations. The spirit of the classic directed Dr Nina's demystifying gaze towards some objects but not others. Thus, it allowed the objects that were not under scrutiny - moustaches and fur-trimmed cassocks, for instance, and books and scientific theories, statues on public squares and portraits in the galeria de fama of the Faculdade de Medicina - to do their animistic thing, making the power divisions and social hierarchies expressed in these objects as real and self-evident as nature itself.

For it is indeed striking that in all of $O$ animismo fetichista there is not one single argument to be found as to why 'induced somnambulism' would be the better term for spirit possession. Dr Nina just mentions French (and occasionally British) thinkers, quotes learned European studies, or postulates 'the latest theories from Europe'. That is all he needs to do to convince himself and his readership of the supremacy of positivist, ocularcentered science.

Europe was the Big Fetish in Dr Nina's Bahia. It radiated power and potency, and endowed everything that could be related to it with status and prestige. The remarkable impact of the mere words of Dr Nina on the 'hysteric' woman - his victory over the forces of the occult - were undoubtedly the result of the way Europe, science and technology, and the modern had become fetishes in their own right.

\section{讙}

In the following chapter, I will show that Dr Nina's ocularcentrism never made any great inroads in Bahian perspectives on the world. This does not mean, however, that Dr Nina's voice had not been heard. I have pointed it out already: in their own way Bahians accord respect to the academic posture and bookishness. When he died, Dr Nina was a famous and wellrespected scholar. His funeral was a pompous event, the church splen- 
didly decorated with 'curtains of black cashmere, lined with silver fringes'; 'decorative shields with inscriptions allusive to the event'; a 'catafalque in renaissance style'; 'silver incense burners and vases with flowers and crotons'; and 'the banners of all the escolas superioras of Bahia'. The prior of the Benedictine order said mass, and four novices sang Gregorian chants. And the dean of the Faculdade de Medicina, a certain Guilhermo Rabello, philosophized the Great Mystery back in place, when stating that

If one finds oneself standing before a túmulo aberto (open grave), all intellectual discussions, all contestations between systems of thought and schools of learning, and even the way in which a thinker had plunged himself in that deep and unfathomable ocean which is the world of the intellect lose their meaning: it all means nothing ... (Ribeiro I995: 62).

This, according to Walter Benjamin, is the allegorical move par excellence: to rob the profane world of its sensuous fullness, to rob it of any inherent meaning it might possess, only to reinvest it with a privileged meaning whose source transcends this world (Cowan I981: II6). Not even buried yet, and poor Dr Nina was already becoming an emblem, an allegorical figure of positivist science. Streets, research institutes, and even Vargem Grande, the town where Dr Nina had been born in far away Maranhão, were named after him. And in the endless dynamics whereby baroque and classic articulations of the world become entwined and entangled, the 'spirit of the classic' that Dr Nina had advocated so vigorously, would soon become 'the spirit of the classic' in quite another sense.

When I had told him I was studying Afro-Brazilian religion in Bahia, the agent from whom I rented my car -a man of Portuguese descent, called Brito - told me he was a medium himself. 'Nothing like that "African stuff," he insisted. He was a spiritista, a follower of Alain Kardec. The spirit to which he was a medium was a German medical doctor, called Dr Adolf Fritz, who had lived and worked in late Igth-century Europe, and had presumably died during the First World War. 'They say he was a racist,' Brito told me. Dr Fritz first manifested himself in a medium in Minas Gerais, but soon, a great number of mediums claimed to receive the spirit of $\mathrm{Dr}$ Fritz and started to perform 'spiritual surgery'. For years, Dr Fritz had used Brito's body to practice spiritual surgery on patients, healing them of all kinds of afflictions. 'We open the bodies, no anesthesia or nothing, and 
then we perform spiritual surgery.' Brito also told me that, when possessed by Dr Fritz, he wrote recipes for his patients in German, a language he himself did not master. 'He is famous, Dr Fritz. There was even a documentary on him that was broadcast on national Tv. You ought to look him up on the Internet.' Which I did.

On the Wikipedia site where his story is recounted, it is stated that the spirit of Dr Fritz had come to Brazil after an invitation of the spirit of Antônio Francisco Lisboa, nicknamed o Aleijadinho, 'the crippled one'. Aleijadinho is by far the most famous sculptor from I8th-century Brazil. A true icon of Brazilian baroque. ${ }^{34}$ 



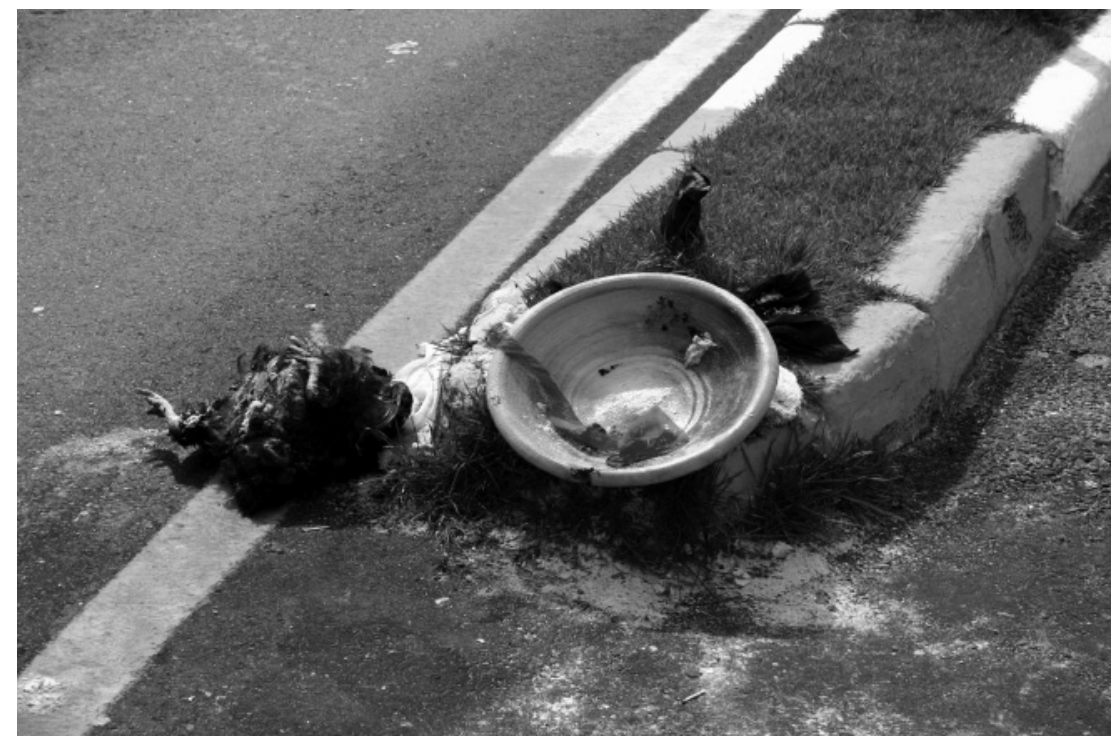

Figure 10 Ebó on the streets of Salvador, 2006 


\title{
B \\ re-eNCODING THE PIIMTIVE
}

\author{
Surrealist appreciations of Candomblé in a \\ violence-ridden world
}

'I love Candomblé!' We were sitting in a fancy bar and the girl was sipping from a spicy, ginger-based cocktail called Maria Bonita. She sported glasses with a hip frame in red and white and she was from Macéio, capital of the neighboring state of Alagoas. Having learned about the topic of my research she beamed with enthusiasm.

'I love everything about it. The music, the celebrations, the mythology. It is beautiful. And l'm devoted to my Orixá, my guide and protector.'

She bared one shoulder to show me a small tattoo, an abstract depiction of an elegant round hand mirror, one of the attributes of the Candomblé sea goddess lemanjá.

'That's right. I'm her daughter. I always thought I was, everyone kept telling me. And then it was confirmed by a mãe-de-santo in Cabula who played the búzios (the cowry shell oracle) for me. Had to go all the way over there, take a bus. It was kind of scary, that neighborhood. She was a black lady, you know. Very old, very kind. Uma daquelas (one of those), who truly know about these things, and who don't charge you. You just leave a donation.' 
All during my research I would meet people with similar stories - and similar shining eyes - when I told them that I was studying Candomblé.

'Ah, cool!', they would say. 'Candomblé!' And then they would have some story or other of their relation with the cult: reveal which of the orixás were supposedly in charge of their head; point out their earrings made of búzios in a golden frame; make a reference to a $\mathrm{CD}$ by Virgínia Rodrigues, who sings Candomblé songs in bel canto; a show by megastar Carlinhos Brown, who constantly makes references to the Candomblé universe in which he grew up; or to a recent exhibition of the elegant black-and-white photographs by Pierre Verger.

The way Candomble is extolled in cultural circles - an extolment that stands in flagrant contrast to the dismissive views of Dr Nina, discussed in the previous chapter - has everything to do with the fact that Candomblé has become the trademark of the Bahian state. In contemporary Salvador, Baianidade, a term that denotes quintessential 'Bahianess', is so thoroughly entwined with the cult of the orixás that it has become very difficult to express a sense of Bahian belonging without making references to the world of Candomblé. For decades the same message has been repeated over and over again: Bahia is Candomblé, and Candomblé is Bahia. Or, in the words of a popular song, celebrating the city of Salvador and the beauty of its inhabitants, all of whom belong to the Candomble deity of beauty, Oxum:

$\begin{array}{ll}\text { Nessa cidade todo mundo é d'Oxum } & \text { In this city everyone belongs to Oxum } \\ \begin{array}{l}\text { Homem, menino, menina, mulher } \\ \text { Toda essa gente irradia magia }\end{array} & \text { Man, boy, girl, woman } \\ \text { Presente na água doce } & \text { All these people irradiate magic } \\ \text { Presente na água salgada } & \text { A gift in the sweet waters } \\ \text { E toda cidade brilha } & \text { A gift in the salty waters } \\ \text { Seja tenente ou filho de pescador } & \text { And all of this city shines } \\ \begin{array}{l}\text { Ou um importante desembargador } \\ \text { Se der presente é tudo uma coisa só }\end{array} & \text { Whether chief constable or fisherman's son } \\ \text { A força que mora na água } & \text { When giving a gift they are all the same } \\ \text { Não faz distinção de cor } & \text { The power that lives in the water } \\ \text { E toda cidade é de Oxum } & \text { Doesn't distinguish between colors }\end{array}$

Due to this new public role, Candomblé has become a veritable 'symbol bank', serving a highly diversified clientele. Populist politicians, gays, black activists, environmentalists, feminists and many others have taken up Candomblé symbols to communicate that their particular worldviews, 
lifestyles or politics are fully in tune with 'the ways of the Bahian people'. Moreover, Candomblés history has been successfully framed as a saga of heroic perseverance in the face of persecution, marginalization, and prejudice - which gives a certain grandeur to identifications with the cult. 'We too endured oppression!' 'We too were victims of injustice!' 'We too remained loyal to our beliefs against all the odds!' Identifications with Candomblé have also been reinforced by the tremendous success of Pentecostalism in Brazil, with its intolerance towards diversity and difference and its relentless campaigns to demonize the cult. In alternative circles, 'simpatisante of Candomblé' is the least that one should be.

With my friend Lobinho, however, it was an altogether different story. I met Lobinho at the very beginning of my research, when he was the manager of a very popular bar-annex-cultural center in Salvador. It was a place where the culturally inclined would gather after their visits to theaters and cinemas, and where gays would meet to warm up for later hours in sleazier places nearby: the kind of place where people considered the cult of the orixás to be the glorious cultural heritage of Bahia. Lobinho, however, entertained a radically different opinion. He deemed Candomblé to be a 'primitive' belief. And what is more, he wanted to make sure that I took notice of his opinion.

Over the years it happened a number of times that he took me apart after having overheard a conversation in which someone had sung me the praise of 'the splendid beauty' of Candomblé's rituals, the 'sagaciousness' of its priesthood or the 'ancient roots' of its traditions.

'I'm not sure what people have been telling you about Candomblé,' Lobinho would say, 'but you cannot, of course, deny that it is a primitive thing.'

As if to prevent those vague grumblings in my throat from becoming objections, he would immediately add:

'Or what term would you use for cutting animals' throats, bleeding them to death, bathing initiates in their blood, and leaving slaughtered chickens on people's doorsteps in an attempt to bewitch them? In my vocabulary that is primitive!'

The fact that Lobinho felt obliged to state his opinion on Candomblé in the privacy of a tête-à-tête indicates the extent to which it has become 'politically incorrect' to declare out loud that Candomblé is a 'primitive' thing. All the more so when you are visibly afro-descendente, like Lobinho. What is more, for all of his reservations about the cult, even Lobinho could not evade involving himself with the ubiquitous legacy of Candomblé in Salvador's public sphere. 
Lobinho lived a bit of a 'bohemian' life, courting the margins of the Bahian capital, cruising the streets and alleys of the old center on his down-at-heel sneakers. It always struck me that he seemed to know all the street kids, transvestites, taxi drivers, gatekeepers, and other restless nighthawks like himself. He visibly enjoyed every inch of Salvador's stinking, noisy and ramshackle glory. Sometimes, after his work in the bar was done, he would take me to some far-off watering hole where he knew the beer would still be bem geladinha (really cold), even at five in the morning, and where he might sing along with Bahian popular music (in which Candomblé deities are frequently mentioned), or joke with the woman selling acarajé (bean fritters), who sought to figure out whether he was a 'son' of Xangô, Ogum or one of the other orixás. At the time of carnival, he would dance his feet off to the Candomble derived sounds of the afoxés, Bahia's famous black carnival bands.

Visits to Candomblé temples - with their late-night ceremonies would have fitted in easily with this cultural itinerary. As Dr Nina already suggested, Salvador has a time-honored local script of bohemian visits to the festas dos orixás. ${ }^{35}$ To Lobinho, however, the terreiros remained a definite no-go area. He even sought to underline that his more evident involvement in the 'cultural manifestations' of Candomblé was inescapable, motivated by 'external pressures', not by any personal desire. When on the and of February - the day consecrated to lemanjá, when hundreds of thousands bring floral offerings to her shrine in the neighborhood called Rio Vermelho - Lobinho showed up in a blue shirt sprinkled with tiny white flowers (blue and white being the colors of the deity), he could not help blushing when I jokingly told him that lemanjá would be very pleased with this subtle tribute. Ignoring the joke and putting on a serious face he stated that as a good manager he would 'of course' have to go along with the wishes and preferences of his clients. When soon afterwards he heard someone telling me how important it had been that the bar had prepared a collective present for the deity, he winked an eye, as if to say 'you and I know how far to go along with that kind of crap, don't we?'

Lobinho's attempts to distance himself from Candomblé must certainly be understood in relation to the fact that he was brought up in a Baptist family, where Candomblé was considered to be 'a thing of the devil'. Up until his early twenties he had been a devout, church-going evangelical. At one point he showed me pictures of that period: a stunningly handsome Bahian, all ironed-out in his spotless and hopelessly unfashionable camisa social (formal shirt). The pictures were utterly incompatible with the nicotine stained fingers that had handed them over to me, the thumbed and 
crumpled envelopes out of which he had produced them, and the messiness of the loft-like apartment in which we were sitting.

It would be too simple, however, to explain Lobinho's ambiguous relation with Candomblé exclusively in terms of his religious upbringing. After all, there was so much about his lifestyle that was in discord with the stern world of Baptism: Lobinho was (more or less openly) gay, a heavy drinker and (marihuana) smoker, and one of the greatest dancers I have ever seen. And although Lobinho was living testimony to the fact that there is no such thing as a complete break with the past (he was very attached to his family, and there was a desperate edge about the carousing and merrymaking, the drinking and smoking, the tireless flirting and the throngs of boyfriends that followed his beaming smile) such internal turmoil did not keep him from continuing along the 'devilish' path.

So why is it that Lobinho kept saying that Candomblé is a primitive thing? What was it that kept him from joining the multivocal choir singing songs of praise? Why did he keep his reserve?

I allow myself the speculation that Lobinho deemed the extolment of Candomblé in terms of 'splendid beauty', 'native philosophy', 'African religion' and 'ancient tradition' incompatible with his understanding of the life world that is Bahia, as well as with the way Candomble is woven into the fabric of that world. I suspect that he felt the need to 'correct' the teachings on Candomblé of his (relatively) well-to-do and largely lighterskinned customers because - rightly or wrongly - he felt that these people were not quite in touch with what Bahian society is like beyond its middle-class horizons. He certainly felt that $\mathrm{I}$, as a European, was not in touch with those realities, always worried that my drive towards immersion would get me into serious trouble (I recall how he came running after me one night in a dance club, when I was on my way out with a guy I had just met: 'You don't think you are going to take this character home with you, now do you?'). His insistence on Candomblé being a sign of the 'primitive' probably sought to express his awareness that the world he so loved and courted is not a museum, tourist playground, culture zone, or potent antidepressant (as a poster from the state tourist organization Bahiatursa puts it) but produces beauty as well as ugliness; wisdom as well as the emptyheadedness and ignorance that is born from poverty; carefully polished traditions as well as brutal violence. He possibly sought to open my eyes to the fact that there is more to Bahia than images of 'a terra da felicidade' - however much he insisted I noted that too.

Lobinho was stabbed to death in his home on New Year's Eve 2003. There were never any answers as to why he was killed, or by whom. The 
police never made much of an investigation. Rumors suggested he might have taken a michê (male prostitute) home, or seduced some 'fucked-up' street kid with a 'rola grande' ('big dick'). Given the many stabbings - no less than eight, someone told me - things might have gotten out of control because of drugs. Yet such unanswerables were soon replaced by a resigned recognition that these ugly things happen in Bahia, and that you will never know the reasons why.

I owe it to Lobinho's memory to reconnect the beauty, the splendor, the wisdom, the solemnity, and all the rest that makes Candomble worth our while to what he kept calling 'the primitive'. I know the term 'primitive' implies a scheme of evolutionary development that has long been discarded for all the right reasons. I am aware it easily reproduces all kinds of stereotypes about black people and black culture that should not be reproduced. I only wished Lobinho had used another term. But he had not. And all the right reasons should not keep me from trying to understand what Lobinho was talking about, to follow the lead he so insistently offered me - and so to find out what he was trying to say.

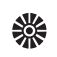

For some years, Lobinho had worked as a civil servant for the Bahian government. In that capacity he had traveled to the remotest corners of the state. His apartment was full with all kinds of cactuses and succulent plants he had collected in those years - prickly, spiny, uninviting life forms, tenderly cared for.

'Things are different in the interior,' he would tell me, then add, somewhat curtly, in order to cut off further questions: 'You just can't imagine what it is like out there!'

Victor later filled me in on what this 'you just can't imagine' might have meant. Born in utter poverty in a village in the Bahian interior, he had many stories to tell about things that are indeed beyond my experiential horizons; things that may be even beyond the evocative power of words, as they belong to the realm of experience, and can only be known in and through the body and in the passing of time. Incest, famine, child abuse, alcoholism, suicides, violence, mob justice, homelessness, constant fear for the incalculable actions of supernatural beings, fear for the 'evil eye' of others, and a profound, generalized distrust in what fellow human beings are up to: it was all there under the swaying coconut trees. I recall, for example, his story about a girl that had given birth to a deformed baby. Instead of supporting the girl to alleviate her agony, or even show sym- 
pathy, the whole village blamed her for having caused the deformation in her child. After all, several neighbors had noticed that, while pregnant, she had been watching two street dogs fucking with too much evident interest. No wonder her child had come out like this. And then there was that story of the neighbor's daughter, who at the age of fourteen had already given birth three times: the first time she had been aborted with herbal infusions, and had covered the fetus with a stone, 'but the neighbors had seen it all'. The second time she had 'pressed the thing out' in the backyard and 'given it to the dogs to eat'. The third time she had hidden her pregnancy by tying a shawl around her belly. When she had given birth in the backyard she had put the child in a bag and thrown it into the cesspool. The crying of the infant had alarmed a sister-in-law, who soon found the child, still alive.

'The little boy now walks around the yard, three years old', was the conclusion to this story.

Victor also had stories closer to his heart, the ones he did not 'want to think of for fear of having to cry': stories of survival, basically, with so much rottenness in them that you cannot but wonder how so much decency sprouted from it.

'One day l'll write a book about them,' he keeps telling me.

Such ugly stories may well have been on Lobinho's mind when he insisted on the validity of the p-word to describe some of the other realities of 'a boa terra' ('the good land', yet another line that is often used to describe Bahia). Yet Lobinho's 'primitive' was not exclusively located back in the state's interior, as he was aware that the city produces its own obstacles to keep people from executing the 'intricate choreographies of step execution and floor pattern' that make up a so-called 'civilized' life. In the urban setting, Lobinho's 'primitive' might have referred to the ever visible poverty and misery he kept pointing out to me; to the foulmouthed language of the prostitutes and transvestites on Carlos Gomes street in central Salvador; to the screaming and shouting of neighbors at any time of the day or night in the popular neighborhoods; to the fighting of two women over a man in front of a congregated audience spurring them on; to the incalculability and ubiquitousness of lethal violence; to the death squads who drastically 'resolve' people's problems with crime; to the obscene lyrics of the pagode or arrocha, and the hip movements and pelvic thrusts of the accompanying dance; to the eternal crotch grabbing and spitting of the men that belong to Bahia's street corner society; to that skin-over-bone crack-user in what must have been her last month of pregnancy I once saw stumbling down the Ladeira do Carmo, half-naked and utterly spaced 
out; or to the empty-eyed beggars who spend all of their days on a piece of cardboard, exhibiting their wounds and ulcers, and of whom you do not even dare to ask yourself what is going on in their heads all day long. In a world where (for all of the rhetoric to the contrary) Europe still retains the powers of a Big Fetish - informing the standards of perfection, guiding the imaginations as to what the world ought to look like after the installment of 'order and progress' - people may take such facts, sights and confrontations to be signals that Bahia fails to live up to the standard of civilization. I hasten to add that most Bahians do not think so in any absolute way as there are many counter discourses readily at hand to dismiss Europe and its standards as irrelevant and undesirable. Yet this idea of being 'second league' in a world order does play up in a nagging, subdued manner; 'subcutaneously', so to speak.

The feeling of not-having-met-the-standard is mercilessly played on in a provocative column by Diogo Mainardi, and I deem it so revealing that I will quote it extensively.

Brazil brought some baroque saints and oratories to the Biennale in Venice. An evidently suicidal initiative. Baroque art in Italy is associated with a Bernini and Borromini, with the Trevi Fountain and the Boboli gardens. To take our saints over there is to expose them to absolute ridicule. Brazilian baroque never was, nor will be, art. It is handicraft. In fact, the contrast between the statues of the Brazilian saints and the Venetian church in which they were exhibited was merciless. Suffice to see the names. San Giacomo dall'Orio has a fresco and a painting by Veronese. There is also a painting by Lorenzo Lotto. One of his minor paintings, but still: a Lorenzo Lotto. There is a complete cycle of Palma, the younger. There is a gothic crucifix by Paolo the Venetian. There is one of the most elaborate wooden ceilings in the architecture of thirteenth century Italy. These poor little Brazilian saints, disproportioned, inexpressive, rudimentary, banal, are completely lost in this noble surrounding.

The problem isn't merely technical.... Our baroque limited itself, in the $18^{\text {th }}$ century, to reproduce the religious iconography of the $\mathrm{I}^{\text {th }}$-century, with simple images of the saints and martyrs showing their classical attributes. Compare them with any object in the church of San Giacomo dall'Orio, like, for example, a Predication of St. John the Baptist, by Francesco Bassano. This canvas contains erudite commentaries on the reformation, on the Council of Trent and on the protestant painters from Germany.

Art is information, interpretation, and discussion. There is nothing of that in the Brazilian saints and oratories [....] Our baroque is mainly the work of slaves. And how to expect individual creative impulses from a slave? Isn't he 
merely doing what his master ordered him to do? Is there for the slave a difference between carving saints from wood and chopping sugarcane? Brazilian baroque was never art. It is nothing but the expression of a backward society. ${ }^{36}$

All these examples suggest that in a place like Bahia, the notion of the 'primitive' is not so easily located with the others (in contrast to the ease with which Europeans manage to do so, no matter how 'uncivilized' their history). In Bahia, 'primitive' is a dimension that can be pointed out in - or rather: attributed to - almost everything. People use the term to refer to corruption, to the greed of Brazil's leaders, to the country's 'third-worldishness', its inability, or even unwillingness, to provide for its citizens the way 'civilized places' are imagined to function, even to its great objects of baroque art.

'I'm embarrassed,' an old lady told me when we were waiting in a long line to be attended by one single employee of the national Bank of Brazil, who had rightly decided not to make the endless queue her personal problem. 'Coming from Europe, you must think this is a primitive place.' And a certain Dr Natalino, from the prestigious Faculdade de Medicina, explained to journalists that the bad study results at his institution had everything to do with the fact that 'a cultura baiana é muito primitiva' (Bahian culture is very primitive). As the Folha de São Paulo reported:

According to Natalino, the sound of the internationally acclaimed music band Olodum [who plays Afro-Bahian music] 'is not music', and the berimbau [a musical bow used in the accompaniment of Bahian capoeira], for having one string only, 'is typically an instrument for those who have few neurons ... it only produces that monotonous noise, pooh pooh pooh pooh pooh pooh pooh. Is that to be considered an indication of elevated intellectual qualities? I would say it is not. ${ }^{37}$

Candomble is often mentioned in the depictions of the failed modernity that the term 'primitive' evokes. 'Believe me, l've seen university professors going at great lengths trying to break the spell of macumba', Eloisa told me, then to conclude that 'you have to realize that this is Brazil.'

The use of the word macumba is significant here. The word refers to the black magic associated with the realm of Candomblé, but in Bahia macumba is often used to reposition Candomblé as a whole into the shadows of the occult. Code-switching between 'beautiful Candomblé' and 
'scary macumba' happens all the time and signals that the designation of the cult in terms of cultural heritage has not barred the continuation of an understanding that Candomblé is a repository of frighteningly effective magical powers, and that the public extolment of the cult covers far more ambiguous understandings of its role in Bahian society.

Macumba stories recognize that Candomblé is rooted in an imperfect world, operates in an imperfect world, addresses the issues of an imperfect world, explains the imperfections of the world, and thus cannot be but a reflection of those imperfections. Although these stories circulate in all classes of Bahian society, my friends from the popular classes were most outspoken about this dark side of Candomblé. They were born into a world where Candomblé was operating as a magical-religious practice, rather than lifted onto the stage as a 'cultural heritage'. Their Candomblé was a cult with a great many faces, with front stages and backstages, with all kinds of people roaming around its universe, with all kinds of priests who have all kinds of intentions, good and bad, beneficent and harmful.

Beauty was certainly not on their minds when they discussed the cult. To the contrary, many of them considered Candomblé to be utterly uncool: the kind of stuff one's mother is involved in, or one knows an aunt to be meddling with, or some biba (effeminate homosexual) in the neighborhood who could not resist the flamboyant, exotic outfits and colorful necklaces of the pai-de-santo. They considered an open involvement with Candomblé to be embarrassing. Not at all something you would put your mind to if you did not have to, let alone make part of your identity narrative.

Only when I explicitly pointed it out to them, they might agree that 'Candomblé is beautiful'. So it was only at my instigation that Manuel raised his depilated eyebrows and said:

'Okay, the places where the tourists go, that is where it is very fancy and beautiful.'

At which point his friend Isodório would correct him, saying:

'No Manuel, there it is very chique!' (A word indicative of the beauty of consumptive power, rather than the beauty of tradition).

'Awesome' would be a term more congenial to their understanding of the cult. Their Candomblé was a repository of powerful, dangerous forces; and you would only seek access to that repository when one or another life crisis forced you to do so - or when the spirits had already made an unsolicited entry into your life. A conversation I had with two middleaged ladies in front of a terreiro called Aganjú, is illustrative of this kind of relationship with the cult. One of them sighed: 
'So much responsibility to be in Candomblé ...'

She explained that she already had two daughters who had been initiated and was now 'praying to God' that the third one would stay out of it.

'Oh yeah,' the other woman replied, with a heavier sigh, explaining that both her mother and herself were initiated, and that she could barely bear the costs of fulfilling her obligations towards her santo. Turning to me she said:

'Poucos vão pelo amor, a grande maioria pela dor (few go out of love, the great majority out of pain).'

Again: in contrast to the Candomble of Lobinho's customers, these ladies were not involved in Candomblé so as to add another dimension to their identity narrative, or to upgrade their Baianidade. They did not 'love' Candomblé and 'everything about it'. Due to some 'pain' or other they had felt that an activation of the links with a religious world that was already theirs might help them out.

Because people were at all times cautious to speak about the dark side of Candomblé, rumors and urban legends about macumba provided me with a window onto the apocryphal portrayals of Candomble that Lobinho might have had in mind when describing the cult as 'primitive'. In these whispered stories, Candomblé comes to the fore as a universe full of violence, threats, fear, madness, conflict, exploitation, corruption, abuse, and an all out warfare of all against all. Thus, if the priestesses of Candomblé appear in the public sphere as black motherly figures, full of kindness and wisdom, macumba stories depict them as greedy, exploitative and inconsiderate. Isidório once told me how his mother had gone to a priestess of Candomblé to ask her to break a spell, which she suspected to be the cause of all the agony that had suddenly come into her life. The priestess had confirmed her suspicions and had offered a solution to the problem at the cost of 600 reais ('at the time that was a double salário mínimo!', said Isidório). Desperate to be freed of the attacks of the occult, the mother finally managed to borrow 400 reais from relatives and friends, which the priestess accepted.

'You can imagine that for months after, a comida foi pouca e pobra' (there was little food on the table and meager food at that).

Violence and abuse dominated the many macumba stories that José, a twenty-five-year-old shop assistant, told me. One of these tales was about a thirteen-year-old girl - 'she was very pretty!' - who had had 'the sixth sense'. 
'You know, like in that movie', José added. 'Or at least, a Candomblé priest, who was a neighbor to the girl's family, had told her mother that she had this gift.' He continued:

The priest managed to convince this woman that her child should be initiated and become a daughter-of-the-saint. The father, however, was fiercely against this idea, and prohibited the mother to continue contacting the priest. Nevertheless, one day, when the father was out of town, the mother brought her daughter to the terreiro, where the child was locked up in a room to be initiated. When after some days, the father returned home, and found out what had happened, he exploded with anger. He immediately went to the terreiro to take his daughter home, but the priest wouldn't let him in. Only when he had arranged a search warrant from the police, he succeeded to enter the terreiro. By that time, however, the priest had fled and was nowhere to be found. They found the lifeless body of the girl in a room, lying on the floor. She had been raped and murdered. All around her on the floor were tufts of cotton [a detail that went unexplained in Josés story]. The mother went mad, and converted to Pentecostalism, hoping that her sins would be forgiven. She is now divorced from her husband. The priest was arrested and sentenced to ten years of imprisonment. At this moment, however, he has already opened another terreiro in another town and continues to work.

'Isn't this Pentecostal propaganda? With that mother becoming an evangelical and all?', I asked José after he had told me the story.

José fiercely denied it, looking at me incredulously for being so naïve. 'No! No! These things happen! They do! It was in the newspapers. I will look up the article for you!'

He then told me a second story, this one staging one of his very best friends, who was initiated in Candomblé.

At the time of his initiation, my friend had to stay in seclusion for three months, and could not leave the quartinho (little room). Yet after a while, he couldn't deal with the isolation, and wanted out, insisting it had been enough. When at one point he left the room and refused to go back in, the priest vowed to put all the orixás on him to make sure he would not have another happy day in his life. One week later, my friend began to suffer from heavy headaches, spasms, and trembling. He became seriously depressed and at one point wanted to commit suicide by throwing himself off the roof of a building. I managed to talk my friend out of it. With the help of a befriended priest from another terreiro we found out that my friend was indeed the victim of a very heavy 
macumba that was made against him. It had been his luck that he happened to have a very strong guardian angel to counter the attacks; otherwise he would have been long dead. My friend is okay now, and is still into Candomblé. Yet he doesn't want to talk about the subject any more. All he keeps telling me is never to initiate into Candomblé. He says that 'once you are in, there is no way out'.

Macumba stories do not limit themselves to the (semi-)domestic settings discussed in the examples above, nor to the life worlds of the popular classes. They also cast public power in another light, as the rumors about Bahia's longtime political leader Antônio Carlos Magalhães (usually referred to as АСM) illustrate. АСм was one of the main architects of the 'Candomblé-ization' of Bahia's culture politics, and although he never declared himself openly to be an adept of the cult, he frequently displayed his good relations with the people from Candomble in the media: visiting old priestesses on their birthdays, participating in syncretistic religious festivals such as the yearly procession to the Church of O Senhor do Bonfim, and making public statements like 'there is no way that you are going to have any contact with power in Bahia if you do not understand religious syncretism. ${ }^{38}$ In macumba stories, such displays of respect and sympathy are not taken at face value. Every single person I asked about it was convinced that the Bahian leader had used 'black magic' to maintain and strengthen his political power, and that he had used divinatory practices from Candomblé to make political decisions. When his favorite son and political 'heir' died in a car accident a rumor started circulating that the all powerful ACм had made a pact with the orixás which is called a troca de cabeça (switching of heads). During a ritual, involving 'lots of sacrifices' and 'lots of blood' in the words of one informant, he supposedly had gained impunity for all the evil forces that his many adversaries might send to him. The price of a troca da cabeça, however, was that these evil forces would henceforth hit the people closest to the one who made the pact. Both the suicide of ACM's daughter, and the death of his son could thus be explained.

The gist of all these macumba stories is to depict Bahian modernity as a failed project. They show Bahia to be a world where the social contract is incapable to temper people's greed and relentless pursuit of power; where no one has great faith in the ability of reason to stand up to the forces of the occult; where 'civilization' is merely a shiny façade that easily succumbs to primitive pressures; and where the transparency of democracy and civil society are illusory, as real power rests behind the curtains, on the backstages of public life. ${ }^{39}$ 
In the public understandings of Candomblé, different qualifications of 'the primitive' come together. Lobinho used the term 'primitive' pejoratively, not unlike the way that Dr Nina had used it, or Brito, who had been so eager to stress that his mediumship of Dr Fritz was 'Kardecist', and had nothing to do with 'that African stuff'. Their 'primitive' was suggestive of such things as backwardness, poverty, ignorance, superstition, a failed modernity, a society whose functioning is nowhere close to the ways of civilized places. And their 'primitive' evoked all the accompanying sentiments: fear for the uncanny dimensions of the cult, repulsion, and disgust. In their understandings, 'primitive' referred to a state of being you would want to get away from by all means.

Not so with the visitors to Lobinho's bar. As stated, they never used the word 'primitive' to qualify Candomblé. And yet, much of their eulogies of the cult were rooted in what is immediately recognizable as a 'primitivist discourse', whereby 'primitive' denotes such qualities as authenticity, purity, unsullied simplicity, origin, corporality and the 'natural'. The 'primitive' evoked in Lobinho's bar denoted a universe you would want to move into: a place of origins and therefore a place of homecoming; a place somewhere at the end of the bus line that takes you into the shantytown Cabula; somewhere in the vicinity of that desolate place where Dr Nina, during his nightly wanderings, found a poetry of a wilder kind; somewhere close to 'the intimate parts of a lover; or to 'one's mother'. Their 'primitive' also denoted the 'commonality of all mankind', an idea that was brilliantly evoked by singer Carlinhhos Brown. Stating that 'Candomble é algo que nasceu junto com o homem de Neanderthal' (Candomblé is something that was born together with the Neanderthal man), ${ }^{40}$ he cleverly avoided the cliché of the primitive African by equating Candomble's origin with that emblem of the European primitive: the Neanderthal man.

Undoubtedly, Lobinho's harsh resumé of Candomblé as 'cutting the throats of animals, bleeding them to death, bathing initiates in their blood, leaving slaughtered chickens on people's doorsteps in an attempt to bewitch them' was a direct response to the near 'beatification' of Candomble in the cultural and academic circles in which he found himself. He sought recourse to this unvarnished, violent image because he felt he needed a potent crowbar to break open the pretty images that dominate public representations of Candomblé. Opting for such carnal, visceral hues he sought to provide me with a glimpse of what he assumed was happening on the backstage of the cult (and in extension of that thought: 
what he had seen happening on the backstage of a terra da felicidade). Lobinho's understanding of Bahia simply did not allow 'the primitive' to be a thing of museums and galleries; the subject matter of aesthetic photography and fancy coffee-table books; the object for the lofty ruminations of an uprooted intellectual audience. His Bahia was a world where people were subjected to forces they cannot (or barely) control; a world somehow passed over when Enlightened ways of thinking and modern ways of being made it south of the equator; a world where the frames between the visible and the invisible were permeable and constantly crossed; an ugly, frightening and unsettling world; a world of prickly, spiny plants; and yet, for all of that, his world, his beloved Bahia, where, as João Gilberto sang, 'tem tanto coisa bonita' (there is so much beauty):

\section{A Bahia que vive pra dizer}

Como é que se faz pra viver

Aonde a gente não tem pra comer

Mas de fome não morre

Porque na Bahia tem mãe Iemanjá

De outro lado O Senhor do Bonfim

Que ajuda o Baiano a viver

Pra cantar, pra sambar, pra valer

Pra morrer de alegria

Na festa de rua, no samba de roda

Na noite de lua, no canto do mar
This Bahia that lives to say

How it is that life can be lived

Where people have nothing to eat

Yet don't die of hunger

Because in Bahia there is mother lemanjá

and on the other side Our Lord of Good Endings

Who helps the Baiano to live

To sing, to dance the samba, to enjoy

To die of joyfulness

at street parties, in the samba de roda

on moonlit nights, in the song of the sea

The question to be asked, of course, is how the public understanding of Candomblé as being 'primitive' in a pejorative sense - so dominant in Igth and early 2oth-century representations of the cult - came to find itself in the company of a new, highly celebratory understanding of Candomblés 'primitive' character. How was the public image of Candomblé reworked to become a repository of all kinds of singularly Bahian virtues? And how was this new, positive image 'animated', so as to seduce new audiences to involve themselves with Candomblé in ever more intimate ways?

This discussion requires yet another look at history: this time, the story of how in the I920s and I930s, a group of avant-garde artists from São Paulo, called the Modernistas, came to re-encode the notion of the primitive in their articulations of what it is that makes a Brazilian 'Brazilian'; how these revolutionary thoughts were modified by the avant-garde in peripheral Bahia; and how these re-evaluations of the primitive became 
the object of a rapidly expanding 'practice of quotation', constantly involving new groups and institutions.

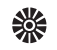

The history of Candomblés public life is best understood as an endless sequence of re-encodings of the cult's assumed 'primitive' character. This history also shows that an insolvable ambiguity has been part and parcel of the ways new publics sought to re-encode the cult. Rejections of the Candomblé universe were never wholehearted, just as appreciations were always hesitant. As Dr Nina already indicated, the very elites who would publicly mention Candomblé and other Afro-Brazilian cultural forms as a sad reminder of Bahia's primitive state seem to have been intrigued and fascinated by them as well. ${ }^{41}$

In the I920s, with the emergence of an artistic and literary movement called Modernismo, muffled associations of the terreiros as places where one could escape to from the oppressive directives of 'civilized' life found public expression. Modernist artists - inhabitants of the booming urban centers of the industrial southeast, principally São Paulo - pursued and succeeded a major re-encoding of the primitive. In their manifestoes and publications, the primitive was no longer seen as detrimental to the civilization of Brazil. To the contrary, the primitive was understood as the unique and vital force of a young state that would enable the nation to free itself from the stifling influence of its doutores, its academics, and its failed attempts to mimic a European order that even in Europe itself had come under attack.

Dadaist and Surrealist influences are evident in the Modernist project. Indeed, there is some irony in the fact that the Modernistas, while rejecting European culture as a valid guideline, were not unsusceptible to the spells of the Big Fetish: they had fully absorbed - 'cannibalized', would be their preferred term - the anti-civilization rhetoric of (European-based) movements such as Dadaism and Surrealism. ${ }^{42}$

The Dadaists' and Surrealists' extolment of the 'primitive' was a direct result of the horrors of the First World War. Shocked that after the biggest mass murder in human history, European societies sought to rebuild the world following the same old, pre-war conventions, Dadaist and Surrealist artists were driven by 'the wish to hit hard on a society of shopkeepers and compromise' (Shelton 1984: 320). Convinced that truth did not reside in the mendacious forms of civilized life, nor in the logic and reason of the Enlightenment, they sought to shake up the existing social order, to shock 
'good taste', and to challenge the world of reason through the release of the imaginative forces of the unconscious. Academic instructions on art and writing were declared anathema, and replaced by any technique that would render them powerless, in order to open the road for an encounter with the 'marvelous'. Automatic writing, the chance encounters of the flâneur, the shock effect of the incongruous juxtapositions of the collage, the exposition of objects trouvés, the play of masks, the induction of trance and hallucinations, anything that would lead the artist 'beyond the ordinary into mythical and mystical realms' was incorporated in the Surrealist repertoire (Tythacott 2003: 73).

From the very beginnings, these attempts to escape from a civilization that was deemed corrupt and corrupting had prompted a fascination for 'the primitive. 'Each grain of dust contains something of the marvelous,' said Joan Miró, 'but in order to understand it, we have to recover the religious and magical sense of things that belong to primitive people' (in Tythacott 2003: 7I). The image of le nègre - with all its connotations of the primitive, the cannibalistic, the anti-European, the unrestrained, the spontaneous, and the erotic - became an important trope to express this desire to be reconnected with truer forms of human being. In the Paris of the I920s, 'any shred of black culture could effectively summon a complete world of dreams and possibilities - passionate, rhythmic, concrete, mystical, unchained: an "Africa”'(Clifford I988: 136).

The Brazilian avant-garde was keenly aware of Dadaist and Surrealist re-encodings of the primitive. Several Brazilian artists (Ismael Nery, Oswald de Andrade, Tarsila do Amaral, Mário Pedrosa) had sojourned in Paris, where they had been in touch with Surrealist circles (Ginway I992: 545). Undoubtedly, these artists reveled in the thought that, as Brazilian nationals, they represented (or at least, were considered to be connoisseurs of) the very 'primitivism' that was so much en vogue in Europe. During a short stay in the French capital in 1923, Tarsila do Amaral wrote:

I feel more and more Brazilian: I want to be a painter of my country... Don't think that this Brazilian trend is looked down upon here. To the contrary. What they want here is that each one brings a contribution from his own country... Paris is fed up with Parisian art (in Damian 1999: 3).

Next to Africa and the Antilles, Black Brazil became a destination on the Surrealist itinerary to explore the expressive possibilities of the primitive. Two Surrealist poets, Blaise Cendrars and Benjamin Péret, visited Brazil for extended periods and both frequented Candomblés. 
Cendrars was well integrated in the Modernist circle of São Paulo (Martins 1992; Noland 2000). Benjamin Péret, upon arrival in Brazil, made it immediately clear in a newspaper interview that he was more interested in 'the exotic elements of Brazilian culture' and therefore was 'less interested in contacting the members of the country's cultural elite', but there were frequent contacts and exchanges between him and the Modernists as well. He wrote several essays on candomblé as 'primitive religion' (cf. Péret 1992), glorifying Candomblé as an institution where 'the religious and the erotic occurred in the same moment' and arguing that the cultists still had 'access to the poetic "marvelous" in ways long lost for Europeans' (in Ginway 1992: 545). The notion of 'energy' is central in his appreciations of 'primitive' Brazil. Péret was evidently impressed with signs of the sheer force of the primitive:

... the negro playing the drum had an athletic figure. His square head was shaved - he looked like a Prussian painted black - and his hands were immense. I'm still surprised that those hands, fiercely beating the drums, didn't reduce them to dust! (1992: 85)

Forms that did not fit the Surrealist understanding of the primitive were dismissed as 'not the real thing'. Péret, who had done his readings and knew the work of Nina Rodrigues, deemed himself immediately capable of distinguishing the 'true' Candomblé from more 'degenerate' forms. After having visited a ceremony in a so-called 'Angolan' terreiro (a line in orixá worship which has assimilated many elements from Catholicism), he mockingly compared the priestess, who had come across as austere and solemn, with 'the local Bishop'. He remarks:

None of these hypnotic dances gave way to the savage and majestic scenes that I witnessed in the terreiro of uncle F. ... [whose Candomblé pertained to the Nagô tradition]. The sensation one had was to be looking at a pale reflection of those other dances, a faded photograph that shows nothing more than the vague contours of the real thing. Could it be that 'civilization' has passed by here? (I992:86)

Through such dialogues and exchanges, Modernist artists began to propagate the liberation of the primitive, the pagan, African and Indigenous elements in Brazilian culture, which were not burdened by 'the plagues of Western culture' (Rowe \& Schelling I99I: 202). If Dr Nina had written about the Bahian blacks being unfit for catechization, they produced 
slogans such as 'We were never catechized. We created carnival.'; 'What obstructed the truth were the clothes, waterproof sheet between the inner and outer world.; 'We have a double and present basis - the forest and the school: barbarians, credulous, picturesque and gentle and at the same time newspaper readers.'; 'We never permitted the emergence of logic amongst us.'; 'We never had grammars' (ibid.).

Oswald d'Andrade's 'Cannibalistic Manifesto', already mentioned in chapter one, is a clear example as to how Modernist artists found themselves in a balancing act of both rejecting and adoring Europe. If the manifesto clearly spoke to a European celebration of the primitive - defining European civilization as potentially alienating, and positioning Brazil's true being, its native originality and authenticity, in the realm of the primitive - it also rejected a mere copying of yet another set of European ideas. The image of the digestive process of cannibalism enabled the appropriation of the civilized Other through a most radical and de-alienating form of incorporation (Ponge 1999).

It needs to be noted, however, that a Parisian reveling in black culture was not picked up by the Modernists. Certainly, black Brazilians and their culture appeared in their paintings, as well as in references to samba and carnival, and (as Wilson Martins remembers) 'it was in that revolution of disrespect of the Modernist movement that we Brazilians developed our monomania of the exotic and the picturesque, with our eternal Afro-Brazilian cuisine, inflicting vatapá (paste of shrimps and peanuts) on all our visitors, not to mention the spectacle of macumba ...' (Martins I992: 982). Yet the role of Blacks in the Modernist imagination was limited to contributing to the 'racial potpourri' that came to redefine the unique mestiço character of the Brazilian nation (Graham, Skidmore, Helg \& Knight I990: 2I). Blacks were not singled out. In fact, the Modernist's favorite cannibals were Indians, not Africans. And next to the distant jungles, they sought the 'primitive' in the 'backward' interior of São Paulo state, or in the 'primitive' baroque of Minas Gerais, which Tarsila de Amaral, after a famous voyage in I924, recalled as follows:

... having passed time in Europe recently, I was really impressed by the popular decorations of the houses in São João del Rei, Tiradentes, Mariana, Congonhas do Campo, Samara, Ouro Preto and other small towns in Minas Gerais, full of popular poetry. A return to tradition and simplicity ... The mural decorations in the corridor of a simple hotel; the lining of the rooms, made of knitted, colored taquarinhas; the paintings in the churches, simple and moving, executed with love and devotion by anonymous artists; Aleijadinho ${ }^{44}$ with his 
statues and the genial curves of his religious architecture; all of this provoked our exclamations of admiration. It was in Minas that I encountered the colors I loved as a child. I had always been taught that these were ugly and hillbilly. I had been made to follow the routines of good taste ... But later, I freed myself of this oppression, using on my canvasses the purest blue, a violent pink, lively yellow, singing green, all in different gradations, depending on the mixture with white. Clean painting. And above all, without fear for the conventional canons (in Khouri 2005: 252).

These recollections of a Modernist search for the primitive are quite revealing about the cultural parameters within which that search took place. For all of their flirting with the cannibals, the Modernists were very much gente fina, 'refined people'. The imagination of another 'primitive Brazil' - which was less about pink rose petals and more in search of nègres boxeurs, less cerebral and more carnal, less insistent on 'having been in Europe recently' and more assertive in the sense of 'keeping it real', less eager to be 'clean' and more focused on the muddy underground of things - became central in the writings of the avant-garde of what was then a provincial capital, thousands of miles from the metropolis of São Paulo: Salvador da Bahia.

\begin{abstract}
灌
The women stamped the earthen floor with their bare feet, dancing. They wiggled their bodies in the way proscribed by the ritual, and yet this movement was sensual and sweet like the hot body of a black woman, like the sweet music of the Negro. Bodies were soaked in sweat and all were taken in by the music and the dancing (...) [the arrival of the orixás] turned the scene into a confused pattern of women and spirits, capricious gods from the distant woods (...) Losing her balance, Maria dos Reis fell to the ground, but even there her body kept shaking to the rhythm of the dance, foam coming out of her mouth and out of her sex organ (Amado I935: 93-94).
\end{abstract}

This is really what it says: espumando pela boca e pelo sexo. 'Foaming from her mouth and from her sex organ.' The moment at a Candomblé ceremony when all the orixás arrive at once to take possession of the bodies of initiates, is always a spectacular scene. And it quite often happens that some Maria or some João falls to the ground. The foaming bit, however, I have never seen. From whatever body opening, for that matter. Mention- 
ing such details, I guess, is one way to suggest that you entertain intimate connections with the world of Candomblé.

Jorge Amado wrote his novel Jubiabá, from which this scene of a 'macumba' is taken, in I935. It tells the story of Antônio Balduino, a black pugilist who 'progresses' from his childhood in a poor neighborhood in Salvador, where 'he had been pure like an animal, his instincts being his only law' (Amado 200I: Io), via a long series of teachings in the school of hard knocks to working-class conscience and parental responsibility. Candomblé is central to the novel: a repository of popular wisdom and a site of popular resistance, uniquely geared to the everyday realities of Black Bahia. The novel was an instant success and became a major bestseller, not in the least because Jubiabá opened up the world of Bahia's Candomblés to a national (and soon international) readership. Although there was some muttering over the 'excessive pornography' in the novel, critics praised the author for his 'realistic' depictions of the Candomblé (never doubting their own ability to pass such judgment).

And yet, Amado's depiction of Candomble has little in common with the photo-realism of Dr Nina's descriptions of the cult. Sure, both authors use the same elements, and although outsiders, they both claim to be representing the 'real' of Candomblé. Yet they come up with completely different readings as to what constitutes this 'real'. If Dr Nina sought to demystify the occult by showing the saintly wardrobe hanging on rusty nails and by introducing a very down-to-earth 'old negress' who informs him that she no longer sleeps with husbands or lovers, and can thus spend the night next to her altar, Jorge Amado opens a window onto a world where ceremonial dresses are always whirling, and bodies engaged in uninterrupted action. His Candomblé is in a state of perpetual foaming ecstasy.

It was then that Joana, who had already been dancing as if she was in a state of trance, became possessed by Omulu, the deity of pestilence. She came out of the camarinho dressed in multicolored clothes, bright red being the dominant color... the upper part of her body was almost naked; a mere white cloth had been wrapped around her breast. And this body of Joana was of a perfect beauty, with her pointed breasts and hard nipples showing through the cloth. At this moment, however, no one saw in her the little negress Joana. Even Antônio Balduino did not see on the dance floor his mistress Joana ... For who had made his appearance there, bared breasts and all, was Omulu, the awesome god of pestilence (Amado 200I: 9I-92). 
Like Dr Nina, Amado finds madness in the terreiros - 'they danced like crazy, rotating their hips, they uprooted themselves completely' (in Hamilton 1967: 247) or 'in the room everyone had gone mad, dancing to the sounds of the drums' - yet this craziness is no longer 'mere hysteria' but transgression, pure human energy, lust, the pulsing life force that Surrealists and Dadaists held in such awe, and that in Amado's work too is used to shatter the fossilized life world of Bahia's academics, politicians, lawyers, clergy and pseudo-intellectuals. Time and again, he lashes out at 'the feeble, watery-blooded little bantams' who make up Bahia's high society, 'the effeminate, stunted, rachitic, vain little milksops', the 'spoiled favorite sons' of married cousins, 'scions of their pure-blooded fornication' (Amado 2003: 104). Time and again, he expresses the frailty of these representatives of Bahia's ruling elites by pointing out their inability to provide a black woman with what she needs, as in that scene in Tent of Miracles where the old Colonel says to the Doctor - who cannot take his eyes off a black woman passing by:

'Doctor, that woman needs a lot of man. That cunt isn't for a half-assed water pipe to pee in, or for any dried-up prick either. She's too much for me now, and she'll always be too much for you' (ibid.).

In the Bahia of Jorge Amado, civilization means decadence and impotence. The primitive, by contrast, an unstaunchable source of energy and life. A truly animating force. The pugilist Antônio Balduino - described as derrubator de brancos, 'the slayer of whites' - is portrayed as a man in immediate contact with his primal instincts and drives. Balduino is always ready to resort to violence, whether in the boxing ring or outside of it. Every now and then, he slips into a little samba to express his more tender emotions. And when Balduino bursts into laughter, it 'echoes all over the city'. The hero of Jubiabá is an icon of primitive force, of the unbeatable will-to-live, boasting the kind of energy that is thought to bring about revolutions and change.

It is remarkable that immediately after the publication of Jubiabá, literary critics were eager to point out that Balduino is not merely some black man from the slums, but the representation of the quintessential Brazilian. As one of them states:

It can no longer be maintained that the writers in our country write 'English' or 'French' novels, as was the usual suggestion before. Today, our novel is Brazilian. And no one is more Brazilian than Antônio Balduino, this extraordinary Negro, invented by Mr. Jorge Amado in his latest novel. ${ }^{45}$ 
This particular re-encoding of the primitive can only be understood in the light of Surrealist and Modernist articulations (Soares 2005). Amado's career started as a member of a group of Bahian adolescents and young adults with literary and revolutionary aspirations who had gathered around the poet Pinheiro Viegas, a middle-aged character who described himself as 'scribe, iconoclast, indifferent bohemian, lyrical ironic, in brief, a smiling skeptic', and apparently 'posed as a homosexual so as to shock the conservative petty bourgeois in Salvador' (Soares 2005: 86). They called themselves the Academy of the Rebels. Their rebellion was directed against the sugary Symbolism and Parnassianism that dominated the deeply conservative Academia Baiana de Letras, but also, and probably more, against the literary circle around the first Modernist literary journal in Bahia called Arco \& Flexa (Bow \& Arrow). These latter poets were very much part of the affluent network of Salvadorian elites, and the Rebels criticized them for focusing on the primitive aesthetics of a conveniently distant jungle - with its 'bows and arrows' - rather than the urban jungle of proletarian Salvador (ibid.: 6r ff.). ${ }^{46}$

Knowing what the world is really like, and expressing that knowledge in poetry and novels - 'keeping it real', in contemporary parlance - pretty much summarizes the intentions of the Academy of the Rebels. In their understanding, the real world was the world of the people, which in Bahia meant black people. They would gather in the popular bars and coffee houses of the old center, in brothels - 'which were not what they are today,' Amado would say many years later, in reminiscence of some French prostitutes with a keen interest in poetry - or on the stairs of the old cathedral of the Sé, facing the Bay of All Saints. Several members of the academy passed time in jail, having been accused of communist activities. In brief, the Rebels sought to immerse themselves in this popular world, courting the rough fringes of Salvador society. Amado, for instance, who began his career as a reporter on homicides for a local newspaper, made it very clear that to know a story, you have to move up close to the source:

... I would go to the police stations to ask what had happened in the night - the accidents, the crimes, the fights, anything; then on to the morgue to see who had died, what condition the corpse was in, how many stabs the body had received, and under what circumstances (Amado I990: I23).

He frequented capoeira schools, was an ogã in a Candomblé temple (ogã is the title for people holding certain honorific offices in the cult $)^{47}$ and sailed off frequently with local fishermen. Edison Carneiro, another mem- 
ber of the group, was ogã in no less than three houses of Candomblé (and would eventually become an important ethnologist of the cult). Sosígenes Costa, the mysterious dandy of the group - never married, an admirer of Oscar Wilde, and always wearing a white carnation on his spotless white suits - appears to have had his links with the Candomblé universe as well: he spoke Yorubá.

In brief, the Rebels were from the streets, not the salons, and they wanted the world to know just that. Up until his death in 200I, when he was the holder of honoree doctorates from various universities, Jorge Amado kept proclaiming that 'the street' had been his best university: 'I learned from the people and from life, I'm a writer, not a man of literature, in fact I'm an obá - because in the Yorubá language of Bahia, obá means minister, elder, sage: sage of the knowledge of the people' (Soares 2005: 9I).

\section{湴}

The importance of Jorge Amado for the divulgation of a public image of Candomblé can hardly be overestimated (cf. Hamilton 1967). His depictions of the cult as a realm of mysteries, ancient wisdom, primitive beauty, popular resistance, and erotic possibility have been key to the formation of public understandings of Candomblé, and they stand at the beginning of endless cycles of quotation. Amado's renditions of a popular Bahia saturated with Candomble were reworked in the songs of Dorival Caymmi and Vinícius de Morais, which in the radio days familiarized the Brazilian nation with lemanjá, Oxalá, Xangô and all the other orixás. The illustrations of Amado's books by the Argentinean painter Carybé gave the Candomblé universe a first official public 'look', which subsequently was to be reproduced in statues and monuments all over the city. Several of Amado's books became theater plays, films, miniseries, and telenovelas, just as themes from his work were picked up and played out by carnival groups. In 1997, carnival itself had as its main theme 'the Bahia of Jorge Amado'. The writer himself was the author of no less than three tourist guides to Salvador. The first one, from the I940s, was subtitled 'A Guide to Streets and Mysteries', in which the 'true soul' of the city is drenched in Candomblé imagery. Pelourinho, the historical center of Salvador, practically became a Jorge Amado theme park after its renovation in I993. Streets and squares were named after characters of Amado novels; and commemorative plates on buildings indicate where certain passages from certain novels had taken place. 
Yet the more profound impact of his imaginations - and their endless quotations in the culture-, tourist- and entertainment industries - is that the black pugilists, the negras fogosas (hot black women), the enchanted visitors, the mulatas dengosas (sweet mulatas), the sage priests and priestesses, the good-hearted malandro (swindler) and all the other emblematic figures that populate his books have become performative scripts: scenarios for daydreaming, engaging both Baianos and visitors to the city. These scripts and scenarios state that level-headedness and staying aloof is not the way to go about getting to know Bahia and foreground the immediacy of the experiencing body as the privileged mode to be in the world. They urge to progress from 'seeing' to 'feeling' to 'being. The ubiquitous presence of Amadiana in present-day Salvador is such that it becomes very difficult to tell where Amado's Bahia stops and where the real Bahia begins. My encounter with that fat man singing his Bahian heart out on the central square of the Pelourinho district, described in chapter one, is illustrative. I had singled out a thoroughly Amadian image, at a point in time when I had not even read Jorge Amado's work.

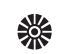

Modernist understandings of the primitive - be it those of the Modernists or those of Jorge Amado and his rebellious soul mates - never questioned the primitive nature of Candomblé as defined by Dr Nina Rodrigues. All they did was to re-encode the 'primitive' in positive terms as a force that would bring the Brazilians back to their 'true' national being and that might fuel revolution and change.

Historically these re-encodings can be traced back to Surrealist discussions on civilization and truth after the horrors of the First World War. Yet I have sought to highlight that an understanding of the impact of new, celebratory encodings of the primitive should at all times take into account the realities within which these ideas were introduced, and to which they were made to speak.

In Europe, the explorations of the 'primitive' by Dadaists and Surrealists sought to highlight the corruption of the model of civilization, its mendacious character, the way it alienated its subjects from their true being. In Europe, the 'primitive' referred to Others: Afro-Brazilians, for instance. These 'primitives' could be embraced as 'truer' human beings, but this approximation was indeed an embrace: an intimacy reserved for specific times and specific places, of limited duration, and with all of the agency being on the side of the 'embracer'. Surrealist critiques of European 
civilization never really altered the hegemony of 'the European standard'. In fact, European critiques on Europe now became another global standard to be met.

Modernists took up that project of criticizing the European standard. In the Brazilian context, however, the 'primitive' could not so easily be positioned with 'the others'. As will be discussed in the following chapter, the avant-garde ideology that had declared racial mixture to be the quintessential character of the Brazilian nation received increasing backup from the authoritarian Vargas regime from the I930s onwards. Through this ideology, the 'primitive' became a constituent part of each and everyone laying claim to being Brazilian. While this 'primitive' was (and is) celebrated as the vital energy of a young nation - the energy of samba, carnival, soccer; the energy of spicy, peppered food; the energy of passionate lovemaking - its appreciation was (and is) in fact far more ambiguous. For the Brazilian nation had only recently put itself on the road to 'order and progress', and the great majority of Brazilians were not (and are not) ready to lament the 'corruptions' of a civilization whose standards they felt (and feel) have yet to be met. Here, the discourse on the primitive always highlighted the imperfections of the Brazilian life world relative to the hegemonic European model: the vital energy of Brazilian soccer taps the same energy sources as the country's endemic violence; the rebolar (hip turning) of the samba is also the jogo de cintura (literally: 'playing of the waist', i.e. flexibility of movement, flexibility to find one's way) that makes clientelistic politics and enterprise work; the celebrated crookedness and street wisdom that is called malandragem is also the very absence of law and order that messes up people's lives; the collective, ecstatic transgressions of carnival are of the same order as the death squads and stabbings.

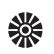

É melhor ser alegre que ser triste

Alegria é a melhor coisa que existe

É assim como a luz na coração

Mas pra fazer um samba com beleza

É preciso um bocado de tristeza

É preciso um bocado de tristeza

Senão, não se faz samba não
It's better to be cheerful than to be sad Cheerfulness is the best thing that exists It is what lightens up one's heart Yet to make a truly beautiful samba One needs a bit of sadness One needs a bit of sadness For without it, one can't make samba ${ }^{48}$

Caught in the prison of a discourse on the primitive, Candomblé-aspublic-culture has become an insolvably ambiguous phenomenon. I can 
only agree with Lobinho that the dominant public representation of Candomblé as 'a thing-of-beauty' has created a public image of the cult that is geared to the taste and aesthetic preferences of the academic and cultural elite in Bahia. ${ }^{49}$ This image also speaks to the increasing number of tourists who visit the cult's ceremonies, and to the aspirations of the Candomblé priesthood to attain public respectability. I do think, however, that Lobinho portrayed his customers a bit too naive when he insisted that they could not see beyond Candomblés beauty. Just as the beauty of the joyful samba cannot do without a 'bit of sadness', the beauty of Candomblé cannot do without its uglier dimensions, which are the very foundations on which its beauty rests. For that reason, Candomblé can never be reduced to a thing of museums, galleries, postcards or academic debates on 'tradition' and 'culture'. To reduce Candomblé to that image, to clean it of its dangerous dimensions, its unsettling, disruptive and fearinducing powers, leaves the cult toothless, impotent and uninteresting. Not something you would deem worthy to tattoo on your body. It is significant that this girl sipping her spicy Maria Bonita cocktail introduced the danger into her eulogy of Candomblé by talking about that bus ride to the poor neighborhood where the priestess would divine her orixá. Just as it is significant that the cocktail of her choice was named after the wife of Lampião, a much-dreaded bandit that roamed the Bahian interior in the I930s, and who left a trace of death and destruction before he and his beloved Maria Bonita were decapitated by government forces. 


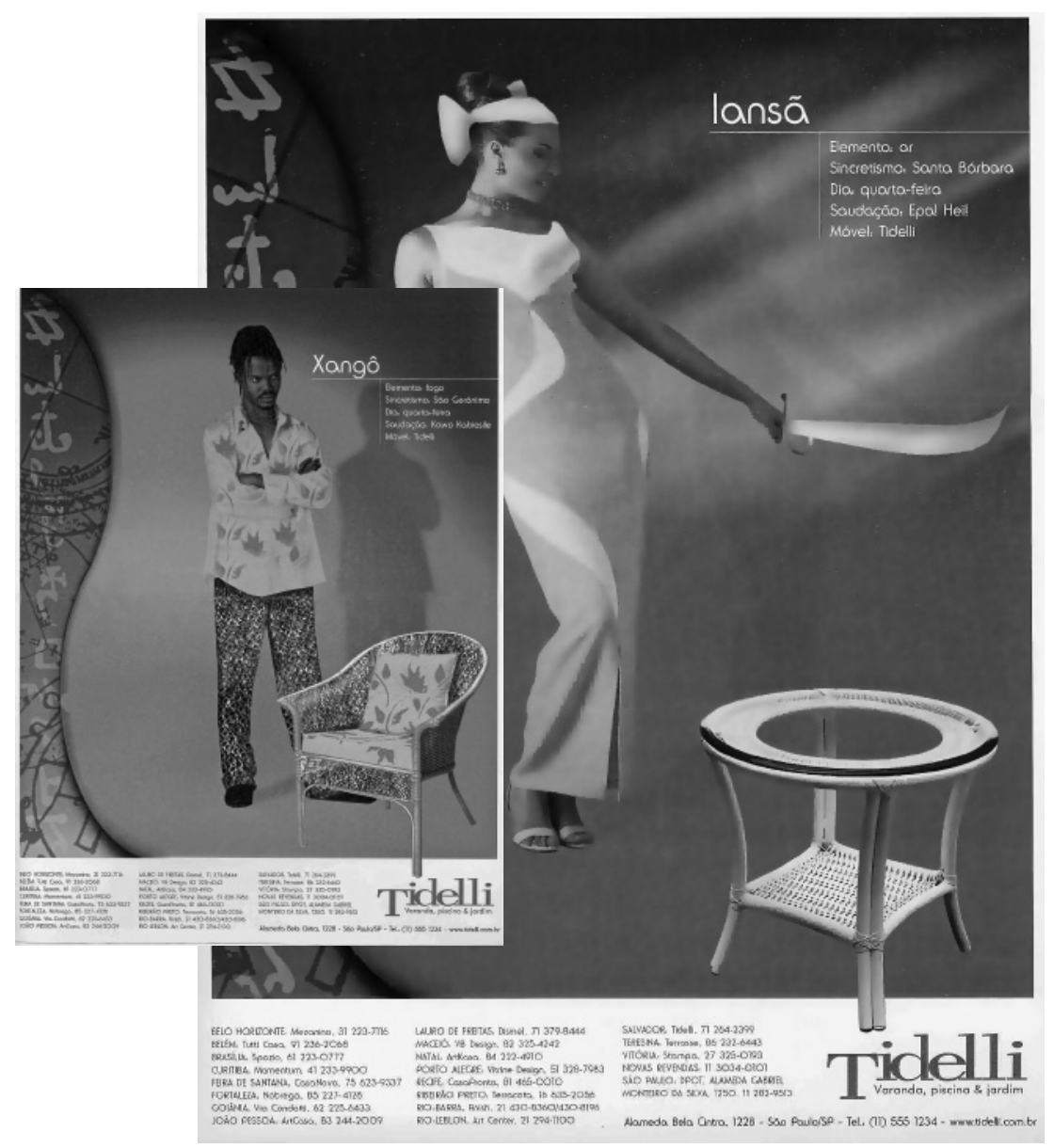

Figure 11 The 'orixá line' in Tidelli's garden furniture: table 'lansã', chair 'Xangô' 


\section{4 \\ aBSTIIACTING CaNDOMBLé}

Defining the 'public' and the 'particular' dimensions of a spirit possession cult

Since Jorge Amado's publication of Jubiabá, endless cycles of quotation have effected a genuine proliferation of Candomblé imagery in Bahia's public sphere. Quoting, as I have stated before, is always a procedure that produces distance. It removes you from the source. It takes the heat out of things, so to speak. 'Look, it has been said before! I'm only quoting!' Yet it also creates little pipelines between fields that were hitherto unconnected. Through these pipelines the color of the quote - its feel, its temperature, its texture - is passed on to the new surroundings in which it was inserted. In this process, both the quote itself and its new context are bound to change their meaning.

In Salvador, the process of quoting Candomblé has now reached a stage that is exemplified by the advertisement campaign of Tidelli garden equipment: the orixás are only recognizable as such because of the presence of emblematic symbols (Xangồs fire, lemanjá's hand-held mirror, Oxóssi's bow-and-arrow, lansás sword). Other than that, they look like the hip members of a young, urban party crowd - beautiful, seductive, desirable and they are supposed to confer meaning onto garden chairs and garden tables. ${ }^{50}$ With the Tidelli posters we are light-years away from Dr Nina's 
ill-lit, messy terreiros, or Jorge Amado's sweaty, foaming ceremonies. And yet, some echoes of these earlier renditions of the Candomblé universe remain.

Quotations of Candomble such as the Tidelli campaign are all over the place in the public sphere of contemporary Salvador. To evoke the sheer density of Candomblé imagery in Salvador, and the accompanying sensation that these images are in a process of 'drifting out of meaning', I was tempted to proceed this chapter with a rather unorthodox form of ethnographic description, namely to simply 'show it all': to start a plain enumeration of the manifestations of Candomblés public forms that would go on-and-on-and-on, page after page, so as to end up with a text resembling that famous Borgesian project of making a map of the empire on a scale of one to one. My list would contain all the Candomblé imagery as it appears in murals, statues, expositions-in-fancy-galleries, posters, bas-reliefs-on-buildings, tattoos, mosaics, graffiti, postcards, grade works, menus, websites, coffee-table books, fashion shows, advertisements, films, tourist trinkets, billboards, CD-covers, Tv documentaries, photographs-innewspapers-and-magazines, logos, sign boards, book illustrations, printed T-shirts and tourist flyers; and then continue with all the streets, condominiums, buildings, restaurants, shops, beauty salons, gasoline stations, shopping malls, hotels and bars that have been named after one or the other Orixá; all the doctoral theses, poems, songs, novels, political speeches, journalistic reportages, interviews, children's books, monographs, sermons, jokes, and do-it-yourself books that speak about Candomblé; and all the performances and events centered around Candomblé, from the renditions of Candomblés sacred dances by the Balé Folclórico da Bahia to the shows of megastar Maria Bethânia, and from the public rituals of the terreiros themselves to the Candomblé-related carnival bands called afoxés. To finish, I would then proceed with enumerating the signs of that other Candomblé being present in Salvador's public sphere: the earthenware dishes with a slaughtered chicken drenched in palm oil on a crossroad; the candle burning under a gigantic gameleira tree; the white flowers drifting out to sea, presents to lemanjá; the severed head of a goat on a doorstep; the omnipresent espada-de-ogum (sword-of-ogum, sanseveria) planted near doors to keep a house free of evil spirits; the woman acting a little funny making you wonder whether it is really her acting out; the elderly gentleman dressed in white from head to toe on Friday, to honor Oxalá; and the little street kiosks selling roots and leaves and herbs and undefined powders and liquids. 
There were a number of things that I liked about this idea of a mere 'listing. First, this inventory would undoubtedly provoke the slightly nauseating sensation of 'excess' that so befits the hyper-divulgation of Candomblé imagery in contemporary Salvador; an 'overdose' that makes you sense - rather than rationally understand - why many priests are worried what is becoming of their creed now that their sacred forms are serving the agendas of countless others. This overdose would also help you to grasp the urgency of their politics of authentication (which will be discussed in the chapters to come). Second, the sheer number of occurrences would obstruct all inclinations to ponder the particular meaning given by a particular person to a particular image. Multitude itself would thus be kept center stage: the pure fact of a proliferation of 'masterless' and utterly versatile images, accessible to all and with no fixed meanings attached to them, always ready to confer meaning on something as banal as a garden seat and something as complicated as the grand totality of life itself. Third, this procedure would acknowledge 'superficiality' as a fact of life, however much that acknowledgement goes against the anthropologist's idée fixe to reveal, or even produce, 'depth' at all times, even when faced with the inescapable superficiality of images that are quotes from quotes from quotes.

What kept me from my Grand Enumeration was the estimation that few people would actually submit themselves to a bombardment of 'instances' and read this chapter up to the point of feeling slightly sick, dizzy and craving for something truly 'meaningful' (Reader: 'Can we now, please, return to the discussion of something more meaningful?' Writer: 'No'). So I have opted for a more organized discussion of Candomblé's public life.

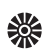

In his elaborate discussion of the notion of the 'public', Michael Warner has argued that the moment of apprehending something as 'public' always implies a negation of that which is 'particular', i.e. that which bears no weight beyond the horizon of particular groups or particular individuals (Warner 2002a; Warner 2002b). In other words, to make something public is to declare the particular to be in excess.

The writing of this book on Candomblé can serve as a concrete example with which to illustrate Warner's argument. To make my story public, to give it public 'weight', I am under pressure to concentrate on what lies beyond the fact that the writing of this book, and the research on which it is based, opened up escape routes from Mlle F.s suffocating life 
world, avenues for immersion, lovemaking, encounters with nègres boxeurs, 'homecoming' - to sneak back into the safety of quoting Marianna Torgovnick (1990; 1996) - and the other pleasant, bodily, life-enriching experiences that Bahia held in store for me. It may well be that personally $\mathrm{I}$ deem these particular experiences far 'weightier' than publically accepted values such as 'the accumulation of academic knowledge' or 'contributing to the corpus of Candomblé studies' under which banners researches like this are carried out. Yet if that were indeed to be the case, I would better not be too noisy about it in public.

This already signals that definitions as to what counts as 'relevant to the public at large' and what counts as 'merely of particular interest' are eminently political issues, and that such discriminations are at all times subject to contestation. Here too, the example of the writing of this book (with its 'particular' and 'public' dimensions) can serve as a concrete illustration. For a long time, says Warner, 'disembodiment' has been a hallmark of the Western notion as to what counts as 'public'. Here is how he puts it:

The validity of what you say in public bears a negative relation to your person. What you will say will carry force not because of what you are but despite of what you are. Implicit in this principle is a utopian universality that would allow people to transcend the given realities of their bodies and their status (Warner 2002a: 380).

This ability to 'abstract oneself' in public discussions has always been an unequally available resource: the white, heterosexual, affluent and educated male would encounter considerably less obstacles to 'abstract himself', thus to gain public weight, than all the others (which is what Warner calls 'the minoritizing logic of public discourses'). And this, then, is the point where contestation occurs.

I fancy the thought that my frequent slippages into a 'confessional style' in the previous chapters are not merely symptoms of the libidinal turmoil of a middle-aged homosexual anthropologist, or signs that I am unable to resist the paparazzo style of truth-making that is gaining force by the day in our media saturated societies, but contestations of the limits of what can be publicly revealed about the fact that anthropological fieldwork is an embodied practice. I do not want to subscribe to the academic worldview that systematically declares the drive to immersion to be 'merely of particular interest' and relegates it to the private sphere, or to literature and poetry. The continually growing interest in the social sciences for 
undoing the Cartesian split, for embodiment, the senses, the carnal and the visceral - and broader: the pre-eminence of the sentient body in such public forms as advertising, popular culture and sports - suggests that I am not the only one looking for alternative definitions as to what ought to be given public weight.

Given the contested nature of the qualification 'public', a number of questions concerning the manifestations of Candomble in the public sphere come up. How did the qualification of Candomblé as a phenomenon of public interest come about, i.e. what dimensions of the cult were declared to be 'merely particular' and therefore 'in excess' to the cult's public significance? Who were involved in producing these definitions of public worth? And how was this qualification - and the stripping therein implied - evaluated by different groups in the course of time? For as Warner succinctly stated: the erasure of 'the particular' may be understood in any number of ways, 'as universalizing transcendence, as ideological repression, as utopian wish, as schizocapitalist vertigo, or simply as a routine difference of register' (Warner 2002a: 377).

To follow the struggles over discriminations as to what does, and what does not, make up Candomblés public significance I will track down the historical developments since Jorge Amado's publication of Jubiabá that were particularly relevant in enabling and stimulating Candomblés public life. These are: the new role of folklore and popular culture in the nation building that took place in the Vargas era (I930-I954), when the culture politics of the state sought to strip Candomblé of (or rather: 'sublimate') its religious, occult and carnal dimensions; the emergence of rebellious youth- and countermovements in the I96os, with their critique on existing social and political structures, their quest for a spiritual revival, and their attempts to reinvest a picturesque Candomblé with critical and spiritual power; the booming of the tourist industry in Bahia, especially since the I970s, which, in its renditions of Candomblé in the public sphere sought to foreground 'the exotic', 'the mysterious' and 'the black body' as signs of a desirable Baianidade; and the growing importance of alternative identity-based politics since the I980s, with their attempts to reframe Candomblé as a site of subaltern resistance to dominant social values.

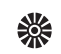

With the coming to power of the populist authoritarian regime of Getúlio Vargas in I930, Modernist redefinitions of brasilidade ('Brazilianess') as a state of racial mixture received ample backup from the state. Especial- 
ly during the dictatorial period of the Estado Novo (I937-I945), the federal government established itself as a center of cultural authority, set on promoting brasilidade as a central, binding value for all classes alike, and stepped in on all levels of culture production (Williams 200I: 259 ff.). Popular culture became an indispensable element in the state's attempts to produce a new model of authenticity (Vianna 2002). Considered to be expressive of an autochthonous 'Brazilian' culture, and the very opposite of the cultural values embraced by the 'backward elites' whose influence the Vargas revolution sought to break, forms of popular culture were lifted on stage, exhibited in museums and divulgated through the new mass media. As early as 1932, the Vargas government declared Rio's predominantly Afro-Brazilian carnival to be a national festival under government sponsorship (Borges 1995: 70-7I). Yet many of the other cultural forms that today are considered to be 'typically Brazilian' - samba, mulatas, feijoada, soccer, capoeira, Candomblé, the baroque from Minas Gerais - were also designated as such in the Vargas era. Popular culture was also reworked and elaborated in arenas of High Culture: the literature of Jorge Amado and other 'regionalist' writers, the music of Heitor Villa-Lobos and the Modernist architecture of Oscar Niemeyer all incorporated 'the popular' in their art.

Scott Ickes (2005) has shown how these national politics worked out in the Bahian capital. If on the one hand, Bahian state authorities courted popular support by taking a favorable position on expressions of popular culture, they showed, on the other hand, the determination to exercise absolute control over the actual production of culture in the public sphere. This created the margin within which Afro-Brazilian cultural expressions began to prosper in public. Ickes recounts, for example, how Vargas' appointed 'interventor' for Bahia, Juracy Magalhães, issued Salvador's first license to teach the Afro-Brazilian martial art capoeira in an academy in 1932, and invited one of the city's leading practitioners to give a demonstration in the gubernatorial palace (2005: 197). For Candomblé, a licensing system was introduced to regulate rather than persecute the cult, although police raids still occurred (ibid.). All terreiros planning to have major ceremonies had to solicit written permission from the police and pay a fee, especially if the ceremonies were to include drumming. Another interesting example from this period is the famous 'Second AfroBrazilian Congress', which took place in Salvador in 1937 and brought together intellectuals, academics, journalists and working-class intellectuals, including the influential priestess Mãe Aninha and the renowned diviner Martiniano do Bonfim, in a series of scholarly presentations on 
Afro-Brazilian traditions. Significantly, Ickes documents that 'the event received half of its funding from the Bahian state government's Legislative Assembly and counted on official hospitality for the visiting intellectual luminaries' (2005: I90). Salvador's mayor even attended the inauguration of a shrine to a Candomblé deity put on for the participants of the Congress (ibid.).

The state sponsoring of events such as these certainly contributed to a growing respectability of the cult. So did the fact that, next to local academics and artists, many foreigners began to take an interest in Candomblé: American anthropologists such as Ruth Landes, Melville Herskovitz, and Donald Pierson, as well as their French colleagues Pierre Verger and Roger Bastide all set out to study the cult in the late I930s and I940s, facts which were not missed by the local press.

The proliferation of Candomblés expressive forms in the public sphere thus took off under the guise of 'Bahian popular culture', 'Bahian folklore' and 'the cultural heritage of Bahia'. From the late ig3os onwards, the designation of the cult as a repository of all kinds of singularly Bahian aesthetic forms manifest itself nationwide in many different arenas of culture production. The growth of the record industry and the increasingly important role of radio broadcasting divulgated motives from AfroBrazilian religion from the Amazon to Rio Grande do Sul, thus expressing and communicating the regional variety and cultural riches of the Brazilian nation (cf. McCann 2004). The songs of Bahian singer Dorival Caymmi familiarized the nation with lemanjá, Oxalá, Xangô and all the other orixás. In fact, as Vagner Gonçalves da Silva and Rita Amaral point out, between 1930 and 1950 'practically all the famous singers from the radio days recorded some song or other alluding to the theme of Candomble', with song titles such as Despacho (1940), Babalú (1943) Salve Ogum (1948), Macumba Gegê (1950), Rei Bantu (I950) and Feitiçaria (1954). All of these songs pick up on Afro-Brazilian religiosity in terms of its exotic character, its occult powers and its mystery. As these authors conclude, the lyrics give a very fragmented and incoherent image of Candomblé, but the songs do speak to an underground reservoir of knowledge on Candomblé in terms of their allusions, their rhythms, their tone, and their between-the-linesunderstandings. ${ }^{51}$ Carmen Miranda's grotesque blow-ups of Bahian/Candomblé dress took Candomblé aesthetics to the film screen, whereas the Argentine artist Carybé, who settled in Bahia in 1938, started to produce his elegant drawings and paintings of the Candomble universe, casting the 'primitive' in the softening light of gouaches and pastels, articulating 
'beauty' over 'shock effect', and thus contributing to the coming about of an image of the cult that was palatable for the middle and upper classes.

The clearest indications of Candomblé becoming an indispensable folkloric element to articulate a 'typical Bahian identity' are found in early tourist guidebooks to the city of Salvador. Time and again, visitors to Salvador were urged not to miss out on what was called the 'barbaric beauty' of Candomblé ceremonies. Bahia of All Saints. A Guide to Streets and Mysteries, Jorge Amado's very own tourist guide to Salvador first published in I944, opens with his by now famous characterization of Salvador as a place where 'mystery flows over the city as an oily substance'. The evocation is, again, a sensation of 'stickiness' that connects everything with everything else:

Mystery flows over the city as an oily substance. Sticky, everyone can feel it. Where does it come from? No one can locate it exactly. Does it come from the drumming of the Candomblés during macumba nights? From the feitiços found in the streets by milkmen and bakers on their early morning rounds? From the sails of the boats anchored on the quays behind the Mercado Modelo? From the street kids, eleven-year-old adventurers, 'captains of the sands'? From the innumerable churches? From the azulejos, the old mansions, the Negroes' laughter, the poor people in their colorful clothes? Where does it come from, this mystery that encircles and overshadows the city of Bahia? (Amado I97I: 25)

In contrast to Jorge Amado's lyrical evocations, José Valladares' Beabá da Bahia (195I) is written in a slightly ironic, tongue-in-cheek tone. The city of Bahia is described as 'the Rome of the fetishist cult in Brazil' and 'A place where you can take - as many already did - a course to specialize yourself in the secrets of black magic' (1951: 93). Dr Nina's suggestion that all Bahians are involved in Candomblé one way or another, has in Valladares' book become common sense.

Directly or indirectly, the entire population of Bahia has the greatest respect for bozó (fetishism). First in line are the initiates. Immediately followed by those who are not initiated, but are devoted believers and take it all to be true, a category which includes many foreigners as well. Then there are those whose belief is not without doubt but who, in case of crisis, immediately run off to a terreiro to find out what is lurking beyond the reach of hearing and seeing. Then there are those who do not believe, but don't take the risk to act accordingly, and finally those who really don't belief nor fear, but prefer not to offend 
the religion of their friends, their compadre, their comadre, their boss, or the family of their fiancée (1951: 93-95).

Another tourist guidebook, this one from 1958, and with the telltale title City of Salvador. The Road of Enchantment has an entire chapter dedicated to the 'road of the orixás' (Brando \& Silva I958).

One of the best experiences that a traveler to the city of Salvador can have is to be invited to appreciate a Candomblé. On this day, the visitor should rest so as to be ready to confront the surprising spectacle of a liturgy that is realized under the star-strewn darkness of those great Bahian nights. Never miss the opportunity when a negress selling acarajé invites you on the path of the orixás. Maybe your body feels tired. Undoubtedly, you've seen a lot of interesting things already, climbing steep streets, visiting old mansions and convents. So now get yourself some rest. For tonight [...] you will visit a Candomblé, of which you've heard so much already. If there is a ceremony on, any taxi-driver will know about it and will take you there (Brandão \& Silva I958: 55).

What is awaiting the traveler according to these authors is qualified as 'the poetry of Bahian nights', 'the barbaric and nostalgic rhythms of the drums', 'dancing to the sound of rustic and primitive instruments' and 'nostalgic chanting' (ibid.). The writers of this guide go to great lengths to frame and explain the scenes that tourists will be witnessing, so that people do not jump to the wrong conclusions. They describe Candomblé in apologetic terms as 'the barbarous and primitive religion of a poor and destitute people' that 'go without bread, electricity and water' and 'only have their gods to turn to', and they underline that no one intending to visit a Candomblé should worry, because

in orthodox Candomblé, it can't be stressed enough, one only finds the practicing of religion. The place called 'terreiro' is a place of worship and that is all there is to it. There is no witchcraft being practiced here, nor curanderismo in the sense of a contravention of the law, nor the illegal practice of medicine (1958: 55).

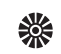

If the texts in these tourist guides would probably reach a rather limited readership, this was certainly not the case with two articles on Candomblé, both appearing in the widely read magazine O Cruzeiro in the early 
I950s. Both, in their own way, link Bahia to Candomblé and Candomblé to Bahia.

O Cruzeiro, founded in 1928, was the first Brazilian magazine with a national circulation, bringing faits divers to Brazilian middle-class homes, and introducing such novelties as the 'photo reportage'. Addressing various persons in a household - but principally the women - the magazine's formula was 'to mix news facts from the world of politics, culture, science, fashion, sports and the entertainment industry with "trivialities with wide popular appeal"' (Andrade \& Cardoso 200I: 247). At the height of its success, in the I950s, the weekly reached a circulation of 720,000 copies. It was at this time that the magazine reports a charity event organized by ladies from the Rotary Club in Fortaleza, Ceará, under the title 'Bahian Candomblé in the terreiro of Iracema. ${ }^{52}$

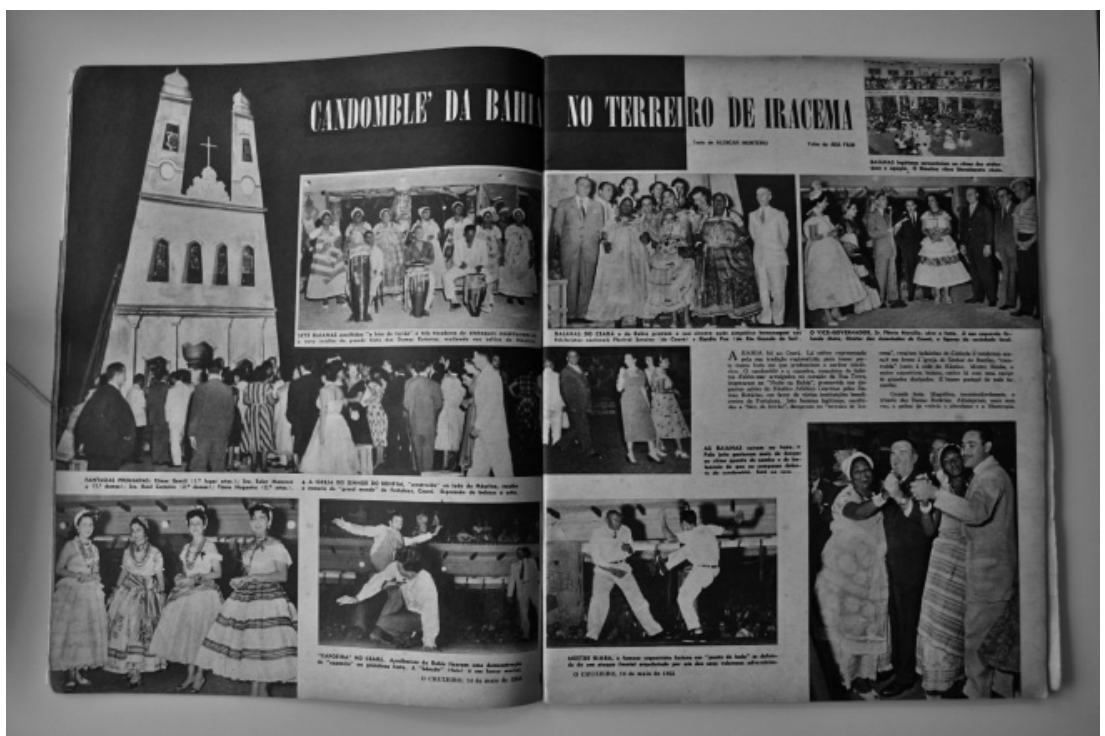

Figure 12 'Bahian Night' in the Fortaleza Rotary Club

The reportage includes pictures of the winners of the beauty contest 'beautiful Bahiana' (their dresses a fusion of 1950s petticoats and the colored necklaces and multilayered dresses of Candomblé priestesses); various impressions of the evening with demonstrations of capoeira; 'sacred drumming, dancing, and chanting by seven real Bahianas', all against the backdrop of a cardboard Church of O Senhor do Bonfim (Salvador's most famous church); and gentlemen asking the ladies from the Candomblé act for a dance.] 
The article highlights just how much, in the mid-I950s, Candomblé had already become a prop for producing a 'Bahian atmosphere'. At first glance, nothing in this article registers reticence vis-à-vis the appropriation of Afro-Brazilian cultural forms in an all white setting like the Rotary Club. One picture shows how the 'elegant venue of the Fortaleza Swimming Club' had been decorated with huge panels, showing larger-thanlife 'primitivist' paintings of half-naked blacks in poses suggestive of some ecstatic dance. The idea of occult practices and energies beleaguering civilization itself - feared by Dr Nina and eagerly awaited by Surrealists and Modernists - seems to be totally absent, lost in the long process of quotation. If anything, the somewhat triumphant tone of the reporter heralds 'civilization's victory', or rather, its successful 'cannibalization' of the African element. For instance, in the caption of the picture where Rotarians dance with the Baianas it says: '... the Baianas join the party. Judging from the way they go for it, they like the hot rhythms of the samba and the balançeio a whole lot better than the doleful beats of the Candomblé. It is written all over their face.'

The Cruzeiro reportage is also indicative of the extent to which public images of Candomblé had become aestheticized and stripped of their rough edges in the process of quotation. Candomblé as 'folklore' or 'popular culture' showed the immaculate white of the adepts' outfits, not the human bodies drenched in the blood of sacrificial animals. It focused on the rhythms of the dance, not the convolutions and spasms of trance. In other words, all elements likely to be labeled 'uncivilized', 'primitive', 'backward' and 'scary' were suppressed in public 'folkloric' representations of the cult (cf. Port 2007). The Carmen Miranda picture below - where the Brazilian film star who made it big in Hollywood boasts the typical, face-covering headgear called adé that is part of garment of some of the orixás - shows how in the process of quotation, Candomblés secrecy and mystery (as well as Jorge Amado's initiates 'foaming from their mouth and their sex organs') could easily transform into this coquettish, vaguely erotic hiding and veil-lifting - totally innocent, but as quoting works: opening up a pipeline to wilder fantasies.

In this way, even the utterly 'civilized' rendition of Afro-Bahian cultural forms in the Rotary Club reveals the insolvable ambiguity of the discourse on the primitive to be operative, eroticizing and 'heating up' the evening, hinting at dangers that might flare up from behind the cardboard set. Undoubtedly to spice up the report on this 'splendid evening', the caption of the photograph showing a capoeira demonstration eagerly reports that the particular move that is depicted is called benção (blessing) and 


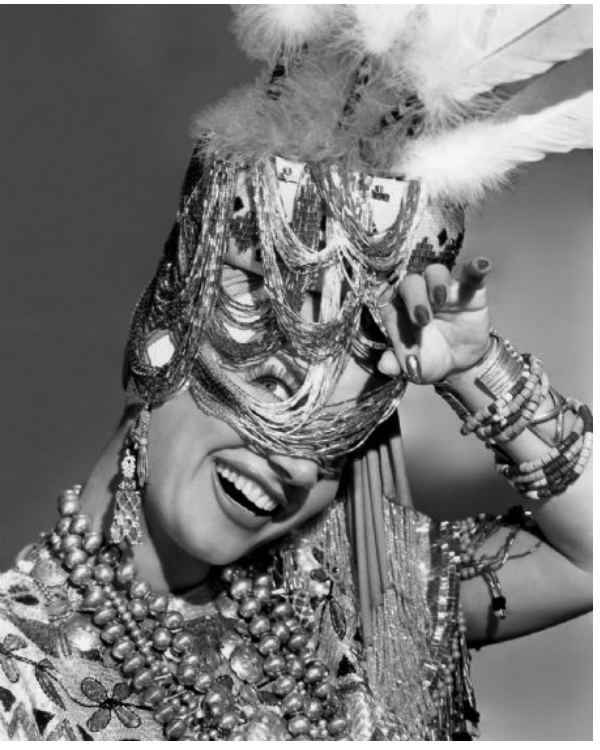

Figure 13 Carmen Miranda

wearing adé-style headgear

is lethal. Also, if we go against the explicit instruction of the text to look at the faces of the Baianas to see how they enjoy 'the hot rhythms of the samba and the balançeio' so much better than their own primitive Candomblé, and focus on the faces of the Rotarian gentlemen instead, one realizes that no one is 'going for it' in the situation that is depicted.

More likely, this picture evidences what at the time was a transgression of racial and class lines and the resulting proximity may well have been a bit 'too close for comfort'. All I see in this picture are evasive smiles; the embarrassment of an elderly gentleman finding himself dancing with someone who could have been his maid hiding behind a ha-ha-ha-ha-aren't-we-having-a-good-timeface; the false pose of the Clark Gable look-alike 'savoring' the bodily intimacy with the 'neguinha'; strained efforts to act out the mestiço nation and yet keep at bay an interracial intimacy that, in its truer form, did not belong to the then and there of the 'Bahian Night' of the Rotary Club.

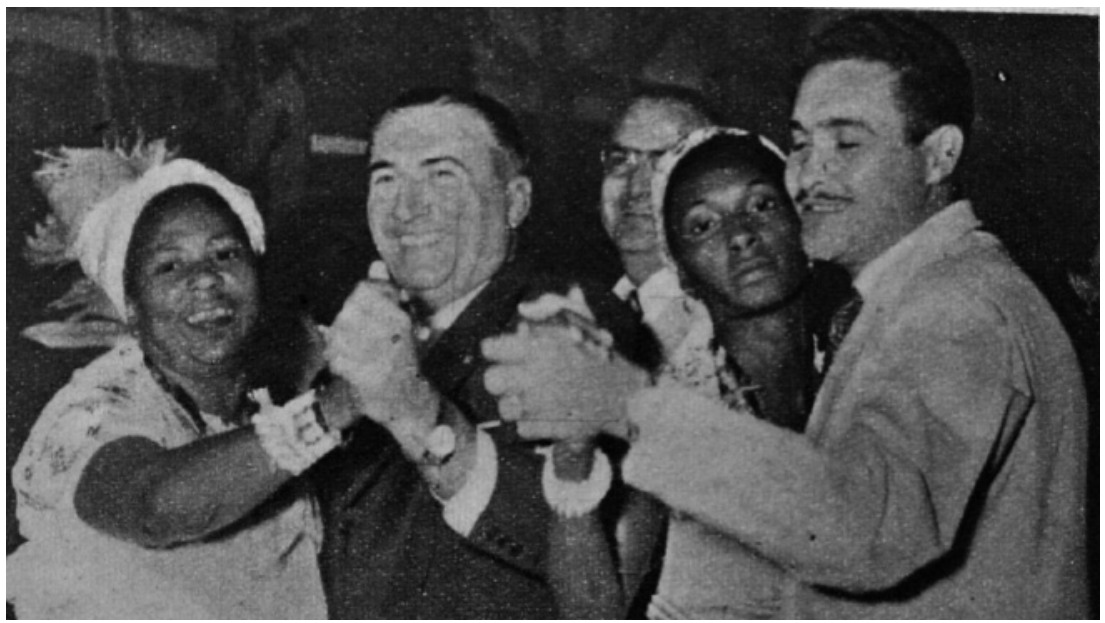

Figure 14 Evasive smiles 
The other I950s reportage on Candomblé in O Cruzeiro articulates the nexus between Candomblé and Bahia in a rather different manner (for some images, see colour section). Under the sensationalist title 'The Fiancées of the Bloodthirsty Gods', journalist Arlindo Silva and photographer José Medeiros published thirty-eight photographs of a Candomblé initiation ritual, publicly revealing what supposedly goes on at the backstage of the cult. Decades later, Medeiros stated that the objective of the reportage had been to show 'the true Candomble' (de Tacca 2003: I48).

The reportage opens with what, even in the I950s, must have been an enumeration of utter clichés, sketching a nightly city of Bahia, with 'deserted quays', 'glimmering street lights', and 'the distant sound of drums' which are taken to be an indication that 'now that the bells of the centuryold churches are silent, a mysterious force descends on the most religious city of all of Brazil. The Bahian Negroes are invocating their gods...' In some passages the text switches to a more straightforward explanatory register, explaining the instruments that are being used in the orquestra bárbara of the Candomblé, but there are frequent lapses back into a style that recalls the suspense of a cheap I950s horror film:

The ceremonial hall is badly lit. In the heat of the night, one detects the fragrance of aromatic and trance-inducing plants... [when the drumming reaches a peak] one of the women cannot resist, succumbs to the spirit and lets herself be won over. Her orixá is violent and tortures her, coming over her as in a series of beatings with an invisible whip. Her face is covered in sweat; her fists are clenched, as her body flounders on the floor. Amidst the noise of the drums one still can hear her screams of fear...

The reportage, however, did not make it into the annals of history because of these not-so-subtle suggestions that the Bahian blacks had been freed from real slavery only to become slaves of the orixás. It is remembered first and foremost because of its shocking imagery. Showing images of initiates, their heads shaven and incised on the top so as to 'plant' the Orixá in the head; apparently in deep trance; covered in the blood of sacrificial animals; and sprinkled with chicken feathers: the 'true Candomblé', in this reportage, is defined as all that which was kept hidden at the backstage of Candomblé. Medeiros was completely aware of the taboo-breaking character of his reportage. In an interview the photographer admits to having traveled to Bahia using a false name for fear of becoming the victim 
of some ugly black magic by angered cultists (de Tacca 2003). Stressing secrecy in the captions and leads ('scenes from a secret ceremony in all of its primitive grandeur'), a voyeuristic camera reveals the 'real face' of 'barbaric beauty' and 'primitive ritual'.

The publishing of 'The Fiancées of the Bloodthirsty Gods' caused a scandal in Bahia. All Bahian newspapers announced the arrival of the new issue of $O$ Cruzeiro containing a 'sensational reportage' on Candomblé, and two of them published one of the photographs on their front page: a picture showing the blood of a sacrificial animal being poured over the head of a young girl with an accompanying headline saying 'The God is thirsty for blood'. The full impact of the arrival of this imagery in the middle-class homes of Brazilian families can only be grasped in juxtaposition with some of the other imagery that can be found in that very same issue of O Cruzeiro (fig.I6).

Understandably, the publication had an enormous impact in Candomblé circles in Bahia (where the echoes of indignation over the publication are heard until today). ${ }^{53}$ Medeiros recalls that the priestess who had allowed the photographer to make the pictures - after having consulted her Orixá for approval - 'suffered many repercussions in the religious environment and even had to explain her motives to participate in the photo session at the police station.' Moreover, 'the initiation of the iaôs was not recognized and they stayed marginalized within the religion.' In popular memory, the verdict on the people involved in the reportage was harsher: rumors have it that the priestess committed suicide whereas the young girls that had been initiated went mad (cf. Castillo 2008; de Tacca 2003).

To summarize Candomblé's 'public value' in these examples from the Vargas era one might argue that the cult was granted public visibility as a sign of Baianidade, and in extension, as a sign of the cultural variety and riches of Brazil as a whole. Its primitivist aesthetics, pointing away from hegemonic European norms and models, made Candomblé a powerful sign of what in a famous Bossa Nova song is called 'o Brasil Brasileiro' (the Brazilian Brazil). ${ }^{54}$ Through Candomblé (and other Afro-Brazilian forms), Brazil reinvented itself as different, other, uniquely itself. And yet, for this 'primitive' dimension to make it to the public sphere, Candomblé had to be thoroughly 'cleaned' and 'domesticated', stripped of such disturbing elements as possession, animal sacrifice, or the pouring of blood over the shaven heads of the initiates. For if public forms of Candomblé constantly reproduced the statement 'yes, we Brazilians are also heirs to an African legacy that makes us what we are: we are a passionate, hot-blooded peo- 
ple', this identification with things 'African' should not impede them from saying 'we Brazilians are a civilized, clean, and modern people'.

The reportage on initiation in O Cruzeiro, showing the 'dirty' and 'primitive' backstage of Candomblé in an uncensored form, caused such shock exactly because it did not veil Candomblé practices such as animal sacrifice and possession, but revealed them. In other words, a careful Modernist re-encoding of the 'primitive' was undone, to lay bare the visceral, primordial, bodily underpinnings of a primitivist aesthetics.

Scandal-provoking revelations of what Michael Taussig (1999) might have called 'the public secret' about Candomblé - that which is generally known but cannot be articulated - would occur at regular intervals in the history of Candomble's public life. If on the one hand, these scandals threatened Brazilian claims to be fully partaking in civilized modernity, one cannot help but conclude that they also re-empowered and animated Candomblé imagery, preventing it from transforming into bloodless folklore, or toothless, museum-like aesthetics. Indeed, it was in the scandalous exposition of the excess to Candomblés public image that Brazilian claims of being a passionate, hot-blooded and bodily people were reinforced and authenticated.

Early in the I960s, a certain fatigue with the folkloric clichés surrounding Bahian culture - including Candomblé - becomes visible. Bahia de Todos os Santos (I960), a film by Trigueirinho Neto, is characterized by what film historian Roberto Stam described as a 'distinctly anti-touristic bent', deromanticizing Bahia 'which up to that point had always been presented as a nonstop parade of samba dancers, acarajé vendors and capoeira performers' (Stam 1997: I82). The depiction of a depressingly poor and destitute Salvador includes scenes that show the harsh reality of the repression of Candomblé by the Vargas' police and the destruction of sacred shrines. Filmmaker Glauber Rocha - the most important exponent of the critical cinema novo that came into being in the early I96os - reviewed Trigeirinho Neto's film and asked himself: 'where is freedom of religion for blacks when police invade macumbas in Rio and blacks in Bahia are exploited as part of the industry of the picturesque!' (ibid.) Clearly then, new understandings of Candomblés public worth were in the making. These might be summarized as 'opposing bourgeois values' and 'opposing institutionalized religion': Candomblé was now reframed as 'radically other'. 
Interestingly, Glauber Rocha's own film Barravento (I96I) is in fact more ambivalent where it concerns its depiction of Candomblé than his anger over police raids in terreiros suggests. The narrative - which recounts the efforts of a certain Firmino, a revolutionary from Salvador who returned to his native Bahian village to free the fishermen from capitalist exploitation and religious superstition - clearly denounces Candomblé as a primitive belief system that keeps Bahians from revolutionary action and progress. In fact, Rocha stated explicitly that the goal of his film was to show that 'underneath the forms of exoticism and decorative beauty of Afro-Brazilian mysticism there dwells a hungry, illiterate, nostalgic and enslaved race' (cited in Stam 1997: 219). The photography and the soundtrack of the film, however, show a filmmaker who is thoroughly enchanted by the aesthetic possibilities of Candomblé: Rocha's style capitalizes on the drumming and the chanting, the bloodbath of initiation, and the sensuous black body, always at the point of being undressed, and frequently given over to ecstatic dancing and the invasion of spirits (Stam 1997: 220).

In addition to Candomblé becoming a vehicle to rethink state suppression and popular resistance (or the lack thereof) in the work of these filmmakers, the Bahian based Tropicália movement, which gained momentum at the end of the decade, also accessed the Candomblé 'symbol bank' to articulate their social critiques (Borim 2002; Dunn 200I). Statements by artists linked to Tropicália on Candomblé give an intriguing insight how a new generation in Bahia discovered a religion that had always been, quite literally, 'around the corner' and yet had been socially inaccessible. Singer Caetano Veloso (and his equally famous sister, singer Maria Bethânia) were from a Catholic, lower middle-class family in Santo Amaro da Purificação, in the heart of the Bahian Recôncavo area - a region with a strong tradition of Candomblé. In his autobiography, Veloso remembers how, for the first time, he was confronted with his aunt Edite being possessed by an Indian caboclo spirit:

I remember the first time I saw Edite possessed. I was still a boy and not allowed to stay till the end of the party. After the samba-de-roda something happened that I was not supposed to see. As I passed through the hallway on my way out, I ran into Edite dressed as an Indian, her eyes closed, being virtually dragged by two other women whose eyes were open. It was she, beyond any doubt, but her face had an expression I had never seen before: her lower lip protruded, her brow was deeply furrowed, her nostrils flared. She looked like an angry man. I was frightened by the evidence that Edite was and was not herself, and was concerned to know whether or not she was awake, what she could possibly be 
feeling. I was scared of finding myself before the unexplainable, scared to find myself in the same situation. This fear never quite left me. It figured in the anxiety surrounding my first communion, as well as in my first experiences with drugs (Veloso 2002: 2II-2I2).

Veloso's link with Candomblé only occurred much later in his life, when meeting with the legendary priestess Mãe Menininha of the Gantois temple in Salvador. This was also the case with Maria Bethânia:

I had never been to the great Candomblés of Bahia. I was frightened. A fear which gives me the shivers, and which I have up to this day. When Vinícius de Morães moved to Salvador, he told me: 'I can't believe a Bahian woman doesn't know Mãe Menininha from Gantois.' So I got to know her as an artist, for she was a fan of mine, but the moment I entered the temple and saw that lady, that little goddess (aquela deusazinha), I thought: 'My God, this is my home. This is where I want to be.' And luckily she, a woman with a wisdom that is unique, understood it all. She only showed me beauty, delicacy and tenderness. ${ }^{55}$

In his songs, Caetano Veloso makes many references to the world of Candomblé, yet in interviews he seems somewhat reserved in making explicit the nature of his involvement with the cult, stressing the cultural side of it, rather than the spiritual or religious side ('I also have a lot of links with Candomblé, because in Bahia that is part of our culture. I respect the world vision of Candomblé... I think it might give me strength. Yet l'm not sure.')

Maria Bethânia shows no such reservations, and her public profile is now constantly cast in terms referring to Candomblé ('emanating a mystical personality', 'a priestess', 'a living lansá', 'an orixá', 'a sacred fire'). Bethânia's statements befit her theatrical, somewhat exalted style of performance. Remembering priestess Mãe Menininha, she said: 'She is the light. Pure gold. She is the sweet embrace, the ever-listening ear. Teaches, guides, receives. That is Mãe Menininha.' She also calls Mãe Menininha 'The living orixá of Bahia'. Explaining her encantamento with Candomblé, she stated that

For a theater person like myself, the beauty of the songs is irresistible, the rhythms, the cloths, the foods. All those annoying and difficult prohibitions disappear, guilt withdraws itself. God means no harm; the santo, if a santo, doesn't do wrong. This creates an intimacy, a trust, and a relaxation that is wonderful. ${ }^{56}$ 
The story of that other famous Tropicalista, Gilberto Gil, is intriguingly similar. Gil too grew up in a Catholic family in Salvador and in an interview recalls that although there was a terreiro in his own street in the Santo Antônio neighborhood, 'all of that took place at a distance.' It was only as an adult that he really contacted the cult. Mestre Didi, a famous Bahian sculptor and son of a prestigious priestess of Candomblé, took him for the first time to a terreiro on the Island of Itaparica in I972. He then frequented the terreiro llê Axé Opô Afonjá, but soon established links with the old house of Gantois 'mainly because of the fact that the people I hang out with had strong ties with Gantois' (Gil, in Sodré \& Lima I996: I68). Again, the figure of Mãe Menininha was crucial in his approximation to the cult. It was she who defined what was going to be the grade of his involvement with the cult after a lengthy divinatory session with the cowry shell oracle. She discovered Logun-Edé to be Gil's orixá and dispensed the artist of all further ritual obligations:

Mãe Menininha didn't think it necessary that I entertained a 'confessional' link with the cult. She told me: 'Every once in while, if you wish, give a present to the saint that reins your head. And if someone tells you you will have to be initiated, tell him or her that's a lie. Tell them Menininha from Gantois told you to say that this is a lie!' And thus I was liberated. I created a cultural link, more than a religious one, with Candomblé. I came to appreciate the cult due to my artistic activities and due to the natural interest I have in it in relation with the theme's I address in my work (I996: I69).

Tropicália's interest in Candomblé highlights the insertion of Candomblé in what, by the late ig6os and early i970s had become a worldwide interest in 'alternative religions and spiritualties'. For this was 'the dawning of the age of Aquarius', when youth cultures experimented with the mindexpanding experiences of drugs, hippies embarked on soul-searching spiritual quests to India, and a return to nature signaled discontent with the course modernization had taken. Caetano Veloso and Gilberto Gil, exiled to London in the late ig6os by the military government, experimented with drugs and, as Gil put it, other 'loucuras' (crazyness).

In Brazil itself, there was a considerable interest in new, alternative forms of spirituality as well (Dawson 2007). A magazine called Planeta discussing all phenomena that could be framed in esoteric, spiritual, paranormal and religious terms - was brought onto the market and turned out to be an instant success. Tellingly, the first issue to appear in Brazil (September 1972) had on its cover a black man wearing the Candomblé 
headgear adé, and both Candomblé and Umbanda were recurring topics, which now found themselves in juxtaposition with articles on flying saucers, the mysteries of the pyramids, the philosophy of Krishnamurti, the 'sexual life of the Kirdis', Zen Buddhism, the threat of nuclear warfare, European witch hunts and the history of mermaids. In this climate, priestess Mãe Menininha from Gantois attained a true cult status. As Reginaldo Prandi remembers the period '...it was through popular music that we learned the names of the orixás, which are also the santos of Umbanda, but now it was necessary to travel to Bahia to be blessed by Menininha; to throw the cowry shells and have one's destiny read; to get a taste of the feitiço, the real one' (Prandi 1999: 132).

The impact of this new public framing of Candomblés worth in terms befitting alternative lifestyles are discernable up to today. Orixás are now frequently described as 'ancient energies' or 'forces of nature'. And increasingly, Candomblé is given an ecological bent. Thus, philosopher Muniz Sodré came to consider Candomblé as a kind of 'proto-ecological way of being in the world':

A long time ago, in a Bahian terreiro, I had a radical ecological experience. It was on a midweek afternoon, and I took some of my friends on a visit to the compound of the terreiro. After having visited the houses, an ogã took us into the woods: he wanted to give one of us a cutting of a plant. There, surrounded by vegetation, all of us witnessed how he embraced the trunk of a tree - the old Apaoká - murmuring some words and asking permission from the tree to break off a twig. I clearly remember this scene, maybe because its simplicity stood in such sharp contrast with the discourse on ecology that is gaining strength in contemporary urban society (and that is even winning seats in parliament). This moment, however, wasn't some talk about the kind of relations individuals should entertain with their natural surroundings; it wasn't a liberal discourse on preservationism; it was about acting in such a way that the natural element, the tree, becomes a partner of man in a play in which Cosmos and world encounter each other. What I found there was a radical ecological posture [... that] followed from the cosmovision of a group in which the brotherhood of man with plants, animals and minerals is an essential given. For the black community (o grupo Negro), the territory, as a single whole, is a patrimony to be respected and preserved (Sodré I988: 167).

To summarize, from the ig6os onwards, critical and alternative counterdiscourses turned to Candomblé, exploring its expressive possibilities. As in the Vargas era, Candomblé's public value was its being 'other'. In the 
I96os, however, this 'other' was not merely in opposition to other regions in Brazil (as the folklore discourse had it), or to Europe (as the nationalist discourse had it), but in opposition to the values of mainstream, consumer society and in opposition to conservative, institutionalized religion. I will return to the emergence of Candomblé in Bahian countercultures in my discussion of the appropriation and reinterpretation of Candomblé by the Bahian gay movement and the Movimento Negro. First, however, a brief look at the exploration of Candomblé by the Bahian tourist industry is necessary.

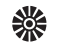

One of the major drives behind the contemporary circulation of Candomblé imagery in the public sphere is undoubtedly the Bahian tourist industry, which in Bahia is inextricably linked with the State Department of Culture. Already in 197I, visitors arriving at Salvador International Airport received an informative brochure - Annuaris Salvador - that mentioned the names and full addresses of terreiros de Candomble that could be visited. Today, visitors to Salvador have already encountered a billboard telling them that they have entered 'the land of magic' before they have even retrieved their luggage. The state tourist information provides all the details regarding the schedules of the ceremonies that take place in the different terreiros, complete with phone numbers and the advice to 'double check' the information. At the entrance of hotels, monumental churches, or simply on the streets of the historical center, little boys hand out copied invitations for nocturnal visits to 'authentic ceremonies of Candomblé.

The first international campaign to promote Bahia as a tourist destination on a world market for exotic travel, discussed by Jocélio Teles dos Santos (2007), is in many respects exemplary of the nexus between Candomble and the tourist industry, and the new framings of the cult made possible by this relationship. The campaign, launched in 1972 , made use of a poster with a title bespeaking the 'flower power' mood of the era: 'Oxum, Deity of Love and of the Sweet Waters'. According to its makers, it showed 'a bit of the mystery of Candomblé' in picturing a female initiate coming out of the room where novices have to stay in seclusion during their initiation. During a congress on tourism the poster was explained as follows:

The hieratic face of a filha-de-santo in trance, with her enigmatic smile, suggestive of a black Mona Lisa, evokes all the aspects of the Negro's mysticism. 
In the glittering of the golden-yellow glass beads of her necklace, we see the rich golden woodcarvings of baroque churches and the deep yellow color of palm oil. This image conveys a mystery that is heavily charged with the exotic, it evokes an atmosphere that, without any doubt, is most attractive to tourists (Santos 2005: 133).

Here then, all the themes discussed thus far - the mystery and secrecy of the backstage, the primitive and the European, the spiritual and the folkloric, and even the baroque - come together in a Candomblé image. The poster - again: according to its designers - spoke to the idea that Candomblé synthesized 'all that goes into the Bahian form of being, the deep roots of the culture and the people of Bahia' (ibid.).

In the long trajectory of Candomblés 'going public', this poster signals the furthest distance from Dr Nina's understandings as to what the vitality of the cult revealed about the state of Bahia. If Dr Nina saw the proliferation of Candomblé as the obstacle that kept Bahia from reaching the standards of European civilization; and if the Modernists felt that Candomblé represented the kind of popular energy that might blow apart a civilization gone decadent; this campaign suggested that there is no opposition between the primitive and the civilized. The mysterious smile of a black woman, possessed by Oxum, the deity of beauty, is put on equal par with the mysterious smile of the Mona Lisa, the icon of European high culture. The color of the ceremonial necklaces is reminiscent of both the golden woodcarvings of Salvador's baroque churches and the color of aceite de dendê, the palm oil that is so amply used in Candomblé food and ritual.

This (imagined) break with any negative reading of the 'primitive' was an important precondition for the Bahian state to go 'all the way' in its pushing of Candomble imagery as the trademark of Bahia. Celebrating the 450th birthday of Salvador in I998, the city government placed twelve larger than life statues of orixás in a public park, engaging Candomblé priests - and the orixás themselves - in the process (cf. Sansi-Roca 2007). Other statues, by the well-known Bahian sculptor Mario Cravo, were placed in front of the central post office; just as artist Bel Borba was allowed to leave a genuine trace of Candomblé images in mosaics on countless walls, viaducts and similar urban spaces. The Museo Afro Brasileiro - with a large collection of Candomblé items - was granted accommodation at the most central square of Salvador's historic center, in the old, prestigious Faculdade de Medicina, the very place where Dr Nina had conducted his research and classes. 
In terms of image production, the proliferation of Candomblé images described in the beginning of this chapter really took off from this period onwards. Yet the tourist industry not only triggered a 'Candombléization' of Salvador's public sphere: it also opened up the terreiros to that public sphere.

As Dean MacCannel and others have argued, tourism exploits a fascination for the 'real life of others', and touristic entrepreneurs produce that 'real life' through the metaphor of the 'backstage'. An encounter with the 'real thing' requires moving off-stage and into the backstage of social life (MacCannell 1999; Urry 2002). Simon Coleman and Mike Crain have phrased the paradox of this project succinctly, when stating that

modern tourism is ... an inherently expansive economy, constantly appropriating and constructing new experiences and places. Yet such activity bears with it the ironic seeds of its own destruction, as the very presence of the tourist corrupts the idea of reaching an authentic and totally different culture. Paradoxically, a nostalgic semiotic economy is produced, one that is always mourning the loss of that which it itself has ruined (Coleman \& Crang 2002: 2-3).

This logic is hard to miss in Salvador. The tourist guides that I interviewed during my research were all very much aware that tourists want the 'real thing', and complained that they had to take their customers further and further into the periphery of Salvador, to temples whose ceremonies are not widely announced and are little visited. For, as Josuel told me, 'the moment my clients see other tourists present, they start complaining that this is nothing but a tourist setup.'

\section{讙}

To finish this Grand Tour of public appropriations and elaborations of Candomblé, I will show how two exponents of the identity politics that gained momentum in the I980s and I990s - the Bahian gay movement and the Bahian Movimento Negro - used Candomblé imagery within the framework of their own political agendas, opening yet another round of public redefinitions of the cult's public worth.

I was alerted to the adoption of Candomble symbols by the gay scene in Salvador during the Gay Pride Parade of 2003, which opened with an ode to the messenger between orixás and human beings called Exú. Surrounded by muscled go-go boys in panther print briefs, outrageously dressed transvestites, pink balloons and rainbow banners, a famous black 
singer sang his praise. Enormous loudspeakers blasted her voice over the many thousands that had gathered on Campo Grande in the center of the Bahian capital. In the light of the previous discussion, the reason why a Candomble deity marked the beginning of the march is not very hard to figure out. Having argued that Candomblé has become the dominant marker of Bahian identity, a highlighting of the Bahianess of the parade would have to include items from the Candomblé symbol bank. There is, however, more to the connection between homosexuals and Candomblé. When afterwards I discussed the presence of Candomblé imagery at a Gay Pride Parade, none of my friends expressed any surprise. They took for granted the strong connections between the Afro-Brazilian cult and homosexuality. They would say things like 'of course, all the priests are bichas' (effeminate, 'passive' homosexuals), and that the temples are 'cheio de bichas' ('full of bichas').

The presence of homosexuals in the Candomblé temples is indeed hard to miss, and anthropologists have discussed this presence at length (Landes 1940, 1947; Fry 1986; Birman 1985; Matory 2005). Patricia Birman, in an interesting discussion as to what might attract bichas to the temples of the cult in Rio de Janeiro, highlighted an affinity between the desire to be bicha and the available spectrum of alternative gender roles within Candomblé. Possession trance, she argued, offers an (often irresistible) opportunity for bichas to have their male bodies invaded by female orixás such as lansá or Oxum or female spirits such as Maria Padilha, Pomba Gira or Cigana. Given the conviction in Candomblé that possession implies the annihilation of self, which is subsequently replaced by the invading spirit, the practice allows bichas not only to dress up like women, but to really become the women of their dreams. In other words, she showed how bichas put a religious practice of divine possession at the service of the gender bending that they were after (Birman 1995). In addition, Peter Fry pointed out that once the terreiro got to be known as a place where bichas go, this designation became something of a self-fulfilling prophecy: men opting for the label 'real men' started avoiding the temples for fear of being accused of being bichas, whereas the latter started frequenting the temples to expose and realize themselves as bichas, 'hunt' potential lovers or hide from hostile families (Fry 1986; Fry 1982).

What is interesting about the case of the Gay Pride Parade, however, is that it hardly qualifies as an example of bichas seeking refuge and the possibility of self-realization in the sheltered confines of the Candomblé temple. To the contrary, this was a spectacle of gays (and the adoption of this English loanword is a significant move towards an identity label, 


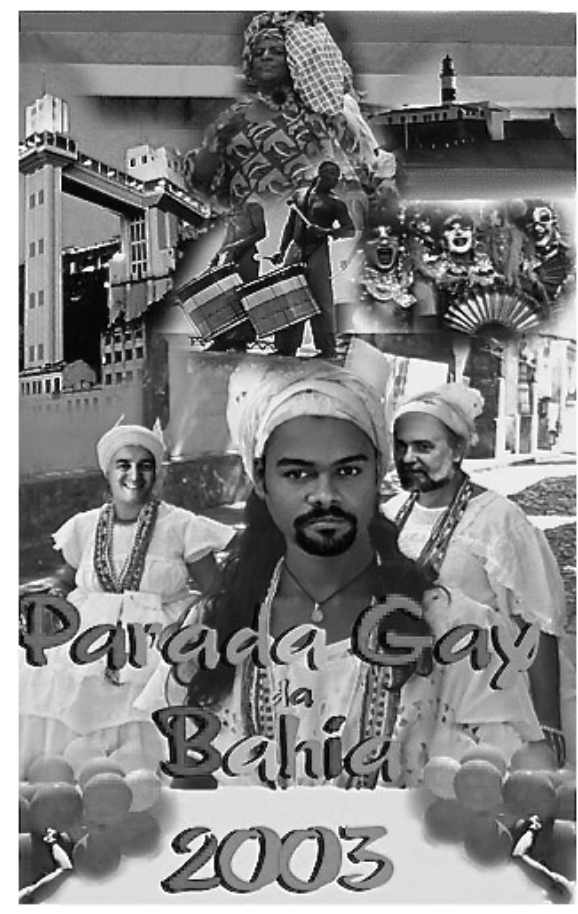

Figure 15 Poster announcing

the Bahian Gay Pride Parade,

with gay activists dressed up as

'Baianas'

as bicha primarily refers to sexual practice, and as such seems to be a less totalizing designation of Self) moving into the public sphere, adorning themselves with the signs and symbols of Candomblé.

Once alerted to it, the adoption of Candomblé imagery can be found in many other public sites of gay life in Salvador. Anchor Marujo, for example, is a popular lower-class gay bar, named after a well-known entity from the AfroBrazilian pantheon, Marujo. This spirit of a drowned Spanish sailor often takes possession of people and is notorious for the way he brags about his sexual exploits, his heavy drinking and his foul-mouthed language (dos Santos I995: I26). The bar boasts a little altar with his statue, some offerings and burning candles. Another public site in Salvador where both Candomblé and gays are strikingly present is Korin Efan, a carnival afoxé. Korin Efan organizes weekly rehearsals that come across as a curious mixture of terreiro de Candomblé and gay dance club. Candomblé songs and rhythms are performed to stir up the spirit of an almost exclusively gay audience, many of whom are cult adepts or even priests (one of the latter always comes in full ornament). There is a lot of flirting going on, and on the dance floor people are having great fun mimicking possession, mocking the authoritative behavior of priests, and exaggerating the dances of orixás and caboclo spirits. 'Candomblé com cerveja', is what Lobinho used to call these meetings, 'Candomblé with beer'.

Given the well-established and long-standing relations between gays and the Candomble universe, it is hardly surprising that elements of this universe migrate to the localities of an emergent gay subculture. The presence of Candomblé imagery and Candomblé ritual during the Gay Pride 
Parade, however, takes developments a step further. Take the way organizer Marcello Cerqueira looked back upon the event:

... our gay pride parade was blessed by the gods, those gods one calls for on a moment like this: Dionysus, Bacchus, Sappho, Logun-Edé, Exú. They descended and played with the crowds, declared themselves solidary with us as they sent a rainbow to bless us all, one of the greatest symbols of nature that was like a punch in the stomach of all homophobes. ${ }^{57}$

Here, a pre-existing affinity between bichas and the Candomblé universe gets publicly translated into the idea that Candomblé is an exemplary religion as far as 'tolerance' towards sexual difference is concerned. The gods are with us, is what Cerqueira seems to be saying. In other words, a local and particular discourse gets 'mapped onto' a global discourse of gay rights and gay emancipation - and vice versa.

It is in this reformulation of what Candomble is as a religion that the transformative consequences of the circulation of Candomblé imagery through various circuits of Salvador's public sphere become visible. In writings on the subject, one finds very clear examples of the entanglement of political activism and religion. Anthropologist Reginaldo Prandi, for example, spoke about Candomblé as 'a religion of the excluded' and remarked that '... no social institution in Brazil, other than Candomblé, accepted the homosexual, always forcing this category to hide itself from view.' He then exclaimed 'How grand and exemplary is this capacity of Candomblé to join saints and sinners, the soiled and the pure, the ugly and the beautiful!' (Prandi 1996: 33). João Silvério Treviso, a São Paulobased historian and the author of a history of homosexuality in Brazil (Treviso 200I), argued that the gay movement has a great deal to learn from the Afro-Brazilians, who 'have managed to overcome the adversities of their tragic history by remaining loyal to their African cultures and creeds.' He suggests that

... to nurture our inner life and boost our self-image, it is fundamental that we uncover from ancient times the myths that are related to us and might function as our roots. In other words, let's do some archeological work to recuperate what was veiled during centuries of Judeo-Christian civilization. ${ }^{58}$

In his proposed 'setup' of what is to become a gay religious cult he first makes his selection of useful Greek gay icons (Ganymede, Apollo, Dionysus, Achilles and Patroclus, Hercules and Iola), then ponders the useful- 
ness of Saint Sebastian ('pierced with arrows in his naked body until death by his soldiers in an obvious act of homo-erotic sadism that attracted so many artists toward this saint - from Michelangelo, in painting, to Yukio Mishima, in literature, to Derek Jarman, in cinema') and then argues that for Brazilians in particular, 'Candomblé offers various orixás with an ambiguous gender, like Oxalá, Iansá, Logun-Edé and Oxumaré.59

\section{鮕}

The Movimento Negro is another example of a circuit where Candomblé gets translated and mapped onto the political projects of outsiders. Jocélio Teles dos Santos, in his rich and detailed account of the progressive entanglement of Candomblé and black emancipatory politics in Bahia, has shown that up to the second half of the ig7os the black movements actually demonstrated a striking reluctance in approaching Candomblé. Marxist ideology ruled the activist discourses at that time and propagated an understanding of Candomblé as a 'sect' and ultimately an alienating institution, all the more so because of its veneration of Catholic saints and its links with Catholic institutions. Moreover, the way Candomblé priests and priestesses sought protective ties with white power-holders was repeatedly held against them (Santos 2005: 192).

By the early I990s, however, Candomblé had become endowed with so much prestige and power that one comes under the impression that even the Black Movements could no longer resist its seductive spells. The role of the afoxés, the traditional black carnival organizations in Salvador, is crucial. Radicalized by North American examples of black power and propagating the black-is-beautiful slogans of the era, they sought to reconstruct the aesthetics of negritude and glorified their African roots, finding in Candomblé a rich reservoir of rituals and symbolic forms (cf. Agier 2000). What such appropriations may have looked like is well articulated by Antônio Risério:

Take the example of the carnival group Badauê. Moa [leader of this so-called afoxé] is frank, as he states right away that its participants do not understand much about Candomblé ('we know just a little bit'). 'But we are eager, and we are curious,' he says, adding: 'but those who really understand do not want to teach us.' Badauê has no special link with a particular temple of Candomblé. Nevertheless, many adepts and even some priestesses do march the streets with the group, for example Ialorixá Omim Baim. 'It is to people like her that we feel connected,' Moa clarifies - 'they give us a lot of power.' Badauê also 
has a 'madrinha', a priestess called Dona Lili, from the Engenho Velho de Brotas neighborhood. It is she who does the ritual 'works' before the group sets out to march the streets, and ritually prepares the rehearsals, etc. Before every rehearsal of Badauê an offering to the gods is made, the padê. In addition, every time that there is a big celebration, for instance a music festival, or right before carnival, there is the matança, the sacrifice of animals. And although the chants are no longer taken from the religious repertoire, they all - almost without exception - deal with the religion, the orixás and its signs and symbols (Risério I98I: 83).

What these examples suggest is that, next to the occult powers for which Candomblé has always been known, feared and revered, the cult had accumulated so much prestige, coming from so many different areas, that it has become a powerful icon in itself. It seems reasonable to suggest that the political potential that Candomblé had gained could no longer be negated by Black activists, who indeed started to attempt to claim the cult as a somehow unalienable part of an Afro-Brazilian, rather than Bahian, heritage. Moreover, when leading terreiros in Salvador publicly broke with syncretism in order to restore their 'true' African roots (which happened in I984), a new understanding of Candomblé as a site of African resistance in a hostile environment became possible.

The aforementioned Antonio Risério, anthropologist and political activist, writes that '... in Brazil, Candomblé functioned as a kind of peaceful and sacred quilombo [as the communities of runaway slaves were called], a centre of cultural resistance of blacks and of their ethnic and social identity, which thwarted the occurrence of a complete unafricanization' (Risério I981: 83). David Covin reports that in the early I990s, the Bahian based Movimento Negro Unificado included in its action program the aim 'to work for freedom of culture and religion for Afro-Brazilians' by 'restoring culture production to the "cultural and religious spaces"' of the Black population, and 'systematically fighting its commercialization, folklorization and distortion' (Covin I996: 48). Teles dos Santos gives many more examples of the rhetoric that now came to dominate the black emancipatory discourse. One activist stated

Both the Afro-Brazilian people and their religion were always victims of serious attacks over the centuries by the catholic church and - ever more virulent in recent times - by the protestant churches, with the objective - well known by the black community - to eradicate from its conscience the experience and the sacred worldview [of its African past] (Santos 2005: I64). 
Again, the involvement of the Movimento Negro with Candomblé triggered a new round of image production, transforming the public look of Candomblé. In the Rio Vermelho neighborhood, a statue representing the goddess lemanjá is a good example: if lemanjá had traditionally always been represented as a white mermaid with long straight hair, she is here represented as a black mermaid with an Afro hairdo.

The examples of the appropriation of Candomble imagery by the gay movement and the Movimento Negro exemplify the repeated encounters of outsiders with Candomblé: elements of Candomblé are subjected to a re-reading, whereby the cult is understood in terms of particular political agendas. It is important to note that this is by no means one-way traffic, and in chapter seven I will discuss how new readings found their way back into the cult.

\section{膘}

Bahia is Candomblé, and Candomblé is Bahia. This message has been so dominant, its presence so ubiquitous, and its appeal so seductive, that in contemporary Salvador it is very difficult to define Bahianess other than in terms referring to orixás, mães-de-santo, azeite de dendê and similar Candomblé related imagery. Each and everyone is drawn into this framing of Bahian identity. Some artist friends complained that state subsidies for art projects always come from the Secretary of culture, which in Bahia is also the Secretary of tourism. 'And so you are always forced to work with the clichés of Baianidade. If your thing is painting still lifes without a plate of acarajé you better go to São Paulo,' one friend commented. A novel by Jean Wyllys, a young writer who sought to escape from the clichés in his portrayal of contemporary Salvador, was marketed in the following manner:

Snapshots of afflicted souls, of urban pilgrims wandering in dark zones, something truly obscure ... the brutal reality of our contemporaneity. Setting: the city where mystery no longer slides from the steep streets, like an oily substance, as in the old days. This is Salvador da Bahia in its post-modern chaos. Without dendê (Wyllys 20oI).

Even the Pentecostal churches in Bahia, declared enemies of the 'demonic' universe of Candomblé, cannot escape the framing of Bahia as the land of the orixás. Whereas the Bahian state often changes the name of the bay that Bahia was named after from Bahia de Todos os Santos (All Saints Bay) 
to Bahia de Todos os Orixás (the Bay of All the Orixás), the Pentecostals now sell car stickers saying Bahia de Um Santo Só (the Bay of One Single Saint).

Clearly, the extensive use of Candomblé by widely different groups, and in widely different arenas, has led to a situation of representational overkill. Neto, who works as a designer in advertising, told me exactly that: in his opinion, Candomblé imagery had been used so exhaustively that it had been emptied out of meaning by now.

'It still works to add a coleur local', he said, hesitantly. 'Like in the books of Jorge Amado. Candomblé adds local color.'

Looking at the souvenir shops at Salvador airport - called 'Magias da Bahia', 'O Segredo dos Deuses' or 'Axé' and filled to the brim with the most kitschy Candomblé statues, key rings, coasters, T-shirts, coffee mugs and other trinkets - the banalization of Candomblé is all in your face. And yet, being the anthropologist that I am, I cannot but observe that time and again, Candomblé imagery has managed to resist the overkill. It is brought back to life by artists, musicians, writers, theater makers, and above all, by the splendid spectacles of the religious ceremonies in the temples. As such, Candomblé is able to animate the notion of Baianidade in ways that the wooden shoes, tulips and windmills in my hometown, struggling to produce a credible notion of Dutchness, do not manage.

Undoubtedly, this resilience in the face of the powers of commoditization has everything to do with the fact that Candomblés public career started off with an appreciation of its primitive quality. Religious practices in Candomblé make ample use of what Mary Douglas called 'natural symbols', or what Begoña Aretxaga has aptly called 'overdetermined primordial symbols' (I995:I25): symbols that 'resort to physiological material of great psychological significance' and 'tap into diverse areas of experience' (I995: I25-I26). In animal sacrifice, these practices dramatically stage the absolutes of life and death; in the shaving of the initiates' hair, the incisions made on the initiate's body, the pouring of blood, the sweating and - who knows? - the 'foaming' from bodily orifices, they display a viscerality that immediately evokes the primordial underpinnings of culture. In spirit possession, Candomblé stages a body that, in the eye of the outside observer, seems to be totally out of control, subject to unknown forces. The sheer carnality of Candomblé practices, their being rooted in the drives and forces of the body, charges the images derived from these practices with an ill-concealed eroticism, or better still, with jouissance, the amoral dimension of all human existence that, as Roland Barthes argued, escapes all cultural signification (Barthes I977). Through such associations 
all attempts to render public images of the cult 'civilized' were, from the very beginning, destabilized. For the evocation of jouissance makes Candomblé both dangerously seductive and seductively dangerous. In Candomble imagery, the potential of black muscle to caress is always, simultaneously, the potential of black muscle to kill.

Anything out of control is always a potential threat, and always calls up moral, legal, and aesthetic powers to discipline it. The signs of the subordinate out of control terrify the forces of order ... for they constitute a constant reminder of both how fragile social control is and how it is resented; they demonstrate how escaping social control, even momentarily, produces a sense of freedom (Fiske 1989: 69).

The link of Candomblé images with jouissance helps to explain that striking paradox of Candomblés role in the public sphere: jouissance endows these images with universal meaning, i.e. with the corporeal, libidinal, biological dimensions of human being that are beyond all cultural particularities. More than anything, it is because of jouissance that these images speak to us all. In doing so, these images of the universality of men threaten the absoluteness of all cultural orderings, and for that very reason they must always remain other, pertaining to the realm of Afro-Brazilians, or rather Afro-Baianos, or rather the Afro-Baiano popular classes, or rather, that sweet old black lady in Cabula, uma daquelas... 


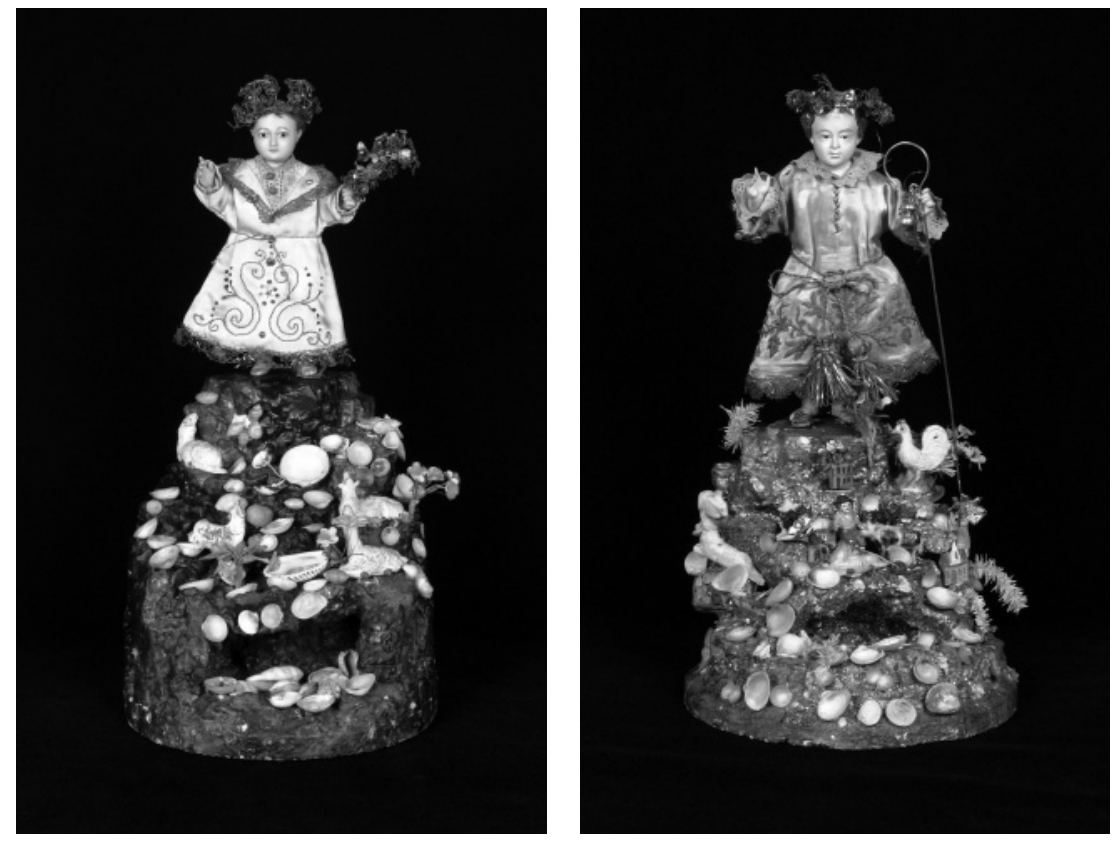

Figure $16 \bigcirc$ Menino Jesus no Monte. Photographer Sergio Benuti Courtesy of the Acervo Fundação Instituto Feminino da Bahia/ Museu do Traje e do Têxtil 


\section{5 \\ allegorical WOrLDS}

Baroque aesthetics and the notion of an 'absent truth'

The montage-like statuettes that you see in the pictures on the left examples of a popular art form from Igth-century Bahia and are called O Menino Jesus no Monte, the Child Jesus on the Mountain. They are sometimes also referred to as lapinhas, 'little caves', as many of them exhibit a dark void in the middle of the mountain, suggestive of a cave. What little information I found on these lapinhas reveals that they were made in Bahian convents in the Recôncavo area. The nuns from the Convento de Recolhimento de Nosso Senhora dos Humildes in the town of Santo Amaro de Purificação where particularly famed for their artistic skills, and produced a great number of these lapinhas. Guarded under glass bell jars or in oratories, they were put on display in Bahian homes in the Christmas period (Marques \& Araújo 2006; Silva 2007).

I do not, however, bring these lapinhas to your attention as an overture to a discussion of the artistic skills of Bahian nuns or of Bahian Christmas celebrations. I present them here, at the beginning of this chapter, because they are a particularly revealing materialization of a baroque 'cosmovision. This cosmovision - which might be understood as the configuration of the relationships between human beings, god(s) and the world they inhabit - needs to be fleshed out halfway this book for a number 
of reasons. Being more explicit about what a baroque register of worldmaking is (and does) may help to clarify the heuristic work that the notion of 'the baroque' has done in the preceding chapters. Moreover, a thorough discussion of a baroque cosmovision helps to prepare an interpretative framework for the chapters to come, which deal with responses in the Candomblé community to that never-ending stream of visitors knocking on the doors of their temples.

So take a good look at these lapinhas, which in their basic structure are all alike. What you see is the child Jesus who, in king-like posture and outfit, reigns over a world that is represented as a pile of fragments: rooster, seashell, rabbit, house, little man, flower, duck. Glued to the mountain in random fashion, these individual elements are mere emblems: their meaning does not exceed the depth of a pictogram. Nothing in these lapinhas invites you to ponder the deeper significance of roosters, flowers or ducks, nor their mutual relations. Quite to the contrary: they invite you to ponder the absence of pattern, harmony and synthesis; they entice you to contemplate the lack of 'wholeness' to the world that they so strikingly express. In some of the lapinhas that are on exhibit in a small museum in the center of Salvador ${ }^{60}$ the piling up of fragments goes even further as the two examples presented above. The result is a veritable jumble of figurative elements. Watching these lapinhas, one can almost see those poor nuns, tucked away in a convent in the Recôncavo, fully absorbed in their frenzied attempt to recreate the world from which they had been banned by gluing ever more emblems to the mountain. Soldier. Church. Carriage. Horse. Negro-with-guitar. Bridge. Bottle. Peacock. More seashells. More flowers. And yet, all that the resulting encrustation of the mountain does is to dramatize the utter failure to grasp the world in its entirety through enumeration. Indeed, the thick crust of emblems first and foremost highlights that dark, empty void in the middle of the mountain: the cave that underscores the hollowness of this universe, its lack of inner meaning and substance.

The one element that brings harmony to these montages is the figure of the Menino Jesus. Only the divine child on top of the mountain, stretching his little hand in a gesture of blessing, allows the fragments to cohere (and to be read as 'the world'), just as it is only this divine presence that is able to negate the emptiness of the cave below. And yet, for as much as the posturing of the kingly child speaks of a triumphant faith that brings order to a meaningless world, these lapinhas strike me as distinctly melancholic. For everything about them - the disproportional size of the child Jesus in relation to the world below; its uninvolved and strangely directionless 
smile; the fact that its little feet just barely touch the mountaintop; the clumsiness with which the shells and other emblems are glued onto the mountain - works to suggest that this divine presence maybe at work in this world, but is certainly not of this world.

Following Walter Benjamin and some of his interpreters, I have already argued that the highlighting of an absent truth that brings the world to order is typical for the representational modes of the baroque that came into being in the early modern era: it is an aesthetics that expressed the disintegration of the sacred canopy and sought to counter it; that registered God's receding from the world of men, and sought to stop this from happening. 'Yes, the world is a meaningful place,' is what these lapinhas seem to say, 'but the source from which this meaning springs forth is beyond our grasp: inaccessible to us mortals.' Or: 'there is truth, but it is not of our own making.' This conjunction of failure and faith, the simultaneous experience of things-falling-apart and the promise of salvation that characterize baroque expressivities is beautifully grasped in a verse by singer and songwriter Leonard Cohen: 'there's a crack, a crack in everything, that's how the light gets in' (in Fabian I998: 34).

This, I would say, is the sensibility that pervades the Bahian baroque: in its insistence that the world of men is a sorry place, full of cracks; and in its aesthetic employment of these cracks, the baroque plays on people's despair over the fact that truth resides elsewhere, as well as on their hope that truth might reside elsewhere. 'Desperate faith' (Cowan I98I: II9) is how the dominant mood of the baroque has been characterized, and that oxymoronic expression is, indeed, a most adequate phrasing of a sensibility that Bahians have cultivated to the full. It is immediately sensed in the interior of Salvador's baroque churches, where the jumble of golden ornaments which messes up the sensorium leaves one confused and disorientated, yet simultaneously evokes a strong sense of a mysterious, transcendent force that keeps this golden mess from disintegrating. It is apparent in the strong messianic undercurrent of Brazilian religiosities, the 'desperate faith' with which the redemptive miracle is awaited or the prophetsavior is embraced. It informs the ubiquitous 'se Deus quiser' ('God willing') with which Bahians resign to their ultimate powerlessness and hand over the course of events to a higher, transcendent agent. It underlies the bittersweet tones of the samba, which tends to juxtapose disillusion ('confesso que eu chorei, pelas ruas da desilusão', 'I confess that I cried, on the streets of disillusionment') with an ecstatic search for a higher truth ('nos braços de Orfeu, me perdi na orgia', 'In Orpheus arms, I lost myself in an orgy'). It pervades the carnival parades, with their immense 'allegorical 
floats' on which all participants have been reduced to emblems ('this year, I am a pyramid'), but only, it seems, to infuse the world with the maddening excess of life's energies that such reductions produce.

The baroque postulate that truth may be operative in the world, but does not pertain to the realm of human signification, reveals the typical multilayered structuring of meaning that has been described as 'allegorical'. I will therefore start my discussion of baroque modalities of worldmaking by asking how allegory represents the world, more in particular how it conceptualizes man's relation to the world and the universe. I will also reverse that question by asking what kind of a world makes the allegorical imagination persuasive: what life conditions, what life experiences cause this particular representational form to flourish?

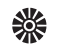

The Greek roots that make up the word allegory - allos, which means 'other', and agoreuei, to speak - already indicate that allegory occurs whenever one text is read through the prism of another (Owens I980: 69). In allegory, this is not a matter of adding another layer of meaning to a pre-existing one, or restoring an original meaning that was lost or obscured, but a far more radical procedure for which Craig Owens uses words like 'confiscation' and even 'usurpation', so as to underscore that the allegorical meaning supplants an antecedent one. Take a painted still life of apples, pears and walnuts. For this painting to be an allegory, information is needed that is not available within the frame of the painting: the allegory depends on an external source of knowledge that informs the beholder what apples, pears and walnuts 'stand for'. Bainard Cowan phrases it as follows: 'In becoming a world of allegorical emblems, the profane world is robbed of its sensuous fullness, robbed of any inherent meaning it might possess, only to be invested with a privileged meaning whose source transcends this world' (Cowan I98I: II6).

In the preceding chapters, several examples of an allegorical rendition of the world have passed. Take that remarkable speech delivered at Dr Nina's funeral, where the Dean of the Faculdade de Medicina pronounced that whatever Dr Nina's intellectual work had meant during his lifetime, 'in the face of death it all meant nothing. This is an allegorical move par excellence: now that Death is evoked as an all-transcending interpretative frame, the ultimate meaning of Dr Nina's work is no longer to be found within the horizon of his writings, but in the infinite mystery of the hereafter. Examples of the allegorical imagination have also passed 
in my discussion of the Modernist's 'reading' of Candomblé through the prism of the primitivist discourse, whereby a religious practice of divine possession was 'robbed' of its mythical and religious meanings and came to signify the energy of primordial, libidinous drives. Or one might think of the confiscation of Candomblé imagery by various outsiders to the cult discussed in the last chapter, which turned Oxalás androgynous character into a sign of Candomblés gay friendliness, the worshipping of Iroko, the tree spirit into a sign of Candomblés proto-ecological stance, and the Candomblé temple into a bulwark of black resistance to white supremacy. In all of these instances, Candomblé images were reduced to emblems in other people's allegorical plays.

Allegory, then, denies that the things of the world possess an inherent or essential meaning. Its basic premise is - as Walter Benjamin stated - that 'any person, any object, any relationship can mean absolutely anything else' (Benjamin, in Owens I980: 84). This denial that meaning is inherent to the world sounds much like that slogan of a secular postmodernism, which states that 'there is nothing outside of the text' (an appropriation of Derrida's famous il n'y a pas de hors-texte that does little credit to the subtleties of this scholar's argument). In fact, however, the allegory that is encountered in the baroque could not be further removed from such a denial. If allegory purports that essential meaning cannot be found in the structures of the symbolic order, this highlighting of the failure of human sense-making serves to throw into relief the infinite field of our not knowing, and to invest that realm with the promise of a higher, transcendental plane of meaning; it creates the possibility of a (divine) agent who is able to tell us what apples, pears and walnuts 'stand for'.

In art history, allegory is usually explained in contrast to the harmonious and synthesizing forms of representation that gained prominence in the Romantic era. This is indeed an efficient way to grasp the specificities of its expressive potential. Where the Enlightenment had positioned man in front of the world, 'a center of experience and action, set over against a world of objects that are to be known and manipulated' (Guignon 2008: 33), the Romantic Movement sought to restore man's connection to the universe. A reunification with the grand totality of being should undo feelings of alienation. Unsurprisingly, then, the romantic mode of representation promises that there is an indissoluble unity of form and substance. Cowan states that a '[romantic] representation of a natural or mythical object [would make that object] part of the transcendent absolute and would offer the perceiver participation in that absolute and an intuitive knowledge of it' (Cowan I98I: III) ${ }^{61}$ 
Abstract as this latter formulation may be, the thought that a representational form has the capacity to draw the beholder into - and thus unite him with - the transcendent absolute that this representation seeks to convey is in fact very familiar to us. Often heard remarks that 'one was carried away by the music', 'lost in the pages of a novel', 'overwhelmed by the architecture of a place', 'awestruck in front of an artwork' all exemplify this conceptualization of the arts as enabling one to partake in the transcendent truths of which they speak. In a romantic understanding of the arts, then, a true work of art effectuates 'an unmediated unself-conscious immersion into the beautiful' (Miller 2003: 156). Or to use an example from the field of religion: the 'sublime' of religious art would enable a religious person to access the divine, thus to become part of a united whole that comprises God, men and the world.

Allegory - and more broadly speaking, the baroque - declares such promises to be false and illusionary (although, as I will elaborate below, it generates a deep craving for the wholeness and symbolic closure which it proclaims to be impossible). If romantic modes of world-making seek to effectuate the sensation that 'subject and object, or self and world, seem tailor-made for one another' (Eagleton 2009: Io), the allegorical mode offers 'awkwardness of fit, breaking-up and scrambling' (Taussig I986: 442). As stated above, allegory's expressive mission in the world is to show that human beings are exiled from the truth they wish to embrace, for that truth resides on an inaccessible plane, 'mountain high' (as the lapinhas so beautifully illustrated) or as deep as 'an open grave' (as was suggested at the funeral of Dr Nina). Allegory proclaims that the worlds we inhabit derive their meaningfulness from an absent, mysterious power that imposes its designs on the world for reasons beyond human comprehension. As such, it squarely belongs to the baroque arsenal of expressive forms that are 'geared to express unavailability' (Osborne 2005: 60): empty emblems, evidently artificial, 'mannerist' and 'kitschy' forms, shallow surfaces, labyrinths, trompe l'oeuil effects, riddles, and mysteries.

The role of miracles in the allegorical imagination is particularly revealing as to the cosmovision allegory seeks to convey. Discussing why the typical allegorical play needs a 'miracle' to come to an end, Cowan stated:

In the unpredictability of [the miracle's] appearance, which is to say its complete lack of 'motivation' by preceding events and behavior, the miracle-ending of baroque drama perfectly sums up the non-dialectical, antinomic structure of allegory ... The last event of the typical Trauerspiel makes the gesture of abdi- 
cation that the Deus ex machina makes, an acknowledgement that the play's agents cannot bring about their own rescue (Cowan i98r: II8).

In other words, the miracle - the impossible happening anyway - calls into being a 'beyond' of the plane of mundane actions and understandings, and situates the ultimate power of definition (i.e. the definition as to what is and what is not possible) in this 'beyond'. Through the miracle, one might say, God flexes his muscles to impress the world with his superior might. And as with muscle men in general, this piece of bravado comes without further explanation.

Many instances of this pointing to an unavailable 'beyond' where a 'privileged truth' is situated have passed in the preceding chapters. One might recall the constant allusions to the 'backstage' as the site of a truer real, as it came to the fore in the frequent references to the secret realms of Candomblé; in Jorge Amado's peeking under the initiates' skirts; but also in Brito being possessed by Dr Fritz, a German spirit for sure, with a doctor's title and all, but more importantly, operating from the realm of the dead. One might think of those saints in the Quarto de Santos, with their feverish gazes, seeing into an invisible beyond, or of the frequent references to mystery and je-ne-sais-quoi in the depictions of Salvador that would make the city into what it is. Even the way in which Europe operated (and continues to operate) as the Big Fetish in Bahia recalls an allegorical structuring of the world. In all of these instances, an absent truth was lifted onto the top of the mountain to invest the world below with its privileged meaning.

In discussions on allegory in literature and the arts, it has often been remarked that its expressive potential has long lost its persuasive power. Against the romantic promise to effectuate 'the unlimited immanence of the moral world in the world of beauty', allegory came to be seen as 'mere convention, inauthentic, not grounded in experience, cut off from being and concerned only with manipulating its repertoire of signs' (Cowan I98I: III). And yet, the persistence of the allegorical imagination up into the present is hard to miss, and this is not only the case in places with a markedly baroque heritage such as Bahia. This brings me to the questions raised at the beginning of this chapter: to whom does the allegorical mode of representation speak? In which worlds and times does the allegorical 
imagination flourish? What alternative notions of 'authenticity' can be articulated in its expressive forms?

Before addressing these questions within the Bahian setting, I will discuss the occurrence of allegorical forms of world-making in imaginaries and sensibilities that pertain to my own life world - for allegorical modes of world-making flourish in both the gay circles and academic (and more specifically: anthropological) circuits in which I move about. This detour is motivated by the consideration that an immediate relegation of this 'outdated' imaginary to the worlds and times of 'not-so-modern-others', might prevent us to consider allegory's presence in (and relevance for) our own forms of world-making.

\section{铛}

Take that intriguing cultural phenomenon called camp, which might be described as a sensibility for cultural forms that are 'truly false', and that comes to the fore in a joyful indulgence in kitsch, pathos, high drama, baroque exaggeration and over-the-top-extravaganza. As Susan Sontag wrote, in her pioneering essay Notes on 'Camp', 'the essence of Camp is its love of the unnatural: of artifice and exaggeration.'

Camp sees everything in quotation marks. It's not a lamp, but a 'lamp'; not a woman, but a 'woman'. To perceive Camp in objects and persons is to understand Being-as-Playing-a-Role. It is the farthest extension, in sensibility, of the metaphor of life as theater (Sontag I990: 280).

Richard Dyer, positioning camp squarely in gay subcultures ('the only heritage we've got'), stated that camp

... is a way of prizing the form of something away from its content, of reveling in the style while dismissing the content as trivial. If you really believed in the emotions and stories of classical ballet, in the rightness and value of royalty, in the properness of supervirility and fascism, then you would not find The sleeping Beauty, the Queen Mother, or John Wayne camp. What I value about camp is that it is precisely a weapon against the mystique surrounding art, royalty and masculinity - it cocks an irresistible snook, demystifies by playing up the artifice by means of which such things as these retain their hold on the majority of the population (Dyer 2002: 52). 
Although I find the spirit of gay partisanship that emanates from Dyer's pondering of camp rather infectious, I am less convinced that the sensibility for camp reveals a spirit of heroic resistance against a hostile world. I rather recognize camp as an instance of the allegorical imagination, indeed, a contemporary expression of the melancholic condition that Benjamin found present in the baroque Trauerspiel and phrased as 'living in a state of being exiled from the truth one wishes to embrace' (in Cowan I98I: II4) - whereby, in this case, one probably ought to rephrase and speak of 'the truth one was instructed to embrace'.

I would say that the affinity of many gay men with the celebration of falsity that is camp - the genuine appreciation of the made-upness of things - has everything to do with the process of self-discovery and selfdefinition that is popularly called the 'coming out'. The simple fact that no one is brought up to be gay, allows for the thought that, however diverse histories of becoming gay may be, they are all permeated with feelings of alienation. After all, the process that is 'coming out' always implies a rupture from a Self that was not only brought up to be straight, but to be naturally straight. As many have argued, heteronormativity is not merely a set of ideas and norms, but is naturalized by 'inscribing' these norms and ideas in the body and the sensorial. To turn boys into straight men, Pierre Bourdieu would say, the body must be honed to eat, drink, walk, sit, stand, squat, gesticulate, look, copulate, dance and talk in ways that are understood as masculine. In this long process the body is treated as 'a living memory pad, an automaton that leads the mind unconsciously along with it, and as a repository for the most precious values' (Bourdieu I990: 68).

'Coming out' is to break with this corporeal masculinity: it leaves one no other conclusion than to acknowledge that the 'naturalness' of straight masculinity is fake. Unsurprisingly then, to be gay is to harbor, and oftentimes cherish, a lifelong suspicion of anything that claims to be 'natural'. This is exactly what camp articulates. Camp is to consider the truth of that which is evidently false and artificial to be more reliable. It is to recognize the authenticity of drag queens, pumped-up muscles, affected gesticulations, lavishly hairsprayed hairdos, artificial suntans, АB B A love songs, Versace sunglasses, and the chemically produced bliss of Viagra and Ecstasy. It is to develop a taste for the venomous 'bitching', the verbal duels that take place late at night, at the bar of some gay club, aimed at destabilizing all appearances as posturing and make-believe. It is also the dream to become an expert in masking and make-believe by pursuing a career in such decorative skills as hairdressing, visagerie or fashion design. As Philip Core once put it succinctly, camp is 'the lie that tells the truth' (Core I999). 


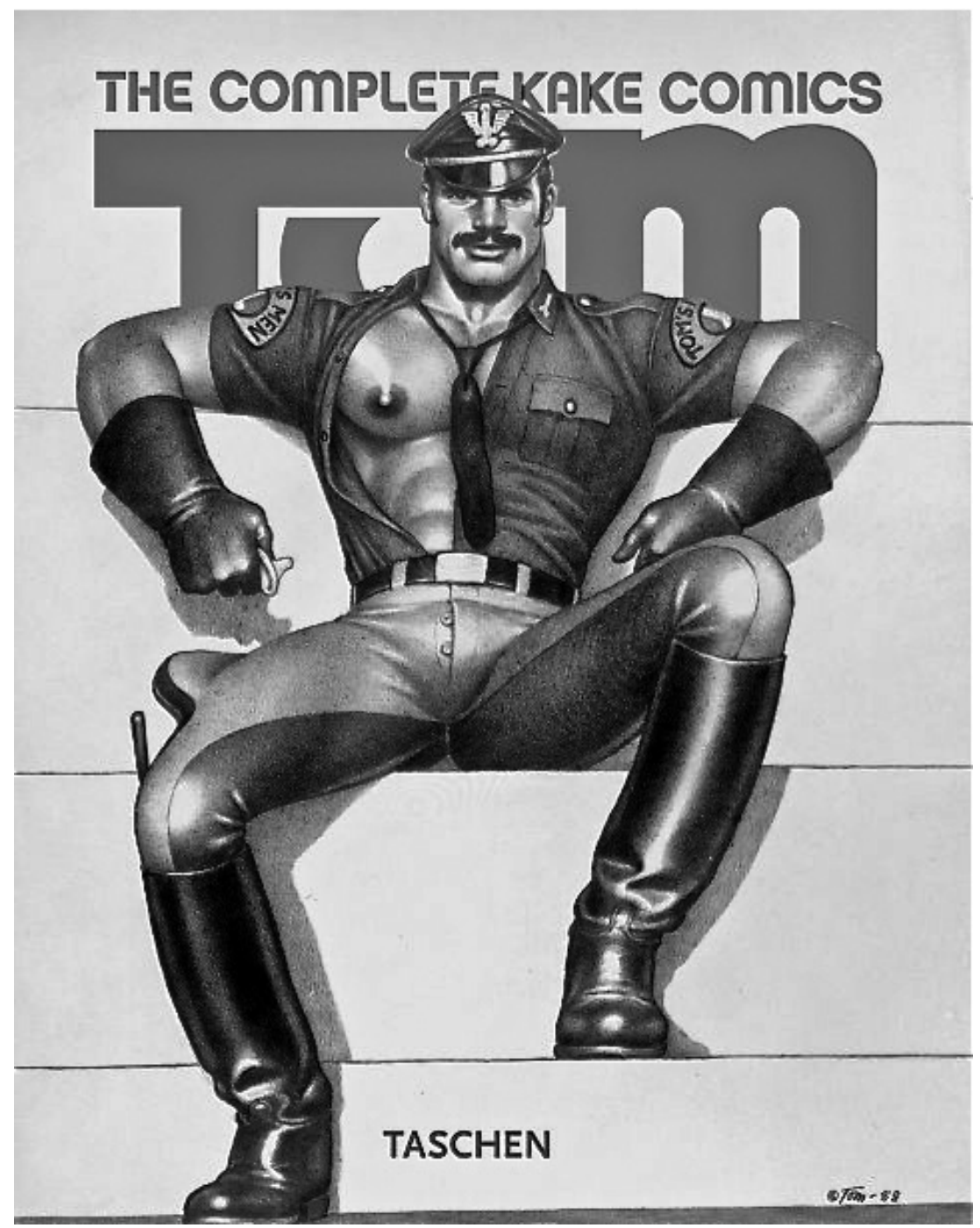

Figure 17 Tom of Finland

And yet, camp's constant attempts to reveal that the natural itself is an invention, and thus cannot provide identities with 'a substantial, stabilizing core' (Cleo I999: 6) can never be equated with mere cynicism or irony. For camp's declaration that fake is the greater truth never mitigates a sentimental yearning for that which is 'naturally' true, and fosters a keenness to register possible signs of that truth. It is here that camp truly shows itself to be an instance of the allegorical imagination. Yes, a camp sensibility revels in the grotesque artificiality of Tom of Finland's renditions 
of 'horse-hung' and pumped-up male bodies. Yet a camp sensibility will always juxtapose the mindful knowing that such males only exist in the exaggerations of fantasy with a body that is not affected by such knowing, and might well get excited over these pictures. In other words, a camp sensibility exploits the fact that the laughing over 'Muscle Marys' cannot undo the desiring body: indeed, camp invokes that desiring body to produce the 'substantial, stabilizing core' which it finds missing in the order of the symbolic. Similarly, tears shed over tearjerkers, over the drunken sobbing of Chavela Vargas songs, or over Maria Callas' larger-than-lifetragedies bring nature back into camp celebrations of over-the-topness: for whatever provoked these tears, they are warm, salty, body fluids; 'overdetermined primordial symbols', as Begoña Aretxaga might have called them, for having deep psychological significance and for tapping into diverse areas of experience (Aretxaga I995: 125). It is thus that one of the masters of camp, filmmaker Pedro Almodóvar, lets one of his characters, the transgender Agrado, explain that she 'adores' farewells and goodbyes, as these provide her with an opportunity 'to cry her eyes out'. Paradoxically, then, a camp celebration of falseness may well turn out to be an attempt to open the gates to the natural.

There are other elective affinities between camp and baroque modes of world-making. If in the baroque Trauerspiel 'the play's agents cannot bring about their own rescue' and are thus condemned to await the miracle with 'desperate faith' (Owens I980b), so gay men given over to camp yearn for that Fulfilling Event that will plug the leaking hole in the system of meaning through which all 'naturalness' drips away. 'Somewhere, over the rainbow ...' a reunion with Nature might come about. And if the waiting for the miracle takes too long, the reunion might be provoked in the nightly jouissance and evasive pleasures of city parks and dark rooms and gay saunas, where the world is restaged as a geléia geral of saliva, sweat and other bodily fluids. Or to quote Agrado on her reunion with nature:

I am very authentic ... The reshaping of my eyes, eighty thousand pesetas. Nose, two hundred thousand. A waste of money, as a year later someone punched it ... Breasts, two, because I'm not a monster. Seventy each. Silicones in my lips, forehead, cheeks, hips, behind. Hundred thousand for one liter of that stuff. You do the counting yourself; I long lost track ... Chin correction, seventy five thousand. Permanent laser hair removal - as women too descend from the apes - sixty thousand per treatment. All I want to say: it costs to be authentic ... 
In this scene too, all the joking and self-mockery cannot conceal that the transgender Agrado offered all to carve her dreamed-up self in the flesh, thus to be reunited with nature. So strong is this yearning - and so undeniably true and uncompromisingly real - that at times one wonders whether the celebration of fake that is camp is all about the fuelling of such desires: whether the appeal of this form is its capacity to replace the lack in all world-making with the real of desire.

\section{菊}

Allow me to take my baroque sensibilities, more in particular my suspicion towards all 'naturalizing' discourses, to the current modes of anthropological world-making.

Anthropology - at least since Malinowksi (1984: 25) - urges its practitioners 'to grasp the native's point of view, his relation to life, to realize his vision of his world.' Whereas the feasibility, or even desirability, of this project has been questioned in the long debates as to 'how anthropology makes its object' (Fabian I983) - the pressure to adopt forms of writing capable to evoke 'the inside view', and make readers part of the strangely human societies under study, is considerable. After all, much of the discipline's authority within the social sciences rests on the idea that anthropologists are not 'armchair scholars', but 'participant observers' who know 'what-it-is-really-like-out-there'. As Clifford Geertz stated in the conclusion of his long and eloquent discussion of the particularities of anthropological authorship,

... the capacity to persuade readers (...) that what they are reading is an authentic account by someone personally acquainted with how life proceeds in some place, at some time, among some group, is the basis upon which anything else ethnography seeks to do - analyze, explain, amuse, disconcert, celebrate, edify, excuse, astonish, subvert - finally rests (I988: I44).

Geertz has a point, of course: 'having been there' does not add up to much if it cannot be evoked in the anthropological text. Indeed, 'having been there' is first and foremost an effect produced through literary strategies and techniques. In the preceding pages of this book you have encountered many of the ingredients that go into the kind of 'naturalism' or 'fieldwork realism' through which the evocation of 'being there' comes about: vignettes describing the local; anecdotes recounting encounters in the field; the introduction of the voices of ordinary Bahians; the highlighting 
of Portuguese terms in italics; fragments from fieldwork diaries; confessions and reflexive self-disclosures.

Yet for all of the realist and naturalist figures of style that authenticate the ethnographic text, one cannot but conclude that anthropologists are allegorists through-and-through. In his I986 essay 'On Ethnographic Allegory', James Clifford already noticed that the cultural descriptions of the anthropologist do not merely 'represent' the realities that were encountered in the field (in the sense of 'making present') but always entail morally charged stories about the culture of the others. All ethnographic texts reveal 'a double attention to the descriptive surface and to more abstract, comparative and explanatory levels of meaning' (Clifford \& Marcus I986: IOI). And any ethnographic attempt to make the 'strange behavior' of others intelligible and meaningful to a (Western) readership requires the introduction of a 'common network of symbols - a common ground of understandable activity valid for both observer and observed', which again implies that 'ethnography's narrative of specific differences presupposes, and always refers to, an abstract plane of similarity' (ibid.). In the words of another anthropologist,

what ethnography did ... was not to present 'the native's point of view' but to present a reconstruction of that view in 'our' terms: terms through which we had necessarily come to understand it; terms in which we were required to represent it; terms which constituted anthropology's own 'making sense' of the diverse ways human beings 'make sense' ... 'local knowledge', or at least knowledge gained in and of some particular locality, was always anthropology's business but it was always rendered into something else ' academic discourse - that could be taken to function 'globally' (Just I995: 285-286).

Recalling recent presentations at anthropological events in which I participated, or texts that circulate in the anthropological community of which I am part, I might add that 'abstract, comparative and explanatory levels of meaning' have come to dominate the production of knowledge in the discipline. The 'local' is no longer that which needs to be explained but an inducement for theoretical expositions, learned references, and displays of erudition. In fact, this is what I tell my students: 'don't expect your readers to be interested in the particularities of Kayapó Indians or Scottish Highlanders or Nepalese weavers just because you are fascinated by them. Come up with a motive for your story that transcends the local and that provides your narrative with a sense of urgency!' With my reading practices, I must confess, it is no different: it is the promise of a theoreti- 
cal insight, or at least, something that transcends the local, that persuades me to wrestle my way through the detailed ethnographical accounts of my colleagues on the habits of the unknown others they have studied. This retreat of the local to the background of debates is also furthered by institutional practices of anthropology: obtaining research funds, being published, 'making it', causing a stir. In brief, realizing oneself as an anthropologist among anthropologists, requires a confiscation of the local, an 'usurpation' of 'the culture of the others' that can thus be invested with the 'privileged meaning' of anthropological debates and anthropological theories. Sure, every once in a while some ethnographer or other will be applauded for saying that 'theories are prone to be outdated soon, whereas good ethnography has no expiry date'. Yet few of the anthropologists that I know study the Others for the sake of knowing them, as if driven by an open-minded curiosity, a disinterested interest in their culture or their otherness per se. I am sure we have all, at one point, had to sit through the long hours of a departmental dinner party next to an enthusiastic colleague who just would not stop dishing up the cultural particularities of his or her fieldwork location (here too, Warner's understanding of 'the public' as that which exceeds the particular makes sense!).

Once ethnography comes to be understood as allegory, intriguing dimensions of anthropological world-making come to the fore that have not been mentioned in Clifford's text. In line with the allegorical imagination - and in odd contrast with the preferred 'naturalist' style discussed above - anthropologists appear deeply suspicious of everything that presents itself as 'natural'. This suspicion comes to the fore most prominently in recent discussions on the concept of authenticity. As Charles Lindholm commented, anthropologists have long been 'scavenging for the vestiges of a vanishing authenticity', but now they generally take up the more lofty position of 'floating above local claims for transcendence or truth'. They have made it their main business to 'demonstrate again and again that these claims are political and ideological representations supplied by selfinterested parties pursuing domination' (Lindholm 2002: 334). Say that something is authentic (or true, or a fact of nature) and a multitude of anthropologists will set out to explain to you how you failed to recognize the constructedness of this 'authentic' something of yours. This response is of course not univocal: some (in a Derridean or Baudrillardean vein) will talk about the mere constructedness of life worlds. Others will stress that life worlds are perceived by people as being 'not of their own making' (in the Marxist sense), or as something in which they are 'hineingestellt' ('placed', in the Weberian sense). Yet as different as such positions may be, 
they have a similar effect in contemporary anthropological writing and thinking: as we descry 'discourses', 'spectacles', 'simulacrums', 'invented traditions', 'staged authenticities', or 'imagined communities', all that was presented to us as natural, God given, common sensical, and of-timesimmemorial can be revealed as being made-up. In brief, anthropologists too are inclined to see everything in quotation marks. 'They may think it is all very real what they are doing and saying,' is what the anthropologist has been taught to say. 'But we know what it really is: a construct!'

The suspicion towards everything that presents itself as 'natural' in anthropological circles borders on a camp sensibility and might well be grounded in comparable life experiences. Long-time fieldwork always implies the re-socialization in another culture, and this process of reinventing oneself along the lines of another culture cannot but lead to an awareness that many of the tacit understandings that had helped the anthropologist to conceive of the world as a 'normal' place are not as selfevident and naturally given as they had seemed to be. Not unlike gays after their 'coming out', anthropologists are prone to point out that the 'natural' is a travesty, a mere costume that helps culture to make a convincing performance. The famous quote 'we project our social categories onto nature and then use nature to justify them' (Lambek I995: 26I) aptly summarizes this view. Clearly, anthropologists do not display their suspicion towards the natural as flauntingly as a troupe of frivolous queens camping the evening away in endless attempts to deface one another. Yet in their own, more 'closeted' ways, they tend to indulge in unmasking the naturalized poses of others, 'robbing' the worlds they study of their 'sensuous fullness', of any 'inherent meaning' they might possess, to invest them with the 'privileged meaning' of Grand Theory.

The analogy with camp does not stop here. For the unremitting selfinstruction that 'reality is artifice' (Taussig I993: xv) produces its own cravings for a reconciliation with nature. In his discussion of the lack in social constructionist approaches to reality, and his exploration of alternative routes to social analysis, Michael Taussig found himself slipping into near desperation:

But just as we garner courage to reinvent a new world and live new fictions - what a sociology that would be! - so a devouring force comes at us from another direction, seducing us by playing on our yearning for the true real. Would that it would, would that it could, come clean, this true real. I so badly want that wink of recognition, that complicity with the nature of nature. But the more I want it, the more I realize it is not for me. Nor for you either ... 
which leaves us in this silly and often desperate place wanting the impossible so badly that while we believe it is our rightful destiny and act as accomplices of the real, we also know in our heart of hearts that the way we picture and talk is bound to a dense set of representational gimmicks which, to coin a phrase, have but an arbitrary relation to the slippery referent easing its way out of graspable sight (I993: xvii).

As in camp, the anthropologist's statement that what is presented as 'natural' is in fact a social construct does not temper his desire for exactly this 'natural' that has been dismissed as fake. And again, it is the body that is made to speak to this desire for a reunion with nature. My earlier chapter on 'immersion' offered many examples. Recall my own craving to be like that fat man watching a concert on the Terreiro de Jesus, stuffing his mouth with greasy bean fritters, yet totally at home in his obese body. Recall the Modernists' desire to cannibalize, rather than understand, the 'other'. Recall the yearning for the maximum consumption of the local, for having a 'taste of blood', for 'throwing oneself headlong in the pleasure of having a body', for giving in to the erotics of the place. These desirous undercurrents in fieldwork practices are inextricably linked to our continuous 'yearning for the true real' (and to an awareness that our bodies might produce that real). Intriguingly, this desire seems to have had its repercussions in theorizing as well: more particularly in the theoretical moves towards the body and towards the Lacanian notion of the Real.

\section{韵}

Over the last decades, anthropologists - and more broadly, social scientists - have worked hard to undo the Cartesian split; to point out the sensual, carnal, visceral and bodily underpinnings of culture; to discuss affectivities, emotions and passions; to move from a study of ideas to a study of practices and embodied performances. The allegorical structure underlying the anthropological imagination casts this massive interest in the body and the senses in a new light. Could it be that this interest signals a slumbering discontent with the constructivist assignment to reveal the artifice of other people's realities?

At first sight this seems not to be the case. Much work on the body and the senses remains within the constructivist paradigm. As stated, discussions of the habitus by Marcel Mauss (I973), Pierre Bourdieu (I990) and their followers have sought to reveal the workings of culture in the 'numb imperatives' that make our bodies walk, sit, eat and sleep in a certain 
way, highlighting that culture manifests itself pre-reflexively, as a 'second nature' (Bourdieu I990: 68). Here, the body is fully 'colonized' by the text, subjected to the powers of reason, conquered for intellectual extraction. I wonder, however, whether the manifest project of the anthropologist to show the all-pervading presence of the work of culture is not also the (more or less) unstated project of bringing 'nature' and 'essence' back into academic world depictions through textual evocations of the flesh.

To speak for myself: as may be deduced from the previous chapters, I find myself driven by an irresistible urge to 'soil' the conventions of academic text-making with such primordial matter as flesh, muscles, body fluids, excrement and body heat, and such carnal activities as sex and eating. Mlle F. keeps me from 'making a total fool of myself' (as she puts it), but she cannot keep me from being aware what these references to the flesh are supposed to accomplish in my text: they are to bring High Theory down by making it 'carnal', or more positively phrased: they animate High Theory by making it 'carnal'. The writing of Michael Taussig, discussing the knowledge that is vomit and diarrhea in drug-induced shamanistic rituals in the Colombian jungle - 'a night-long Dada-like pandemonium of the senses' - offers another example of this trend.

In the excretions are visions. The stream of vomit, I had been often told, can become a snake or even a torrent of snakes, moving out from and back into you. In the streaming nasal mucus, in the shitting, in the vomiting, in the laughter as in the tears, there lies a sorcery-centered religious mythology as lived experience, quite opposed to the awesome authority of Christianity in its dominant mode as a state religion of submission. In [...] yagé [the name of the drug taken] nights, there is no way by which shit and holiness can be separated, just as there is no way of separating the whirling confusion of the prolonged nausea from the bawdy jokes and teasing elbowing for room in the yagé song's irresistible current, with neither end nor beginning nor climactical catharses but just bits and pieces in a mosaic of interruptedness (Taussig I986: 4I2).

Here, the body is no longer fully 'colonized' by the text. In this writing, the body of the reader is mobilized to resist the text. Or to be more precise: the nausea that comes up when the reader tries to imagine what yagé nights must be like, is invited to obstruct the allegorist's attempt to invest bodies with the privileged meaning of theory. Apparently, a triumphant deconstructivism ('the body is culture') fuels the desire to arrive at some phenomenological/ontological ground in which to anchor our stories of constructedness ('the body cannot be reduced to culture'). 
Once it is recognized what these evocations of the carnal and the visceral do in a text, anthropological discussions of the body reveal an intriguing double move: they convincingly argue that (for example) 'excrement is culturally constructed' and rejoice in the knowledge that there is an 'indelible residue of nonsense' in such a statement (Eagleton 2009: I44). Yes, menstrual blood is an 'overdetermined primordial symbol' (and one only needs to read Begoña Aretxaga's work on 'The Dirty Protest' (I995) in Northern Ireland to understand what the exploration of such an understanding holds in store for the cultural analyst). And yet, menstrual blood can never be reduced to such explanations, however sophisticated they may be. When confronted with the material presence of menstrual blood (says Victor, who of late is cleaning houses in Amsterdam), one backs off in disgust, one's discursive 'understanding' rendered impotent and defaced as utterly lacking. As Julia Kristeva put it succinctly in her essay on the abject: the repugnant skin that covers a glass of hot milk 'draws me towards the place where meaning collapses' (Kristeva I980: 2).

\section{轃}

This (fantasmatic) quest for a solid ground on which to erect our stories of constructedness might also explain the increasing interest in anthropology for the Lacanian philosophy of scholars such as Julia Kristeva (I982), Slavoj Žižek (I989; I997; I999), Yannis Stavrakakis (I999), Alain Badiou (2005; 2003b), Terry Eagleton (2009) and other thinkers who promise, in true baroque fashion, that there is such a thing as an essential, ultimate real, even if this real resides in an inaccessible 'beyond'. The Lacanian Real is located beyond the orders of language and the symbolic, and can only be conceptualized as a radical negativity; it is the-rest-of-what-is, a dimension of being that can never be grasped in positive form and can only be detected in the way it acts 'as a drag' on our discourses (Eagleton 2009: I44), prohibiting symbolic closure within the realm of the known, blocking all attempts to produce a convincing, totalizing metaphysical account on the state of things in the world. Yet as we have seen in the previous chapters, this Real that is the-rest-of-what-is also contains the promise of change, energy, revitalization and renewal.

There is an intriguing, unstated (not to say: explicitly disavowed) religiosity to much of this thinking. For what other than a miracle is that intriguing and much discussed phenomenon that Jacques Lacan labeled as object petit $a$, an ostentatiously unpoetic algebraic sign which refers to the manifestation of something that is hors discourse and signals the inher- 
ent failure of all signification; a 'blockage' in meaning production that reveals 'all symbolic truth to be not-all' (Stavrakakis I999: 68); or in yet another phrasing, 'an internally shown exteriority surfacing at the intersection of symbolization with whatever exceeds its grasp' (ibid.). Is not the much discussed 'surplus of meaning' that is the Real a secular rephrasing of the 'wholly Other' (Otto 1958)? A theologia negativa that purports that the divine can only be understood in terms of what it is not? Or the unanswerable God in that famous statement in which theologian Karl Barth sought to differentiate the human affair called 'religion' from the absent truth that is God: 'For Man, God is always on yonder side, always new, far, strange, sovereign, never within reach, never in his possession: saying God means saying miracle'? (Barth 2008: 95) And is not Julia Kristeva's (I982) understanding of the 'abject' (the skin that develops on a glass of hot milk, excrement, menstrual blood) as an intrusion of the Real in the cultural order - forcing us to reject its presence, and in that very act, constituting ourselves as cultural beings - not exactly how Mary Douglas (2002), Edmund Leach (1986) and other anthropologists from the British structuralist school came to understand the sacredness of 'anomalous beings' pangolins, hermaphrodites, otters and other beings whose mere existence on the face of the earth flout the cultural/classificatory orders through which man reckons himself able to make sense of the universe, and who, for that very reason, are both sacred and polluting, hedged with taboos as well as the object of veneration?

The resonance of these Lacanian thinkers among anthropologists who are unsatisfied with making the deconstructive move over and over again is not all that surprising. All these philosophers have been pointing out that cultural orders cannot be totalized, and thus confirm the anthropologist's suspicion towards the 'natural'. Where they move ahead, however, is in stating that the failure of culture is itself an essential truth - or rather: The Essential Truth, which cannot be deconstructed. In their recognition of the-rest-of-what-is in both its dimensions of ultimate failure and ultimate truth, these thinkers meet up with the spirit of the baroque, which links the presence of an all-transcending power in yonder realms to the promise that symbolic closure might come about.

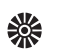

Having traced the allegorical imagination in the life worlds of gay subcultures and some of the more interpretative, reflexive currents in anthropology I will now curve my way back to Bahia and ask what life conditions 
and life experiences relevant to the Bahian setting caused this particular representational form to flourish?

The historical reasons for the widespread presence of baroque forms in Bahia have been discussed in the introduction to this book and need not be repeated here. Here I would want to move an understanding of the continuous prevalence of baroque forms in Bahian world-making in a somewhat different direction. What the previous discussion on allegory has shown is that, although the coming about of allegory needs an allegorist, its persuasive power lies in the fact that sometimes the world itself acts as such. Baroque forms such as allegory, says Michel de Certeau (2000), speak to the experiences of people in tumultuous times and places. They flourish in worlds where major revisions on man and the world are in the making; where people find themselves caught betwixt and between irreconcilable paradigms and enmeshed in violent social and political upheaval; in worlds characterized by shifting borders, the constant displacement of peoples, and a proliferation of syncretist forms. Considering Bahia, and the specific circumstances of life that make people receptive for allegorical renditions of the world, one immediately thinks of Bahia's immense slave population, subjugated to extreme powerlessness, and condemned to a life of gruesome, radical ruptures - spine-chillingly described in the work of Mary J. Karasch's Slave Life in Rio de Janeiro, I808-I840 (I987) and other historians, and punching your stomach when you alert yourself to the reality traces of igth-century photographs of slave markets (Ermakoff 2004). Roger Bastide summarized the conditions underlying the life experiences of slaves as follows:

The black was forcibly uprooted from his land, shipped to a new habitat, integrated into a society that was not his own, in which he had found himself in a subordinate economic and social position. Slavery had shattered his African tribal or village community and its political organization, and it destroyed the forms of family life, leaving nothing of the original social structures intact. He entered a new system of stratification in which the white man occupied the summit, the free mestiço or the caboclo the intermediate level, leaving to him the lowest position of all, that of the slave (Bastide I978: 43).

One can see why an aesthetics that rejects the possibility of harmony in a man-made world, and seeks redemption in an inaccessible beyond, must have had its appeal in a slave society such as Bahia. ${ }^{62}$

Yet one might also think of the tribulations that befell the Bahian population as a whole: the ubiquitousness of sudden and premature death in 
colonial society due to natural catastrophes, epidemics, or sudden eruptions of violence: events that ravaged whole communities and left deep cleavages in people's life histories and trajectories. Traumatic experiences and life-disrupting calamities and catastrophes feed the spirit of baroque, reinforce its impulses, animate its forms of world-making, lend credibility to its readings of the human condition. Indeed, there is an unmistakable correspondence between discussions on calamities, the traumas they provoke and the present discussion of allegorical world-making. Calamity has once been described as 'the unmistakable reminder that the affairs of this life are not of our own ordering' (Ambrose Bierce, in Stavrakakis I999: 68). In a similar vein, many authors have argued that at the heart of trauma lies the realization that the social, moral and cultural orders that had always been taken for granted were in fact founded on make-believe. War, violence, epidemics, earthquakes and other trauma inducing events and occurrences cause 'the breakdown of the fabric of consensual reality [and the] coherence of everyday life' (Kirmayer I996: I82); 'the shattering of a victim's fundamental assumptions ... the core of [his] conceptual system' (Janoff-Bulman I992: 53); 'the massive disintegration of the individual's symbolic world' (ibid.: 63); and 'the loss of the basis that enabled victims to oversee and predict events and happenings in their life world' (Herman 1997). This loss of a stable 'world reading' in trauma, the sudden revelation that the world is not the place one had always thought it to be, strongly resonates with the baroque insistence on the absence of inherent meaning in man-made worlds.

The news of Lobinho's brutal death brought this insight home to me most forcefully. The news reached me when I was in the Netherlands, but a visit to Bahia soon afterwards taught me that nothing was the same. All that had been lovable and enjoyable about Bahia now seemed monstrous. Where I had seen picturesque streets I now saw cockroaches the size of rats. Where I had courted seductive men sporting gangster looks I now backed off in fear. Where I had appreciated looseness and spontaneity I was now disgusted by the excess, the lack of control and restraint. Same streets, same men, same dances. I was experiencing a typical baroque metamorphosis of a wet dream revealing itself to be a nightmare, paradise revealing itself to be hell. Nothing had changed. But with Death in the role of allegorist it was all different now.

Alongside its capacity to express and resonate with the rifts and cleavages that life brings forth in turbulent times and places, the baroque speaks to a worldview in which people are subjected to powers beyond their grasp. Thinking of the Menino Jesus no Monte, I restate that alle- 
gorical worlds instruct people to accept the world's mysteries for what they are, to resign themselves to their fate, to 'take things as they come', to submit themselves to authority without further questions. Faith - the 'desperate faith' of expecting a redemptive miracle (Cowan I98I) - is what it proposes as the adequate mind-set to face the tribulations of the world. Not 'agency', or willpower, or a drive towards inquiry. Allegory belongs to the world of the absolutist rule of emperors and kings; to the world of that proverbial priest who comforts the mourning mother with proverbial wisdoms such as inscrutable are the ways of the Lord and unfathomable for the mind of man are the mysteries of His Providence'. It belongs to the rigorously hierarchical world of Candomblé, where one is instructed 'not to ask questions' but simply to perform the traditions, so as to provoke the possibility to let oneself be written by the world. It flourishes in the life worlds of those subjected to these powers: the slave quarters, where not all people were like the heroic runaway slave Zumbi of Palmares; it speaks to the liberated slave population of the post-abolition era; and the subsequent generations that lived, and continue to live, the endless humiliations and indignities of being poor and powerless: of being present in, but not living, the reality of a modern consumer society, with all its manufactured dreams and desires. The people who are learning, every day, the deceitfulness of a world that, through its media of mass communication, broadcasts the neoliberal dream that all that it takes to 'make it' is willpower, when in fact 'making it' - or not making it - depends on having been born in one bed and not another, on thus having the right contacts, on being integrated into clientelistic networks. 'Desperate faith' is indeed an adequate disposition to face the world when you are black, poor and without proper contacts in Bahia. Here, Eliana's estimation of the maneuvering space she has to advance in life is emblematic: 'Praying is the only option I have.'

\section{嚕}

And yet, no religion can survive on the mere reassurance of its priests that 'somewhere out there' it all makes sense. People need signs of that absent truth that runs their lives: signs of its existence and reality.

'If only I had been possessed once,' Victor told me repeatedly. 'Just once. Then I could be sure that all of what people say about orixás and everything else truly exists.'

And this is indeed what we have seen, and will see in the chapters to come: worlds susceptible to the expressive forms of allegory develop a 
craving for encounters with that absent truth. What is more, they have developed a whole repertory of 'techniques' and 'practices' to invoke signs of that absent truth, or even to provoke the coming of a 'fulfilling event' that might bring coherence to allegorical worlds. Indeed, some authors have argued that allegory's highlighting of an absent truth that might bring order to the world only serves to make that truth ever more precious and dear, and spurs people on to invoke its signs with a greater urgency and a desperate faith. That igth-century scene discussed in chapter two, where we encountered a mass of Bahians running in joyful procession behind the propped-up cadaver of an infant in the sweet expectation that this 'little angel' might contact that distant God on their behalf is emblematic in this respect. The scores of miracle workers, prophets, visionaries, spirit mediums, clairvoyants and diviners from Brazilian religions - and their apparent appeal - are another example. ${ }^{63}$ And so is that continuous drive towards immersive forms of being, provocations of the kind encountered on Avenida Oceânica, where for a moment all was being 'said' in the ecstasy of a carnival crowd. 'Experiencing transcendence in immanence', is how Vivian Sobchack describes this human capacity to produce bodily experiences that lend themselves to be interpreted (or rather: experienced) as encounters with the divine (Sobchack 2004: 197). ${ }^{64}$

This desire to be fulfilled by the forces of a beyond, then, is exactly the point where allegorical and symbolic modes of representation cease to be opposites, but meet and reveal their dialectical relationship: allegorical worlds, I would argue, give birth to the dream of symbolic closure. They mobilize people's desire to bring about this closure, to immerse themselves, to become possessed, to step out on the dance floor and consume the dance, to transcend oppositions and become part of the Geléia Geral, to baffle themselves with miraculous occurrences. It is in the interplay between allegorical world-making and the desire to mend the holes in the fabric of meaning that miracles do their work; that prophets find an audience; and that anthropologists find themselves driven towards immersion.

These ideas on the interplay between allegory and desire set the tone for the chapters to come. In the following chapter, I will point out how the allegorical imagination (in)forms the responses of the Candomble community to the hyperproliferation of images of and narratives about their creed in the public sphere. The title 'bafflement politics' refers to the way in which cult houses publicly stage miraculous events and mysteries, so as to evoke that 'all-transcending beyond' and thus authenticate their voice as the true voice of Candomblé. 


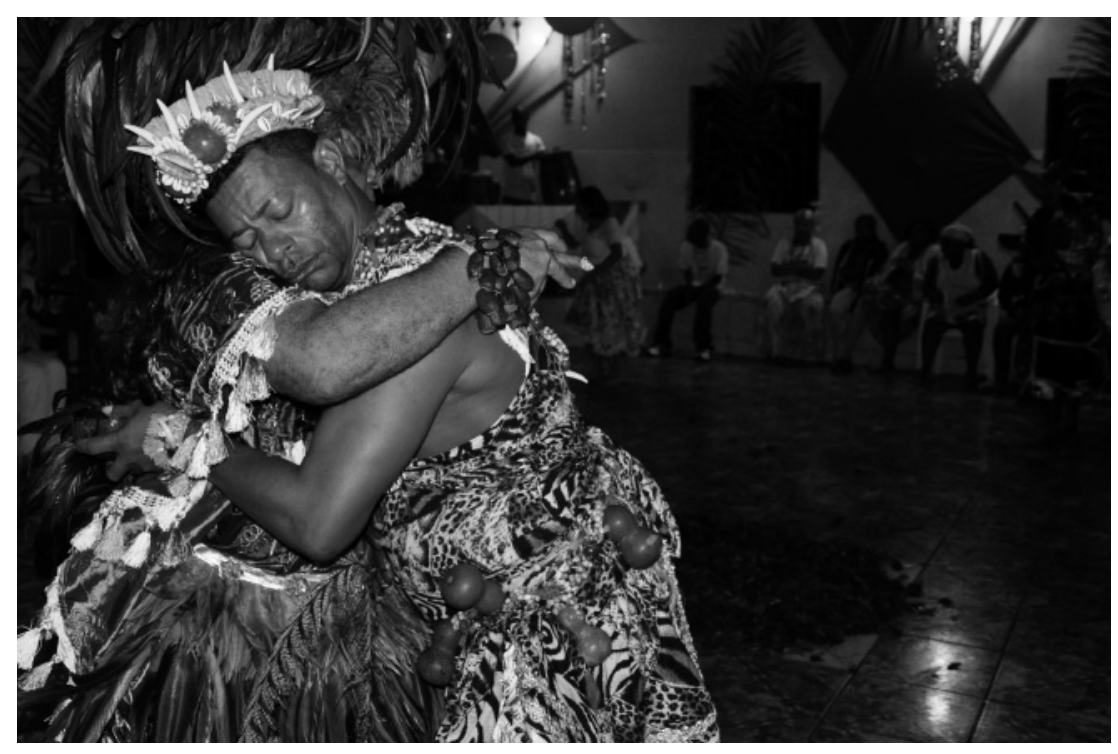

Figure 18 Ceremony of the caboclo-spirits, 2009

Photographer Koštana Banovid 


\section{6 \\ BAFFLEMENT POLITICS \\ Possessions, apparitions and the really real of Candomblé's miracle productions}

I was giving a visiting colleague a tour of Salvador, and the ogã must have seen us coming, climbing the many steps leading to Casa Branca, one of the oldest and most reputed terreiros of Salvador. Undoubtedly, he had assumed that we were just another couple of curious tourists. We started chatting.

'Oh yes,' he said. 'There are a lot of tourists that visit here and they always ask a lot of questions. They always want to know about possession. Whether it is for real, and stuff like that.'

My colleague, missing out on what I took to be a veiled instruction not to ask questions about the cult, asked if it had happened that tourists would fall in trance during the ceremonies. He nodded.

'Sure, it happens that tourists fall in trance. Every once in a while it happens. At one time, we even had visiting nuns falling in trance!'

The ogã seemed quite eager to serve us this little detail. There was pride in his voice, triumph in his laughing eyes when he countered my expression of disbelief.

'Yeah! Nuns! Freiras!' 
The image is, of course, quite commanding. One can almost see it happen: little blond backpacker girls - of the kind that swarm Salvador's historical center by the dozens - being invaded by the African Other they had come to gaze at. Rheumatic and pale nuns' bodies surrendering to the sensual beating of the drums; their wimples and rosaries flapping around in the whirling movement of the dance. Tourist curiosity and catholic propriety being crushed under the sheer force of the spirits.

The ogã's story is instructive as to how people from Candomblé seek to counter the predicament that, in the public sphere of contemporary Salvador, any image of their cult 'can mean absolutely anything else'. It is also an apt illustration as to how the allegorical imagination, discussed in the previous chapter, informs cultists how to go about this challenge.

Clearly, the two categories that were introduced into the ogã's little story - the clueless tourists and the nuns - were not randomly chosen. Both were emblematic figures, 'robbed of their sensuous fullness' and assigned with the single role of representing Candomblés long history of encounters with curious outsiders. In the theater of his mind, the ogã did not, however, allow these nuns and tourists to simply gaze at the spectacle, so as to be able to make up their minds about the dancing bodies and whirling spirits in front of their eyes. He did not want them to take their opinions back into the world, where they would add yet another outsider's impression of Candomblé to yet another round of meaning production. Instead, he summoned a mysterious, formidable force to descend from the skies to bar all further opinionating, end all theorizing, and bring all speculation to a halt. What he wanted us to see was the improbable - not to say miraculous - scenario of nuns and tourists becoming possessed by spirits they did not even believe in.

I would say that this scenario eloquently expresses the way in which the allegorical imagination calls forth the workings of an absent truth that brings the world to order. Central to the ogã's story was the thought that the force at work in the tourist's and nun's bodies manifested itself, regardless of what tourists and nuns tend to believe in, deem real, or credible, or possible. This force, one might say, was real beyond belief. It was true beyond human imaginations of truth and falsehood. Thus, the clueless tourists in his story would probably not have been able to say what had gotten into them when they were seized by unknown forces. Given their experiences, however, they would no longer have to ask the question whether these forces were for real. Just as the nuns, still shaky from their ecstatic dance, would no longer be able to dismiss the reality of possession as a lesser, 'primitive' form of belief or superstition. 
With so many different voices involved in defining Candomblé, many cultists feel pressed to publicly assert their voice as the one and only 'true voice of Candomblé. This chapter will discuss some of the authenticating strategies that I have encountered which aim to achieve that goal. As this discussion implies a move to the Candomble side of the encounters between cultists and curious outsiders, a brief introduction of the Candomblé life world is warranted.

A recent survey showed that there are I,I63 terreiros in the city of Salvador (Santos 2008). These temple compounds are home to the assentos (the objects in which the orixás of the individual community members have been 'seated'), and home to the familia-de-santo, the 'family-of-the-saint', as the religious community of the terreiro is often called (cf. Lima 2003). The task of terreiros is, among other things, to oversee the initiation of spirit mediums and to organize the annual cycle of rituals and festivities in honor of the orixás and other spiritual entities. In addition to such religious tasks, terreiros operate in what Brazilian scholars have aptly called the 'market for salvation': they seek to generate an income by providing spiritual, divinatory, and curative services to a clientele consisting of both cultists and non-cultists. As discussed, their economic activities may also include macumba practices or entertaining tourists. Yet these latter activities will rarely be admitted in public.

Taken together, the terreiros make up a highly heterogeneous field. Cultists recognize the traditions of different nações (nations), such as Nagô-Ketu, Jeje, Angola, Caboclo. Within these traditions, moreover, the autonomy of the individual terreiro is such that considerable variation is found in the religious doctrines and ritual practices of particular houses (Capone 1999; Lima 2003; Parés 2006; Wafer 199I). The autonomy of individual terreiros is further increased by the absence of a central institution with enough power to impose a canon of Candomblé orthodoxy. ${ }^{65}$ The multifariousness of religious practices does not mean, however, that Candomblé is merely an 'umbrella term' that covers a fragmented reality. Cultists retain a strong sense of community, especially now that Candomblé is threatened by the increasingly powerful Pentecostal churches, whose pastors equate Afro-Brazilian religion with demon worship. Another force that seems to work toward homogenization, rather than fragmentation, comes from a relatively small number of terreiros belonging to the NagôKetu tradition. Casa Branca, Gantois and llê Axé Opô Afonjá are terreiros with historical records that go back to the first half of the igth century. 
They have a prestigious clientele of artists, intellectuals, media celebrities and local politicians. In addition, they boast the 'certificates' of purity and authenticity conferred by generations of anthropologists who have studied their rites and beliefs. With all of this symbolic capital these NagôKetu terreiros have managed to acquire so much prestige and status that their particular understanding of the religion of the orixás is highly influential among the more peripheral cult houses in Salvador (and beyond). In the public sphere, Ilê Axé Opô Afonjá is probably most outspoken about the way Candomble ought to be practiced. As will be elaborated in the next chapter, the terreiro has become one of the bulwarks of a so-called 're-Africanization' of Candomblé ${ }^{66}$ since Mãe Stella, the priestess of the house, penned a manifesto in 1984 in which she publicly broke with the syncretism that had long dominated the cult. Many of the more peripheral terreiros try to mimic the rituals, ceremonies and purist aesthetics of the more prestigious cult houses and seek to implement some of their doctrinal rigor and orthodoxy.

In the public sphere one cannot but conclude that the 'old houses' have been quite successful in establishing themselves as the prime authorities on Candomblé, which cannot be bypassed when Candomblé becomes the object of public attention. ${ }^{67}$ When in commemoration of Salvador's 450 th anniversary twelve larger-than-life statues of the orixás where placed in the center of town, the priesthood was consulted at every stage of the project, having a say as to where the statues were to be placed, which orixás were to be represented and what they should look like (Sansi-Roca 2007). The state tourist organization Bahiatursa - as we have seen a bulk consumer of items from the Candomblé symbol bank - seeks to reproduce the orthodox ideological line of llê Axé Opô Afonjá when divulgating information on Bahian Candomblé as the 'true and authentic form' of Afro-Brazilian religion. In an interview, the marketing director of the organization told me that in its flyers, brochures, websites and activities, the organization only wanted to divulgate the 'correct information. 'Our goal is to avoid polemics at all times,' he added. He obtained this 'correct information' through his contacts with Mãe Stella, whom he considered to be 'the most studied of them all (a mais estudiosa de todas) and very enlightened.' Bahiatursa, he continued, was also informed on a correct understanding of religious matters by

... the so-called ogãs and obás, who are very enlightened as well, including people such as [ethnologist] Pierre Verger, [songwriter] Vinícius de Morães, who frequented Mãe Menininha, [singer] Gal Costa, [singer] Maria Bethânia 
... they are all enlightened persons from our Brazilian culture who frequented Candomblé.

The mainstream Bahian press and Bahian television stations also tend to comply with priestly demands - more particular those of llê Axé Opô Afonjá - where it concerns Candomblés public representation. On the whole, journalists pay respect to the 'mysteries' and the prohibition to ask questions about the 'secrets'. They label Candomblé a 'religion' rather than a 'cult', 'sect' or 'tradition' and reproduce the idea that true Candomblé is a purely African formation. More and more, they use Yorubá, rather than Portuguese, terms in reports on Candomblé events and happenings.

Other clear indications of the success of Candomblés public politics are the ubiquitous and prominent presence of Candomblé representatives at ecumenical meetings, mass rallies, demonstrations, political events and other gatherings where a presence of 'all the beliefs of all the Bahian people' is sought. Thus, in 2005, Mãe Nitinha, the priestess of the Casa Branca, was elected by the former Brazilian president Luiz Inácio Lula da Silva to represent Candomble in the country's multireligious delegation that was sent to Rome to attend the funeral of the Pope John Paul in (yet, to the dismay of some, and the amusement of others, the priestess never made it to Rome as she missed the plane). ${ }^{68}$

A last indication of Candomblés increasing say in its public presence that could be mentioned here are successful court cases prohibiting the use of Candomble symbols for carnival parades. In I993, for example, the city had to tear down all the decorations through which it had sought to express that year's carnival theme 'Bahia, land of the orixás' when a court had ruled that this was a profanation of the sacred symbols of Candomblé. The reversal with the situation in Dr Nina's days is remarkable: where he could quote citizens from Salvador demanding a prohibition of the drum bands that paraded the streets at the time of carnival 'for being true Candomblés'; the contemporary situation shows a Candomblé priesthood that prohibits the citizens to dress up in Candomblé attire.

In the light of a long history of persecution and marginalization, these actual political achievements are impressive. However, where it concerns the struggle over the 'true meaning of Candomblé these political gains do not add up to much. Public claims by the priesthood that only they, and they alone, have knowledge of Candomblés true being cannot enforce their truth against other claims - made by anthropologists, black activists, Pentecostal pastors or others - about what Candomblé 'really' is. For the 
priests to authenticate their voice as the true voice of Candomble they need to transcend the realm of discursive meanings.

At the heart of these authenticating strategies is what I call 'a politics of bafflement'. The basic form of these politics has already been shown in the ogãs allegory on nuns and tourists: it is the evocation of an intruding force, an agent from beyond the horizons of what is known - inexplicable as to what it is, yet undeniable as to its powers. This baffling force, I will argue, has become a central reference in the priesthood's attempts to reduce all discursive forms of meaning production in the public sphere to 'mere opinionating. Spirit possession is the most visible and most spectacular instance of this force-from-beyond, and as such the public display of possession in religious ceremonies plays a major role in authenticating the priestly voice in the public arena. Yet I will make clear that this forcefrom-beyond is also invoked in constant references to apparitions, miracles and other mysterious occurrences - events that highlight the infinity of not knowing that is at the base of Candomblés bafflement politics.

\section{鳔}

At Olga de Alaketu's terreiro Otávio was caught by his orixá. He started jumping on his feet. He leant over to one side, then to the other. He rolled his eyeballs. And then Otávio was gone. The chubby cherubim-like adolescent, with his acne, his straightened black hair and his best shirt from the Sarttore collection had metamorphosed into lansá, the warrior goddess, who announced her arrival with a loud, grunting howl.

Let us not be baffled right away: this possession had been kind of expected. In the car, on our way to the terreiro, Otávio had already told us he had taken a bath, to clean himself of the couple of beers he had taken earlier in the day.

'With beer in my body, the orixá won't come', he explained.

And when we arrived at the terreiro he had said that the coming of lansá was certain for his body was restless.

'It is as if waves of heat and cold go through my body.'

The eyes of his boyfriend Jorge - a silent kid with the fluffy beginning of a moustache who followed Otávio like a shadow - shone with excitement. Victor responded by saying that it would be a good thing if he became possessed, because that was the kind of stuff I was interested in. Coming from Victor's mouth, the remark sounded like a command.

Entering the terreiro, Otávio told me he was nervous.

'I feel like I need to pee all the time!' 
The possession came early in the evening. The xiré, the opening dance sequence, had only just begun when lansá arrived. With tender care, Jorge took off Otávio's sneakers and rolled up the legs of his trousers, after which the ogã of the terreiro came to take Otávio/lansá to the room behind the ceremonial hall. When after some ten minutes Otávio returned, the expression on his face was both apologetic and proud. He took my hand to let me feel his. It felt cold.

'See? It feels cold!'

I remember that I made a mental note saying: 'See? Always the body that is to prove the truth of the matter ...!' And indeed, when a handsome young man standing close to us became possessed by Xangô and turned up his eyeballs, Otávio hissed at me not to miss out on the really real: 'Look at his eyes! Look at his eyes!'

Doubt about the authenticity of a possession is always present at celebrations and ceremonies (cf. Birman I995). It always struck me that people were quite eager to point out the possibility of fake and trickery. Later, in an interview, Otávio told me that 'there are people who fake being possessed by the orixá.' When I asked him why they would want to do so, he answered

\begin{abstract}
Because they think it is pretty when another person manifests the spirit. So when they don't receive the spirit, when they don't have that gift, that mediumship, they fake being possessed. And then there are people who go to the ceremonies of the caboclos and the exús [spirits that are offered large quantities of alcoholic drinks], and they only fake possession so that they'll be offered beer, or champagne, or wine. But they are not possessed. Not the slightest bit. They are faking it ...!
\end{abstract}

However, it is only the authenticity of the particular instance of possession that is questioned - the little biba who was visibly too eager to show his dancing skills, the lady who might have simply fainted because of the heat - not the possibility of the phenomenon as such. And you can therefore never be sure. I always felt that such emphatic hints that possessions might be faked only served to introduce a general confusion over the phenomenon, the creation of what Michael Taussig called an 'epistemic murk' (I986: I2I) which questions the absoluteness of the boundaries between the certain and the uncertain, the believable and the unbelievable, and that thus creates a domain of 'chance and perhapsness', 'contradiction and ambiguity' (ibid.: 465) in which improbable and strange phenomena may occur. 
And strange and improbable phenomena do occur. As stated in the introduction of this book, I never stopped being puzzled over the phenomenon of spirit possession. In the course of my research I have witnessed many instances of possession, and although the sheer repetition did make the phenomenon more familiar, I could never escape from that very basic sentiment of being baffled.

I am certainly not the only anthropologist to have observed that no matter how spirit possession is tackled theoretically, its most immediate experience escapes our understanding. Janice Boddy (I994), Paul Stoller (1989; 1995), Michael Taussig (I986), to name but a few authors, have all remarked that whereas the Otherness of possession (its uncanny inexplicability, its screaming incompatibility with Western notions of personhood, its seemingly disdain for self-control, its radical otherness) demands explanation, this explanation highlights the inadequacy of our conceptual categories, rather than the phenomenon itself (Boddy I994: 40I).

This is not to say that there is a lack of imaginative approaches to possession. To the contrary. In anthropological literature, the phenomenon has been cleverly linked with the battle of the sexes, as women - whose predominance as mediums has universally been noticed - can have their fleeting moments of prestige when possessed by a spirit (Boddy I989). It has been described as a catharsis that works on deep-seated psychic conflicts and may bring about healing (Obeyesekere 198I). It has been explained in terms of neurobiology, where 'the impact of patterned, repetitive acts on the human nervous system' are said to produce trance-like states (Lex I979). It has been read as a 'text' inscribed in the body in which new meanings are produced and the sediments of history are articulated (Taussig I986). It has been appreciated as a kind of Surrealist performance, in which reality is attacked and the inadequacies of the world are addressed (Stoller 1995). And recently, a colleague of mine proposed that we should probably stop thinking about possession as something radically other, as we all might well be living in a state of enduring, serial possession. Could there be any other way of being, he asked, now that we have learned that identification is all that we have in that impossible project of coming to a sense of self?

Thought-provoking comments. And yet, no matter how clever our attempts to break the mystery through explanation, something about possession remains enigmatic, unapproachable, resisting the word, refusing to be signified, displaying the failure of representation. When faced with people falling into trance, thoughts like 'oh well, aren't we all possessed' are not likely to cross one's mind. One is simply flabbergasted, not 
knowing what to think about the occurrence that is happening before one's eyes. Even Ruth Landes, who in her early study on Bahian Candomblé comes across as a stout and stalwart character, admitted that she felt 'keyed up and restless' when the drumming reached a peak during one of the first trance inducing ceremonies she witnessed (Landes I947: 50).

\section{衡}

It can be argued that in many ways possession trance is as mysterious a phenomenon for the Candomblé community as it is for anthropologists and other baffled outsiders. There are important differences to be noted, of course. I have already pointed out that the idea of spirits taking possession of a human body is widely accepted in a society in which immersion is the preferred mode of relationality. Spirit possession is a common occurrence, not only in Candomblé, but in many other religious denominations as well. Moreover, Candomblé myths explain the raison d'être of the phenomenon. One of those myths, recounted by Reginaldo Prandi in his widely read Mítologia dos Orixás (Prandi 200I), states that in the beginning of times there was no separation between the orum (as the heavenly realm of the orixás is called in Candomblé), and the aî (the earth, habitat of human beings). Men and orixás moved back and forth between heaven and earth, mingled freely, and shared their lives and adventures. It was only when a human being soiled the immaculate purity of the heavens that Olorum, the supreme Deity, was angered and decided to separate heaven and earth. After complaints from the orixás, who missed their sojourns among the humans beings, Olorum decided that the orixás were allowed to return to the earth every once in a while, on condition that while being on earth they would take the material body of their devotees.

Now the orixás had their horses,

They safely could return to the aiê

Mounting the bodies of the devotees.

The human beings made their offerings to the orixás

Inviting them to Earth, to the bodies of the iaôs

And so the orixás, they came and took their horses.

And while the human beings played their drums,

Ringing their batás and agogôs,

Roaring the xequerês and adjás

And while the human beings sang

And shouted hoorays and applauded, 
Inviting all the initiates into the circle of the xirê

The orixás danced and danced and danced

The orixás could live with the mortals again

The orixás were happy

In the circle of the initiates, in the bodies of the iaôs

They danced, danced, danced.

Candomblé had come into being (Prandi 200I: 527)

Priestly discourses also provide explicatory frames for possession: the phenomenon is presented as 'the most intimate experience of the mutual bond between spirits and their mediums' (Berkenbrock 1999: 197) or as a type of reciprocal exchange between orixá and devotee: the devotee worships his or her orixá by observing the taboos, participating in the rituals, sacrifices, and celebrations, and in doing so gains access to divine protection and axé, the life force that realizes growth and prosperity. Within this scheme of offering and receiving, possession entails a veritable booster of axé, not only for the receiving medium, but also for the Candomblé community at large (Santos 1998: 39-40).

And yet, one must observe that whereas the phenomenon itself is embedded in explanatory frames, people from Candomblé tend to accept the mystery as to what exactly happens for what it is: a reality locked up in the here and now of bodily experience, refusing any further signification or abstraction. A Candomblé priestess told anthropologist Luis Nicolau Parés:

No one can ever really talk with certainty about the mysteries. The mysteries are the mysteries. The secrets are the secrets, and no one will ever know anything. Those who study, those who come to observe, they are observing, but they don't know the deep knowledge. For one says one thing, and another says another thing, and so they only leave one confused. I always leave the researchers em balanço (dangling) ... (Parés I997: 2).

These words - contrasting an impenetrable 'mystery' with the 'confusion' of the researcher's sayings and the 'labyrinth' of the human mind - are already suggestive of the argument I want to make about possession as an instance of bafflement politics: statements as to what constitutes the essence of Candomblé can no longer hide their historicity, and ever more clearly reveal the particular interests they serve, all truths proclaimed about the cult take on the aspect of 'mere opinions'. In such a world, phenomena that make no sense within our interpretative frameworks - that 
leave us dumbstruck and without words - become increasingly attractive. The thinking of the French philosopher Alain Badiou (2005; 2003b) helps to explain why this is the case.

Badiou's philosophy is a search for a notion of truth that is universal, rather than particular; essential rather than communitarian and historical. He states that for a truth to be universal it must be 'eventual': it cannot be found in (nor founded on) the realm of the known, the realm of ideologies, received wisdoms, beliefs that where passed down the generations, opinions and opinionating. As stated in the introduction, Badiou maintains that "knowledge as such only gives us repetition, it is concerned only with what already is'. For truth to acquire a foundational quality it needs to be grounded in a realm 'beyond what is', and hence comes to depend on an eventful supplement that interrupts repetition (Badiou 2003a). Thus, in his famous tract on the radical conversion of Saint Paul from Persecutor of Christians to Apostle of Christianity, Badiou points out that Paul had not been won over by representatives of the Church or presented with the Gospel. His conversion began with a mysterious voice that spoke to him when he was traveling to Damascus. This voice came out of the blue, out of nowhere: it was neither solicited nor expected. "It happened", purely and simply, in the anonymity of a road' (Badiou 2003b: 7). A miraculous event like this, says Badiou, is '... of the order of what occurs, it is singular. It is neither structural, nor axiomatic, nor legal. No available generality can account for it, nor structure the subject who claims to follow in its wake ...' (Badiou 2003a: I4). In other words, because of the radical otherness of this miraculous event, its truth pertained to no one, it did not reflect (and was thus not 'tainted' by) particular agendas, particular desires, particular needs.

No preconstituted subset can support it; nothing communitarian or historically established can lend its substance to the process of truth. Truth is diagonal relative to every communitarian subset; it neither claims authority from, nor (this is obviously the most delicate point) constitutes any identity (Badiou 2003a: I4).

Paul's conversion to 'the universal truth of Christianity' thus entailed the 'declaration' of this miraculous event (the recognition that it happened) and his remaining faithful to this event (allowing it to reorganize his universe).

Many stories as to how people entered the initiation process follow the exact same pattern sketched by Badiou in his discussion of Saint Paul: it 
concerns a decision to make an inexplicable and incalculable 'event' axiomatic in a new vision of the world. Thus, initiation into the cult very often follows after a series of inexplicable bodily experiences. Most of the time these are fainting spells or 'absences' (ausências), but they might also be depressions and illnesses that cannot be readily diagnosed. When a medical doctor or psychiatrist cannot help to solve the problem, a Bahian will sooner or later consider the possibility that the affliction is in fact $o$ chamado do santo (the calling of the saint). ${ }^{69}$ All the more so when such unsolicited bodily experiences occur in a temple during a ceremony. Initiation is the recognition and declaration of the Event. As Roger Bastide explained, initiation frees the non-initiated persons of the violent and disrupting intrusions of santos brutos (undomesticated spirits) and gradually develops an orderly relation between the medium and his or her orixá (Bastide I96r: I89).

Linking the initial fainting spells to the calling of the orixá is of course an explanatory act: it is to draw the inexplicable into the known world by naming a cause. Yet what struck me during interviews was that the inexplicable was always underlined and held out to me as the principle ingredient of the narrative. Rather than saying 'I started to have fainting spells' people would say 'there was nothing wrong with me, and all of a sudden I started to have these fainting spells.' Or: 'I was not really into Candomblé, but the orixá took me anyway.' It was as if through such phrasings, people from Candomble sought to make the inexplicable and unsolicited nature of the forces that had seized them even more poignant, so as to ground the truth of the orixá's intervention in their lives beyond all human scheming and calculation, beyond all willing and desire. In other words, the incalculability and inexplicability of the Event authenticated the divine agency behind their initiation. The case of Walmir is the best example I have of this logic.

\section{嚕}

Someone had told me I had to talk with Walmir, because 'Walmir too was from Candomblé. I happened to know Walmir. A man somewhere in his forties, friendly eyes behind glasses, slightly bald. Not someone you would immediately think of as a cultist: a white Brazilian (whatever that means) from the neighboring state of Sergipe, a university-trained journalist, writer of poetry and self-declared romantic. Yet I was made to understand that looks and background were not relevant here. Walmir was the man to talk to. 'Haven't you interviewed him yet?', people kept asking me. 
When we met he told me that his story was going to be 'kind of weird'. He had been with a couple of friends. It was on a beach in Alagoas. They had encountered a flying saucer. Not just once, but various times.

I recall how Walmir looked at me at this point, assessing the impact of his words, probably seeing an expression of disbelief on my face. Yes. A flying saucer. Disco voador.

The information he had just given me was indeed hard to process. I had assumed that the story about his explorations of Candomblé would have been yet another story about a quest for the spiritual, guided by the enchantment of the drumming and the songs, the beauty of rituals, the strong sense of community in Candomblé, the sex appeal of Afro-Brazilians. And in fact, as the interview proceeded, these elements were all part of the narrative: Walmir told me about the distant drumming he used to hear during his childhood, about his early flirtations with Zen Buddhism, about the wink of recognition he had found in the counterculture of the Tropicália movement, where the lyrical beauty of Candomblé had been voiced so splendidly by singers such as Caetano Veloso, Gilberto Gil and Maria Bethânia. He talked about his black lovers, first an alabé (drummer from Candomblé) who had introduced him to temple life, then a pai-desanto.

'I love the sense of humor in Candomblé,' he said. 'The laughter!'

After initiation he became possessed by different spirits, exús, caboclos, padilhas. The possessions that came were frequent, and sometimes lasted for days on end. They were tiring him out, he said, especially the exús, who would possess him at home. Later he received his orixá, a much more powerful experience.

'O yeah? What was it like?', I hear myself asking him on the tape. I sound terribly stupid, interrupting a story that had already moved beyond a regular interview, Walmir's soft voice adding a subtle aura of importance and consequence to his words.

'It was beautiful', he answered. 'Muito bonito.'

Eventually he had opted out, given up on the idea of having himself initiated and becoming a pai-de-santo. He told me he could not stand the animal sacrifices. He hated the endless preoccupation of the cultists with money. And the thought of bearing the responsibility for a following of initiates was simply too frightening.

But all of it had started with the flying saucers.

'You know, I really did not have any particular interest in science fiction or UFo's or what have you. But I saw flying saucers anyway. And it wasn't just me. My friends saw them as well.' 
He explained that after his encounter with the flying saucers it was not difficult to believe. Anything. Whatever. The experience had been 'fundamental'. It had broken open all assumptions as to what is and what is not believable. It was 'beyond words'. It could 'not be communicated'. But even that did not matter. Just thinking about the encounter made him happy. With closed eyes and a blissful smile he murmured 'plenitude, plenitude'. Such fullness.

Walmir's case has had a deep impact on my understanding of bafflement politics, undoubtedly because of the many incongruities that were part of his story. There was the irony that this self-declared 'romantic soul' had his revelation not through the agency of a befittingly exotic spirit - a sultão-da-mata (sultan-of-the-woods), cigano (gypsy), mermaid, or other colorful exotic entity from the Candomblé pantheon - but by a flying saucer, a high-tech device with flashing lights and bleeping sounds (at least, that is how I imagined it: for fear of breaking the magic of his tale I never asked what the flying saucer had looked like). There was the hesitance with which Walmir - a journalist, an academic, a man of facts - started his story, his visible embarrassment about having to bring up something as outrageous as a flying saucer in his narrative. And then, there was the absolute absence of hoo-hah when he recounted the event: there was only a simple, plain report on what had happened on that beach in Alagoas. All of this underscored the logic of the truth event: an unsolicited and out-ofthe-ordinary event occurs - 'too weird to be true' - and yet, the sheer factuality of its occurrence, the undeniable reality of its having taken place, forces one to reconsider all definitions of the possible and the impossible. It was thus that Walmir's capacity to believe was expanded: it was thus that he was made to accept the presence of an absent truth that brings the world to order.

\section{讙}

The case of Luis - a thirty-five-year-old sales representative - is in many ways similar to Walmir's story in that his story also concerns an attempt to ground his beliefs beyond available frameworks of interpretation, in incalculable events and spontaneous, unpremeditated occurrences. Where it differs is that Luis was quite obviously looking for the miracle, hoping to encounter it, rather than simply being confronted with it. In other words, he seemed - paradoxically - to be designing his truth event.

I met Luis in a shop that sells religious articles, where he was buying some herbs and minerals for a ritual bath he was about to take. We entered 
into a conversation, and he started to talk about his recent experiences with a spirit that kept possessing him. He pointed out a big tattoo on his arm, a portrait of a Cheyenne Indian with waving black hair. He told me that the prime reason for choosing this particular tattoo was the fact that the black hair had served the purpose of covering up an earlier tattoo that he did not like anymore. Two weeks later, however, he had become possessed by a Cheyenne Indian. This was indeed a strange occurrence. Indian caboclo-spirits are well-known entities in Candomblé cosmology, but as far as I know, North American Plain Indians descending from the skies have not yet been reported. His mãe-de-santo, however, insisted that this was the spirit who was taking possession of his body. He told me that ever since, he had been surfing the Internet to find all kinds of information about Cheyenne Indians.

Weeks later he called me from his mobile phone. He was somewhere on the highway to the neighboring state of Sergipe, and told me, quite excited, that while making a sanitary stop he had found 'a strange bone' that might well have been from an Indian. Thinking that anthropologists know about bones and Indians, he wanted my opinion on his finding clearly hoping that this bone might be interpreted as a sign of the authenticity of his possessions by the Indian spirit.

Unmistakably, Luis sought to underline the unsolicited and incalculable nature of the occurrence of his Cheyenne Indian spirit by stressing that the choice for the Indian tattoo was motivated by no other reason than the practical consideration that an earlier tattoo had to be covered up. Just as Walmir had had no previous interest in UFo's, Luis was no particular fan of Hollywood Westerns: his interest in the Cheyenne Indian had been 'purely pragmatic'. In his narrative, this theme of the unsolicited nature of the possession is then carried over to the story of the bone, which immediately reminded me of the well-known phenomenon of 'spontaneous icons'. As Bruno Latour pointed out:

As is well known from art historians and theologians, many sacred icons that have been celebrated and worshipped are called acheiropoiete; that is, not made by any human hand. Faces of Christ, portraits of the Virgin, Veronica's veil; there are many instances of these icons that have fallen from heaven without any intermediary. To show that a humble human painter has made them would be to weaken their force, to sully their origin, to desecrate them (Latour 2002: I6). 
The magic of these spontaneous icons thus operates according to the same logic as Walmir's revelations on that beach in Alagoas: they are incalculable, and no human agency was involved in their production and occurrence. As such, they are taken to be 'the living imprint of the living God exclusive of any artistic workmanship' (Debray and Rauth 1995: 544).

Luis' finding of his 'Indian bone' was probably not unsolicited - it was clearly informed by his wish to authenticate the identity of the spirit that had possessed him. However, he sought to copy the logic of spontaneous icons, putting his faith in a bone found at a roadside while taking a leak rather than in his findings on Cheyenne Indians on the Internet, or the reassurances of his mãe-de-santo.

\section{讙}

A last example of the centrality of unsolicited and inexplicable occurrences in religious narratives concerns an experience $\mathrm{I}$ had in a terreiro in the Tororó neighborhood. In July, the month during which many of the caboclo spirits are honored and celebrated, I took Thomas, a Dutch friend who was visiting, along to a celebration. When we entered, the priest was already possessed by a caboclo. As is their habit, the caboclo walked around the temple, drinking beer from a bottle, smoking cigars and talking to the public, responding questions and giving advice. When he saw Thomas, he immediately walked up to him, and urged me to translate his words. Holding Thomas' hand, and with eyes staring into a distant nothingness, he said that my friend was writing a book, but that he should be writing 'that other thing. He was quite insistent, repeating his statement various times.

'Yes, if you want to shine, if you want to make a lot of money, you should be writing that other thing.'

From the face of Thomas I could already see that the caboclo had struck a chord. Later Thomas told me that there was a major struggle in his life whether he should devote his time and energy to finishing his dissertation on European law or work on a film script he kept hidden in his office drawer. We were both speechless as to the accuracy of the caboclo's intervention. The spirits often speak in very general terms, so that one can always find something truthful in it. This caboclo, however, had hit the nail on the head without any prior knowledge. He had never met us, let alone could know what Thomas was doing in his life.

This case is illustrative of the way Badiou conceptualizes the relation between the truth event and the act of believing. For Badiou, belief differs 
from mere opinion by a declaration of faith to a truth-event, by accepting its occurrence and being, even if that acceptance requires a drastic reordering of one's worldview. In the instant discussed above, I have not declared myself faithful to the miraculous sayings of the caboclo, no matter how undeniable the truth of this event. Do I now believe in the authenticity of this spirit? No, not really. But the whole event did highlight the politics of my saying 'I don't believe these things': that remark is forever exposed as an act of not wanting to go into believing spirits and messing up my worldview (not to mention my academic credibility).

Afterwards, I used the example in many conversations with cultists, saying that this event really had left me baffled. They would only nod their heads. Or they would say, 'Yeah, it is like that, the spirits do things like that, strange little things, to make sure that you'll start to take them seriously.'

\section{䜪}

Bafflement politics evoke an absent and inaccessible yet incontestable truth to win over non-believers to believe, or to confirm believers in their creed. Bafflement politics cannot only be pointed out in conversion processes. In the public sphere, bafflement politics are at the service of a priesthood that seeks to authenticate itself as the true voice of Candomblé. The public presentation of spirit possession - the way cultist's (refuse to) talk about it; as well as the way they stage it and enact it in public ceremonies - offers many examples of how cultists seek to ground their beliefs in an absent truth, thus to win over their imagined audience.

Let me start by discussing the speech acts around spirit possession: one of the forms through which the phenomenon of spirit possession becomes 'public'. As stated in the introduction to this book, anthropologists (including myself) and other curious outsiders are instructed not to ask questions about possession trance. ${ }^{70}$ Rita Segato reported that

\footnotetext{
Trying to push the issue [of possession experiences] a bit further, or trying to understand the subtle difference between what people describe as a 'normal' state of consciousness and the state of possession is considered rude and disrespectful towards the privacy entitled to the people who go into a trance (Segato I995: I02).
}

In the scholarly literature on Candomblé, the prohibition to ask questions or speak about possession is discussed under the label 'secrecy': the many 
rules and regulations that determine who has access to what knowledge, and at what time; who is allowed to speak and who is to remain silent; who has access to certain areas of the temple; who is allowed to see sacred objects or witness ritual practices and who is not. These rules apply within the temple walls, involving all the members of the temple community, but also between temples (who are competitors on the 'market of salvation goods'), as well as in the interactions between cultists and non-cultists. Breaking these rules and regulations may invoke the wrath of both priests and spirits (cf. Johnson 2002). There is an evidently performative side to secrecy, in the sense that it is a performance that seeks to communicate to a wider audience that there are impenetrable mysteries in Candomblé. In other words, people from Candomble will not say what the mysteries are, but they want to make sure that the world knows that they do have them. A clear example is the talk about what I would like to call 'postpossession amnesia. Time and again, I was told that the medium who goes into a trance has no recollections of the 'time-out' that is possession trance. Many ethnographers have reported similar remarks. Roger Bastide states bluntly: 'all that was done or said during the crisis [of possession] is forgotten afterwards' (Bastide I978: 192). Landes introduces 'an old priestess', saying

This god business is a mysterious force that sweeps over you. I don't like it. You become a slave to the saint, and sometimes you go around possessed for three days! You have no wants, your body is dead, you don't feel anything at all (Landes I947: 57).

Rita Segato reports from Recife that '... it is being said that, during possession, consciousness disappears. To be more precise, self-consciousness disappears, the body becomes the vehicle of experience itself, without further mediation' (Segato I995: 99). In some temples in the southern state of Rio Grande do Sul, people are not even supposed to remember that they were possessed (Silva 2000: 60).

Ruth and Seth Leacock, who discuss this 'post-possession amnesia' at length, urge their readers to consider an alternative view. The mediums with whom they spoke also fiercely maintained that they had no recollections whatsoever of their trance experiences (Leacock \& Leacock 1972: 266ff.). Yet the Leacocks do not take the validity of the accounts of their informants for granted, no matter how resolutely stated. They report that mediums that had claimed complete amnesia in one interview, during other interviews would demonstrate to have clear recollections of specific 
happenings during the possession rituals that had been discussed earlier. When confronted with such incongruities, mediums would always deny it: 'the fiction was always maintained that they had been told by their friends what had taken place' (ibid.). These anthropologists conclude that mediums subscribe to an ideological rule that what knowledge there is should not come to the ears of others.

What is important to my argument, of course, is not so much whether post-possession amnesia is reality or fiction. It is plausible that, just as most people do not remember their dreams, and Freudian psychiatrists have to train their patients to remember them, trance states are likely 'forgotten' if there is not a tradition that urges the mystic to report on them. What is important to see is how this 'ideological rule' reproduces a blank space on the map, an area of not knowing: a mystery.

This is basically the argument of José Jorge de Carvalho (I992). The constant references to post-possession amnesia provoked the author to speak of a specific Afro-Brazilian 'mystical style'. He points out that in the Catholic tradition, as in other 'classic' traditions of mysticism, the mystic is urged to share his or her experiences with the community of believers. The mystic is supposed to translate his or her experiences into essays, poetry, autobiographical reports and tracts. It is the linguistic translation of mystical experience that is valued in these traditions: the greater the sophistication of the mystic's wordings, the fancier the metaphors, the more subtle the tropes to describe the mystic experience, the more important these experiences are as a contribution to a 'science of the soul'. In Candomblé there is no such attempt to exteriorize the subjective experience of trance through language. De Carvalho expresses his surprise after reading an interview with the famous Salvadorian priestess Olga de Alaketu in the aforementioned magazine called Planeta (I974).

I consulted the article in the expectation of finding yet another dialogue with a spiritual leader, along the lines of the interviews that the magazine had published before in issues dedicated to yogis, Sufis, Rosicrucians, theosophists, Christian leaders, Buddhists and the like. To my surprise, I had to conclude that Olga de Alaketu simply does not show us the play of her subjectivity. She expresses herself in a completely exteriorizing way - she speaks about the ceremonies, the liturgical calendar, the genealogy of her temple, the history of her cult, etc. She doesn't reveal anything about an interior world, a psychological dimension, or the individual that is Olga de Alaketu. She does not bring into play that confessional style; she does not give us an autobiography of her soul, which subsequently could serve as a pedagogical tract on a spiritual doctrine. 
Although she comes across as exalted at all times, she always remains remote, always remains enigmatic (de Carvalho I992: 85).

He points out a similar absence of an exteriorizing of the subjective experiences of possession in the Xangô cults of Recife; here too, all the stress is on the pomp and splendor of the ritual, the beauty of the performance, the 'speaking' of the body in the dance, that communicates the mystical experience to the community of believers, rather than a verbal rendering of the experience.

In Candomblé, talk [about possession] is not in a discursive, personalized mode [...] The quality of individual spirituality is evaluated by the community in terms of aesthetics and intuition and not by way of some explicit philosophical, theological or ethical question (de Carvalho I992: 86).

What we see then, is that the performance of secrecy is all about foregrounding silence; suggesting but not saying; closing off rather than opening up; veiling rather than revealing; creating shadows, twilight zones and a pervading awareness of that which is absent. It aims at keeping the inexplicable inexplicable and seeks to guarantee the survival of the mystery in all its enchanting ineffability.

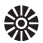

In Candomble's attitude towards the media, the performance of secrecy moves up to more dramatic levels. Every newcomer to Salvador with an interest in the Afro-Brazilian traditions is immediately made to understand that taking pictures of Candomblé ceremonies - let alone filming them, or making sound recordings - is not done. Tour guides instruct the groups they take on a Candomblé tour that taking pictures or photographs, filming or making sound recordings is strictly forbidden and cult houses that receive a lot of tourists have signs on the wall to remind visitors of these prohibitions. Visitors who ignore them may be in for serious trouble. Twice, I witnessed ogãs taking tourists' cameras by force: in both cases, the tourist - while standing outside the barracão, the large open space in a cult house where public celebrations take place - had taken pictures of a ceremony through the open window. In one case, the film was confiscated. In the other case, which concerned a digital camera, the tourist was forced to delete the images just taken. Tour guides told me 
they had even witnessed the memory cards of digital camera's being taken out and destroyed.

Documentary filmmakers, journalists and anthropologists have run into similar problems. Interviews with priestesses in documentary films often show how the filmmaker ran into a wall of silence, with the priestess refusing to answer questions saying that the secrets cannot be divulgated. The few interviews with priests and priestesses that I have seen on Bahian television are very clear examples: the priests persevere in their performance of secrecy, the interviewer gets nowhere asking 'stupid questions', and the interview ends up being chitchat about the more folkloric aspects of the cult while never coming close to what the cult is all about. Another example was the priest who, not without glee, told me that an American film crew had wanted to film a celebration in his temple, and that he had agreed on condition that the orixás had to be consulted first and give their permission. Every day he threw the oracle of the cowry shells to divine the wish of the gods, but they never consented, and after a week, so the priest said, the film crew had to pack its bags and return to the UsA.

As with the prohibition to talk about possession, it is important to see that the attempts to 'keep the media out' are in fact performances, communicative acts that address the public at large, or curious visitors such as anthropologists or filmmakers. ${ }^{71}$ (In the next chapter, I will return to the adoption of new media in Candomblé circles). What these performances seek to convey is that the mystery of the coming of the orixá is to remain immediate, in the double sense of 'restricted to the here and now of the experiencing body' and 'without a mediating device'. Even explanations as to why the orixás cannot be photographed or filmed underline this stress on immediacy. Several cultists told me that, even if you were to violate the prohibition to take their pictures, the orixás would not appear on film. 'Go ahead,' is what the caretaker of the shrine of lemanjá in Rio Vermelho told me when I had asked him whether I could make some photographs of the many statues of the goddess inside. 'But you might as well save your money, for lemanjá won't appear on your film.' (Which in fact was what happened, because for mysterious reasons I lost the film).

Clearly, saying that the orixás cannot be photographed is to say that the mystery of divine presence cannot be taken out of the here and now of the moment of possession. It is another way to prohibit all further representation of the momental truth of the orixás hierophany, and to safeguard what Walter Benjamin would probably have called its 'aura'.

Aversions and prohibitions notwithstanding, some terreiros have come to the conclusion that in a media-saturated society such as Brazil, media- 
tion cannot be avoided, and they have sought to develop forms of representation they deem adequate. The result is an intriguing expansion of the performance of secrecy to new media. In I994, Ilê Axé Opô Afonjá produced a videotape entitled 'This is our universe, this is our belief' (produced by Jacyra Oswald). ${ }^{72}$ Explicitly produced for public circulation (the tape is shown to all visitors to the little museum on the temple's compound, sold in the little museum shop, and there are versions in Portuguese and English) and resembling something of a manifesto, it self-consciously seeks to 'correct' prevailing representations of the cult, and it has a clear political objective, that is made explicit on the cover of the tape where it reads:

Mother Stella's (ode kayode) narrative, a mark of cultural and religious resistance preserving the purity of our religion's rituals - the Candomblé - as it is understood in ilê axé opô afonjá - her house. ${ }^{73}$

I purchased the video produced by Ilê Axé Opô Afonjá during one of my visits to the compound of this temple, or to be more precise, the little museum that is attached to the temple. The museum comes under the resounding Yorubá name Ilê Ohun Lailai, meaning 'house of antiquities', and is basically a large room exhibiting some ritual objects, garments, photographs, as well as certificates and honorary medals that some of the priestesses have received. There is also an old-fashioned cupboard, showing behind its glass doors the statues of Catholic saints that once adorned the altars. The middle-aged woman who took care of the place at my first visit was not very talkative. Even before I had had a chance to look around, she urged me to sit down in front of a television, insisting that I should watch a video on 'the traditions of the house'. Being an anthropologist, I politely accepted the invitation. It turned out to be the right move. The woman hurried off to fetch the tape, while complaining that 'most tourists lacked the decency and respect' to take the twenty-or-so-minutes to be informed about her creed.

The message that the video seeks to get across is simple and straightforward: Candomblé is a cult of African origin; Candomblé has the deepest respect for the forces of nature; and Ilê Axé Opô Afonjá has been a guardian of the traditions for many generations. The style of the video is what we might call 'arty'; it strives to be tasteful and modern, and clearly shows the signature of the elitist clientele of the house. Most striking, however, is the fact that the video represents Candomblé in a highly abstract fashion. There are no shots whatsoever of rituals or any other religious practices. 
In fact, the universe that is shown has no people in it. The only human figures that appear in the video are a nude black dancer who - in Martha Graham-esque fashion - represents the female orixás; a black man who holds some of the insignia of the male orixás (but who can only be seen in a shadowy profile and remains faceless); and - in the very last shot - we find a black family (man, woman and two children) entering the barracão. Again, we only see these people from the back, and never get to see their faces. Moreover, the barracão they enter is ostentatiously empty and dark, in a clear attempt not to give away any image of religious practice to the eye of the camera.

What we do get to see are images taken from documentaries on nature (erupting volcanoes, ocean waves, birds flying over a swampy river, crocodiles, a roaring jaguar, thunderclouds, rain, waterfalls, tropical woods, etc.); African wax prints waving in the wind; African artifacts half hidden in the woods with a 'searching' camera finding them; religious paraphernalia tastefully assembled on white draperies; and a 'tour' of the compounds of llê Axé Opô Afonjá, showing the houses for the different orixás, with ostentatiously closed doors and equally ostentatiously closed shutters. In a voice over, Mãe Stella explains what-is-what-and-who-is-who in the Candomblé universe, using a lot of Yorubá terms - but here too, the speaking seems to aim at revealing as little as possible: the text is limited to the barest of facts, and the staccato mini-sentences, spoken by the priestess, suggest that she is unwilling to reveal even this little.

Having seen the video, I could hardly blame those tourists who did not sit through it to the very end. The performance of secrecy is key to understand this curious production: showing absences, silences, empty spaces and shadows, closed doors that will not open, 'incomprehensibility' is all that This is Our Universe, This is Our Belief tries to communicate. Veiling and revealing at the same time, it seeks to entice outsiders with mystery while not giving anything away.

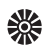

Possession ceremonies, finally, are a further spectacularization of the central role of mystery, and probably the prime asset in Candomblés bafflement politics. These ceremonies are public events and brought to public attention through all available channels. For those who are not within reach of the sound of the drumming or the fire crackers blasted into the sky, or who did not receive information by word of mouth, there are several options to find out when and where a ceremony is going to take place: 
newspapers list the most important temples with full address and phone number in their 'what \& where' sections, the registers of the Federação Nacional dos Cultos Afro-Brasileiros (where temples have to report and register their celebrations) are open for consultation, and the tourist office publishes a weekly calendar of the upcoming ceremonies. The ceremonies usually attract a very heterogeneous audience consisting of members of the temple, guests of honor, cult adepts, inhabitants of the neighborhood where the temple is situated, as well as tourists and anthropologists.

During these ceremonies, mystery is put on display in a highly dramatic form. The xirê, the opening round dance of all the initiates, circles around the central pillar (or a marked spot in the center of the dance floor) where the secrets of the house were 'planted' when the building was constructed. The many prostrations of the initiates towards this spot remind the audience of its centrality. The priest and his or her initiates enter and re-appear from the adjacent rooms of the ceremonial dance hall, forbidden areas for all who are not part of the temple, as it is here that the orixás are taken to be dressed in their godly attire. Although these spaces are shielded from view by curtains, glimpses of the backstage of the house can be caught as the curtains are in constant movement due to electric fans and people moving in and out. Another attribute in this play of veiling and revealing is the adé, the headgear that covers most of the face of the possessed with strings of beads.

If the presence of hidden, inaccessible areas is thus emphatically highlighted, possession itself is staged in all openness. The moment when the spirits arrive is for all to see. The way a 'daughter' of Xangô or Oxóssi, or a 'son' of Omulu transforms into a vehicle for the deity has to be witnessed in every little detail, right in front of the gathered audience. In his Candomblé classic Candomblés da Bahia from I948, Edison Carneiro writes:

[The initiate] will feel convulsions all over her body, enters into a dizzy spell, loses her balance, walks as a drunkard from one side of the dance floor to the other, looking for someone to hold on to, and finally, taken over by the orixá, will acquire another posture and recover her senses. With closed eyes (or eyes wide open, as is the case in the Candomblés do Caboclo) she will start the dance, maybe speak, and in fact, take over the celebration, which for a while will be completely focused on her (Carneiro I967: 60).

The spectacular scene of the arrival of the spirits usually succeeds in baffling spectators. Audiences may doubt the particular possession of a particular person, and they may have their reservations about the sincer- 
ity of this or that temple, but in general the reality of the coming of the orixás (or in the case of tourists: of 'something inexplicable happening') is not questioned. As old and shriveled ladies turn into fierce dancing warriors and a young man becomes old Oxalá, trembling all over his body; as giggling schoolgirls all of a sudden roll over the floor, stiff as a broomstick; as tourist guides wrestle their way out of the temple for fear of being caught by the spirit; as anthropologists become 'restless and keyed up' when the drumming reaches a peak, they all become extras in this theater of the really real.

Even the busloads of sweating gringos - gazing at the spectacle with open mouths and incomprehension written all over their face - contribute to highlight the power of an absent truth, spectacularizing the ineffable and thus authenticating the beliefs of Candomble for both the religious community and the society at large.

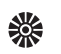

It is in reference to baffling instances such as the ones discussed above that Candomblé priests build their notion of 'deep knowledge'. These are the performances with which they seek to oppose the disruptive effects of the cult's hyperdivulgation in the public sphere. Recall Mãe Stella's statement quoted in the introduction to this book:

\footnotetext{
Our religion is so strong and so mysterious that it raises the curiosity of those who are outside. They seem to think that a host of curious questions, sometimes even impertinent ones, is synonymous with knowledge. But I tell you; those ways are dangerous, leading into veritable labyrinths, and with dire results. I therefore advise visitors and friends of the Axé: don't ask questions, just observe! (Santos I993: 88)
}

Do not ask questions, just observe. Be baffled. In line with Badiou's understanding of the truth event, the argumentative power of possession, clairvoyance and other miraculous phenomena lies in the combination of their being both overwhelmingly real and utterly inexplicable. To parade these instances in public as the true manifestation of Candomblés power is to cast the 'essential Candomblé' in impenetrable mystery. It is also to proclaim all discursive knowledge to be 'superficial. ${ }^{74}$

The success of this politics has been amply documented in the previous chapters: mysteries and secrets work as a magnet and attract scores of curious outsiders. As long as these outsiders stick to testing their dis- 
cursive powers on the impenetrable rock of Candomble mystery, they in fact contribute to making public the power and prestige of Candomblé. All that the priests need to do is to dismiss this interpretative work as 'evidently superficial' or 'missing the point entirely'. However, when outsiders appropriate the baffling powers of Candomblé and seek to make them do their work beyond the realm of discursivity - in music, in dance, in the arts - Candomblés politics to stun people into believing are in trouble. The panicked responses to such incidents demonstrate just how much the Candomble priesthood has built its public politics on the thought that mystery will keep the threat of hyperinterpretation at bay.

\begin{abstract}
灌
This folklorization is a lack of knowledge and understanding! I once talked to a girl who dances (or danced) in the Balé Folclórico da Bahia. I said: 'You dress like lansá?' and she: 'But Mãe Stella, this is only to pay tribute to my santo.' Little does she know, does she? Goes there dressed as lansá, to dance onstage, and afterwards goes out to have a beer ... daughter of lansá! Drinks whiskey, sleeps around .... It's folklore, but it is also a lack of respect. If someone who thinks that she is paying tribute already speaks like this, just imagine what a layperson would say! (Mãe Stella, in Pretto \& Sherpa 2002: 39)
\end{abstract}

The Balé Folclórico da Bahia exists since I988. The company recruits its dancers 'from the street', as the company's choreographer and instructor told me in one of our conversations. If they prove to be talented they are subjected to a tough regime of daily training and rehearsal. There is never a shortage of candidates. For this is Bahia, where - as Caetano Veloso once put it - 'dançamos com uma graça cujo segredo nem eu não sei' ('we dance with an elegance whose secrets even I don't know', in Vianna i995: I47). Moreover, the Balé Folclórico is an internationally acclaimed dance company, and performs all over the world, offering young dancers a rare opportunity to travel abroad and expand their horizons.

In Pelourinho, the historical center of Salvador, the Balé Folclórico performs every single night in theater Miguel de Santana, where, next to such dances as samba de roda, maculêlê, and the martial art capoeira, they give a demonstration of sacred dances from Candomblé. Dressed in the attire of the orixás, the dancers perform the dances of the possessed in a spectacularized way. Another production, called 'The Court of Oxalá', represents the stories of the different orixás, and has a central role for the trickster god Exú, here presented in the figure of a madman. 
As the quote from Mãe Stella indicates, in some Candomblé circles, these programs are deemed highly controversial. Mãe Stella repeatedly attacked the Balé Folclórico in the strongest of terms:

There are these folklore shows that exploit what is most serious in Candomblé: the manifestation of the Orixá in his sons and daughters. So the tourist will see the show, sees the youngster 'dressed as the Orixá', imitating the battle cries [of the warrior spirits], dancing the sacred dances. Then this tourist will decide to go visit a religious ceremony, and who knows, will find that same handsome lad truly transformed in Xangô, Oxóssi or Ogum. What will he think? If he has a bit of good sense, he will conclude that Candomble is nothing serious, that it is no different from the samba de roda, that it is folklore (Santos \& Martins I989: 20).

Candomble is a religion. It has nothing to do with the folklore shows that can be seen in nightclubs, where they put on the orixás dance, as if the dancer were a filho-de-santo ... These shows are nothing but vulgar imitations. Having to witness how the sacred is profaned onstage, how these dances are performed in a sequence that includes maculêlê, capoeira, or samba de roda is saddening to all serious people, regardless of whether they are priests or laymen (Santos I993: 34-35).

Mãe Stella is not the only one to show such indignation. In an interview, the secretary-general of the Federação Nacional dos Cultos AfroBrasileiros stated

... it is a sad fact that neither I nor the Federation have the power to call the Balé Folclórico da Bahia to a halt ... I consider them to be one of the main exhibitors of Candomblé in the world, they show many of the particularities of our religion ... well, this much I must admit: they do not show initiation rituals ... But the dances of the orixás! The dances of the orixás! I'm afraid there is no way to stop them. Every once in a while, one of their productions is broadcast on TV. I watch it in horror! The exhibition! I know that in that dance group there are numerous people who belong to the African religion. No doubt about it! And they sing and play the 'deep' music and words (músicas e letras de fundamentação) that they should not be singing and playing. But we can't prohibit it. Such is the fact. However, I condemn it with all my might...

Both the artistic director of the Balé Folclórico da Bahia and the choreographer have been confronted with the critiques. The latter - tall, black, flamboyant, charismatic, raised in a poor neighborhood called Caixa 
d'Água from where he made it to dance academies in New York and the Netherlands, and a worshipper of the orixás himself - told me that it would simply be no option to leave out Candomblé from a program of Bahian music and dance. Candomble was the secret foundation of all the rest. He stressed that, out of respect, they never entered into the 'spiritual part of Candomblé. They never included sacrifice, or rituals.

'We just take the forms, the specific movements, which we then stylize by exaggeration. For let's face it, the dancing that goes on in the terreiros is far too boring to put on stage!'

When I pressed him to respond to the critique of llê Axé Opô Afonjá, he got irritated.

'Oh, these religious people. We are artists!'

Stretching his muscled legs high up in the air he continued, laughing:

'... haven't we seen Maria Magdalena spread her legs? Haven't we seen Jesus as a homosexual? So what's all the fuss about?

llê Axé Opô Afonjá, he insinuated, had been taken over by white people. They were the ones to make all this noise.

'Have you heard of that white attorney from São Paulo? Believe me, she's the one to make most of the decisions over there!'

The director too stressed that the Balé Folclórico da Bahia showed nothing that could not be also seen in the public ceremonies of the terreiros themselves, where everyone is welcome.

'So what are the secrets we're giving away?'

He too was under the impression that llê Axé Opô Afonjá had been taken over by the ambitions of 'that white woman from São Paulo' and suffered from the influence of all the intellectuals who would go there.

I really do not get their policy. They criticize us, but when they want to produce a video about their terreiro they contact us whether we can send over some dancers. Juanita [Elbein dos Santos, an Argentinean anthropologist who wrote a classic monograph on Ilê Axé Opô Afonjá] caused a scandal when her documentary film on the secret cult of the Eguns was broadcast on national Tv. But when we were invited to stage some of the dances of the orixás for an international congress on African Religion, with priests and priestesses from all over the country, as well as representatives from African countries, the people from Ilê Axé Opô Afonjá - including Juanita - made a point of ostentatiously leaving the room. The Africans, on the other hand, were very enthusiastic!

The director continued by saying that the national ballets of Cuba and Haiti also put on a section of the dances of the orixás in their programs, 
and that Casa Branca and Gantois (the other 'historic' and prestigious terreiros, and the eternal competitors of llê Axé Opô Afonjá) spoke very positive of the Balé, and never made problems.

'And just look how Ilê Axé Opô Afonjá is accessing the media all the time, seeking publicity, organizing events. If they are so concerned about keeping Candomblé a religion: then why don't they restrict themselves to their religious tasks!'

Mãe Stella and her following, however, do not seem to be impressed with such arguments. A priest subscribing to the ideological line of Ilê Axé Opô Afonjá asked me: 'When do we see people dressed up as nuns, monks and bishops in a carnival parade? When do we get to see the consecration of the Holy Eucharist in Teatro Miguel de Santana? When?'

磷

Jean Baudrillard's notion of the simulacrum may help to clarify what is at stake in these venomous attacks on the Balé Folclórico da Bahia. Other than mere imitations, simulacras become a reality on their own, producing the same symptoms as the original referent. As such, they mess up distinctions between 'true' and 'false', 'original' and 'copy', 'real' and 'imaginary', 'sacred' and 'profane' and cause havoc in the regimes of truth that buttress the symbolic order (Baudrillard 200I: 17I). The autonomous power of the simulacrum was brought home to me during a rehearsal by the Balé Folclórico da Bahia to which I had been invited after an interview with the choreographer. In a studio somewhere on the second floor of an old mansion in Pelourinho, boys and girls were stretching and flexing their muscles in utmost concentration and dedication. After an hour, the drums were beaten, the sacred songs were sung, and the pupils started to dance. The spectacle was nowhere close to the somewhat obligatory fatigued dancing of initiates one often sees in the terreiros. Here the movements were dramatized, stylized and highly energetic. There was no adherence to any liturgical sequence. The dancers' beautiful and sweating bodies were only dressed in tights and shorts instead of the baroque costumes of initiates who incorporate their orixás. Yet for all the obvious differences with a religious ceremony, the rehearsal produced a genuine effervescence that filled the studio to the brim, transcending the mere rehearsal, producing a spectacle that sent shivers up and down my spine and was as powerful as a religious ceremony of Candomblé. 
Afterwards, dancers told me they would sometimes feel the coming of their orixás during rehearsals, and they recalled instances of possession. When I asked the dance instructor about it he flatly denied it.

'What do you think? Orixá é burro? (The Orixá is a jackass?) Would not know the difference between a rehearsal and a ceremony? Come on!'

For me, however, it was clear that both public ceremonies of Candomblé and the Balé work with the same energies, the same enchantment, which in Candomblé terminology is labeled axé, the vital, life-giving force that puts the universe in motion and makes possible growth, progress, and prosperity. In fact, in an interview, this is exactly how the artistic director of the Balé Folclórico da Bahia, put it: 'o mistério do Candomblé é o encanto do axé. The mystery of Candomblé is the magic of its axé.

Given the prevalent bafflement politics in Candomblé - a politics that grounds the 'real truth' of the religion of the orixás in impenetrable mystery - the conceptualization of axé as a force that does its work both in and out of religious settings cannot but raise grave concerns. For it is here that the simulacrum of Candomble has absorbed the ineffable and noetic qualities of ritual and ceremonial practices, the very stuff through which the Candomblé community had sought to ward off the simulacrum's unsettling effects.

\section{䑏}

I started my introduction to this book with the observation that the Candomble priesthood in Salvador is adamant in its insistence that the cult's 'deep knowledge' is inaccessible to all discursive forms of knowledge. Only through the time-consuming and experiential path of initiation - so the priests kept saying over and over again - may one hope to acquire a true understanding of the mysteries that are at the heart of their religious practices and beliefs. In this chapter, I have shown how this stress on an 'inaccessible truth' plays a crucial role in the boundary politics of a cult that has become the object of endless discursive elaboration by outsiders, including a large number of anthropologists: how the mysteries are reproduced in speech acts, media performances and the public display of spirit possession.

Whereas such boundary politics are successful in empowering the priestly voice in the public sphere, they do not prevent that the full appropriation of Candomblé by outsiders has a profound and lasting influence on the cult. Due to the ever more public life of Candomblé, and due to the fact that cultists cannot be reduced to their religious identifications, 
public understandings of the cult have permeated the cultist's own understandings about their religion at all levels. 


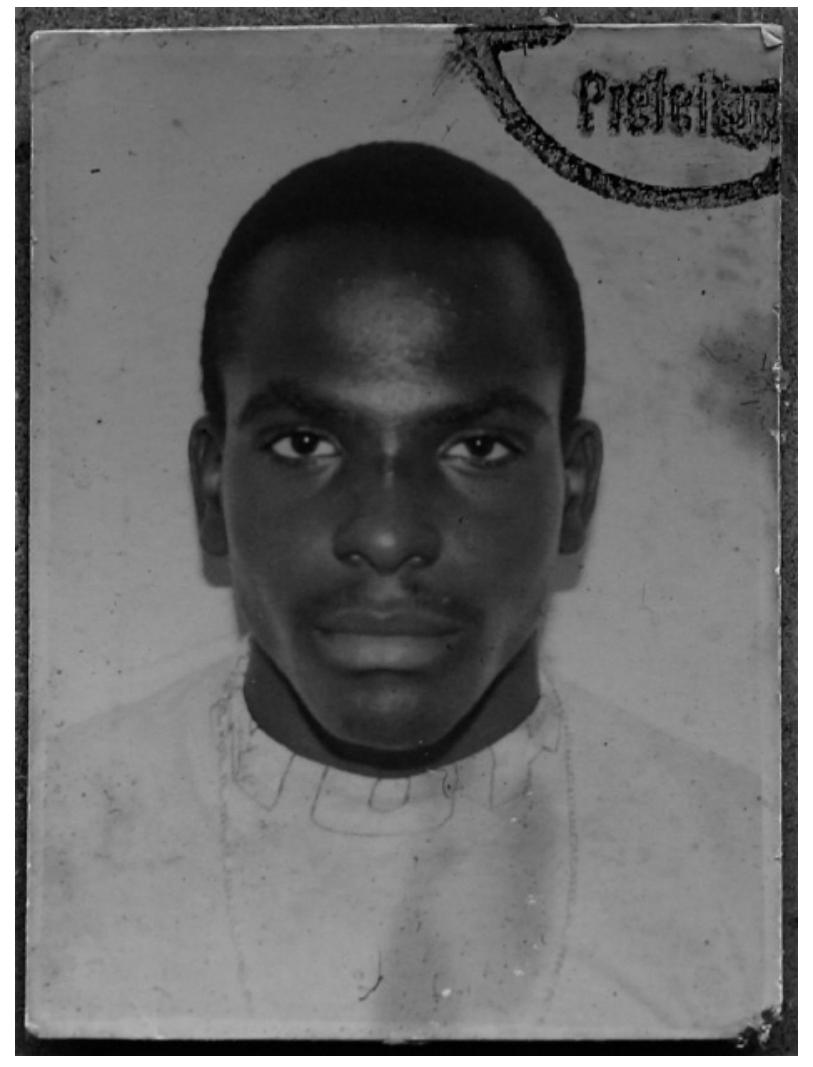

Figure 19 Brought up in the Candomble life world, but not to be reduced to it: Victor at the age of 14 


\section{7 \\ THe permeaBle BOUNDarY

\author{
Media imaginaries in Candomblé's public \\ performance of authenticity
}

On one of my visits to Gantois I caught sight of Luis, a fellow anthropologist. He was standing on the other side of the barracão, the great ceremonial hall of the terreiro. As it was very crowded, it was impossible to reach him. We acknowledged each other's presence with a nod.

The purpose of my visit to Gantois was a celebration in honor of Oxum, the Candomblé deity of beauty and of the sweet waters. The barracão had been decorated with garlands and cloths in the yellow and golden colors of the orixá. As always, the splendid performance sought to recreate an 'Africa' on Brazilian soil - with non-stop drumming, Yorubá chanting, and an impressive gathering of temple dignitaries dressed in their imported Nigerian garments: grands boubous, wax-print dresses, and colorful kaftans with matching hats.

For some reason, my observer's eye lingered on the floral decorations that hung from the ceiling: Styrofoam balls in which little dried flowers and golden, spray-painted leaflets had been stuck. These floral balls, fastened to the ceiling with velvety ribbons in a soft yellow tone, could only be described with the word 'Biedermeier' - the romantic rococo style of early I9th-century Vienna. I am not sure whether I had already made a 
mental note saying 'these quaint little bouquets don't look like Africa to me' when I met Luis' eyes, who clearly had been observing me observing the floral decorations. We both burst into laughter, having seen something to which we, as anthropologists, should not have been paying attention. Clearly, our fieldwork diaries of that day were supposed to mention the ritual sequence of the ceremony, the names of the orixás that had come to celebrate, the presence and absence of honorary guests, the quality of the drumming and the food. They should not, however, mention Biedermeier bouquets hanging from the ceiling.

In all of its triviality, the example shows that the people from Gantois had found themselves seduced by an aesthetic that runs counter to their ideological, political and religious pursuits. One might add: Graças a Deus! (Thank God!) As long as the suicide bomber wears a pair of Levi's; as long as the Serbian nationalist listens to Ав ВА; as long as the right-wing populist leader marries a foreign spouse; as long as the communist leader cannot resist his longing for fancy sport cars, some opening to the-rest-ofwhat-is remains. And so it is in Candomblé. Whatever the people from Candomblé have been made into in the allegorical plays of others (and whatever they have made themselves to be in their own performances), they can never be reduced to their religious makeup. People from Candomblé are consumers and media audiences; they invest their 'belief energies', as Michel de Certeau (1984: 63) once phrased it, in politics, in the emergent gay subculture, in the joy of a Sunday afternoon on the beach, in academic careers; they get carried away by spirits, but also by music, films, telenovelas, books, fashion, and spray-painted floral balls fastened to the ceiling with soft yellow velvet ribbons. In brief, their imaginaries always exceed their explicit intentions.

All of this may sound like stating the obvious, and yet it is not when returning to the study of Bahian Candomblé. For one rarely reads about people from Candomblé being anything other than religious subjects. In anthropological writing it is as if their minds and beings are wholly occupied by their religious identifications. Thus, the people from Candomblé that figure in the anthropological literature tend to prepare inhame (yams), not spaghetti carbonara or mousse de maracujá; they wear a contra-egum (amulet), not the latest Swatch (or the look-alike made in China and sold at Sete Portas); they tell oriki (myths of the orixás), not the latest gossip on this or that telenovela actress.

Fact is, of course, that they do both. Yet in the anthropologist's discourse, as well as in artistic representations of the cult, the people from Candomblé are reduced to their religious makeup. 
What was at stake in this anthropological giggling over the floral decorations in Gantois, I would say, is the production of authenticity. The moment of becoming aware of this Biedermeier presence in an all-African performance of a celebration of Oxum was the exact moment when I had to make up my mind about the kind of authenticity I would like to pursue in my project. If I were to let myself be guided by the impulses of the spirit of the classic, I would remain silent about those Styrofoam balls. I would gloss over them. Deny them. Declare them to be 'matter-out-ofplace' (Douglas 2002). For in the particular register of world-making that I have called the classic one reaches authenticity by cleaning up categories, fixing classificatory schemes, drawing absolute lines and turning a blind eye to the-rest-of-what-is.

If, by contrast, I were to obey the impulses of the spirit of the baroque, I would have to take notice of those decorations. I would have to expose them in a flaunting way. To put them center stage in my narrative. For as I have argued in previous chapters, this modality of world-making situates authenticity in the impossibility of symbolic closure. In the modes of the baroque, authenticity comes about by constantly pointing out the falsity and made-upness of the seamless, harmonious worlds of the classic.

Needless to say, I keep opting for the spirit of the baroque. That is, as far as the guidance of spirits is something one can choose...

\section{䜪}

The impulses of the classic and of the baroque are not only at work to produce authenticity in the (anthropological) descriptions and representations of Candomblé. They are also informing the authenticating strategies of cultist's who, as we have seen, feel pressed to assert their own voice in the public sphere. The anthropological tendency to confine people from Candomblé in their religious beliefs, to highlight 'tradition' and downplay 'modernity', thus to produce 'authentic' cultists, has its pendant in the purist line in Candomblé, an anti-syncretistic movement that wants to banish everything 'un-African' from the Candomblé universe. Mãe Stella from Ilê Axé Opô Afonjá is an important proponent of this purist movement. In this chapter I will show how she is guided by the spirit of the classic to draw rigid boundaries between what does and does not pertain to true Candomblé.

My main objective in this chapter, however, is to break open Candomblés essentialized (self-)image and - in the spirit of the baroque - focus on the points where discourses become contradictory, and professed sancti- 
ties lose their coherence. An in-depth discussion of two instances of Candomblés public performances will show how the religious imagination has become inextricably entangled with the imaginaries of modern mass media. The first case discusses the increasingly popular practice of making video registrations of important Candomblé ceremonies among cultists. A discussion of a number of these home videos shows how cultists seek to authenticate their 'African' creed not by inscribing it into a vocabulary of tradition, but by inscribing it into the styles and aesthetics of television. The second case concerns the way Candomblé priests with ambitions in the public sphere have to engage in a form of 'celebrity politics'. As notions of authority that exist within the walls of the terreiro are not recognized by the public at large, Candomblé priests have to buttress their authority in the public sphere by employing a media discourse on fame.

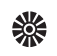

As stated, Mãe Stella is probably the main proponent of the purist line in Candomblé. The impulse of the classic clearly dominates the kind of world-making she believes in. 'Iansá is not Santa Bárbara', was the famous phrase with which she sought to undo the syncretism that was, and is, such a prominent feature of Candomblé religious practices. Sure, she said, Santa Bárbara was an elevated spirit, worthy of all respect. Yet to put the food offerings for lansá at the feet of a statue of Santa Bárbara simply does not make sense. It is, as she repeatedly phrased it, 'incoherent'. Mãe Stella used that same qualification for the people from Candomble who walk in procession to the church of the Bahian patron saint, O Senhor do Bonfim (syncretized with the orixá Oxalá), for a ritual washing of the church building, or for cultists who go to mass after the initiation ceremony. 'Incoherent'. Candomblé and Catholicism worship different 'energies', she keeps repeating. And: 'one needs to separate'. When asked whether syncretism was not the appropriate religion for mestiços, she stated:

People who practice syncretism don't believe in anything. It is a loss of force, of Axé. It doesn't make sense for me to take a fitinha do Senhor do Bonfim [a colored cotton ribbon with the name of the Bahian patron saint, said to bring luck] and put it on an image of Oxalá. Because the one thing has nothing to do with the other. It only adds to the folklorization of Candomble and it disrupts all that is connected to the Axé. These are other energies. Orixás are forces of nature, and the saints of the Catholic religion are elevated spirits, canonized, beatified. For us, they are Eguns [spirits of the dead] (in Campos 2003: 59). 
Purifying Candomblé, bringing orixá worship back to its own African being, is what drives Mãe Stella to the public sphere where her vision has gained much influence. There is an almost 'protestant' sternness to this vision of a purified Candomblé.

Today, the worst enemies of Candomble are those who practice it in an aleatory way. Those who do not know the fundamentos, who do not have the base nor the certainty as to what it is that they are doing. They distort everything. They are unscrupulous. The police, the State, the Church, they are no longer our enemies. Enemies are the so-called adepts. Those who distort everything, making a mess of Candomblé. The fanatics of other religions are enemies as well, but they can't harm us (ibid.: 6o).

Visions such as the one expressed by Mãe Stella and her ideologues, I would say, are expressive of what, in Lacanian thought, is referred to as the dream of 'symbolic closure'. They are essentialist fantasies that dream up the possibility to be fully restored to one's true original being; they promise to undo history, and the alienation it brought forth; they suggest that one can reach a state of being fully at one with one's imagined African self and with one's imagined African world. Indeed, in their own way, they promise a 'homecoming' or a 'reunion with the fullness of one's true being', and in that sense these dreams are not unlike the dreams that brought many curious outsiders to the threshold of the Candomble temples.

To call these visions 'fantasies' is not to say they are unreal. ${ }^{75}$ In the subjective experience of ritual performances, or in the subjective experience of reading a book, seeing a film or listening to a concert - with their appeal to the 'willing suspension of disbelief' - the worlds of one's imagination may come to be experienced as fully real. Moreover, invocations of the-rest-of-what-is, as discussed in the previous chapter, may produce world-engulfing sensations that wash over the cracks, tears and rents that prevent symbolic closure from happening. Here too, people may have experiences whereby their imagination of the world and their experience of it seem to coalesce. ${ }^{76}$ Recall for instance how Walmir, when remembering his encounter with the impossible flying saucer, whispered 'plenitude, plenitude'. Or recall my own sensations at the Avenida Oceânica, described in the introduction.

At this subjective, experiential level, then, a truly African Candomblé may be realized in the spectacles of the spirit possession ceremonies, in the drumming, the dancing, the chanting in Yorubá, the dressing up in 
Nigerian garments, and most of all, in the receiving of the African spirits. Indeed, at this level, all that it takes for this Africa to be real is 'the willing suspension of disbelief'. At several points in my field notes I keep instructing myself that a mere deconstruction of the splendid performances I had been witnessing will not do. Thus, after a visit to a particularly impressive celebration in favor of Xangô in terreiro Ilê Axé Aganjú in Lauro de Freitas, I wrote: 'when each and everyone is totally engaged, totally involved, totally immersed, it becomes kind of useless to question the authenticity of the Africaness that is being staged here. Tonight, I was in Africa. An Africa, perhaps. But Africa, nonetheless.'

However, to bring up such subjective experiences in public, to make them part of an ideological claim or a political project, necessarily means that such experiences of wholeness have to be made over to the symbolic order. And that, as Terry Eagleton and other Lacanian thinkers have explained, is impossible. The subjective experience of wholeness is lost once it has to be articulated in the play of difference that is language; in 'that knowledge-without-a-subject which is science or theory'; in the register of discourse, which is always characterized by 'lack, absence, difference, conflict, fissure, dispersal, fragmentation and heterogeneity' (Eagleton 2009: 5). Contrary to the fleeting sensation of a full and undivided identity that is possible in subjective experience, identity in the realm of the symbolic order can only ever be a thoroughly differential affair, '... a question of assuming a place in a symbolic order, a system of roles and relations in which you are an exchangeable function rather than a unique, irreplaceable, living and breathing animal' (Eagleton 2009: 6).

The impossibility to move the purism that is possible at the level of experience to a public level is well illustrated in a foreword that Mãe Stella wrote to the biography of the French anthropologist Gisele Binon-Cossard who turned mãe-de-santo in Rio de Janeiro.

... Omindarewa, a French girl born in Morocco, wife of a diplomat, an elegant mother to her children who then became the spiritual mother of many other sons and daughters, is now a wise lady of over seventy years of age ... Gisele Cossard, this French girl, was already called by the orixás at birth, which is surprising, given that she is a European woman by birth and by origin. Given the profession of her father, her cradle could have stood in many places in the world. However, she was born on the boundary between Europe and Africa: she saw the light, for the first time, in Morocco, a place where African culture is strong and active, as is most evident in its musical traditions. Nothing more natural than the calling of the 'African French woman' (françesa africana) by 
the Orixá in its plenitude. The divinity chooses who is worthy of him. When, at the age of 36 , Gisele was chosen by lemanjá to be her daughter, all was clear. These facts prove that, for the Orixá, there are no ethnic boundaries or any such thing (Mae Stella, in Dion I998: 7).

This text, I would say, exemplifies what a search for 'coherency' leads up to: a constant necessity to mend the rents and fissures that the classic narrative of an authentic African Candomblé produces. ${ }^{77}$ For the increasingly complex world in which Candomblé operates refuses to comply with the narration of purity. Boundaries between Candomblé and society at large are ever more permeable. Skillful reasoning may explain the presence of a French diplomat's wife in an African religion and safeguard the project of purity. Yet the presence of the non-African in Candomblé is not always that clearly marked. One area where this fact can be brought to light is the insertion of Candomblé in contemporary media practices. In what follows, I will show that the religious imagination of the people of Candomble is permeated by the aesthetics, formats and styles that dominate the public sphere of the media-saturated society that is Brazil.

\section{涴}

For all of the stress on the inarticulability of 'deep knowledge', and the insistence that only initiation will lead to a true understanding of Candomblé, my previous discussion of the video production by llê Axé Opô Afonjá called This is our Universe, this is our Belief already indicated that cultists have sought recourse to new technologies of (mass) mediation so as to mark their presence in the public sphere. Video productions are but one example. Terreiros have opened their own websites, published their own books and journals, launched CDs with sacred chants and rhythms, and have worked with documentary makers, photographers and artists. In addition they organize study meetings and festivals to which they invite the press, hoping to get (and often getting) media coverage. ${ }^{78}$

Although these developments have given rise to controversy and contestation, taboos on the use of new media have been questioned and renegotiated, and cultists are now reimagining their creed in the visual and discursive modes of new media, facing and addressing issues such as: what can be shown to the eye of the camera? What can be said in public? How - if at all - can new media convincingly represent the embodied knowledge that Candomble esteems? What style is to be employed? What aesthetics? 
With no religious guidelines that might inform attempts to visualize the realm of the sacred, and with no traditional iconography from which to build forth, cultists come to depend on the modes of perception and appraisal that they have cultivated as modern media consumers. In a country such as Brazil - with its huge media industry, its high rates of media consumption, and a social imaginary that is imbued with media images, styles and aesthetics - it is hardly surprising that religious and media imaginaries have become inextricably entangled. An emerging literature has explored this entanglement for many different religious denominations. ${ }^{79}$ Candomblé is no exception to this development. In their search for public representations of their creed, they have given more and more credit to new authoritative voices - people who may know little about 'deep knowledge', but who know all about 'looks', about what a good video production should look like, or a photograph, or a sound recording, or an article.

To show where things are heading at this point in time, I will focus on an emergent 'tradition' of making 'home videos', registrations of the important ceremonies that mark the progress of a cultist in the initiation process. ${ }^{80}$ The 'home videos' that I have obtained during my research and that I will analyze were made by and for cultists: they were produced as souvenirs of an important rite of passage in the religious life of an individual cultist, and were produced for what we might call their 'personal memory bank' (Morris 2000). That is to say, they were never intended to circulate beyond an inner circle of friends and relatives. To refer to Michael Warner's notion of 'the public' once more: in these video productions the 'particular' has not been stripped so as to be able to claim a universal 'public worth'. Unsurprisingly then, these home videos are strikingly different from the video produced by llê Axé Opô Afonjá that was discussed in the previous chapter. From a traditionalist's perspective, they evidence a very 'relaxed' attitude towards notions of 'Africaness', 'tradition' and 'authenticity'. And yet, these tapes are most certainly concerned with issues of authentication. What I will argue is that they tap another source of authenticity: they introduce 'televisual looks' - rather than 'African looks' - to authenticate their representation of a religious event.

\section{灌}

I obtained the home videos that I will discuss from a guy called Antônio. I first met Antônio on the occasion of an important ceremony called deká, the rite of passage that marks the change in status from initiate to ebomi 
('older brother/sister') and that opens the road for a cultist to establish his or her own cult house. Usually the deká is held after seven years, but in the case of Gil - the spirit medium whose rite of passage was being celebrated - it had taken fourteen years to accumulate the necessary financial means ('and wisdom', as someone later confided to me in private). The deká was held in the terreiro of Pai Wilson, a ramshackle construction in a poor and densely populated neighborhood in Salvador. The temple was packed. So much so that many visitors had to stand outside in front of the building. When Antônio arrived he carried a huge television camera on his shoulder with a spotlight fixed on top that lit up the entire terreiro as he entered. The camera was so big and unwieldy that it made me wonder how Antônio would be able to wrestle himself into the crowd. It turned out to be easier than I had imagined. Pai Wilson made sure that Antônio was given all the leeway he needed and could do his work to the best of his abilities. Acting as if he was the director on a film set, the priest pushed people backwards against the wall, ordered people out, and shouted angrily at some of his novices who did not help him sufficiently in accomplishing his task. When after a lot of drumming and singing Gil finally arrived - incorporating Ogum, the orixá to which he was initiated - it was again Pai Wilson who made sure that no one got in the way of Antônio and his camera.

So Gil/Ogum danced - swirling, bending, circling and shaking - and Antônio never left the possessed medium, moving backwards all the time to keep the camera and spotlight fixed on the dancing God. It turned into the strangest pas-de-deux. I was unable to say whether the camera was courting the God, or whether the God was courting the camera.

During a break in the ceremony, I walked up to Antônio, who was smoking a cigarette outside. I expressed my puzzlement over the fact that he had been allowed to film a religious ceremony of Candomblé.

'I've always been told one is not allowed to film the orixá.'

'I do it all the time,' he said.

He explained that his business was to produce and sell videos of weddings, birthday parties, or tourists on their tour of the city. Of late, Candomblé priests and priestesses had begun to ask him to make reportages of religious ceremonies as well.

'These are important occasions in the life of our people, so they want a video tape to remind them.'

He then gave me his business card, saying that he would gladly sell me a copy of the tape he was making. I suggested I would have to ask Pai Wilson to see whether or not he would agree with selling a copy of the tape, 
but Antônio (undoubtedly reading the covetousness on my face) brushed aside the suggestion.

'I don't know... just give me a call and we can settle this among ourselves. Pai Wilson has other things on his mind right now.'

A week later, I called Antônio to ask about the tape, and he told me he would pass by my house that very same day 'since he was going to be in the neighborhood anyway'. Some hours later he had installed himself comfortably on the sofa and readily accepted a beer, but it turned out that he had not brought the video and he proved hesitant to talk about his video productions on Candomblé. When I asked him whether he himself was into Candomblé he grumbled 'more or less' - keeping his eyes averted and clearly not feeling at ease going into the subject. He did tell me that he would be invited by priests to film 'all kinds of rituals', even matanças, the bloody animal sacrifices that are usually performed backstage, with only close affiliates of a temple being allowed to witness the event. But surely, these tapes cannot be sold, I intimated. Oh well, he had some very interesting tapes, and he might consider selling a copy. Including matanças? Sure. And what about temples that do not want their tapes to end up on the market? Well, you know, of course, some temples would order him to shoot a ceremony and then they would ask for the original tape to make sure that it would not enter into circulation. But others did not care about such things.

'Not everybody is the same, you know.'

From the tone of his voice I could tell that I had clearly been too pushy. Antônio selling videotapes of Candomblé ceremonies was in such flagrant contradiction to my experience that people from Candomblé were extremely cautious as to what they will reveal about their religious life, that I could not resist asking him one question after another. Yet it was obvious I was on my way to spoil a potential informant on mediation and Candomblé. Having expressed my surprise over his business I had revealed myself not to be the ignorant tourist he had probably figured me to be: Antônio seemed not at all happy with where the conversation was heading. He cut my questioning short, saying it was 'just like weddings, people simply want a tape to remember the happy event', finished his beer and said he had to go on. Later that week, however, he called me to ask if I still was interested in buying some tapes. He told me the kind of money he expected for a tape and insisted we were to meet on anonymous ground for the transaction to take place: a gas station in a neighborhood called Engenho Velho. 
When we met he acted cool. Laughs and jokes and cordial handshakes. But he could not hide the fact that he was nervous as he handed over the tapes. I drove back home, a trophy hunter after a successful raid. The considerable sum of money I had had to pay was already forgotten. They were mine: a number of videotapes with registrations of religious ceremonies of Candomblé, shot by a semi-professional videomaker from within the community. Secrets materialized. A native's point of view that could be wrapped up and shipped back to my office in Amsterdam.

The videos turned out to be of dreadful quality. They were copies copied onto tapes that had already been used, and were of the cheapest quality. Having seen their content, however, I could not care less...

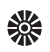

Of the three tapes that I had bought from Antônio, the first one showed Gil's deká - the one where I had also been present (I appear on the tape a few seconds, a sweating white man standing in a corner chewing gum). In striking contrast to the video produced by Ilê Axé Opô Afonjá that was discussed in the previous chapter, this tape lacked any clear political or educational objectives. The video was clearly produced for internal consumption only - its circulation was to be restricted to a circle of relatives and friends, rather than to address an imagined 'world out there' which presumably needs to be instructed about 'our universe and our belief' or corrected in its 'erroneous views' on Candomblé. ${ }^{81}$

The registration of the deká ceremony on videotape reveals a number of things about the use of a video camera within the temple walls. To begin with, there is no great concern with the performance of the secrecy principle. Possession trance is filmed without any reservation, and Antônio had apparently been taken backstage as well, to make a shot of the splendor of the food and the presents in their lavish display.

Second, as a self-portrait, the tape obviously seeks to communicate the splendor, success, and prestige of Pai Wilson's house. There should be no doubt in the viewers mind that this was an occasion with lots of axé. In this respect, the tape is not very different from the one produced by Ilê Axé Opô Afonjá. Although addressing another audience, both seek to enhance the prestige of the house they show. Where the two tapes do differ, however, is in the language of 'success' they employ. Ilê Axé Opô Afonjá builds its prestige on such notions as 'Africa' and 'ancient traditions', and on its employment of an artistic 'avant-garde' aesthetics, with abstracted imagery, shadow plays and Martha Graham-esque Ausdrück- 
tanz. The video made at Pai Wilson's house employs a radically different vocabulary: it takes a lot of time to show the many guests of importance who were present at the event, 'dressed to kill', and in addition it borrows its notions of prestige and splendor from society at large, in particular from the way 'glamour' is represented in the world of the popular media. This is most clearly the case in a lengthy shot of an almost surreal marzipan portrait of the spirit Ogum on a huge birthday cake, framed by garlands of little whipped cream rosettes and with the name Ogum written in golden syrup. The scene where Gil/Ogum dances towards the camera with his arms full of bouquets of roses wrapped in rustling cellophane that he had received from the cultists of the house has a similar 'popular' look.

Third, it is interesting to note that, whereas the tape produced by llê Axé Opô Afonjá seeks to correct public representations of Candomblé, the video made at the house of Pai Wilson attempts to absorb the 'iconic' representations of Candomble that one finds in the public space. The portrait of the orixá Ogum on the marzipan top of the birthday cake, for example, is clearly a reproduction of a painting by the aforementioned painter Carybé. The ceremonial outfits of the possessed mediums also seem to be 'frozen in time', so as to be compliant with this public 'look' of Candomblé. In an intriguing reversal of Michael Warner's argument, the prestige of that which is public, i.e. that which transcends the idiosyncrasies of any one particular house, is here being 'contracted' for the greater glory of one particular event: Gil's deká.

Finally, it needs to be noted that the presence of the camera itself during the ceremony is a clear sign of prestige: the leeway given to Antônio to make his shots, and the way the camera presence was allowed to dominate the event, show how media presence may upgrade the importance of a religious event. This idea that within the temple walls, religious notions are increasingly articulated through (and religious rituals increasingly employ) 'languages' originating in and pertaining to the public sphere plunges the Antonio tapes squarely in debates on media and the religious imagination. The two other tapes that I obtained through the deal with Antônio will serve to elaborate this point.

\section{澏}

The other two tapes contained the registration of a celebration in honor of lemanjá - a so-called third year's 'obligation' - and a celebration for Ossaim, Orixá of the virgin forest and medicinal leaves. Both were shot in terreiros that I do not know. The editing of these tapes is remarkable, as 
the registration of the religious ceremonies has been formatted as if they were an episode of a telenovela or a miniseries. Priests and initiates are being announced in a title sequence as if they were actors, and important visitors are literally being announced as 'special guest appearances'. On the lemanjá tape, the woman who was responsible for the celebration is portrayed in a baroquely decorated oval frame (in the full attire of a medium for lemanjá, and judging from her facial expression in a state of possession). As the names of the 'actors' roll over the screen, the imagery shows a collage of footage that seems to have been copied from different sources: jumping dolphins, whales in a bay surrounded by snowcapped mountains, surfer waves, seashells, bikini beauties from Copacabana beach, tropical fish in an aquarium and shots from the yearly Festa de Iemanjá in Salvador, a massive picturesque gathering where hundreds of thousands make floral offerings to the goddess on a beach in one of Salvador's suburbs. The Ossaim tape is similarly formatted as a TV program, but as this one concerned a celebration for the orixá of the forest and medicinal leaves, the title sequence shows images of woods, flowered alpine meadows, plants and trees.

What is most intriguing about these tapes is the fact that these registrations of Candomblé ceremonies have been framed as 'televisual' realities. They exploit the style and format of a TV program, and have no qualms about mixing religious ceremony with TV imagery. They obviously play with the fact that video offers the possibility of 'miming' television. When I met Antônio on another occasion, later during my fieldwork, and asked him what had made him decide to use these particular formats and images, he said that the priests had asked him to do it that way. He explained that my-wedding-as-an-episode-of-a-telenovela was a very successful formula for wedding reportages. Birthday videos, or the videos registering the celebration of girls reaching the age of $\mathrm{I} 5$ were also oftentimes edited in such a way that this special day looked like an episode from a soap opera. Another format he would use was called 'The making of...', whereby he had to follow the bride-to-be buying her clothes, being groomed at the hairdressers, etc., just as the camera would take you behind the scenes of big musical productions or to the set of major film productions.

Such examples really beg the question how televisual realities impact on people's lives. Why would one aspire to be 'just like on Tv'? Certainly, the televisual mimicry evidenced in the videos of the Iemanjá and Ossaim celebrations can be linked to the issue of prestige. The importance and prestige of the televisual medium itself - the recognition that television is the prime arena where judgment is passed as to what is noteworthy and 
what is forgettable - is used to upgrade the prestige of the celebration. The presence of the camera during the ritual, and the subsequent appearance of the event on the television screen offers the delightful fantasy of 'having been on TV' - and thus of having been important enough to be in the eye of the nation (cf. Couldry 2003). And yet again, when contrasted to the Ilê Axé Opô Afonjá videotape, one begins to sense that something more might be at stake in such mimetic moves.

Of course, at first sight one is tempted to say that the insertion of bikini beauties and alpine meadows in the depiction of a religious ceremony bears witness to the fact that both the producers and consumers of these videos are not at all concerned with questions of authenticity. This is a plausible enough interpretation if authenticity is understood in the 'classic' sense of a restoration of Candomblés 'African roots' and 'ancient traditions' as envisioned by llê Axé Opô Afonjá. And yet we need to ask ourselves if it might not be the case that these videos seek to produce an authenticity of another kind. Could it not be that the source of authentication that these videos draw upon is not Mother Africa, but television itself? In other words, could it not be that these videos seek to inscribe Candomble rituals into the real of everyday realities by using televisual styles and formats?

In an interesting analysis of the appeal of the telenovela in Brazilian society, Esther Hamburger manages to convey just how much this genre has entered the collective imagination of the Brazilians. She argues that the telenovela, being for everyone, and therefore for no one in particular, is an important ingredient in the glue that holds the Brazilian nation together (Hamburger 1998; see also Oosterbaan 2005). Topics raised in telenovelas become national debates and the styles they divulgate have pervaded people's sense of propriety. What Hamburger maintains about telenovelas can easily be extended to talk shows, miniseries and other TV entertainment: it is in these televisual genres that Brazilians are taught how to dress, how to decorate their homes, how to celebrate their birthdays, how to seduce their lovers and how to manage their marriages. Clearly, the great majority of Brazilians encounter many (often insurmountable) obstacles in their aspiration to live up to such televisual teachings, but I can only concord with Hamburger that the great majority continuously tries, because '...in copying the models of telenovelas, television spectators show that they are "into it" and show their willingness to move beyond the limitations imposed upon them by their social conditions, their identity, gender or race' (Hamburger I998: 443). 
I can think of any reason to assume that the televisual teachings of 'what life ought to look like' would halt before the realm of the religious. To stick to the case of Candomblé, anthropologist Rita Laura Segato has made it abundantly clear that people from Candomblé are as avid television spectators as other Brazilians:

In 1980, during the last period of my fieldwork among the xangôs [another Afro-Brazilian spirit possession cult] of Recife, I found myself hindered by an obstacle that was as unforeseen as it was inconvenient. All the days of the week, from Monday until Saturday, at eight o'clock at night, the [cultists] would stop their domestic tasks or rituals to watch the telenovela. Whether toques [celebrations in honor of the orixás] or boris, the ritual washings of the head that open up the complex sequences of the initiation ritual, everything, literally everything, would only start after the last scene of Água Viva was over [Água Viva being the prime time telenovela of that period]' (Segato 1994: 52).

A more recent example as to how the telenovela captures the national imagination, including the imagination of Candomblé, concerns the $\mathrm{O}$ Globo telenovela Caminhos da Índia (Roads of India), broadcasted in 2009, which takes typical Brazilian romantic drama to an Indian setting, replete with saris, elephants, incense and Hindu gods. Visiting Bahia in this period, I was struck how Lakshmi and Brahma were on everybody's lips, familiarized as if they were Brazilian gods through-and-through. Bookshops in Salvador had put up special displays of books on India, Hinduism and curry; the owner of the one India garment shop on Avenida Sete de Setembro, a shop I had seen withering away for years, smilingly told me 'business had been very good, very good indeed!'; and a spirit medium, who had been advertising her consults all over town using the image of the sea goddess lemanjá, decided to reprint her posters with an image of the elephant-headed Hindu god Ganesh. At the open-air market of Sete Portas, the Hindu deity Lakshmi had received a prominent place on the altar of a shop owner.

With the people from Candomblé being as enchanted with $\mathrm{TV}$ as everybody else, it should come as no surprise that in honoring their spirits, they seek recourse to televisual styles and formats. However, the question of what it is that these styles and formats offer to the religious imagination needs to be pursued further. 


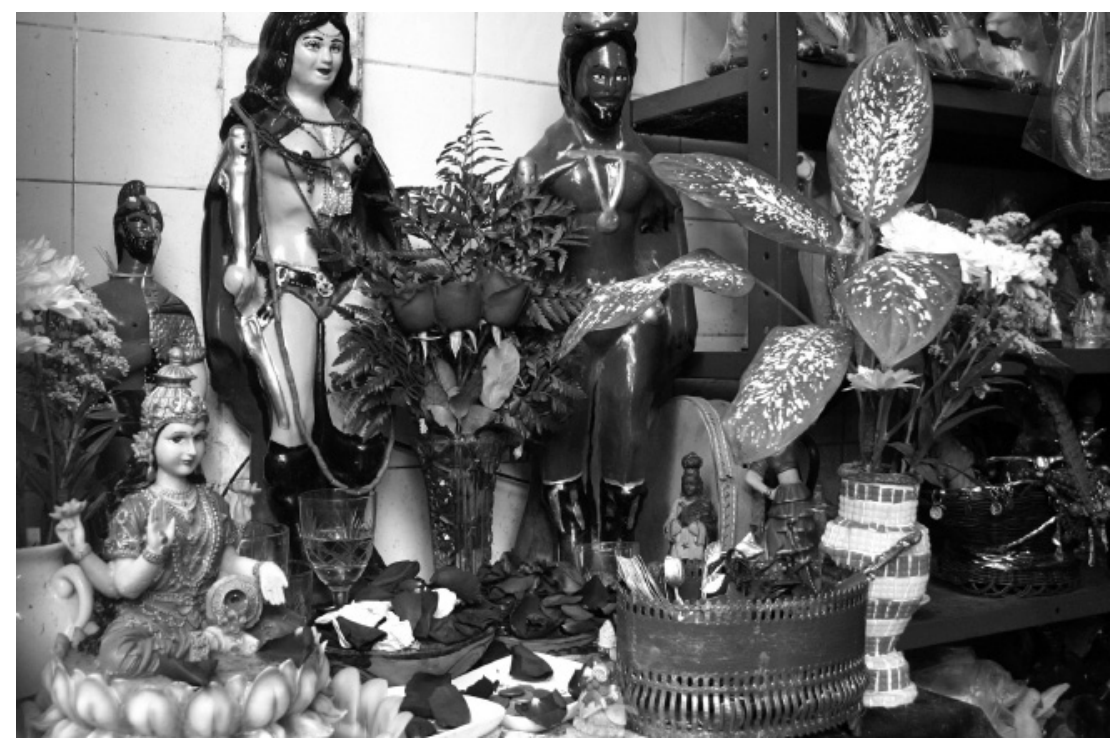

Figure 20 Candomblé altar in Salvador. The statue on the left is the Hindu

deity Lakshmi

The Antônio tapes make it strikingly clear that technology never comes in a 'purely' instrumental or material form, as sheer technological possibility at the service of the religious imagination. It is exactly as Antônio told me: media technologies have been developed and used in other settings and arenas (in Antônio's case weddings, birthday parties and tourist outings), so when they enter the field of religion they come with a history. The priests and initiates who ordered Antônio to produce these tapes also wanted their ceremonies to look something like wedding videos. Introducing video cameras, in other words, implies the introduction of more or less fixed formats and styles, and these in turn imply established opinions as to what televisual realities ought to look like.

A discussion of the notion of 'style' may prove helpful to deepen an understanding as to why people would want to cast the important moments of their religious life in a 'televisual look'. A style coordinates all the channels through which meaning is communicated in such a way that unity is achieved at all levels of experience between what is being said and how it is being said (Douglas I976: I05). Therefore, within a certain style there will always be the tendency to subject all the elements to its demands. Elements that do not 'fit' into a style are easily recognized, and produce the sensation that 'something is not right': the mediated notion does not convince. In her discussion of the 'pentecostalization' of the pub- 
lic sphere in Ghana, Birgit Meyer highlighted the relevance of the notion of style for the study of religion and media. Style, she argues, is akin to Foucault's notion of discourse, in the sense that it imposes its own regulations and constraints on its users. What links people to a certain style, however, '... is not that style's capacity to make true statements about the world but, rather, the mood it radiates. Style, by putting things in a certain way, speaks to, as well as evokes, emotions. Employing an ensemble of recurring key terms and conventions, 'style makes people feel at home in, as well as confident with, a particular discourse' (Meyer 2004: 95, italics mine).

This capacity of a style to bind people together by making them feel comfortable in a particular discourse attests to the importance of the concept for the social scientist. The effect of a narrative that does not 'fit' into a style, or proves incompatible with media formats, far exceeds an affront to aesthetic sensibilities: it risks being unreal.

This point is brought to the fore most forcefully by Michel de Certeau in a discussion of how media produce their own standards of credibility. Media formats and styles - de Certeau speaks of 'narrative models' - are far more than the mere 'packaging' of a narrative. In contemporary societies, where people are exposed to a non-stop media bombardment, they have a 'providential and predestining function' (Certeau I984: I86). Through constant exposure, people become so accustomed to certain styles and certain formats that these have come to shape people's sense for what is convincing or credible (not to mention their sense for what is hip or old-fashioned, cool or outdated, desirable or distasteful). What de Certeau maintains, then, is that televisual formats and styles 'have the twofold and strange power of transforming seeing into believing, and of fabricating realities out of appearances' (I984: 187).

The relevance of these thoughts for religions that seek to access the public sphere, and face the task of being publicly credible, should not be underestimated. Success in the public sphere means accessing broadcast media, and accessing the media requires playing along with the stylistic and 'formatic' requirements that lend credibility to the mediated message. Following de Certeau, a religious ritual, broadcast on television, convinces first and foremost by looking like a 'professional' Tv registration, that is: by avoiding any breach with televisual styles and formats. Similarly, a sacred narrative transmitted through radio will have to be compatible with the dominant styles and formats in radio production. It becomes credible because it is convincing as a radio format, not because of its content. Charles Hirschkind, in his study of (cassette) taped sermons in Cairo, shows that the Islamic preachers who prove to be successful in what is a 
highly competitive market, are those who have sought to engage the tastes, desires, and sensory experiences of media consumers (Hirschkind 200I; cf. Öncü 2006). In his discussion of the appearance of TV-personalityspirits (among a wide range of equally fantastic spirits) in the celebrations of the Venezuelan Maria Lionza cult, Rafael Sanchez states that televisual realities have trickled into the cult's practices from all sides. Spirit possession, says Sanchez, 'literalizes Tv', as the spirits greet their audiences in formulaic statements reminiscent of the statements by anchorpersons on Venezuelan television; and all during their performance they use 'the codified speech patterns, bodily language, and dress styles that the media has popularized for a large gallery of characters' (Sanchez 200I).

So how to describe the particular styles that make up the Brazilian 'televisuals' that media consumers in this country have grown accustomed to - so much so that they feel 'at home' in them? What is the 'ensemble of recurring key terms and conventions' that makes up the televisual style? Searching for an answer to these - admittedly somewhat grandiose - questions, I consulted a Brazilian manual for television production and direction (Bonasio 2002) assuming that here I would find the basic guidelines Brazilian TV-producers work with. Reading such chapters as 'writing', 'aesthetics in the media', 'presenting and acting for television' or 'lighting for television' it became evident that I could in fact have picked any manual from any other place: the 'language' of TV-making seems entirely universal. Nonetheless, reading the manual was a revealing exercise as it conveyed a clear sense as to what is particular to televisual styles.

'Perfection' is the word that probably best captures what Valter Bonasio's readership should strive for when producing television programs. The televisual world is a world of perfection. Take the telenovela. Whereas the telenovela characters are victims of the most capricious whims of fate, living tumultuous lives full of drama, stylistically they are never out of control. These characters never mumble, or stumble over their lines, but always articulate their words clearly. They may be thrown out of their homes and end up living in the gutter, but never ever will they have a pimple on their face or a dripping nose. The kitchen sink unit in their home may be a mess - if that is what the story line requires - but it is never a dirty mess (let alone a stinking mess). It is a well-arranged mess. In talk shows it is no different: conversations should be smooth, messages should be clear, and although drama is sought and produced (there is a lot of crying going on in Brazilian talk shows - with the talk show host often joining in) guests should at all times produce coherent stories. Needless 
to say, the Kleenex should always be within reach, and the weeping guests should show concern over their mascara and makeup.

Defining television as a most 'intimate' medium, that is being watched 'in the intimacy of the home, from only a few meters distance', Valter Bonasio's manual puts great stress on 'looking natural'. We read: 'For television, it is absolutely essential that the presenter acts in an easy-going and comfortable style. Naturalness is the key word for you to appear well on TV' (Bonasio 2002: 203). The way to achieve this 'natural look', however, is not relaxation but absolute control. Over and over again, Bonasio instructs TV producers and directors to be in full control of every single detail. Do not use office chairs so the presenter will move and turn unnecessarily. Do not use jewelry that might tinkle and do not use it excessively. Do not gesticulate. If people refuse makeup, take a shot and show them what they look like in the studio lights. Use discrete colors, because they look better on $\mathrm{TV}$. If you want to be taken seriously on television, dress yourself in accordance with the style and format of the program (...) because clothing speaks about the person even before a single word has been spoken' (Bonasio 2002: I43).

What this television manual brings to the fore is that televisual realities radiate perfection, and such a description may be more accurate than other possible descriptions of televisual styles such as 'modern' or 'urban'. The cultists who hired Antônio to make a video of their rite of passage and asked him to make it look like a telenovela, wanted to position their 'future remembrance' of this important moment in their religious life in this same world of 'perfection. ${ }^{82}$

The person who came closest to putting it that way during my research was Clarice, a middle-aged medium. We were watching a videotape that registered the celebration of the I6th birthday of the bond between a spirit called Martim Pescador and her sister, and referring to the way she was dressed for the occasion she said: 'For my orixá $\mathrm{I}$ only want the very best.' The 'very best' was a green evening gown - green is the color of the orixá Oxóssi - a glittering and glamorous affair, that could have been taken out of a I950s Hollywood production. Clarice's 'very best' was not something she learned from the dominant voices of Candomblé in the public sphere who are busy redefining Candomblé as an African religion, and who would probably have wanted Oxóssi to look like an indigenous hunter, with feathers and wax prints and raffia. Her notion of the 'very best' was rooted in the glamorous world of perfection that she watches every night in front of the television. 
The home videos that I have discussed counter both sacerdotal and anthropological portrayals of the cult as a sovereign universe that is somehow immune to the world in which it operates. They unmistakably speak of a desire on the part of cultists to bring their religious activities into consonance with their daily life worlds (rather than locate these activities in an imagined 'traditional Africa'). Employing a 'televisual' language and style - that speaks to the tastes and aesthetic ideals of Brazilian media consumers - these tapes signal the cultists' wish to make their enthusiasm, faith, dedication and love towards Candomblé known and understood for an imagined public that is located beyond the strict confines of the temple - a public, moreover, they consider themselves to be part of. In other words, what these tapes seek to communicate is that you may impress some re-africanizing hardliners (and the odd anthropologist) by dressing up in Nigerian garments - but your mother, neighbors and colleagues from work will definitely be more impressed when a celebration marking an important moment in your religious life 'almost looks like TV'.

The broader relevance of this finding is that it confronts us (once more) with the extent to which television is emanating an 'aura' that is all its own, and bestows blessings on all that is caught in its blue lights. What is more, in a thoroughly mediatized society such as Brazil, television has become the authorizing medium par excellence, the site where the shift is being made between what matters and what not, between what is noteworthy and what can be ignored, between what is merely of individual interest and what should be brought to the attention of the nation. Whatever is processed and emitted by television gains importance, prestige and status. And whatever seeks to mirror its forms and styles may expect to appear 'larger than itself'. Television, in other words, is a major production site of social value, and the locus where individuals and groups alike seek to realize themselves.

The observation that the expressive potential of modern mass media is used to both authenticate Candomblé (by inscribing it into the real of the cultists' everyday life world) and authorize Candomblé (by expressing its value in a language of prestige that is universally accepted and understood) clearly calls for a revision of ideas still current in many religion and media studies where the presence of modern mass media in the realm of religion is largely understood in terms of a secularizing agent, destined to 'cheapen' authentic messages and to dissolve religious identities shaped within the confines of 'traditional' settings. Clearly, the material that 
I have presented here does not allow for such an antagonistic and onedimensional portrayal of the relationship between media and religion. The spheres of modern mass media and Candomblé are linked in unexpected and complicated ways. New media technologies open up new possibilities for the religious imagination, just as they cast existing practices of mediation in a new, and not always favorable, light. Jeremy Stolow's remark that media and mediation constitute inherently unstable and ambiguous conditions of possibility for religious signifying practices...' (2005: I25) is therefore accurately phrased and an important reminder as to what we should expect to find when studying the relationship between religion and media: an ongoing struggle over the proper way to render present the sacred.

My second example of the inextricable entanglement of religious and media imaginaries - and hence of the permeable boundary - focuses on the way that, in a thoroughly mediatized society such as Bahia, the public articulation of religious authority comes to depend more and more on 'celebrity discourses'.

Throughout my research, I was struck by the fact that the birthday or funeral of an important priestess, an important ceremony in the "liturgical' calendar of Candomblé, the reopening of a prestigious temple, or the official recognition of a temple as part of Bahia's patrimony (tombamento) have become important media events. Celebrities from the world of politics, culture, and media and members of the Candomblé priesthood use these events to appear jointly in front of cameras and microphones and thus make public their mutual links, affinities, and affections. Elsewhere, I have discussed this exchange of 'mediatic' and 'religious' aura in detail (van de Port 2005c). Here I want to focus on the single aspect as to how the imaginaries of media and religion become inextricably entangled.

The priestly ambitions to go public, and assert themselves as the true voice of Candomble, confront them with the issue of how to establish their authority as religious leaders in terms that will appeal to the public at large. The resources available to the priesthood to put together a convincing performance of religious authority within the religious community add up to little in the public sphere. A mass audience is not informed about the weight and importance of such traditional resources of priestly authority as 'seniority' (in terms of the initiation process); the 'standing' of one's religious forebears; the accumulated power of axé as it is manifested 
in the pomp and splendor of ceremonies; as well as the terms of address, the ritualized salutations, and the thousand-and-one little dos-and-don'ts through which the temple hierarchy comes into being. Claiming authority in the public sphere has thus forced the priesthood to find new modes of address. They now have to speak a language and employ a vocabulary and imagery that will serve their claim to be recognized as 'the authentic and authoritative voice of Candomblé.

Part of what they have to realize is 'public intelligibility'. In Bahia, priests and priestesses can of course seek to embody the iconic representations already present in the public sphere, and this is in fact what many of them do. Yet priestly power also gets somehow 'translated' in the terms of (powerful) others.

Again, the example of Mãe Stella from Ilê Axé Opô Afonjá is most instructive. As stated, she has always been a staunch advocate of the recognition of Candomblé as a religion in its own right, and even in her old age she is crusading against earlier understandings of Candomblé as a 'cult', 'sect', 'animistic practice', or 'Negro folklore'. Driven by the spirit of the classic, she also dismisses all forms of syncretism with Catholicism as 'a relic of the past'. A restoration of the 'African purity' of Candomblé is what her terreiro is after. Mãe Stella seems to be well aware that the public sphere is the arena where this fight for recognition has to be fought, and although a visibly media-shy figure, she does seek publicity to pursue her politics. As we have seen, she has published a number of books, gives public speeches, and appears on TV and in the newspapers. Although her politics have been highly successful, this success comes at a cost. Take the following laudation for Mãe Stella that I found in a Bahian newspaper. The text mentions, among other things, that

... the priestess was chosen by the United Nations to represent the tradition of the orixás in Rio de Janeiro, next to the most diverse religious leaders such as the Dalai Lama of Tibet and Rabbi Henry Sobel. As a recognition of the utmost importance of the cultural and social work that Mãe Stella has done in Bahia and in Brazil she has been invited to conferences at universities and international institutions such as the Brazilian Contemporary Arts in London, Harvard University in Washington, and the Caribbean Institute in New York. The priestess also received the medals 'Maria Quitéria' and the 'Ordem do Cavaleiro,' the trophies 'Esso' (a prize for black writers) and 'Clementina de Jesus,' and a great homenagem by the Bahian people in 1995 (...) To foreground her dedication and activities to strengthen the Candomble religion with its traditions of thousands of years, Mãe Stella has now received from the Federal 
Government the medal of the 'Order of Cultural Accomplishment,' and will see her temple of Ilê Axé Opô Afonjá be declared to be part of the National Historical Patrimony. ${ }^{83}$

I can hardly think of a better demonstration of how the simple fact that Candomblé has accessed the public sphere profoundly changed the articulation of priestly authority - indeed, how Mãe Stella became dependent on public criteria to argue her authority as a religious leader beyond the walls of her terreiro. In Candomblé ethnographies (as well as in Mãe Stella's own publications) the sources of sacerdotal power and prestige - and consequently, authority - are always explained in religious terms. We thus learn that in Candomblé, religious knowledge can only be obtained by going 'through the motions' of the ritual cycle, year in, year out, and it is only with the passing of time that the embodied knowledge the cult seeks to install in its adepts 'sinks in'. Within the temple walls, the length of someone's initiation is therefore the prime criterion of religious authority: authority is with 'os mais velhos' - 'the oldest', i.e. those who are in the know (Lima 2003).

In the public sphere, however, the authority of the priestess can no longer be solely based on her having lived up to such religiously defined criteria. If a priestess like Mãe Stella wants to be publicly recognized as an authoritative voice, she needs to have recourse to a form of impression management that stresses values that a much wider audience is able to recognize and appreciate. And thus we are served this cocktail of fame that mixes 'worldwide recognition' (Mãe Stella's election by the United Nations, and invitations to travel to places around the world) with academic prestige (Harvard and other universities), state decorations, and the full weight of Culture. The juxtaposition of Mãe Stella with the Dalai Lama and Rabbi Henry Sobel puts them on equal 'auratic' levels. What the laudation makes visible then, is that the resources to construct a public notion of Mãe Stella's authority differ hugely from those that make up the display of authority in her own temple: in the laudation, the priestess comes to represent ethnic, traditional, cultural, and socio-political values, rather than religious ones.

It is hard to miss the irony in all of this. More than anything, it was Mãe Stella's vision to 'restore' Candomblé to its status of 'African religion' that drove her to the public sphere. Out in the public sphere, however, all kinds of extra-religious qualities have to be mobilized so as to create a publicly recognizable profile of authority: what we find, then, is that her authority as a religious leader is rooted in the culture politics of the Bahian state, 
in her representing Afro-Brazilian culture, and increasingly in her being simply 'famous'.

Public intelligibility is not the only issue to be dealt with when a public authorization of being the one-and-only authentic voice of Candomblé is on the agenda. What priests-going-public need to accomplish as well is public credibility, and it is this issue that takes us linea recta to the murky meeting ground of religious and media imaginaries that were already explored in the videotapes. As stated in my discussion of the home videos, the credibility of a religious leader is to be realized in a media performance, and due to this fact new standards come into play: standards that may have little to do with the religious notions as developed and understood within the confines of a particular religious community, but all the more with the cultivated modes of perception and appraisal with which modern media consumers judge media performances. And with these new standards, new authoritative voices gain prominence: the voices of media experts, artists, designers, people who know about 'looks' and media 'appeal', and most of all, the people who embody the successful mix of all these things: celebrities.

\section{落}

One example of how celebrities come to back up public statements about religious power is a leading article in Carta Capital, a prestigious Brazilian monthly. The article was titled 'The Power of Candomblé' and reported the reopening of Gantois - a famous Candomblé temple in the Bahian capital Salvador that had been closed for four years awaiting a successor for the deceased priestess. ${ }^{84}$

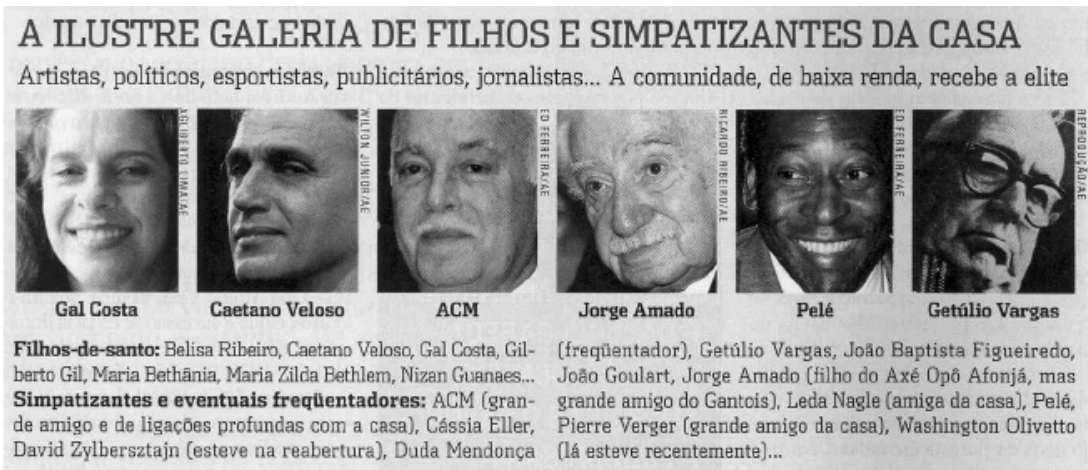

Figure 21 'The illustrious gallery of initiates and supporters of the house' Courtesy of Carta Capital 
In a separate text box, the article contained a series of photographs of famous people under the title "the illustrious gallery of initiates and supporters of the house'. We see pictures of such mega stars as singers and 'Tropicalistas' Gal Costa and Caetano Veloso, next to the Bahian leader ACM, writer Jorge Amado, soccer player Pelé, and the former president of the republic, Getúlio Vargas. ${ }^{85}$ Underneath the photos are written the names of a great number of other celebrities who visited the Gantois temple, or may be considered 'grandes amigos of the house'. Fame is the common denominator of this heterogeneous collection of individuals, and it is the fact that famous people frequent Gantois that should convince the reader that the temple has access to a tremendous reservoir of occult powers. In other words, the logic being followed in this rhetoric suggests that Gantois is a powerful house because that is where the celebrities go.

The rhetoric of this article is effective because in Bahia - like just about anywhere else in the world - more and more people imagine that the locus for ultimate self-realization is a spot in front of a television camera and that 'a worthy life' is a life that is taken to be noteworthy by the media (Couldry 2003). When my Bahian friend Xandra had asked her sixyear-old niece what she wanted to be when she was grown-up, the little girl had instantly answered that she wanted to be 'famosa' - famous. 'She didn't even know to say famous for what!' Xandra exclaimed. 'In our days we wanted to be medical doctors, or teachers, or stewardesses! But now everyone just wants to be a celebrity. Even a six-year-old can't think of anything else!' I came across many similar stories. Edson, a recent migrant to the city, contemplated writing a letter of admission to the reality show Big Brother Brazil, as a daily appearance on the O Globo network would surely mean a ticket out of poverty. Gean was convinced that some spectacular suicides attempts, kidnappings, or particularly gruesome murders were first and foremost attempts by the perpetrators to have their 'five minutes of fame. And Christina, who was about to visit Rio de Janeiro for the first time in her life, dreamed not of visiting such highlights as the Sugarloaf Mountain or Corcovado, but of the possibility to visit the studios of the broadcasting giant O Globo, where she hoped to meet the stars as they went to work.

I also found a whole media industry catering for the dreams and desires that the notion of 'fame' engenders. Gossip magazines, weekly celebrity talk shows on Tv such as Show de Fama, society columns in the newspapers, fan clubs and websites dedicated to this or that celebridade, TV shows such as Big Brother Brazil or Princeza de Um Dia, and several Shows de Caloures ('talent scouting' shows) provide a concrete avenue to the much desired 
fame and make the promise that 'you too can be famous' seem to be ever more realistic. This cult of the celebridade in Brazil is such a pervading and ubiquitous facet of contemporary social life, that it is regularly mocked in television comedy, portrayed in a recent telenovela (called Celebridade) and discussed in bestsellers with titles such as The Divine Comedy of Fame. Purgatory, Paradise and Hell for Those who Dream to be a Celebrity (Sá 2004) and Smile, You are Being Filmed! (Silva \& Mello 2004).

It is once more Michel de Certeau's notion of 'belief-energy' (I984) that is helpful to understand the appeal and success of the celebrity discourse. De Certeau observes that people's capacity to believe, to invest certain propositions or institutions with their 'belief-energy' is no longer directed towards the domains of institutional politics and institutionalized religion. The places, objects, and propositions deemed worthy to invest with our capacity to believe, de Certeau maintains, are found in the cinema, the soccer stadiums, the sports in general, the arts, the concert halls and pop festivals, and more generally, the leisure activities in which we engage. These are the areas where heroes and idols are made, and it is in these areas that the projects can be found to which lives are devoted. One cannot but notice that these areas where de Certeau finds belief-energy concentrated are also the 'natural habitat' of the stars.

In Bahia, much of this is immediately visible. Numerous scholars have pointed out that in all of Brazil, the religious field is characterized by the crumbling hegemony of the once all-powerful Catholic church, and what has followed is a 'fluidity' of belief and religious 'nomadism' (Montes I998). The political field, given overall corruption and a state that continues to fail as a provider, goes from one credibility crisis to the next. Soccer, music, TV-drama, dance, carnival and other street festivals, however, are vital strongholds of belief-energy. And this is where the celebrities come in. Through what must be a complex trafficking of emotions and fantasies - cinematic experiences that make themselves felt in the field of politics; the thrills of the concert hall that become relevant to the sphere of religion; standards for what makes a convincing performance by an actor, musician, or sportsman being employed to judge the performance of the politician or the religious leader - media idols are made into receptacles of our belief-energy. This, I would say, might explain why celebrities have become so crucial in the public articulation of authority and leadership. For it is their capacity to enchant, to make us believe - wholeheartedly - in their art that political and religious authorities are after when displaying their connectedness to the 'stars', or when casting their public personas in the celebrity model. 
This line of reasoning might explain why priests overcome their media shyness and open up their terreiros for the cameras to show the world how celebrities have come to their premises - just as it explains all those joint media performances of Candomblé priests with the fine fleur of Bahian society. What the priests get out of these media performances is public credibility. How that works is best illustrated in a discussion of a new media figure: the celebrity pai-de-santo.

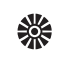

Augusto César is an interesting example of a Candomblé priest whose public authority seems to rest on the exploitation of the 'celebrity' discourse. This priest was initiated in Gantois, and runs a posh temple in Lauro de Freitas, a neighboring town of Salvador. He frequently appears in the society columns of newspapers, celebrity magazines, and online gossip sites. In the articles that I found the priest is portrayed as a curious mixture of the 'chic' of high modernity and the 'primitivism' that Candomblé still evokes. 'His Candomblé has nothing to do with pretos velhos [the spirits of old slaves]', is how one of the articles opens. ${ }^{86}$ 'To the contrary, the babalorixá is a spiritual guru for artists, socialites and businessmen of the high society in Rio. His consultations cost a fortune, but the beau monde thinks it is worth the value.' César's fame is constructed in several ways. There is certainly great stress on his being a native from Bahia (considered to be the cradle of Candomblé and therefore a source of authenticity: in one of the articles, the readership is informed that César has all the ingredients he needs for his Rio de Janeiro clientele directly flown in from Bahia, Terra dos Orixás). The fact that he is from the 'line' of Mãe Menininha, the legendary Bahian mãe-de-santo who died in 1986 is equally highlighted. ${ }^{87} \mathrm{In}$ one of the articles, an 'old lady' is quoted as saying, 'I just love Candomblé. Augusto is noble; he is from the line of Mãe Menininha. He follows the traditions, but at the same time, he is so sophisticated!'

It is this juxtaposition of tradition and contemporary chic that dominates all reports on the priest: the journalists obviously cannot resist the ticklish effects of the incongruities that the story of Augusto César holds in store (nor, admittedly, can I...). 'Given his fear of flying, César sits in a plane with amulets in one hand, and a strip of Lexotan in the other.' Or: 'one will never find him smoking a charuto (cigar) but a pack of Carlton is always close at hand. Or an article goes on and on about César having been to the art academy; César going to France at least once a year; César being addicted to Veuve Cliquot champagne; César wearing only 
Armani suits; César using only the most expensive of African fabrics for his priestly attire; and César having had his face lifted at least five times by high-society plastic surgeon Paulo Müller. Yet after this lengthy enumeration of high-society characteristics, the article abruptly concludes that his followers in Rio de Janeiro need not worry: 'while it is true that in Bahia, César asks his clients for the sacrifice of an ox, goats or ducks, the sacrifices for his Rio clientele are mais light - lighter'. Again, the idea is invoked that just below the perfume and champagne hover scenes of bloodshed and primitive ritual.

Most important in the media construction of César as the celebrity priest (and here, the tongue-in-cheek undertones of the previous examples are considerably less audible), are the enumerations of celebrities that visit him for consultation and advice. Revista $\mathrm{Oi}^{88}$ for instance, knows that 'among his clients there are people like singer Zeca Pagodinho, actress Maria Zilda, socialite Lilibeth Monteiro and producer Flora Gil, wife of minister Gilberto Gil' and 'it has been said that he had an affair with actress Sônia Braga, which he neither confirms nor denies. Then, as if to save César's authenticity, it is hastily added that '... obviously, in his house in Portão, close to Salvador, he also receives lots of people who are not so famous.'

The fact that César initiated Flora Gil, the young wife of the aforementioned Gilberto Gil, is what probably added most to his public fame. It shows how complicated the play of aura snatching may become: Gilberto Gil, the songwriter and popstar who became a politician; his wife, who became a celebrity by being 'the-wife-of'; and the famous couple making sure that the world will know about their intimate relationship with a Candomblé priest Augusto César (who was padrinho at their wedding, and is said to have moved with the Gils to Rio de Janeiro where he was given an apartment in the same condominium in Gávea where the Gils have set up house). The dependencies are certainly mutual. Gilberto Gil, black, Bahian, made famous because of his involvement with the I970s counterculture of the Tropicália movement, needs him, because a public display of intimacy with a Candomblé priest signals his continuous involvement with Afro-Brazilian realities - even now that he has made it all the way up to far-away Brasília. As we have seen in chapter four, he tends to explain his links with the Candomblé universe somewhat offhandedly, arguing that he came to appreciate the cult due to his artistic activities and due to the 'natural interest' he had in Candomble in relation with the themes he addressed in his work. Interestingly enough, the religious link is established through his wife Flora, who - although she is white - has gone 'all 
the way' and got herself initiated. This is how Gil Gilberto talks about his wife's involvement in an interview:

She really likes the community stuff, the historical mode of Bahia. She feels deeply attracted to all of that. Candomblé, without doubt, is her way to relate with those sentiments. She loves it. The most important moments for her are the 'obligations', this thing of going there, stay the night [in the temple], to wake up in the morning and to go and fetch water from the well, to go to the kitchen to do her things, clean vegetables and kill the animals. All of that, she loves intensely.

Yet let us stay focused on the relationship of the Gils with Augusto César. In the following excerpt, Flora Gil explains how César sent her to a famous diviner (babalao) in Rio de Janeiro to find out the 'master of her head'. What is most striking, however, is to see how Flora Gil, the famous 'wifeof', is in the business of producing religious authority:

I was preparing to be initiated (fazer meu santo) in a Bahian temple, when, to my surprise, I had to come to Rio de Janeiro to obtain absolute certainty as to who is my Orixá. My priest, Augusto César do Portão, asked me to play [the cowry shell oracle] with Father Agenor, a very trustworthy person. I thought I would meet up with a strong black man, tall, and with a heavy Bahian accent. However, I found myself in the company of a white gentleman, thin, small, and with refined manners. The occasion really made me want to cry, but he said 'hush hush, you're from Euá, just like me'. From then on, there grew a deep friendship which up to this day installs me with pride, love and thankfulness. It was he who talked to my priest, instructed him about my obligations, explained everything, took care, gave me attention, calmed me down and gave me his friendship, which I take to be a treasure. Well, it is difficult to talk about my father Agenor. He is all goodness.

Again, one is struck how in the public eye, César's (and Pai Agenor's) authority comes to depend on the authoritative voice of celebrity. It would not have done to ask any old Candomblézeiro about the qualities of Augusto César as a religious authority and to report it in the press. It would not have done to report Augusto César's praise of the old babalao Pai Agenor. Most likely, people would have shrugged their shoulders. It is only when confirmed by a public celebrity that the public authority of these religious leaders comes about. Even when explicitly delegating praise and respect to both her religious guides, it is her own voice, the voice of Flora Gil, the 
voice of fame, that matters in the public sphere. She is authoritative in that she has the power to indicate what has value and what not. Augusto César's display of celebrity behavior, without any doubt, may be read as an attempt to capture the authoritative voice of fame.

The examples that I have given are suggestive of the ways in which the authority of religious leaders comes to be dependent on 'celebrity status'. They make clear that while priestly authority may be unchallenged within a terreiro, any wish on the part of priests to mean something in the public sphere creates a dependency on the voice of celebrities. Religious specialists not only have to show that they are in close contact with celebrities, but they have to live up to celebrity status themselves by mimicking 'star' behavior, creating media appeal, display their services to the stars or even show that they have an influence on media production.

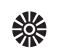

The developments described above are clearly not without repercussions for the performances in the temple. Indeed, I have pointed out the permeable boundary and moved into the murky meeting ground of religious and mediatic imaginaries to argue that it is seriously misleading to maintain a strict separation between the Candomble of the terreiros and the Candomblé of the media. So let me conclude this chapter with a brief exposition of how an awareness of the inextricable entanglement of religious and media imaginaries can help us to look beyond the performance of 'tradition' in Candomblé temples and get a hold of what this performance instructs us not to see.

All major ethnographies of Candomblé maintain that the authority of the priest or priestess within the temple is absolute. During the great public ceremonies of the cult, this is made visible in what struck me as a highly convincing performance: in Gantois, for instance, drums fall silent and everybody rises (while initiates drop on their knees) when the priestess enters the ceremonial hall. Initiates, when asking the priest's and priestess' blessings at the beginning of a religious ceremony, have to prostrate themselves, their whole face on the floor. Temple dignitaries higher up in the hierarchy can only address the priests and priestesses on their knees, and they, just like the initiates, should not hope to have much of a response, as the main act of priests and priestesses is to try to look as uninvolved as possible in what goes on around them. The ogãs too are equally obliged to perform acts of submission during public ceremonies regardless of whether they are university professors, politicians, artists, or 
the adolescent boy from the neighborhood. Now, this whole performance underscores the absolute and unquestionable authority of the priests, and one might say that within the temple community the description of the priest as an 'absolute ruler' is adequate.

Nonetheless, it is clear that 'public' criteria for authority trickle through into the inner realm of the temple, as social realities do not follow neat anthropological distinctions between public and private realms. Initiates of Ilê Axé Opô Afonjá or other people who wanted to convince me of the power and importance of Mãe Stella, for instance, would always refer to her fame and worldwide recognition. Rarely, if ever, would they mention her religious qualities. Visitors to the small museum on the compound of her very own temple are shown a video of her fiftieth birthday - showing the coming and going of important people to pay their respects to the celebrant - which again may be seen as an indication that public notions of fame are now an integral part of the construction of Mãe Stella's authority as a religious leader.

The public aspirations of the priests even affect the very performance of authority in their temples. As we have seen, many celebrities do not want the kind of religious commitment that ogã-ship implies, but seek a more casual relationship with the cult. What this means is that the presence of these powerful outsiders in the world of Candomble is no longer institutionalized through the office of the ogã, and these sympathizers can no longer be neatly inserted in the internal hierarchies that structure power relations in the temple.

In a cult where - to quote Mãe Stella - 'hierarchy is all: beginning, middle and end' (Santos I993), the emergence of the famous aficionado does not remain without consequences. During the public ceremonies in which the absolute authority of the priest is made visible, the presence of these 'sympathizers and friends of the house' has created an odd differentiation between those pertaining to the religious hierarchy, who have to go through all the prescribed prostrations, and those who are 'honorable guests' or 'sympathizers', who shake hands or even hug the priest - suggesting a notion of equality that contradicts Candomblé notions of hierarchy. As we have seen, Gilberto Gil apparently received his 'initiation light,' a vip treatment that according to some was also given to Maria Bethânia. (When I asked some initiates whether indeed Bethânia was shaven and all, they immediately made me understand that the rules do not count for people like Bethânia.) The latest gossip in Salvador is that the granddaughter of Mãe Carmen from Gantois, a young woman with beautiful 
thick and straight hair, was the only one out of eight initiates in a barco (the group of initiates that goes out) who was not shaved.

The new significance of Candomblé in the public sphere and the aspirations of the Candomble priesthood to be recognized as the authentic and authoritative voice of their cult have triggered a complex reconfiguration of power relations: as with the video production discussed before, one must conclude that priestly authority is no longer solely made in the interior of the temples. Increasingly, that authority comes to depend on and needs to adapt itself to - the authoritative voices of the media.

\section{衡}

So the purity that rigid boundaries produce is not to be found. Not beyond the fleeting moments of experience where 'all falls into place', that is. These stories about Africa, roots, origin: for all of the longing that goes into them, they do not add up. The moment they are to be articulated, incoherency and contradiction abound. In the Heart of Africa one finds a Biedermeier bouquet dangling from the ceiling, as if to remind you that Africa too is an open-ended idea. Recall how Dr Nina, in the late Igth century, quoted worried Bahian citizens who had noticed that a group of visitors from Vienna were visiting Salvador at the time of carnival, and who imagined that these Austrians would keep their pens poised to report to the civilized world that in Bahia the primitives and their noisy Candomblés were taking over. Well no. Candomblé has cannibalized Viennese aesthetics. The Catholic saints may have been taken off the Candomblé altars, but Biedermeier bouquets adorn the African rites. As if it were the most natural thing on earth. All boundaries are permeable. 



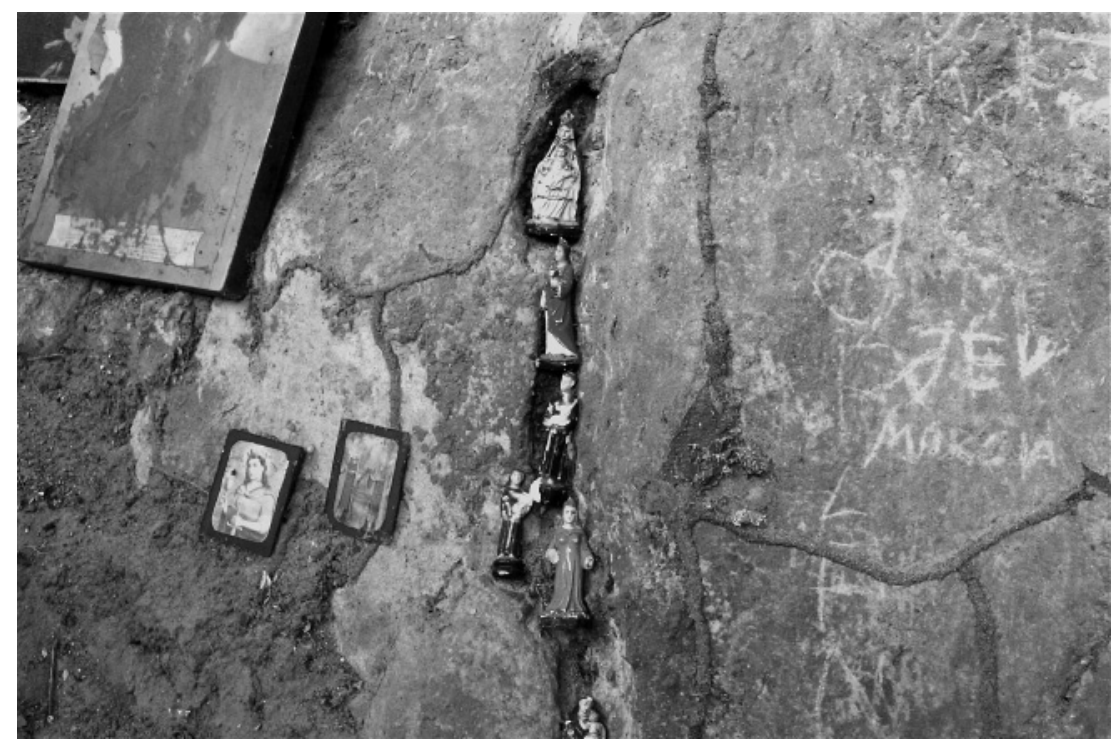

Figure 22 Cracks in the Wall, Milagre de São Roque, Bahia, 2007 


\title{
Conclusions
}

\section{cracks IN THe WaLL}

\author{
Invocations of the-rest-of-what-is in the \\ anthropological study of world-making
}

One day, when we were returning from the village where Victor grew up, he told me to leave the BR-342, the highway that connects Salvador with the Bahian hinterland. Behind those hills, he said, pointing at a ridge of green hills to the left of the road, lies O Milagre de São Roque - the Miracle of Saint Rochus. It was a place where his madrinha used to take him when he was a small boy. Usually they would go there on foot, all the way from Amélia Rodrigues, to fetch holy water from a spring. Yet sometimes his madrinha - who was a mãe-de-santo - would organize a pick-up truck to take all of her initiates at once.

'I'm sure it is the kind of place you like,' Victor reassured me as I found myself cursing while trying to get off the BR-342 with its racing traffic. There had been no sign to indicate the exit. Worse: there was no exit to the pot-holed dirt road he had wanted me to take.

We passed some ramshackle dwellings, and a group of sugarcane cutters taking a break at the roadside, basking in the late afternoon sun. We drove past endless meadows, and the listless gazes of white cows. And then we headed in the direction of the wooded hills.

'It has been a long time,' Victor said. 'But I think that this is where it is.' 
On one of the hills stood a small, whitewashed chapel. Around it some wooden shacks, closed. Signboards indicated 'drinks for sale', but there was no one to be seen. Victor explained that every August there was a big pilgrimage to this place. And on Sundays too, groups of pilgrims would make it over here.

We parked the car and I followed Victor down a path that led into a valley.

The Miracle of Saint Rochus turned out to be a truly enchanting place. The wild profusion of plants and trees of the tropical forest - all imaginable forms and all imaginable shades of green - had receded to form an open space. Right in the middle of this clearing stood two monumental bushes of bamboo. They seemed to be moaning and groaning as the wind caused their gigantic poles to rub against each other. To the left rose a grey wall of rock, leaning slightly forward to create a natural shelter. From the long strings of creepers that hung down from the rock water dripped into puddles below, producing a soft sound of trickling and leaking. The water seemed to be coming from nowhere. No source, no river. Not even a visible crack in the wall. Nothing to explain the falling water. Milagre de São Roque.

'See, and then we would fetch the water like this and take it home,' Victor said, as he held out an empty plastic bottle he had found to catch the falling drops of water.

Yet my eyes were already wandering over the space underneath the rock. In the mud lay hundreds of images, paintings, statues, crucifixes, wood-carved figurines, ex-votos, feathers, candles, vases, and earthenware dishes. I recognized São Jorge, Santa Bárbara, São Cosme e Damião, Jesus, São Roque, Sant' Antônio, and a great many versions of the Virgin Mary. Nossa Senhora da Aparecida. Nossa Senhora da Conceição. There were images of Oxumaré, the orixá associated with the rainbow-colored snake. Statues of lemanjá, in her sky-blue robe. There was even a little statue of a fat, smiling Buddha. Clearly, Milagre de São Roque must have been Mãe Stella's worst nightmare.

The devotees who had left these objects had put them at the very foot of the rock. Yet the wind, the rain - and who knows what else - had turned it all into a sacred dump. A jumble of fragments; a muddy mess; the heapedup, material remains of the stories, sufferings, hopes, wishes, devotions, promises and beliefs that had brought the pilgrims to this place. And yet, in defiance of the overall chaos that presented itself to the eye, Milagre de São Roque struck me as an utterly harmonious place. Maybe it was because of the holy mud that covered all these divine beings indiscrimi- 
nately. Maybe it was because of the overall aura of sacredness that brought coherence to the place. Maybe it was the silence, highlighted by the dripping water, and the distant moaning of the bamboo. Or maybe I had been reading too much about the baroque.

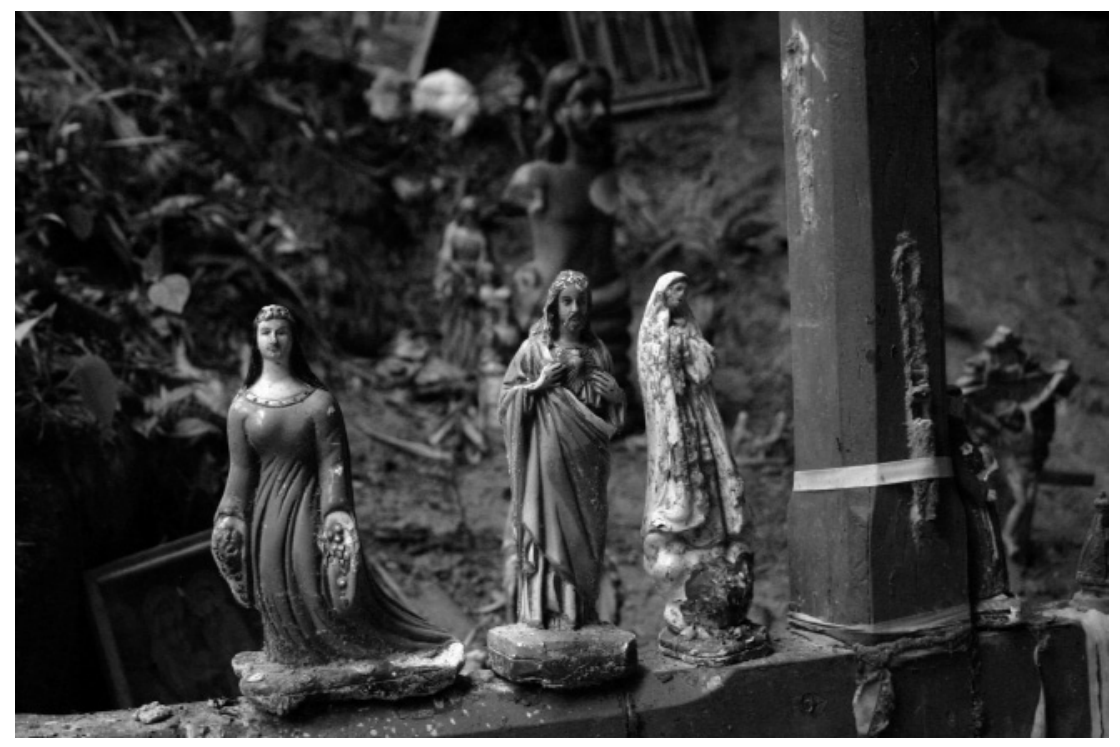

Figure 23 Milagre de São Roque, Bahia, 2007

'They really ought to clean it up here,' Victor said, as he threw the empty bottle into the woods.

He walked back to the clearing, and sat down on a boulder to enjoy the sun, leaving me to explore and take pictures. As always, he kept his distance from the religious things he showed me, never getting too close, never touching anything. As always, he seemed intrigued by my curiosity, my gaze, the gaze of Dr Nina; intrigued by a worldview in which spirits and gods and occult forces are not for real but mere figments of the imagination; intrigued, but not quite convinced by the totalizing pretensions of this perspective.

\section{䜪}

In this book, I have focused on the thought that there is something we might call 'the-rest-of-what-is': a 'beyond' to the horizons of meaning within which people make sense of the world and of themselves. The writings of philosophers and cultural analysts such as Yannis Stavrakakis (I999), Slavoj Žižek (I989, I997, I999), Alain Badiou (2002) and Terry 
Eagleton (2009) on the Lacanian concept of 'the Real' have been helpful in pondering this notion. The Lacanian 'Real' refers to the existential human condition that the symbolic order, which enables us to make sense of ourselves and the world, fails to capture the experience of our selves and the world in its entirety. In The Sublime Object of Ideology (1989), Slavoj Žižek describes the Real as

... the starting point, the basis, the foundation of the process of symbolization ... which in a sense precedes the symbolic order and is subsequently structured by it when it gets caught in its network: this is the great Lacanian motif of symbolization as a process which mortifies, drains off, empties, carves the fullness of the Real of the living body. But the Real is at the same time the product, remainder, leftover, scraps of this process of symbolization and is as such produced by the symbolization itself (1989: I69).

Intriguing contradictions abound in this Lacanian notion of the Real. First of all, the Lacanian Real must be conceptualized as a radical negativity in that it resists all symbolization, representation and narration. Any claim to be able to articulate the Real is false, for an articulation of the Real would imply that this 'beyond-of-our-knowing' now finds itself within the horizons of the known - and is thus no longer what it was. In philosophical terms, the-rest-of-what-is must therefore be conceptualized as forever strange. It is the elusive, mysterious, ungraspable, inarticulable, inexplicable, baffling dimension of being. In his remarkable study Trouble with Strangers. A study of Ethics (2009), Eagleton puts it like this:

[The Lacanian Real is] a version of Kant's unknowable thing-in-itself ... we can grasp this alien phenomenon only by constructing it backwards, so to speak, from its effect - from how it acts as a drag on our discourse, as astronomers can sometimes identify a celestial body only because of its warping effect on the space around it (Eagleton 2009: I49).

And yet, for all of its ungraspable characteristics, the Real derives its solidsounding name from its unchanging and stone-like nature: it is, as Žižek puts it 'the rock upon which every attempt at symbolization stumbles' and 'the hard core which remains the same in all possible worlds' (I989: I69).

The other major contradictions that are to be faced when pondering the notion of the Real concern the way people experience and evaluate its presence in their lives. As stated, the Real reveals our structures of signification to be lacking: it is the excess, the surplus, the 'beyond' of our 
realities; the inevitable by-product of the process whereby form is carved out of the formlessness that has been called the 'plenum of existence'. As 'that which is, but cannot be for "be" to be' (if you forgive me for slipping into glossolalia), the Real is experienced as a constant threat to the stability of cultural definitions of what is possible, normal, credible or true. Unrelentingly, the forces of the Real besiege the fortresses of meaning. It is therefore not surprising that people shy away from confrontations with anything or anyone who raises an awareness of the Real and erect taboos and prohibitions to prevent this from happening. Capable of shattering consensual realities and the coherence of everyday life, intrusions of the Real are always deeply traumatic.

And yet, it is exactly because of its location beyond symbolic form and order, that the Real is also positively evaluated as fullness, totality, healing and wholeness. As the-rest-of-what-is, it is the promise of the infinite that the baroque trompe-l'oeuil ceiling holds out to the congregation of believers; or the endless possibilities that the secret room in the terreiro de Candomble offers to the visitor's imagination, exactly because its doors remain shut. Traumatic encounters with the Real may be experienced as blissful plenitude (as in Walmir's meeting with the impossible flying saucer) or the 'All' that mystics (and at least one ecstatic anthropologist) have described as 'the oceanic feeling'. 'Nothing is lacking in the Real,' says Žižek. 'The lack is introduced only by the symbolization' (I989: I70).

Eagleton goes to great lengths to discuss the effects of the Real, how this 'absent truth' intrudes in the lives of people - and keeps pointing out its frightening yet potentially blissful dimensions. He thereby usefully distinguishes the impact of the Real at the level of the experiencing subject and at the level of the symbolic order.

To start with the former, in the experience of the subject, the-rest-ofwhat-is is the awareness of 'something in the subject which is more than the subject' (Eagleton 2009: I42), which is to say: all the experiences that need to be excluded and prohibited so that the subject can come up with a stable definition of self. At this experiential level, one might say, the-restof-what-is is that which is in excess to our imagined selves: the thoughts we cannot think, the feelings we cannot feel, the impulses upon which we cannot act if we are to remain who we take ourselves to be. It is 'a kind of foreign body lodged inside us'; an 'alien wedge' at the core of our being that prohibits us from being at one with ourselves, or worse, that threatens us with the madness that the medical world has labeled schizophrenia and psychosis. And yet, as a reminder that there is more to ourselves than 
we can think of, the-rest-of-what-is is also 'a potential means to redemption' (2009: I43).

However, the-rest-of-what-is is not merely discernable in subjective experiences. As an absent truth, it is also operative in the structures of meaning through which we come to know the world. Here, the-rest-ofwhat-is is 'the meta-sign or empty element in any semiotic system whose function is to indicate the truth that it cannot be totalized', says Eagleton (2009: I44). It is 'the joker in the pack' (ibid.), 'the point at which our signmaking trails off into incoherence and our meanings begin to unravel at the edges'; and as such 'it registers itself not directly, but as the outer limit of our discourse or the silence inscribed within it' (Eagleton 2009: I44). More concretely, the-rest-of-what-is manifests itself in the world through catastrophes, accidents, traumatizing incidents, fateful occurrences, terminal diseases and baffling events that disrupt the 'agreeable fabrications' that we call reality, 'skewing the subject out of shape and bending the symbolic order out of true' (Eagleton 2009: I42). ${ }^{89}$

As a philosophically inclined thinker, Eagleton seeks to push the idea that there is a rest-of-what-is to its final logical consequences. He fiercely rejects the thought that the Real has any historicity to it, or might be relative to the particularities of place. His Real is a principle, and as such '... utterly unhistorical, always returning to precisely the same place, as indissoluble as a stone in a stream' (2009: I42). As an anthropologist, however, I hesitate to think about the-rest-of-what-is in such essentialist terms. Which is why I began this chapter with the story of the Milagre de São Roque.

\section{鳃}

For all of the enchantment of the place, I found no miracle at Milagre de São Roque. I am sure that geologists are perfectly capable to explain how a specific geological formation may push subterranean water currents to the surface to produce this dripping and trickling. To my mind, there was nothing strange about the phenomenon. It was fully explicable within my horizons of meaning. As far as this miraculous water was concerned, I surrendered to the impulse of the classic, and subscribed to the thought that 'to name is to know'.

The locals living in the vicinity of Milagre de São Roque, however, had designated this water coming from nowhere as one of the impossibilia through which the divine manifests itself. Subject to the impulse of the baroque, they found a miracle - a phenomenon that questions mundane 
definitions of the possible, and as such, provides a gateway to the-rest-ofwhat-is. Unsurprisingly then, Milagre de São Roque became a pilgrimage site, where people in need of divine help pay their debts to saints and spirits, and bottle the miraculous water for later use at home.

What the example makes clear is that we do not all share the same horizons of meaning. What is baffling to some need not be baffling to others. What pertains to the-rest-of-what-is for some may fall well within the horizons of the known for others. Moreover, those horizons of meaning are never fixed, and may change over time, as the story of Walmir and his encounter with a flying saucer made clear: the miraculous occurrence had allowed him to redraw his previous understandings of 'what is'.

It is in stressing the need for such differentiations that anthropology has an important contribution to make to the exciting debates on processes of world-making that were started by such thinkers as Žižek, Eagleton, Badiou and Stavrakakis. Anthropologists might bring the boldness of philosophical speculations about the-rest-of-what-is back to the 'streets', to 'the world out there', where one is soon confronted with the fact that there are different horizons of meaning, and as a consequence, different 'beyonds'.

Such anthropological amendments to philosophical speculation should not, however, keep anthropologists from alerting themselves to the more general conclusion that the-rest-of-what-is is an inescapable dimension of all world-making - including their own. The fact that I could explain away the miracle at the Milagre de São Roque is not to say that my world contains no mysteries. In this book I have shown, over and over again, that my own life and being is shot through with inexplicable occurrences and mysteries. They are only situated elsewhere. No story comes without the shadow of its own impossibility. And it is this insight that opens up new avenues for the study of culture.

Putting the-rest-of-what-is center stage - focusing on the failure of cultural forms, the limits of a social construction of reality - may well go against deeply ingrained inclinations of anthropologists. After all, anthropologists tend to investigate the ways in which socio-symbolic formations succeed in producing 'meaning'. We have been instructed to study the work of culture in its positive, enabling dimensions. 'Explaining how other people make sense of the world' is still an adequate summary of the dominant anthropological research agenda. In contrast to this upbeat tale of people's capacity to make sense of themselves and the world, the Lacanian philosophers who have inspired the thinking that has gone into this book highlight symbolization as a process that is bound to fail. Time and 
again, they have pointed out that the structures of meaning that allow us to come to terms with the world do violence to the experience of being; that sense-making only goes that far; that 'symbolic closure' - the total capture of experience in a structure of meaning - is an impossibility; that the symbolic constructions we have at our disposal are lacking; that at the bottom of all meaning lies a residue of nonsense.

Sure, their focus on the 'failing' of the symbolic order does not mean that they descry lack and incompleteness always and everywhere. To the contrary: it is exactly because of the awareness of the lack in symbolic modes of world-making that these thinkers have come up with such wonderful and insightful descriptions of the pivotal role of fantasy in covering up the rents, fissures and black holes in the structure of meaning (cf. Žižek I997; Stavrakakis 1999; Veenis 2008; Thoden van Velzen \& van Wetering I988). As Stavrakakis argued, fantasy supports reality: it emerges exactly in the place where the lack in the other becomes evident (1999: 46). Indeed, reality can only acquire a certain coherence and become desirable as an object of identification by resorting to fantasy.

In addition, it was the awareness of lack that spurred these scholars on to rethink the Lacanian register of the 'imaginary', and its role in processes of world-making. Eagleton understands the imaginary as a register of sense-making that is rooted in the very early development of consciousness,

... where there is as yet no clearly organized ego or centre of consciousness, [and where] there can be no genuine otherness [as] my interiority is somehow 'out there', as one phenomenon among others, while whatever is out there is on intimate terms with me, part of my inner stuff (Eagleton 2009: 3).

He shows how this particular register lives on in processes of world-making as a kind of 'imaginary misrecognition, in which subject and object, or self and world, seem tailor-made for one another' (2009: I0). The register of the imaginary allows for the sensation that 'rather than being stonily indifferent to our ends, the world appears to be on familiar terms with us, conforming obediently to our desires and bending to our motions as obsequiously as one's reflection in the glass' (ibid.). These thinkers thus purport that to focus on the 'lack' that is at the heart of all meaning production is to put questions of cultural enchantment high on the research agenda.

Lacanians do, however, argue that enchanting fantasies wither away; and that the moments of bliss and plenitude that the register of the imagi- 
nary brings about are fleeting moments, passing illusions. Such fantasies and moments may become important anchor points for alternative reality constructions, yet sooner or later they will fade, giving way to new cracks and fissures in the newly erected structure of meaning, new attempts to cover them up, and new inklings that it might well be that it is through the cracks that 'the light comes in'.

Let me briefly summarize what an awareness of the lack in all story-telling - their story-telling, my story-telling - has done for this research project, to then conclude with a sketch of what such an awareness might do for the anthropology of religion, and beyond, anthropology as a whole.

The question to be asked, of course, is: what would have been lost had I ignored that revelation on Avenida Oceânica that revealed 'what it is all about' yet could not be put into words? What is it that I would have missed, had I ignored that late-night instruction to remain loyal to that experience, declaring it to be relevant to the ecstatic 'then-and-there' of the Avenida Oceânica, but not to the sober 'here-and-now' of my study? What would have escaped my attention, had I proceeded my study of Candomblé as a confident constructivist, ever ready to invest the beliefs and practices of the locals with the privileged meanings of anthropological theory? What would I have prohibited myself from grasping, had I opted for the kind of ocularcentered 'let's just see what we have here' that characterized Dr Nina's early explorations of the Candomblé universe, or the logocentered 'to name is to know' of many of my colleagues? My interlocutors from Candomblé would probably have answered: 'on that path, you will only get to know the "superficial things"'. In my translation this became: 'I would have locked myself up in the theater of the academic imagination'. Or: 'I would have shrunk the horizons of the possible to that which mindful reasoning accepts for fact'. Or: 'I would have handed myself over to the demands of Mlle F., for whom dancing is first and foremost "mindfulness to step execution and floor pattern".

So I decided to keep mystery center stage. I decided not to subject mystery to demystification, but to face it for what it is - and more importantly: what it does - in the world-making of my Bahian interlocutors, and in the world-making that is this text. As I have shown throughout this book, this decision sensitized me to the fact that there is a rest-of-what-is, and helped me to see all the contradictory responses to its presence pointed out by the Lacanian philosophers. Attempts to fight off the unsettling 
intrusions of the rest-of-what-is were found with Dr Nina, who sought to ban the invisible forces of the occult from a positivist, ocularcentered conception of what is real. Mãe Stella fought the rest-of-what-is as she took the Catholic saints of the Candomblé altar, seeking to undo a surplus of history that prohibited Candomblé to refind its purely African self. Victor fought it, as he kept his distance from the sacred leftovers at the Milagre de São Roque. The Vargas state fought it, as it allowed Candomblé to be part of the national heritage on condition that it could only manifest itself as 'culture'. Pierre Verger fought it, although he excused himself for doing so by saying that he was 'too French' to become possessed by a spirit. The dancers at the Balé Folclórico da Bahia did not fight it enough - as the orixás came down in what was a mere rehearsal for a secular dance show - but then they had a choreographer to restore the order by saying that orixás are not jackasses who do not know how to distinguish a ceremony from a theatrical spectacle. And of course, I fought it. All throughout the research and writing process of which this book is the result I fought it. For facing up to the-rest-of-what-is is not exactly the same as allowing the-rest-of-what-is 'in'.

Alongside to these and other examples of fighting off intrusions of the Real, however, it became clear that the-rest-of-what-is was constantly invoked as a sacralizing force, capable of infusing reality definitions with a sense of the incontestable; of infusing mindful knowing with an embodied, experiential sense of apprehension; of infusing particular truths with a sense of the universal; of infusing the real that comes into being in the symbolic order with a sense of the Real as discussed by the Lacanians; of infusing man-made religious propositions with a sense of the divine. Driven by doubt and skepticism; wavering belief and disillusion; deceit and a pervading sense of things having been 'made up', outsiders and believers gathered at the threshold of the terreiro de Candomblé to invoke that which seems to be in excess to the symbolic. Priests and activists, Surrealist artists and anthropologists, filmmakers and writers, Brazilians and tourists: they all found themselves posing at the gates of this great unknown that is the-rest-of-what-is. At the limit of the cultural order, where the sensible may give way to the merely 'senseable', they sought to connect cultural form to a sacred beyond, and infuse the truth of their imaginations with a truth that transcends all cultural formulation. And again, so did $\mathrm{I}$.

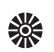


Anthropology, the study of human sense-making, has much to gain by taking the failure of the symbolic order as a starting point for analysis. To begin with, keeping this failure center stage forces us to act upon that often proclaimed - yet difficult to accomplish - ideal to think 'culturein-motion. What is more: it actually provides guidelines as to how to go about it. For Lacanian thought highlights the eternal dynamic of lacking subjects, who desire a fullness that the structures of meaning cannot provide, who dream up that fullness in fantasy, or even manage to produce that fullness by checkmating language, and who live happy and content until the moment that some roof tile or other falls on their head, to make them aware that '... the network of signifiers in which we have our being is not all that there is, and the-rest-of-what-is may chance to break in upon us at any moment' (Lacan, in Bowie I991: I03).

Another gain that comes with this approach is that it gives us - academic researchers, writers, thinkers - a solid motive to 'once and for all' break out of the stifling theater of our own academic imagination, to free ourselves from the incentives of the spirit of the classic, which keeps telling us that the complexities of the world can be caught in fixed categories of thought and rigid structures of meaning - when all the evidence (and a long history of critical thinking) suggests that no such thing is possible. Taking the failure of the symbolic order as a starting point for investigation is to reject any notion of a privileged narrative, and to subscribe to the idea that academic researchers are not all that different from the people they study, with whom they share the predicament - and the challenge - of having to make sense of Being with a signifying capacity that fails us over and over again. Accepting this failure for a fact is an invitation to open up our academic modes of world-making to the surprises of the infinite; to foster a willingness to let our methods be derailed by the unexpected and the incalculable, with the expectation that it is 'through the crack in the thing that the light comes in'. It is to provide ourselves with an opportunity to explore innovative, creative forms of report.

A third, and final answer to the question what might be gained from a focus on the way in which cultural forms fail us, is related to that issue philosopher Bernard Williams once presented. Discussing deconstructionist tendencies in academia, he asked 'If you reject the possibility of truth, what is the call for truthfulness a call for?' (2002: 2). It is not without reason that in Lacanian thought the-rest-of-what-is is called the Real with a capital R. There is, in this thinking about the lack that is constitutive of all self- and world-making, the (re)introduction of an 'essence', an ontology, a truth. Most anthropologists - working in a constructivist paradigm 
that relativizes all truth claims - shy away from opening up their thoughts for something that is true. Yet the truth that Lacanian thinkers have introduced in cultural analysis and the social sciences is that there is always an excess to a particular representation of the world. For the time being, I have embraced that truth. And I have sought to argue that if anthropologists want to move beyond a mere arguing of the made-upness of things, and address the processes of authentication and sacralization through which people manage to perceive the made-up as the really real, they had better allow themselves to 'tarry with the negative' (Žižek I993: cf. Port 2005).

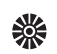

So much for advertising the possibilities of a baroque anthropology. As the whole point of raising an awareness of the cracks in the wall has been to not privilege one narrative form over another, I will end with pointing out one of the cracks in the structure that I have erected for you.

About a year ago, a new tenant moved into one of the apartments in my block. I do not know him personally, he uses another entrance, but from the room that is my study, at the back of my apartment, I can see the rear of his apartment. He has a dark complexion, has loud conversations on his mobile phone in Spanish, and his balcony has been decorated with buckets full of white plastic flowers, a plastic palm tree and a hammock. I am pretty sure he is from Latin America.

As of late, this new tenant is not doing well. At irregular intervals, he is overtaken by something that makes him shout and scream at the top of his voice, in a rather spine-chilling way.

'My goodness, it sounds as if he is possessed,' is what I said to Victor when I heard it for the first time, for indeed, the shouting - in a highpitched tone, as of a bird - reminded me of possessions I had witnessed in Bahia. Later, I could also see him walking around his house, and coming out on the balcony, with a terrible, otherworldly expression on his face.

Victor responded by saying 'Será? You think people become possessed in Amsterdam?' He seemed more comfortable with the diagnosis 'the new tenant is mad', a thought that - of course - had crossed my mind as well.

Sometimes, for days on end, it would remain quiet in the block, allowing me to think that the new tenant's next-door neighbors had taken care of whatever it was that was going on. But then, in the middle of the night, and more and more in the bright light of day, the screaming and frantic walking would start again. 
So it happened at several moments during the writing of the final draft of these conclusions on 'the-rest-of-what-is' that I found myself closing doors and windows, and using earplugs, trying to shut out those unsettling screams of my poor neighbor.

I finally decided to call the emergency number, confused as to the consequences - let alone the 'meaning' - of that call, but unable to leave the possible psychosis of a tenant in my block unattended. The woman on the other side of the line thanked me for calling, and said she would send someone over to have a look. Half an hour later, two policemen arrived at my door. Blond, blue-eyed policemen. They were polite, the politeness of police officers who have seen and heard a lot of bullshit, and have made up their minds a long time ago as to what is what. I took them out onto my balcony, and found myself pointing to the neighbor's apartment. There! Over there! That apartment, right there! They said they would go over there and have a look.

It has been silent for quite some time now. I imagine the bird spirit has been sent off with some psycho-pharmaceutical drug or other, and reassure myself with the thought that its panicked shrieks had not been a happy song. Yet the whole episode brought home to me, in an inescapable and rather unsettling way, that one's attempts to close in on the-restof-what-is are bound to run into the strongest of inhibitions. In spite of blissful moments on the Avenida Oceânica; adventurous, mystical mindexpansions; and baroque celebrations of the miraculous: when the-restof-what-is comes to you from another angle - the rear of an apartment in the block, for instance - everything inside you tells you that this is a place where you do not want to go. This radical otherness must remain other. Any call to study the-rest-of-what-is and its workings in the cultural production of the real is therefore half-hearted. Any word written about it is always also a desperate attempt to keep it at bay. 



\section{Notes}

I This is a famous samba, written by Herivelto Martins.

2 All throughout this book, translations from Portuguese sources are by the author, unless indicated otherwise.

3 As Michel de Certeau argues in his study of mysticism, such practices are standard in the mystic's way to 'articulate his experiences in socially recognizable terms' and make these experiences 'legible to the eyes of the unbelievers' (I992: I5).

4 The 'plenum of existence' is a term found in the work of religion scholar William James (1977) and elaborated in anthropological fashion by Michael Jackson (I989). It refers to 'a phenomenal field prior to the interpretive structures (and concomitantly, subject-object bifurcations or conceptual discriminations) that we subsequently impose upon it' (Krueger 2007: II).

5 For a further discussion on the unease of anthropologists when they find themselves at the edge of rationality, see Stoller (I989).

6 Alain Badiou and Slavoj Žižek certainly do not seem to be courting the thought of 'going religious' (cf. Žižek 20oI). In recent work, Terry Eagleton has reflected on the possible 'religiosity' of his own thinking (2009; 2010).

7 Next to the famous (if rather impenetrable) discussions of the baroque by Walter Benjamin (2003) and Gilles Deleuze (1993) - also discussed by Hills (2007) - I have consulted Brown 2003; Buci-Glucksman I992; Calabrese I992; Chiampi I998; Deleuze I993; Hampton I991; Lambert 2004; Ndalianis 2004; Owens I980a, and other authors mentioned in the text.

8 Art historians might point out that much of what I call Bahian 'baroque' is in fact 'rococo'. Given that I am primarily interested in the baroque as a generic aesthetic impulse, I allow myself to ignore such stylistic differences. 
9 From the invitation to the workshop 'The Baroque as Empirical Sensibility. An international Worshop in the Social life of Method', Manchester, June, 2 OII.

Io For a thoroughly Baroque appreciation of Bahian society, see Araújo (2008).

II But see the recent paper of Peixoto (2009).

I2 Arthur Cravan was a curious character who made it to the footnotes of history by being the nephew of Oscar Wilde and by gaining the admiration of such armchair pugilists as André Breton, Francis Picabia and Marcel Duchamp. For biographical info on Cravan, see Borràs (I996) and Pierre (I992).

I3 http://www.pbm.com/ lindahl/lod/vol3/gavotte.html

I4 For an excellent discussion, see Silva (2000).

I5 Verger also stated: 'Personally, I do not like intellectuals very much. They are people who are always representing, and knowing they will be represented, they cultivate this attitude, pretending to be something that they are not' (in Cida \& Echeverria 2002:I8I).

I6 For a similar critique, see Stoller (I989).

I7 Manfred Metzner and Michael M. Thoss (eds.), Pierre Verger. Black Gods in Exile (catalog to the exhibition). http://www.schwarze-goetter-im-exil.de/ eng/pub/verger-intro.html, last accessed i6 December 2008.

I8 I found this translation in Linger (I992). Quem me vê sempre parado/ Distante garante que eu não sei sambar .../ Tô me guardando pra quando o carnaval chegar/ Eu tô só vendo, sabendo,/ Sentindo, escutando e não posso falar .../ Tô me guardando pra quando o carnaval chegar/ Eu vejo as pernas de louça/ Da moça que passa e não posso pegar .../ Tô me guardando pra quando o carnaval chegar/ Há quanto tempo desejo seu beijo/ Molhado de maracujá .../ Tô me guardando pra quando o carnaval chegar/ E quem me ofende, humilhando, pisando,/ Pensando que eu vou aturar .../ Tô me guardando pra quando o carnaval chegar/ E quem me vê apanhando da vida,/ Duvida que eu vá revidar .../ Tô me guardando pra quando o carnaval chegar/ Eu vejo a barra do dia surgindo,/ Pedindo pra gente cantar .../ Tô me guardando pra quando o carnaval chegar/ Eu tenho tanta alegria, adiada,/ Abafada, quem dera gritar .../ Tô me guardando pra quando o carnaval chegar/ Tô me guardando pra quando o carnaval chegar/ Tô me guardando pra quando o carnaval chegar.

I9 www.luzdafloresta.com.br

20 http://www.cuidardoser.com.br/a-passagem-do-crer-a-experiencia-deDeus.htm 
2I The quote is often referred to, see for example http://veja.abril.com. br/orio97/p_or2.html, last accessed I6 December 2008.

22 For interesting discussions on notions of personhood and notions of 'self' in Candomblé and other Afro-Brazilian cults, see Segato (I995: 92ff).

23 Ivonne del Valle (2002), in her discussion of the Jesuit Baroque, also speaks of an aesthetic of 'conquest, seizure and subjugation'.

24 For other early explorations of the Afro-Brazilian religious universe, see Rio 2006 [1906]. Some igth century novelists - José Alencar, Xavier Marques - also had explored the Afro-Brazilian religious universe. For a discussion of these early renditions, see Sampaio (2000).

25 As illusões da catequese, Revista Brasileira, tomo Ix, I897, p. 322-335.

26 Biographical information on Raimundo Nina Rodrigues is scarce and fragmented. I have consulted Lima (I984); Ribeiro (I995); Corrêa (I998).

27 Explaining fetishism along these lines, Dr Nina replicated exactly what Auguste Comte in his Cours de Philosophie Positive (1864) had developed as the 'law of the three stages'. In this influential study, Comte argued that human development passes through a theological and metaphysical stage before reaching positivism; and that the early theological stage was divided in another three phases, the first of which was fetishism (followed by polytheism and monotheism).

28 cf. Velho (1992).

29 The detailed enumeration of igth century advertisements for photography in Bahian journals and newspapers by Sampaio (2006) reveal a similar trend: time and again, the 'perfection' and 'naturalness' of portraits made with the new techniques were being stressed.

30 André Amaral de Toral (I999), discussing the great number of photographed portraits of soldiers in the Paraguayan War makes a related point about how the trace was played in commemorative practices surrounding fallen soldiers, arguing that the photograph gained importance as the ultimate image of those who did not return.

3I If 'stiff' poses were necessary to avoid blurring the image, these poses remained in vogue long after photographic techniques required long minutes of motionless posturing.

32 The one photographed portrait of Dr Nina that I found is exactly the same as the painting: only the academic regalia have been added.

33 Ferreira (I998;1999); de Azevedo (I987); Leite (I996).

34 http://pt.wikipedia.org/wiki/Dr._Fritz

35 In historical studies of the samba, this point is repeatedly made, cf. Sandroni (200I); Vianna (2007).

36 Veja on-line, 27 june 200 . 
37 Folha de São Paulo, or May 2008.

38 Folha de São Paulo I997. For an extended discussion of ACM's Candomblé politics, see Santos (2005) and Port (2005a).

39 Macumba stories might well be understood along the lines sketched by Peter Geschiere (1997) on the 'modernity of witchcraft'. Or as a collective fantasy, as elaborated by H.U.E. Thoden van Velzen \& W. van Wetering (i988).

40 http://www.terra.co.m.br/istoe/Reportagens/fashion.htm

4I In fact, as historian Gilberto Freyre rightly suggested, their very idea of branqueamento, the whitening of Brazilian society through miscegenation, staged the coming about of the Brazilian nation as a scenario of seduction, attraction and erotic interest across the racial dividing lines. See: Freyre (200I).

42 Elisabeth Ginway (I992) stated that surrealism is indirectly responsible for the re-evaluation of African culture in Brazil and Cuba.

43 Famous I8th century sculptor from Minas Gerais, widely believed to have been a mulato.

44 Also called quartinho, the small room where initiates stay in seclusion during initiation.

45 The words are from Humberto Bastos, a literary critic from the Rio de Janeiro based newspaper Diário de Notícias. I found his article called 'the negro in literature' as a clipping in the library with only the year 1935, and was not able to trace the exact date of its appearing.

46 Most members of the group were migrants from the Bahian interior, enchanted by the bustle of big city life, and evidently intrigued by the new ideas that came trickling in from São Paulo and Rio de Janeiro. The majority had also dropped out of school, choosing journalism as their profession.

47 As early as 1927 he was ogã in the terreiro of the then famous pai-de-santo Procópio; he was close friends with the legendary mãe-de-santo Menininha do Gantois; and in 1957, another prestigious terreiro in Salvador, llê Axé Opô Afonjá, granted him the office of obá orolu.

48 Samba da Benção, Vinícius de Morais/Baden Powell.

49 cf. van de Port 2007.

50 In fact, it is the very ubiquitousness of Candomblé imagery in Salvador that is played upon in this campaign. Under the names of the different orixás are enlisted the natural elements with which this particular orixá is associated; the corresponding Catholic saint in the sincretist tradition; the day of the week that is consecrated to the orixá; and the Yorubá phrase with which the orixá is greeted when possessing its medium. All of this is stock information, published so frequently and divulgated on so massive 
a scale that in the city of Salvador this listing first and foremost evokes a somewhat fatigued 'what's new?' Underneath the enumeration stands another reference: furniture, Tidelli - in exactly the same font as the info on the orixás, and thus suggestive of an equally matter-of-factness.

5I See http://www.doafroaobrasileiro.org/r.html

52 O Cruzeiro, I4 may I955.

53 Lisa Earl Castillo, who discusses the case in her dissertation, received the following comments from a woman who clearly remembered the event. 'That magazine, I was really young when I saw it. O Cruzeiro was much read, and we at home would buy it. One day, mother was leafing through it and all of a sudden she saw that reportage. She was frightened! I think all of the people from Candomblé were shocked when they saw it! Because there where the iaôs entering the camarinha, receiving blood poured over their heads, that kind of thing. It was a scandal. In those days, I was very young, a little girl, and I was horrified, I felt very bad. And most people maintained that the priestess or priest who had allowed that interview had done it for the money. Everyone knew something was going to happen to them, because even today this is taboo, so you can imagine in those days! And it was the first time. Nothing had ever happened like that before (Castillo 2005:4I).

54 João Gilberto/Ary Barroso.

55 http://marieclaire.globo.com/edic/edıI5/rep_bethania.htm

56 Ibid.

57 Marcelo Cerqueira, GGB - http://www.ggb.org.br/editorial.html

58 http://clubesafobrasil.5owebs.com/trevisan.html

59 Ibid.

6o The collection of 'Meninos no Monte' can be found in the Museu Henriqueta Catharino, which pertains to the Instituto Feminino da Bahia, once an old boarding school for rich girls in the center of Salvador, now with a wonderful collection of popular religious art.

6I Cowan and others use the notion of the symbol for this romantic form of representation. For anthropologists this particular understanding of the symbol, capable to restore the rift between Man and Nature by highlighting that inner experience and the outer world belong to the same order, may turn out to be somewhat confusing. In our understanding of symbols in semiotic terms as 'vehicles for meaning', we have been discussing the gap between the signifiant and the signifié for decades, pointing out that the relation between these two dimensions of the sign is not 'natural' but 'arbitrary', which introduces an instability and contingency at the heart of symbol systems. Our understanding of the symbol is thus much closer to 
the allegorical mode of representation and its proposition that 'any person, any object, any relationship can mean absolutely anything else'.

62 One is tempted to point out the significance of Rachel Harding's finding that possession in Candomblé in the new world is far more frequent than in Africa (Harding 2003:155).

63 For a discussion of these movements, see Narber (2003).

64 Although her phrasing of ex-stasis is loaded with philosophical jargon, it articulates a possible relation between the baroque understanding that people are exiled from the truth they wish to embrace, and the equally baroque preference for ecstasy: 'Our ontological capacity for transcendence emerges from and in our ontic immanence. No matter how seemingly "beyond" or "outside" of quotidian space, time, and "bodiliness" we imaginatively, intellectually, or spiritually remove ourselves, our bodies in the "here" and "now" still provide the material and sensual grounds ... where that transcendent experience "makes sense" ... This experience of transcendence in immanence occurs constantly in myriad circumstances both trivial and significant, quotidian and ritual ... in which ex-static transcendence is not only purposefully solicited but also formally shaped and experientially heightened. No matter the circumstance, however, the structure of this experience is paradoxical in that it emerges from our sensual embodiment even as it seems to release us from our bodies' ontic constraints and demands' (Sobchack 2004: 197).

65 At the time of my research, FEBACAB was the representative organ for Afro-Brazilian cults in Bahia.

66 For a full discussion of the so-called reafricanização, see for example Dantas (I988), Matory (1999) and Capone (I999).

67 The politics of these terreiros lean heavily on their contacts with people of power and influence, some of whom may have been elected ogã and take place in various arenas, and with various means. In chapter 7 this will be discussed.

68 Folha on line 05 February 20o8, http://wwwi.folha.uol.com.br/folha/cotidiano/ult95u369688.shtml, last accessed I2 September 2008.

69 In Candomblé, there is in fact a whole vocabulary to label spontaneous fainting spells: they are called, bolar no santo (rolling to the saint), cair no santo (falling to the saint) or possession by santos brutos (unruly saints).

70 The few interviews with priests and priestesses that I have seen on Bahian $\mathrm{TV}$ are very clear examples of this particular politics of representation: the interviewees persevere in their performance of secrecy, the interviewer gets nowhere asking 'stupid questions', and the interview ends up being a 
chit-chat about the more folkloric aspects of the cult while never coming close to what the cult is all about.

7I Candomblé's outspoken dismissal of new media's potential to provide a suitable site for hierophany coincides with (and receives further backup by) the primitivist discourse discussed in previous chapters. This discourse constructs the cult as a realm of 'authenticity' and 'uncorrupted African tradition'. As Beth Conklin (1997: 715) has convincingly argued, the designation of peoples and places as 'authentic' often leaves 'little room for intercultural exchange or creative innovation, and locates 'authentic' indigenous actors outside global cultural trends and changing ideas and technologies', all the more so when the 'authentic indigenous actors' adopt these narratives about themselves. And this is exactly what one finds in Candomblé. Both sacerdotal and society-wide discourses on authenticity, not to mention the discourses of influential anthropologists such as Pierre Verger (2000), Roger Bastide (I978, 2000) and Juana Elbein dos Santos (I975), reinforce the very idea that traditional religion and modern media technologies are incongruous.

72 This is reminiscent of what Harald Prins (2002: 58$)$ has called the 'indigenous self-fashioning' made possible by new media, or the 'indigenous media productions'.

73 ODE KAYODE is the Yorubá name of the priestess. Notwithstanding the 'activist' profile that is being sought in such a text, the credits mention that the video was 'winner of the public concourse of videographic projects organized by the Cultural Foundation of the Bahian State' - a sure sign that the project received financial aid from the Bahian government.

74 Speaking of a 'bafflement politics' is not meant to say that in Bahia clever priests shrewdly trick outsiders into belief: it is a mode of persuasion that addresses believers as much as outsiders. The term 'politics' draws attention to the rules and social practices through which baffling instances are embedded in ideological propositions.

75 One of the great insights that follows from the cultural analysis that is informed by the thinking of Jacques Lacan is exactly the idea that the colloquial opposition between reality (as the domain of things 'as they are') and fantasy (as the domain of 'make-believe') is highly misleading (Žižek I997:66).

76 In a famous letter to Sigmund Freud, Romain Rolland wrote the following on the 'oceanic feeling': 'the [oceanic] sentiment I experience is imposed on me as a fact. It is a contact. And as I have recognized it to be identical (with multiple nuances) in a large number of living souls, it has helped me to understand that there was the true subterranean source of religious energy 
which, subsequently, has been collected, canalized and dried up by the Churches, to the extent that one could say that it is inside the Churches (whichever they may be) that true "religious" sentiment is least available.' In: Parsons (1998).

77 For an interesting discussion on the way an increasingly white Candomblé becomes narrated, see Silva and Amaral (I993).

78 In recent debates it has been stressed that religion has always depended on practices of mediation in its attempts to render present the transcendental realm to which it refers. In other words, media are constitutive of the religious imagination. Instead of studying the relation between religion and media, religion is therefore best studied as a practice of mediation. See, De Witte (2003); Guadeloupe (2009); Meyer (2009); Brent (2005); Stolow (2005).

79 Cf. Birman (2006); de Abreu (2005); Hamburger (I998); Mattos (2000); Oosterbaan (2005); Segato (I994); Port (2006).

80 For a full discussion, see Port (2006).

8I As Vagner Gonçalves da Silva (2000) has remarked for São Paulo, the registration of ritual events by photo cameras or video equipment is already a common sight in the Afro-Brazilian religions, and is not only done by the researchers of temples, but also by the temples themselves. He noticed that videotapes and photographs are not only a souvenir for the participants in the ritual, but are also used as a kind of 'proof' that the event happened, and can be used against allegations that someone is a charlatan priest who was never initiated.

82 'Future remembrance' refers to the documentary film on Ghanian studio photographers by Tobias Wendl and Nancy DuPlessis, Future Remembrance. Photography and Image Arts in Ghana (1998).

83 Tribuna da Bahia, 20 November 1999.

84 Carta Capital, I2 June 2002, I4-20.

85 The accuracy of this enumeration is disputable.

86 A Tarde, $\mathrm{I} 3$ March 2003.

87 For an analysis of the fame of Menininha, see Jocélio Teles dos Santos (I998).

88 www.revistaoi.com./br/nova/augusto_cesar.asp, last accessed Io August 2005 .

89 As older literature in anthropology has pointed out already, the-restof-what-is also manifests itself in the 'anomalous beings' described by thinkers such as Mary Douglas (2002) and Edmund Leach (1986): beings whose very presence on the face of the earth highlights the inadequacy and ultimate contingency of the classificatory schemes on which the cultural 
order rests. As these anthropologists pointed out, the stability of the cultural order requires that these impossible beings remain tabooed, repressed, denied and forgotten; and yet, the fact that they exist and their existence cannot be fully unthought may also be invoked to 'throw doubt on the finality of fact', as Barbara Babcock (1975: 186) phrased it, and thus provoke renewal and change. 



\section{Bibliography}

Agier, Michel

2000 Anthropologie du carnaval: la ville, la fête et l'Afrique à Bahia. Paris: Parenthèses.

Amado, Jorge

197I Bahia de Todos os Santos. Guia das ruas e dos mistérios da cidade do Salvador. Salvador: Martins.

I990 Conversations avec Alice Raillard. Paris: Gallimard.

200I Jubiabá. Rio de Janeiro: Record.

2003 Tent of Miracles. Madison: University of Wisconsin Press.

Andrade, A.M.R. and J.L.R. Cardoso

200I Aconteceu, virou manchete. Revista Brasileira de História 21: 243-264.

Araújo, Emanuel

2008 O teatro dos vícios. Transgressão e transigência na sociedade urbana colonial. Rio de Janeiro: José Olympio.

Aretxaga, Begoña

I995 The Dirty Protest: Symbolic Overdetermination and Gender in Northern Ireland Ethnic Violence. Ethos 23(2): I23-I48.

Baal, Jan van

I97I Symbols for Communication. An Introduction to the Anthropological Study of Religion. Assen: Van Gorcum.

Babcock, Barbara

I975 'A Tolerated Margin of Mess'. The Trickster and his Tales Reconsidered. Journal of the Folklore Institute II(I/2): I45-I86.

Badiou, Alain

2002 Ethics: An Essay on the Understanding of Evil. London: Verso.

2003 Saint Paul: The Foundation of Universalism. Stanford: Stanford University Press. 
2005 Infinite Thought: Truth and the Return to Philosophy. London: Continuum.

Barth, Karl

I968 The Epistle to the Romans. Oxford: Oxford University Press.

Barthes, Roland

I977 Image, Music, Text. London: Fontana.

2000 Camera Lucida. Reflections on Photography. New York: Hill \& Wang.

Bastide, Roger

I945 Imagens do Nordeste místico em branco e preto. Rio de Janeiro: $\mathrm{O}$ Cruzeiro.

I96I O candomblé da Bahia, rito Nagô. São Paulo: Companhia Editora Nacional.

I978 The African Religions of Brazil: Toward a Sociology of the Interpenetration of Civilizations. Baltimore: Johns Hopkins University Press.

Bataille, Georges

I989 Theory of Religion. New York: Zone Books.

Baudrillard, Jean

200I Selected Writings. Cambridge, uk: Polity.

Bellman, Beryl Larry

I984 The Language of Secrecy: Symbols \& Metaphors in Poro Ritual. New Brunswick: Rutgers University Press.

Benjamin, Walter

2003 The Origin of German Tragic Drama. London: Verso.

Berkenbrock, Volney

I999 A experiência dos Orixás. Um estudo sobre a experiência religiosa no Candomblé. Petrópolis: Editora Vozes.

Birman, Patrícia

I985 Identidade social e homossexualismo no Candomblé. Religião e Sociedade I2(I): 2-2I.

I995 Fazer estilo criando gêneros: possessão e diferenças de gênero em terreiros de umbanda e candomblé no Rio de Janeiro. Rio de Janeiro: EduERJ.

2006 Future in the Mirror: Media, Evangelicals, and Politics in Rio de Janeiro. In Birgit Meyer \& Annelies Moors (eds.), Religion, Media, And the Public Sphere. Bloomington: Indiana University Press, pp. 52-83. 
Boddy, Janice

I989 Wombs and Alien Spirits: Women, Men, and the Zar Cult in Northern Sudan. Madison: University of Wisconsin Press.

I994 Spirit Possession Revisited: Beyond Instrumentality. Annual Review of Anthropology 23(I): 407-434.

Bonasio, Valter

2002 Televisão. Manual de Produção \& Direção. Belo Horizonte: Editora Leitura.

Borges, Dain

I995 The Recognition of Afro-Brazilian Symbols and Ideas, I890-I940. Luso-Brazilian Review 32(2): 59-78.

Borim, Dario

2002 Morte e Vida Tropicália: o ideário sócio-politico na obra de Caetano Veloso. Hispania 85(3): 494-504

Borràs, Maria Lluisa

I996 Cravan. Une stratégie du scandale. Paris: Édition Jean Michel Place.

Bourdieu, Pierre

I990 The Logic of Practice. Cambridge, uk: Polity Press.

Bowie, Malcolm

I99I Lacan. Cambridge, USA: Harvard University Press.

Braga, Julio

I995 Na gamela do feitiço: repressão e resistência nos candomblés da Bahia. Salvador: Edufba.

Breton, David le

2000 Playing Symbolically with Death in Extreme Sports. Body \& Society 6(I): I.

Brown, David H.

2003 Santería Enthroned: Art, Ritual, and Innovation in Afro-Cuban Religion. Chicago: Chicago University Press.

Browning, Barbara

I995 Samba: Resistance in Motion. Bloomington: Indiana University Press.

Brumana, Fernando Giobellina

2007 Reflexos negros em olhos brancos: a academia na Africanização dos candomblés. Áfro-Ásia 36: I53-I97.

Buci-Glucksman, Christine

I992 La folie du voir. De l’esthétique baroque. Paris: Galilée. 


\section{Calabrese, Omar}

1992 Neo-Baroque: A Sign of the Times. Princeton: Princeton University Press.

Campos, Vera Felicidade de Almeida

2003 Mãe Stella de Oxóssi. Perfil de uma liderança religiosa. Rio de Janeiro: Jorge Zahar Editor.

Capone, Stefania

I999 La quête de l'Afrique dans le candomblé: pouvoir et tradition au Brésil. Paris: Karthala.

Carneiro, Edison

I967 Candomblés da Bahia. Rio de Janeiro: Edições de Ouro.

Carvalho, José Jorge de

I994 O encontro de velhas e novas religiões. Esboço de uma teória dos estilos de espiritualidade. In R. Zickman (ed.), Misticismo e Novas Religiões. Petrópolis: Vozes.

Castillo, Lisa Earl

2008 Entre a oralidade e a escrita. A etnografia nos candomblés da Bahia. Salvador: Edufba.

Certeau, Michel de

I984 The Practice of Everyday Life. Berkeley: University of California Press.

1992 Mysticism. Diacritics 22(2): II-25.

2000 The Possession at Loudun. Chicago: University of Chicago Press.

Chiampi, Irlemar

I998 Barroco e modernidade. Ensaios sobre literatura latino-americana. São Paulo: Editora Perspectiva.

Cipiniuk, Alberto

2003 A faça pintada em pano de linho: moldura simbólica da identidade brasileira. Rio de Janeiro: Editora PUC.

Cleto, F.

I999 Camp: Queer Aesthetics and the Performing Subject: A Reader. Ann Arbor: University of Michigan Press.

Clifford, James

I988 The Predicament of Culture: Twentieth-Century Ethnography, Literature, and Art. Cambridge, usA: Harvard University Press.

Clifford, James and George E. Marcus

I986 Writing Culture: The Poetics and Politics of Ethnography. Berkeley: University of California Press. 
Cole, Sally C.

2003 Ruth Landes: A Life in Anthropology. Lincoln: University of Nebraska Press.

Coleman, Simon and Mike Crang

2002 Tourism. Between Place and Performance. New York: Berghahn Books.

Conklin, Beth A.

I997 Body Paint, Feathers, and vcrs: Aesthetics and Authenticity in Amazonian Activism. American Ethnologist 24(4): 7II-737.

Conner, Randy P. and David Hatfield Sparks

2004 Queering Creole Spiritual Traditions: Lesbian, Gay, Bisexual and Transgender Participation in African-inspired Traditions in the Americas. New York: Harrington Park Press.

Core, Philip

I999 Camp: The Lie that Tells the Truth. In F. Cleto (ed.), Camp: Queer Aesthetics and the Performing Subject: A Reader. Ann Arbor: University of Michigan Press.

Corrêa, Mariza

I998 As ilusões da liberdade: a Escola Nina Rodrigues e a antropologia no Brasil. Bragança Paulista: Edusf.

Couldry, Nick

2003 Media Rituals: A Critical Approach. London: Routledge.

Covin, David

I996 The Role of Culture in Brazil's Unified Black Movement, Bahia in I992. Journal of Black Studies 27(I): 39-55.

Cowan, Bainard

I98I Walter Benjamin's Theory of Allegory. New German Critique 22: I09-I22.

Csordas, Thomas J.

I990 Embodiment as a Paradigm for Anthropology. Ethos I8(I): 5-47.

d'Andrade, Mário

200 I Macunaíma. o herói sem nenhum caráter. Belo Horizonte and Rio de Janeiro: Livraria Garnier.

d'Andrade, Oswald

I990 Os Dentes do Dragão. São Paulo: Globo.

Damian, Carol

I999 Tarsila do Amaral: Art and environmental concerns of a Brazilian Modernist. Womans Art Journal 20: 3-7. 
Dantas, Beatriz Góis

I988 Vovó Nagô e Papai Branco: usos e abusos da África no Brasil. Rio de Janeiro: Graal.

Day, Gail

I999 Allegory: Between Deconstruction and Dialectics. Oxford Art Journal 22(I): I05-II8.

de Abreu, Maria José A.

2005 Breathing into the Heart of the Matter: Why Padre Marcelo Needs No Wings. Postscripts I(I.3): 325-349.

Debray, Régis, and Eric Rauth

I995 The Three Ages of Looking. Critical Inquiry 2I(3): 529-555.

Deleuze, Gilles

I993 The Fold: Leibniz and the Baroque. Minneapolis: University of Minnesota Press.

Dion, Michel

I998 Omindarewa. Uma francesa no candomblé. A busca de uma outra verdade. Rio de Janeiro: Pallas.

Douglas, Mary

I976 Wereldbeelden. Utrecht: Spectrum.

2002 Purity and Danger. New York: Routledge.

Dunn, Christopher

200I Brutality Garden: Tropicália and the Emergence of a Brazilian Counterculture. Chapel Hill: University of North Carolina Press.

Dyer, Richard

2002 The Culture of Queers. London: Routledge.

Eagleton, Terry

2009 Trouble with Strangers: a Study of Ethics. Malden: Wiley-Blackwell.

2010 Reason, Faith \& Revolution. Reflections on the God Debate. New Haven: Yale University Press.

Ermakoff, George

2004 O negro na fotografia brasileira do século XIX. Rio de Janeiro: G. Ermakoff Casa Editorial.

Ewing, Katherine Pratt

I994 Dreams from a Saint: Anthropological Atheism and the Temptation to Believe. American Anthropologist 96(3): 57I-583.

I997 Arguing Sainthood: Modernity, Psychoanalysis, and Islam. Durham, usA: Duke University Press. 
Fabian, Johannes

I983 Time and the Other. How Anthropology Makes its Object. New York: Columbia University Press.

I998 Moments of Freedom. Anthropology and Popular Culture. Charlottesville: University of Virginia Press.

2000 Out of Our Minds. Reason and Madness in the Exploration of Central Africa. Berkeley: University of California Press.

200I Anthropology with an Attitude: Critical Essays. Stanford: Stanford University Press.

Fichte, Hubert

I987 Xangô. Die afroamerikanischen Religionen. Bahia, Haiti, Trinidad. Frankfurt a. Main: Fischer Verlag.

Fiske, John

I989 Understanding Popular Culture. London: Routledge.

Freyre, Gilberto

200 I Casa \& Senzala. Introducao à historia patriarchal no Brazil. Rio de Janeiro: Editora Record.

Fry, Peter

I982 Para inglês ver: identidade e política na cultura brasileira. Rio de Janeiro: Zahar.

I986 Male Homosexuality and Spirit Possesion in Brazil. Journal of Homosexuality II(3): I37-I53.

200I Feijoada e soul food 25 anos depois. In P.F. Neide Esterci and Miriam Goldenberg (eds.), Fazendo Antropologia no Brasil. Rio de Janeiro: DP\&A.

Geertz, Clifford

I957 Ethos, World-View and the Analysis of Sacred Symbols. The Antioch Review, vol. I7 (4): 42I-437.

I973 The Interpretation of Cultures. Essays in Interpretative Anthropology. New York: Basic Books.

I983 Local Knowledge: Further Essays in Interpretive Anthropology. New York: Basic Books.

I988 Works and Lives: The Anthropologist as Author. Stanford: Stanford University Press.

Geschiere, Peter

I997 The Modernity of Witchcraft: Politics and the Occult in Postcolonial Africa. Charlottesville: University Press of Virginia.

Gilroy, Paul

1993 The Black Atlantic: Modernity and Double Consciousness. Cambridge, usA: Harvard University Press. 
Ginsburg, Feye, Lila Abu-Lughod, and Brian Larkin

2002 Media Worlds: Anthropology on New Terrain. Berkeley and Los Angeles: University of California Press.

Ginway, Elisabeth

I992 Surrealist Benjamin Péret and Brazilian Modernism. Hispania 75(3): 543-553.

Gonçalves, Margareth de Almeida

2005 Império da Fé. Andarilhas da alma na era barroca. Rio de Janeiro: Rocco.

Gouldner, Alvin

I973 Romantiek en classicisme. Dieptestructuren in de sociale wetenschappen. De Gids, jrg. I36, nr. I: 3-29.

Graham, Richard, Thomas E. Skidmore, Aline Helg, and Alan Knight

I990 The Idea of Race in Latin America, I870-I940. Austin: University of Texas Press.

Guadeloupe, Francio

2009 Chanting Down the New Jerusalem: Calypso, Christianity, and Capitalism in the Caribbean. Berkeley and Los Angeles: University of California Press.

Hamburger, Esther

I998 Diluindo Fronteiras: Telenovelas no Cotidiano. In Lilia M. Schwarcz (ed.), História da Vida Privada 4. São Paulo: Companhia das Letras, pp. 439-489.

Hamilton, Russell G.

I967 Afro-Brazilian Cults in the Novels of Jorge Amado. Hispania 50(2): 242-252.

Hampton, Timothy

I99I Introduction: Baroques. Yale French Studies 80 (Baroque Topographies: Literature/ History/ Philosophy): I-9.

Hanssen, Beatrice

I999 Portrait of Melancholy (Benjamin, Warburg, Panofsky). MLN I44(5): 99I-IOI3.

Harding, Rachel E.

2000 A Refuge in Thunder: Candomblé and Alternative Spaces of Blackness. Bloomington: Indiana University Press.

Harding, Susan Friend

2000 The Book of Jerry Falwell: Fundamentalist Language and Politics.

Princeton: Princeton University Press.

Herman, Judith Lewis

I997 Trauma and Recovery. New York: Basic Books. 
Hess, David J.

I99I Spirits and Scientists. Ideology, Spiritism and Brazilian Culture. University Park: The Pennsylvania State University Press.

Hills, Helen

2007 The Baroque: Beads in a Rosary or Folds in Time. Fabrications: The Journal of the Society of Architectural Historians, Australia and New Zealand, I7(2): 48-7I.

Hirschkind, Charles

200 The Ethics of Listening: Cassette-Sermon Audition in Contemporary Egypt. American Ethnologist 28 (3): 623-649.

Ickes, Scott

2005 'Adorned with the Mix of Faith and Profanity that Intoxicates the People': The Festival of the Senhor do Bonfim in Salvador, Bahia, Brazil, I930-I954. Bulletin of Latin American Research 24(2): I8I-200.

Jackson, Michael

I989 Paths towards a Clearing. Radical Empiricism and Ethnographic Inquiry. Bloomington: Indiana University Press.

Janoff-Bulman, Ronny

I992 Shattered Assumptions. Towards a New Psychology of Trauma. New York: Free Press.

Jay, M.

I988 The Rise of Hermeneutics and the Crisis of Ocularcentrism. Poetics Today: 307-326.

James, William

I977 A Pluralistic Universe. Cambridge, usa: Harvard University Press.

2008 The Varieties of Religious Experience. A Study of Human Nature. Rockville: ARc Manor.

Johnson, Paul Cristopher

2002 Secrets, Gossip, and Gods: The Transformation of Brazilian Candomblé. Oxford: Oxford University Press.

Just, Roger

I995 Cultural Certainties, and Private Doubts. In Wendy James (ed.), The Pursuit of Certainty. Religious and Cultural Formulations. London: Routledge, pp. 285-309.

Karasch, Mary C.

I987 Slave Life in Rio de Janeiro, I808-I850. Princeton: Princeton University Press. 
Keane, Webb

2003 Semiotics and the Social Analysis of Material Things. Language and Communication 23(3-4): 409-425.

Kearney, Richard

20 Io Anatheism. Returning to God after God. New York: Columbia University Press.

Khouri, Omar

2005 Os modernistas de São Paulo e a (Re)descoberta do barroco. In P. Tirapeli (ed.), Arte Sacra Colonial Barroco Memória Viva. São Paulo: Imprensa Oficial do Estado de São Paulo e Editora da UNESP, pp. 246-253.

Kirmayer, Lawrence

I996 Landscapes of Memory: Trauma, Narrative, and Dissociation. In P. Antze and M. Lambek (eds.), Tense Past: Cultural Essays in Trauma and Memory. New York: Routledge, pp. I73-I99.

Kristeva, Julia

I982 Powers of Horror: An Essay on Abjection. New York: Columbia University Press.

Krueger, Joel W.

2006 The Varieties of Pure Experience: William James and Kitaro Nishida on Consciousness and Embodiment. William James Studies vol. I (I): I-37.

Kulick, Don

I998 Travesti: Sex, Gender, and Culture among Brazilian Transgendered Prostitutes. Chicago: University of Chicago Press.

Lambert, Gregg

2004 The Return of the Baroque in Modern Culture. London and New York: Continuum Press.

Landes, Ruth

I940 A Cult Matriarchate and Male Homosexuality. Journal of Abnormal and Social Psychology 35: 386-97.

I947 The City of Women. New York: Macmillan.

Latour, Bruno

I999 Pandora's Hope. Essays on the Reality of Science Studies. Cambridge, USA: Harvard University Press.

Latour, Bruno and Peter Weibel

2002 Iconoclash. Cambridge, USA: ZKM

Law, John

2004 After Method. Mess in Social Science Research. London: Routledge. 
Leach, Edmund

I986 Culture and Communication, the Logic by which Symbols are Connected. Cambridge, uk: Cambridge University Press.

Leacock, Seth, and Ruth Leacock

I972 Spirit of the Deep. New York: Anchor Books.

Lewis, J. Lowell

1992 Ring of Liberation. Deceptive Discourse in Brazilian Capoeira. Chicago: Chicago University Press.

Lex, Barbara

I979 The neurobiology of ritual trance. In C.D.L. Eugene d'Aquili and John MacManus (eds.) The Spectrum of Ritual. New York: Columbia University Press, pp. II7-I5I.

Lima, A. Lamartine de

I984 Roteiro de Nina Rodrigues. Ensaios/Pesquisas 2 do Centro de Estudos Afro-Orientais. Salvador: Universidade Federal da Bahia.

Lima, Vivaldo da Costa

2003 A família de santo nos candomblés jejes-nagôs da Bahia: um estudo de relações intragrupais. Salvador: Corrupio.

Lindholm, Charles

2002 Authenticity, Anthropology, and the Sacred. Anthropological Quarterly: 33I-338.

Linger, Daniel Touro

1992 Dangerous Encounters: Meanings of Violence in a Brazilian City. Stanford: Stanford University Press.

MacCannel, Dean

I999 The Tourist. A New Theory of the Leisure Class. Berkeley: University of California Press.

McCann, Bryan

2004 Hello, Hello Brazil. Popular Music in the Making of Modern Brazil. Durham, USA: Duke University Press.

Malinowski, Bronislaw

I984 Argonauts of the Western Pacific. Prospect Heights: Waveland Press.

Maltz, Bina, Jerônimo Teixeira, and Sérgio Ferreira

I993 Antropofagia e tropicalismo. Porto Alegre: Editora da Universidade Federal do Rio Grande do Sul.

Marques, Lúcia, Emanoel Araújo, Ecyla Brandão, and Museu Afro Brasil. 2006 Meninos Deus: os meninos do Recolhimento dos Humildes e outros Meninos Deus. São Paulo: Imprensa Oficial Museu Afro Brasil. 
Martins, J.S.

2002 A imagem incomum: a fotografia dos atos de fé no Brasil. Estudos Avançados I6: 223-260.

Martins, Wilson

I992 Cendrars e o Brasil. Hispania 75(4): 979-987.

Matory, James Lorand

I999 The English Professors of Brazil: On the Diasporic Roots of the Yorùbá nation. Comparative Studies in Society and History 4I(OI): 72-I03.

2005 Black Atlantic Religion: Tradition, Transnationalism, and Matriarchy in the Afro-Brazilian Candomblé. Princeton: Princeton University Press.

Mattos, Sergio

2000 A televisão no Brasil: 50 anos de história (I950-2000). Rio de Janeiro: PAS.

Mauad, Ana Maria

I997 Imagem e auto-imagem do Segundo Reinado. In L.F. de Alencastro (ed.), História da vida privada no Brasil. Vol. 2. São Paulo: Companhia das Letras, pp. I8I-232.

Mauss, Marcel

I973 Techniques of the Body. Economy and Society 2(I): 70-88.

Mazzarella, William

2004 Culture, Globalization, Mediation. Annual Review of Anthropology 33: $345-367$.

Meyer, Birgit

2004 Praise the Lord. Popular Cinema and Pentecostalite Style in Ghana's New Public Sphere. American Ethnologist 3I(I): 92-IIo.

2009 Religion, Media, and the Question of Community. New York: Palgrave Macmillan.

Meyer, Birgit, and Peter Pels

2003 Magic and Modernity: Interfaces of Revelation and Concealment. Stanford: Stanford University Press.

Middelanis, C.H.

2005 Blending with Motifs and Colors: Haitian History Interpreted by Edouard Duval Carrie. Small Axe:Io9-I23.

Miller, William Ian

2003 Faking It. Cambridge, U K: Cambridge University Press.

Mitchell, W.J.T.

2005 What do Pictures Want? The Lives and Loves of Images. Chicago: University of Chicago Press. 
Montes, Maria Luisa

I998 As figuras do sagrado: entre o público e o privado. In Lilia M. Schwarcz (ed.), História da vida privada no Brasil 4. São Paulo: Companhia das Letras, pp. 63-I7I.

Morgan, David

I998 Visual Piety: A History and Theory of Popular Religious Images. Berkeley: University of California press.

Morris, Rosalind C.

2000 In the Place of Origins: Modernity and its Mediums in Northern Thailand. Durham, usA: Duke University Press.

Narber, Gregg

2003 Entre a cruz e a espada: violência e misticismo no Brasil rural. São Paulo: Editora Terceiro Nome.

Ndalianis, Angela

2004 Neo-Baroque Aesthetics and Contemporary Entertainment. Cambridge, usA: The Mit Press.

Nóbrega, Cida, and Regina Echeverria

2002 Verger: um retrato em preto e branco. Salvador: Corrupio.

Noland, Carrie

2000 The Metaphysics of Coffee: Blaise Cendrars, Modernist Standardization and Brazil. Modernism/Modernity 7(3): 40I-422.

Obeyesekere, Gananath

I98I Medusa's Hair: An Essay on Personal Symbols and Religious Experience. Chicago: University of Chicago Press.

Öncü, Ayse

2006 Becoming 'Secular-Muslims': Yashar Nuri Öztürk as a Supersubject on Turkish Television. In Birgit Meyer and Annelies Moors (eds.), Religion, Media and the Public Sphere. Bloomington: Indiana University Press.

Oosterbaan, Martijn

2005 Mass Mediating the Spiritual Battle: Pentecostal Appropriations of Mass Mediated Violence in Rio de Janeiro. Material Religion: The Journal of Objects, Art and Belief I(3): 358-385.

Ortiz, Renato

I999 A morte branca do feitiçeiro negro. Umbanda e sociedade brasileira. São Paulo: Editora Brasiliense.

Osborne, Peter

2005 Walter Benjamin: Critical Evaluations in Cultural Theory. London: Routledge. 
Otto, Rudolf

I958 The Idea of the Holy. Oxford: Oxford University Press.

Owens, Craig

I980 The Allegorical Impulse: Toward a Theory of Postmodernism. October I2 (spring): 67-86.

Parés, Luis Nicolau

I997 The Phenomenology of Spirit Possession in the Tambor de Mina. An ethnographic and audio-visual study. London: soAs.

2006 A formação do Candomblé: história e ritual da nação jeje na Bahia. Campinas: Editora Unicamp.

Parker, Richard G.

I999 Beneath the Equator: Cultures of Desire, Male Homosexuality and Emerging Gay Communities in Brazil. New York: Routledge.

Parsons, W.B.

I998 The Oceanic Feeling Revisited. The Journal of Religion 78(4): 5OI-523.

Pels, Peter

2003 Spirits of Modernity. Alfred Wallace, Edward Tylor and the Visual Politics of Fact. In Birgit Meyer and Peter Pels (eds.), Magic and Modernity. Interfaces of Revelation and Concealment. Stanford: Stanford University Press, pp. 24I-272.

Péret, Benjamin

I992 Euvres complètes. Tome 6 Paris: Librairie José Corti.

Pessoa, Fernando

2002 The Book of Disquiet. New York: Serpent's Tail.

Pierre, José

1992 Arthur Cravan. Le prophète. Paris: Actual.

Pinney, Christopher

I997 Camera Indica: The Social Life of Indian Photographs. Chicago: University of Chicago Press.

2004 Photos of the Gods. The Printed Image and Political Struggle in India. London: Reaktion.

Plate, S. Brent

2005 Walter Benjamin, Religion, and Aesthetics: Rethinking Religion through the Arts. New York: Routledge.

Ponge, R.

I999 Surrealismo e novo mundo. Porto Alegre: Universidade Federal do Rio Grande do Sul. 
Port, Mattijs van de

1998 Gypsies, Wars and Other Instances of the Wild. Civilization and its Discontents in a Serbian Town. Amsterdam: Amsterdam University Press.

1999 'It Takes a Serb to Know a Serb', Uncovering the Roots of 'Obstinate Otherness' in Serbia. Critique of Anthropology, I9(I): 7-30.

I999 Amália. Some Reflections on the Death of a Portuguese Star. Etnofoor 12(2): 7-25

200I Geliquideerd: Criminele Afrekeningen in Nederland. Amsterdam: Meulenhoff.

2005a Candomblé in Pink, Green and Black. Re-scripting the AfroBrazilian Heritage in the Public Sphere of Salvador, Bahia. Social Anthropology I3 (I): 3-26.

2005b Circling around the Really Real. Possession Ceremonies and the Search for Authenticity in Bahian Candomblé. Ethos 33(2): I47-I79.

2005c Priests and Stars. Candomblé, Celebrity Discourses and the Authentication of Authority in Bahia's Public Sphere. Postscripts I.2/I.3: 30I-324.

2006 Visualizing the Sacred. Televisual Styles and the Religious Imagination in Bahian Candomblé. American Ethnologist 33(3): 444-46I.

2007 Bahian White. The Dispersion of Candomble Imagery in the Public Sphere of Bahia. Material Religion 3(2): 242-273

2007b Crossing the Sertão. Going Places to Make Things Come Your Way. Etnofoor 2O(I): 97-Io6.

2009 'Don't Ask Questions, Just Observe!'. Boundary Politics in Bahian Candomblé. In Birget Meyer (ed.), Aesthetic Formations. Media, Religion, and the Senses. New York: Palgrave MacMillan, pp. 3I-53.

Prandi, J. Reginaldo

I996 Herdeiras do axé: sociologia das religões afro-brasileiras. São Paulo: Hucitec.

I999 Referências sociais das religiões afro-brasileiras: sincretismo, branqueamento e africanização. In Jefferson Bacelar (ed.), Faces da tradição afro-brasileira. Rio de Janeiro: Pallas.

200I Mitologia dos orixás. São Paulo: Companhia das Letras.

Pretto, Nelson de Luca, and Luiz Felipe Serpa

2002 Expressões de sabedoria: educação, vida e saberes: Mãe Stella de Oxóssi, Juvany Viana. Salvador: EDUfBa. 
Reijnders, Frank

I99I Metamorfose van de Barok. Amsterdam: Duizend \& Een.

Reis, Joao José

I996 Identidade e diversidade étnica nas irmandades negras no tempo da escravidao. Tempo 2(3): 7-33.

2003 Death is a Festival: Funeral Rites and Rebellion in NineteenthCentury Brazil. Chapel Hill: The University of North Carolina Press.

Ribeiro, M.A.P.

I995 A morte de Nina Rodrigues e suas repercussões. Afro-Asia I6: 54-69.

Risério, Antonio

I98I Carnaval ljexá. Salvador: Corrupio.

Rio, João do

2006 As religiões no Rio. Rio de Janeiro: José Olympio.

Rodrigues, Raimundo Nina

I988 Os Africanos no Brasil. Brasília: Editora Universidade de Brasília.

2005 O animismo fetichista dos negros baianos. Salvador: Teatro xviıl.

Rowe, William, and Vivian Schelling

I99I Memory and Modernity: Popular Culture in Latin America. London: Verso.

Rushdie, Salman

I99I Imaginary Homelands: Essays and Criticism, I98I-I99I. London: Granta Books.

Sá, Xico

2004 Divina Comédia da Fama. Purgatório, paraíso e inferno de quem sonha ser uma celebridade. Rio de Janeiro: Objectiva.

Sampaio, Gabriela Reis

2000 A história do feiticeiro Juca Rosa: cultura e relações sociais no Rio de Janeiro imperial. Ph.D. thesis. Campinas: Universidade Estadual de Campinas.

Sampaio, Maria Guimarães

2006 Da photographia à fotografia (I839-I949). In A. Alvez (ed.), A fotografia na Bahia, I839-2006. Salvador: ASA Foto, pp. I3-83.

Sanchez, Rafael

200I Channel-Surfing: Media, Mediumship, and State Authority in the María Lionza Possession Cult (Venezuela). In Hent de Vries and Samuel Webber (eds.) Religion and Media. Stanford: Stanford University Press, pp. 388-434. 
Sandroni, Carlos

200 Feitiço decente: transformações do samba no Rio de Janeiro, I9I7I933. Rio de Janeiro: Jorge Zahar Editor: Editora UFRJ.

Sansi-Roca, Roger

2005 The Hidden Life of Stones: Historicity, Materiality and the Value of Candomblé Objects in Bahia. The Journal of Material Culture Io(2): 139-I56.

2007 Fetishes and Monuments. Afro-Brazilian Art and Culture in the 2oth Century. Oxford: Berghahn.

Santos, Jocélio Teles dos

I995 O dono da terra. O caboclo nos candomblés da Bahia. Salvador: Sarah Letras.

2005 O poder da cultura e a cultura do poder. A disputa simbólica da heranca cultural negra no Brazil. Salvador: Edufba.

2008 Mapeamento dos terreiros de Salvador. Salvador: UfBA, Centro de Estudos Afro-Orientais.

Santos, Juanita Elbein dos

1998 Os Nago e a morte. Petrópolis: Vozes.

Santos, M.S.A.

I993 Meu tempo é agora. São Paulo: Oduduwa.

Santos, Maria Stella de Azevedo, and Cleo Martins

I989 Manifesto. Para que o Candomblé sobreviva. Planeta 2or (junho): I9-22.

Savigliano, Marta

I998 From Wallflowers to Femmes Fatales: Tango and the Performance of Passionate Femininity. In William Washabaugh (ed.), The Passion of Music and Dance: Body, Gender, and Sexuality. London: Berg, pp. I50-I73.

Scarry, Elaine

I985 The Body in Pain: the Making and Unmaking of the World. Oxford: Oxford University Press.

Schüssler, Alexandra

2006 Wahnsinn auf Papier und Leinwand. Sublimation und Exploitation im Haus der Künstler in Gugging. Ph.d. thesis. University of Amsterdam.

Schwarcz, Lilia Moritz

I993 O espetáculo das raças: cientistas, instituições e questão racial no Brasil, I870-I930. São Paulo: Companhia das Letras. 
Segato, Rita L.

I994 A tradição afro-brasileira frente à televisão, ou, Duas mortes entre a ficção ea realidade. Religião e Sociedade I6(3): I5-63.

Segato, Rita Laura

I995 Santos e daimones: o politeísmo afro-brasileiro e a tradição arquetipal. Brasília: Editora UnB.

Shelton, Marie Denise

I984 Le monde noir dans la literature dadaiste et surrealiste. The French Review 57(3): 320-328.

Silva, Ana Beatriz Barbosa, and Eduardo Mello

2004 Sorria, você esta sendo filmado. Rio de Janeiro: Editora Gente.

Silva, Darwin and Motta Brandão

I958 Cidade de Salvador. Caminho do encantamento. São Paulo: Companhia Editora Nacional.

Silva, Edjane Cristina Rodrigues da

2007 Representação do Menino Jesus no Monte e Produção Artística no Recolhimento de Nossa Senhora dos Humildes/BA. Revista Ohun 3(3): 162-I80.

Silva, Rita de Cássia Amaral and Vagner Gonçalves da

I993 A cor do Axé: brancos e negros no Candomblé de São Paulo. Estudos Afro-Asiáticos 25: 99-I24.

Silva, Vagner Gonçalves da

2000 O antropólogo e sua magía. Trabalho de campo e texto etnográfico nas pesquisas sobre religiões afro-brasileiras. São Paulo: Editora USP.

Silva, Viviane Rummler da

2006 Miguel Navarro y Canizares e a Academia de belas artes da Bahia. Relações históricas e obras. Revista Ohun 2(2): 219-26I.

Skidmore, Thomas

I990 Racial Ideas and Social Policies in Brazil, I870-I940. In Richard Graham (ed.), The Idea of Race in Latin America I870-I940. Austin: University of Texas Press.

Soares, Angelo Barroso Costa

2005 Academia dos Rebeldes: Modernismo à Moda Baiana. Universidade Estadual de Feira de Santana.

Soares, Mariza de Carvalho

2000 Devotos da cor. Identidade étnica, religiosidade e escravidao no Rio de Janeiro, século XVIII. Rio de Janeiro: Civilizacao Brasileira. 
Sobchack, Vivian

2008 Embodying Transcendence. On the Literal, the Material and the Cinematic Sublime. Material Religion. The Journal of Objects, Art and Belief vol. 4, no. 2: 194-203.

Sodré, Muniz

I988 O terreiro e a cidade. A forma social negro-brasileira. Petrópolis: Vozes.

Sodré, Muniz and Luís Filipe de Lima

I996 Um vento sagrado. História de vida de um adivinho da tradição nagô-ketu brasileira. Rio de Janeiro: editor Mauad.

Sontag, Susan

I990 Against Interpretation and Other Essays. New York: Picador.

2002 On Photography. London: Penguin Books.

Souza, Marina de Mello e

2006 Reis negros no Brasil escravista. História da festa de coroação de Rei Congo. Belo Horizonte: Editora UFMG.

Stam, Robert

I997 Tropical Multiculturalism. A Comparative History of Race in Brazilian Cinema and Culture. Durham, usA: Duke University Press.

Stavrakakis, Yannis

I999 Lacan and the Political. London and New York: Routledge.

Stoller, Paul

I989 The Taste of Ethnographic Things: The Senses in Anthropology. Philadelphia: University of Pennsylvania Press.

I995 Embodying Colonial Memories: Spirit Possession, Power, and the Hauka in West Africa. New York: Routledge.

Stolow, Jeremy

2005 Religion and/as Media. Theory, Culture and Society 22(4): II9.

Tacca, Fernando de

2003 Imagens do sagrado. Revista da Antropologia Social. UFPR, edição especial da IV Reunião de Antropologia do Mercosul.

Taussig, Michael T.

I986 Shamanism, Colonialism, And The Wild Man: A Study in Terror And Healing. Chicago: University of Chicago Press.

I993 Mimesis and Alterity: A Particular History Of The Senses. New York: Routledge.

I999 Defacement: Public Secrecy and the Labor of the Negative. Stanford: Stanford University Press. 
Thoden van Velzen, H.U.E. and W. van Wetering

I988 The Great Father and the Danger: Religious Cults, Material Forces, and Collective Fantasies in the World of the Surinamese Maroons. Caribbean Series. Vol. 9.

Toral, A.A.

I999 Entre retratos e cadáveres: a fotografia na Guerra do Paraguai. Revista Brasileira de História I9: 283-310.

Torgovnick, Marianna

I990 Gone Primitive. Savage Intellectuals, Modern Lives. Chicago: University of Chicago Press.

1996 Primitive Passions. Men, Women, and the Quest for Ecstasy. Chicago: University of Chicago Press.

Trevisan, João Silvério

200 I Devassos no paraíso. A homosexualidade no Brasil, da colonia à atualidade. São Paulo: Editora Record.

Tythacott, Louise

2003 Surrealism and the Exotic. London: Routledge.

Underwood, David K.

2002 Toward a Phenomenology of Brazil's Baroque Modernism. In E.J. Sullivan, (ed.), Brazil. Body \& Soul. New York: Guggenheim Museum, pp. 504-524.

Urry, John

2002 The Tourist Gaze. Thousand Oaks: Sage Publications.

Vailati, L.

2006 As fotografias de 'anjos' no Brasil do século xix. Anais do Museu Paulista: História e Cultura Material I4: 5I-7I.

Valladares, José

I95I Beabá da Bahia. Guia Turística. Salvador: Livraria Progresso Editora.

Valle, Ivonne D.

2002 Jesuit Baroque. Journal of Spanish Cultural Studies 3(2): I4I-I63.

Veenis, Milena

2008 Dromen van dingen. Oost-Duitse Fantasieën over de westerse consumptiemaatschappij. Ph.D. thesis. University of Amsterdam.

Velho, Yvonne Maggie Alves

I992 Medo do feitiço: relações entre magia e poder no Brasil. Rio de Janeiro: Arquivo Nacional, Orgão do Ministério da Justiça.

Veloso, Caetano

2002 Tropical Truth. A Story of Music and Revoluation in Brazil. New York: Knopf. 
Veloso, C., and C. Dunn

I996 The Tropicalista Rebellion. Transition 70: II6-I38.

Verrips, Jojada

2006 Aisthesis and An-aesthesia. Ethnologia Europea 35(I-2): 27-33.

Vianna, Hermano

2002 The Mystery of Samba. Popular Music \& National Identity in Brazil. Chapel Hill: University of North Carolina Press.

2007 O mistério do samba. Rio de Janeiro: Zahar: UFRJ Editora.

Vinkenoog, Maarten

2003 Droomreizen in Bahia. Onmoetingen tussen jongeren en hun geexotiseerde 'Ander'. Master Thesis. University of Amsterdam.

Wafer, James William

I99I The Taste of Blood: Spirit Possession in Brazilian Candomblé. Philadelphia: University of Pennsylvania Press.

Warner, Michael

2002a The Mass Public and the Mass Subject. In Michael A. Elliott and Claudia Stokes (eds.) American Literary Studies: A Methodological Reader. New York: New York University Press, pp. 243-264.

2002b Publics and Counterpublics. Public Culture I4(I): 49-90.

Williams, Bernard

2002 Truth and Truthfulness. An Essay in Genealogy. Princeton: Princeton University Press.

Wiliams, Daryle

200I Culture Wars in Brazil: The First Vargas Regime, I930-I945. Durham, usA: Duke University Press.

Witte, Marleen de

2003 Altar Media's "Living Word": Televised Charismatic Christianity in Ghana. Journal of Religion in Africa 33(2): 172-202.

Wolin, R.

I994 Walter Benjamin: An Aesthetic of Redemption. Berkeley: University of California Press.

Wyllys, Jean

200I Aflitos. Salvador: Casa de Palavras.

ŽiŽek, Slavoj

I989 The Sublime Object of Ideology. London: Verso.

I997 The Plague of Fantasies. London: Verso.

I999 The Ticklish Subject: The Absent Centre of Political Ontology. London: Verso.

200I On Belief. New York: Routledge. 



\section{Index}

'Absent truth' 34, 37-38, 8I, I59-I6I, I64-I65, I77, I80-I8I, I84, I96, I99, 202, 207; see also Allegory

Abolition 3I, 70, 90, I80

Academy

Academic writing and forms of report I5, I7, 20-22, 29, 44, II5, I75

Excluding mystical roads to knowledge 23

'Academy of the Rebels' I2I

Acheiropoeiete I97

Aesthetics

and the re-africanization in

Candomblé 225

as aesthesis 58

Baroque aesthetics 86, I59ff.l; see also Baroque

in Candomblé video productions 34

in colonial society 43

in the academy 22

Primitivist aesthetics I4O, I2I

Televisual aesthetics 232

'Aesthetics of persuasion' 37, 57

Africa

as 'primitive' 73, 93, II2, II5-II6, I40-I4I, 266n.42 as the dominant referential framework in Candomblé studies 4I, 43, I87

Performance of Africa in Candomblé 42, 57, I03, I52-I53, I86, 204-205, 2I5-2I7, 2I9-222, 225, 228, 233-234, 236-237, 246, 258,268 n. 6

Alaketu, Olga do 5I, I88, 20 I

Allegory and 'broken' biographies I78, I80 and ethnography 172 Baroque 33, 8I, 87, I59ff.

Amado, Jorge II9-I22

Animal sacrifice 36, IOI, II2, I40-I4I, I53, I55, I95, 224, 243

Animism 6o, 70-75, 9I

Anthropology/Anthropologist(s) see also Body, Anthropologists and their and constructivist argumentation 26-27, 30

and fieldwork 7, 22, 25, 3I, 53, 63, I30, I7I-I74, 216

and philosophy 255, 259

as allegorist $44, \mathrm{I} 7 \mathrm{I}-\mathrm{I} 72$

as paparazzo 77

Antropofagia 6o, 70, 73, 9I; see also 
cannibalization

Artifice 27, 33, 38, 80-8I, 86-87, I64, I66-I68, I73-I74

Authenticity/Authentication

an camp $\quad$ I67

in anthropology 26, 77, 220, 260

in Candomblé I6, I29, I86, I89, 2I5ff.

'Bafflement politics' I83ff.

Baianidade 33, I00, I09, I3I, I40, I54, I55

Balé Folclórico da Bahia I28, 208-2I2, 258

Baroque

and camp I66

and the senses 57, 6o, 268n.64

and vision $58,78,80,82-87$, I59ff.

as alternative to academic forms of writing 4I, 44, 63, I60, I70, I76, 217, 260

as the dominant aesthetics of the

Bahian life world 3I, 47ff., 62, 66, 94

Churches 43, I47, I6I

Historical Baroque 38-40, 96, 106I07, II7, I6I

Bastide, Roger 42-43, 50, I33, I78, I94, 200, 269, 274

'Belief-energy' 240

Bicha I49-I5I

Biedermeier 215-2I7, 246

Blood 49, 52, IOI, III, I37, I39, I4O, I42, I55, I74, I76-I77, 224, 267n.53

Body

and aesthetics II8

Anthropologists and their 29-30, $53,62,72$

as an instrument of naturalization I67ff. as evidence of authentic

possession $\mathrm{I} 88$-I89

Black 33, 49, II8-II9, I23, I3I, I42

Colonized by text 28, I75

Enabling 'symbolic closure' I74

in anthropological texts 2I, 77, 176

in Candomblé I4, 30, 56, II8-II9, I3I, I55, 200, 202, 206-207

in dance 55, $\mathrm{II} 8,2 \mathrm{O} 2$

in mysticism I7, I9, 52, 60

The-body-that-cannot-be-told

$2 \mathrm{I}-22,28,30,52, \mathrm{IO} 4, \mathrm{I} 69$

Boundary making 34, 58, 75, 90, 2I2, 2I5ff., 220, 235, 244

Brotherhoods (irmandades) 39, 4I

Caboclo I42, I50, I82, I85, I89, I95, I97-I99, 206

Camp I66ff., I69, I73

Candomblé

and carnival 92, I28, I5O, I52-I53, I87, 2II, 246

and ecology I45ff.

and gay movement 33, I5off.

and Movimento Negro I46, I48, I52ff., I54

and tourism 33, 50, I23, I25, I34I35, I46ff., I54, I68, I83, I85-I86, 202, 205-206, 209 as beauty IOO-IOI, I03-I04, I08, II9, I22, I25, I34, I42-I43, I95, 202

as challenge to academic forms of knowledge production I6ff. as danger Io7ff. as exotic spirituality 23,33 , I3I, I43-I44, I47, I95, 24I as folklore $33, \mathrm{I} 37, \mathrm{I} 46,208-209$, 236; see also Balé Folclórico da 
Bahia

as primitive see primitive

as revolutionary force 32 , I2off.,

I42

as trademark of Bahia Ioo, I47

as tradition and cultural heritage

I03, I25, 236, 24I, 269n.7I

Baroque aesthetics in 39ff., 42-44

General information I89ff.

Claiming to be 'religion' I87ff.

in film I4Iff.

in the press 187

Persecution of I3, IOI, I53, I87

Public worth of 32, I3Iff., I4I, I45, I48, 222, 24I

Cannibalization 3I, 60-6I, II4-II5, II7-II8, I37, I74, 246

Capoeira 54, 92, I07, I2I, I32, I36-I37, I4I, 208

Carnival II, 3I, 49, 53, I24, I32, I6I, I8I, 240; see also Candomblé and carnival

Casa Branca I83, I85, I87, 2II

Catholicism 39ff., 56, 60, 70, 75, II6, I52, 20I, 2I 8,240

Celebrities 235ff.

Civilization 6I, 89, 91-92, I05-IO7, III-II2, II4-II7, I2O, I23-I24, I37, I4I, I47, I56, 246

Coherence 34, 38, I79, I8I, 2I8, 25I, 253,256

Colonial society 39 ff., 54 , I79

Constructionism/ constructivism 20, 24, 26-30, I73-I77, 220, 255-259

Credibility 29, 76, I99, 23I, 238, 240$24 \mathrm{I}$

O Cruzeiro 36, I35ff.

'Cultural enchantment' 28-30, 35, 254,256
Dadaism II4

Death 29, 85, I03, I55, I62, I79

'Deep knowledge' I3-I6, 22, 28, 57, I92, 207, 2I2, 22I-222

Desire I5, 38, 50, 52, 56, 66-67, 8I, II5, I70, I74-I75, I8O-I8I, 232, 256, 259

'Desperate faith' 33, I6I, I69, I80-I8I

Dr Fritz 95-96, II2

Dr Nina see Nina Rodrigues

Erotics 38, 5I, 53, 72, II5-II6, I22, I37, I55, I74, 266n.4I

Europe 32, 5I, 6I, 73, 9I-95, I03, IO6IO7, II2-I24, I46-I47, 220

Event (Badiou) 25, 34, 93ff., I69, I98I99, 207

Fantasy 7, I8, 29, 63, I69, 228, 256, 259, 266n.39, 269n.75

Festa de orixá 102, 227

Fetishism 50, 52, 70, 74, 88-94, I06, II4, I34, I65, 265n.27

Folklore 33, I3I, I46; see also Candomblé as folklore

Fundamentos see 'deep knowledge'

Gantois 85, 88, I43-I44, I85, 2II, 2152I7, 238-24I, 244-245

Geléia Geral 62, 66, 78, I69, I8I

Glossolalia I8, 253

Gypsy 8, I96

Homosexuality 52, I08, I2I, I30, I49, I5I, 2IO; see also Candomblé and gay movement, and bicha

Ilê Axé Opô Afonjá I44, I85-I87, 204205, 2IO-2II, 2I7, 22I-228, 236-237, 245, 266

Ilê Aganjú I08, 220 
Image(s)

and baroque instructions on vision 69 ff.

Animation of 75,80

Photographic 78-79, 84, 87

Power of $76 \mathrm{ff} ., 85$

Theory of the 73

'Imaginary' 256

Immanence I65, I8I, 268n.64

Immersion 47ff., I03, I30, I64, I74

Initiation I3-I6, 50-53, IIO, I85, I93-

I95, 2I2, 22I, 235, 237, 245

Jesuits 39, 57

Jouissance 25, I55-I56, I69

Jubiabá iIgff.

Lacanian thought $7,23,28-29,37$,

I74, I76-I77, 2I9-220, 252, 256-260

Logocentrism I5

Macumba ('black magic') Io7ff., I85

Madness I09, I20, 253

Mãe Stella I3, I5, I86, 204-205, 2072II, 2I7-22I, 236-237, 245, 250, 258

Mãe Menininha I43-I45, I86, 24I

Magic

and the 'primitive' II5

in anthropology 2I, 28-29, 73, 75

in Candomblé 93, I07-I08, III, I4O, 2I2

in photography $79,85,87$

of Bahia 7, II, 50, 58, I00, I34, I46

Media imaginaries 215ff.

Metamorphosis 38, I79

Milagre de São Roque $249 \mathrm{ff}$.

Miracles 34, 38, 75, 85, I20, I6I, I64I65, I69, I76-I77, I80-I8I, I83ff., I96, 249, 254-255, 273

Modernistas 32, II3-II4
Modernity 3I, 9I, I07, III-II2, I4I, 2I7, 24I

Mystery II, I9, 28, 67, 95, I33-I34, I46I47, I54, I62, I65, I9O, I92, 20I-2I2, 257

Mysticism I7-I9, 25-26, 29, I42, I46, 20I, 263n.3

Natural 44, 80, 84, 86, II2, I45, I68I74, I77, I79, I89, 233, 265n.6I

Nagô 42, 5I, II6, I85-I86

Nina Rodrigues, Raimundo 3I-32, 66, 68ff., II6, II9-I20, I23, I27, I34, I37, I47, I62, I64, I87, 246, 25I, 257

Ocularcentrism 3I-32, 67, 78, 80, 87, $94,257-258$

Ogã 67, I2I, I86, 202, 244-245, 268 n. 67

Orixá I2, I4, 4I-42, 64, IIO-III, II8, I22, I27-I28, I33, I37, I39, I43, I45, I52, I8O, I85-I95, 203-2I2, 2I5-229, 233, 266n.50

Otherness 22-23, 30, 172, I90, 193, 256, 26I

Pentecostalism 49, 56, 60, IIO, I54I55, I85, 230

Péret, Benjamin 52-53, II5-II6 Photography as reality trace $79,84,178$ in baroque understandings of vision $78 \mathrm{ff}$.

in commemorative practices 85 in magical practices 85,87 Introduction in Brazil $78 \mathrm{ff}$.

'Plenum of existence' I7, I9-20, 44, 253, 263

Portraits 69ff.

Possession see Spirit possession 
Post-possession amnesia 200-20I

Poverty 32, 62, IO3-IO4, II2, 239

Priest(ess)

as media figures 35

as icons of baianidade 236

Authority of I6, 35, I32, I80, 218, $235 \mathrm{ff}$.

'Primitive'

as characteristic of Bahian society IO4-II3, I47

as characteristic of Candomblé IOI, IO3, I33, I35, I4O-I42, I55, 242

as understood by modernistas II4ff. as understood in Dr Nina's days 32, 70, 73-75, 88, 93

Celebration of the $99 \mathrm{fff}$.

Profanation 187, 209

Public I27ff.

Purity 3I, 35, 42, II2, I86, I9I, 204, 221, 236, 246

Quotation 48, 53, 60, II4, I22, I27, I30, I37, I66

Race 32, 53, 7I, 73-74, 89, 9I, 228

'Real' (The Lacanian) 7, 23-24, 28-29, 37, I74, I76, 219-220, 252, 256-260

Religion see Candomblé claiming to be 'religion'

Romanticism 22-23, 38, 63, I63-I65, 267n.6r

Sacred I7, 29-30, 34, 58, I29, I6I, I77, 222,235

Secrecy 203, 206-2I0

Secret I3, 34, I4I, I65, I87, I92, 253

Sex see Erotics

Slavery 57, 90, I39, I78
Slaves 40, 43, 58, 77, I06, I39, I53, I78 Spirit of the classic 35-44, 62, 66-67, 70, 78, 80-8I, 89, 94-95, 2I7-2I8, 236, 254, 259

Spirit possession and 'deep knowledge' I4, 57, I92, 207, 2I2

and nuns I83-I84, I88 and secrecy I4, I92, I99ff. and tourists $183-184,202,205-207$ Inexplicability of 34, I88, I90, 202, 207

Local explanations of I9I

Prohibition to film 202

Spiritism 56, 92, 95, II2

Spontaneity 86, I79

Style $34-35,37,39,56,79,90$, I30, I7II72, 20I, 204, 2I8ff.

Subjectivity 20, 20I, 219-220, 253-254, 256, 259

Superficiality I4, I6, I29, 207-208, 257

Surrealism I8, 2I, 52, 99ff., II4, I37, I90, 258

'Symbolic closure' 29, I64, I76-I77, I8I, 2I7, 2I9, 256

'Symbolic order' 7-8, 23-24, 33, I63, I69, I76-I77, I79, I8I, 2II, 220, 252253, 256, 258-259

Syncretism 42, III, I53, I78, I86, 2I72I 8,236

Telenovela 77, I22, 216, 227-233

Television I87, 203-204, 2I8, 223

'The-rest-of-what-is' II, I8-20, 23, 25-26, 28-30, I76-I77, 2I7, 2I9, 249 ff., $25 \mathrm{I}-252$

Tourism I03, I22, I48; see also Candomblé and tourism

Transcendence 26, I3I, I72, I8I, 268 Trauma 7, 66, I79, I8I, 268 
Trompe l'oeuil 33, 38, 58, 80, I64, 253

Tropicália 6I-62, I42, I44, I95, 239, 242

Truth see 'absent truth'

UFO'S I95, I97

Vargas regime 32, 60, I24, I3I, I4OI4I, I45, 258

Verger, Pierre 5I, 53, 64, I00, I33, 258, 264n.I5

Video-tapes 204ff., 22Iff.
Violence 2I-22, 32, 99ff., I2O, I24, I79, 256

Vision see Baroque and vision

Whites 39-40, 49, 74, 9I, I20

'World-making' IIff., 62, I64, I66, I69-I70, I74, I78-I79, I8I, 2I7-2I8, $249 \mathrm{ff}$.

'Writing culture' 20-2I

'Written-by-the-world' I8, 29

Xiré I89, I92, 206 


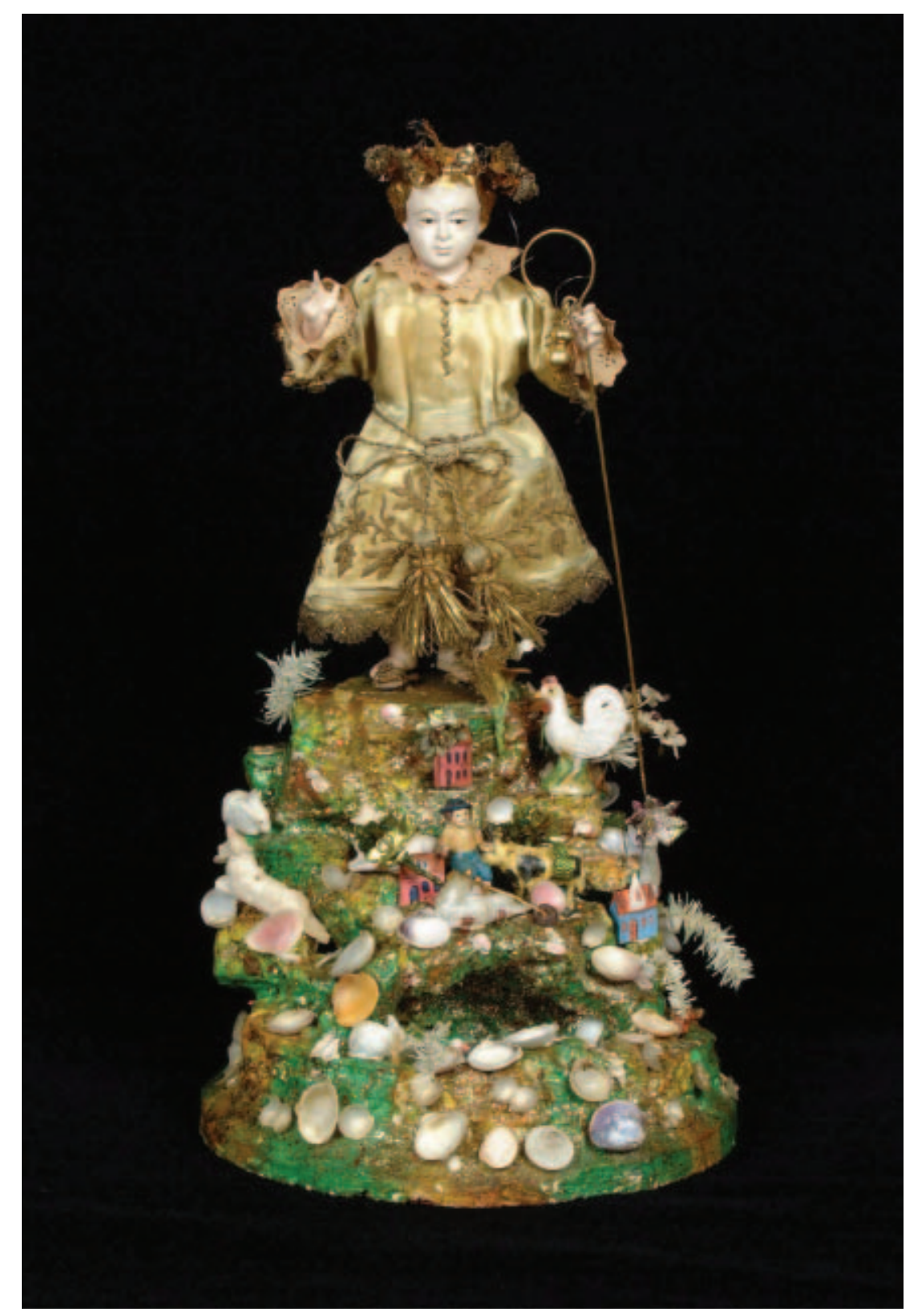

menino Jesus no monte, the child Jesus on the mountain 

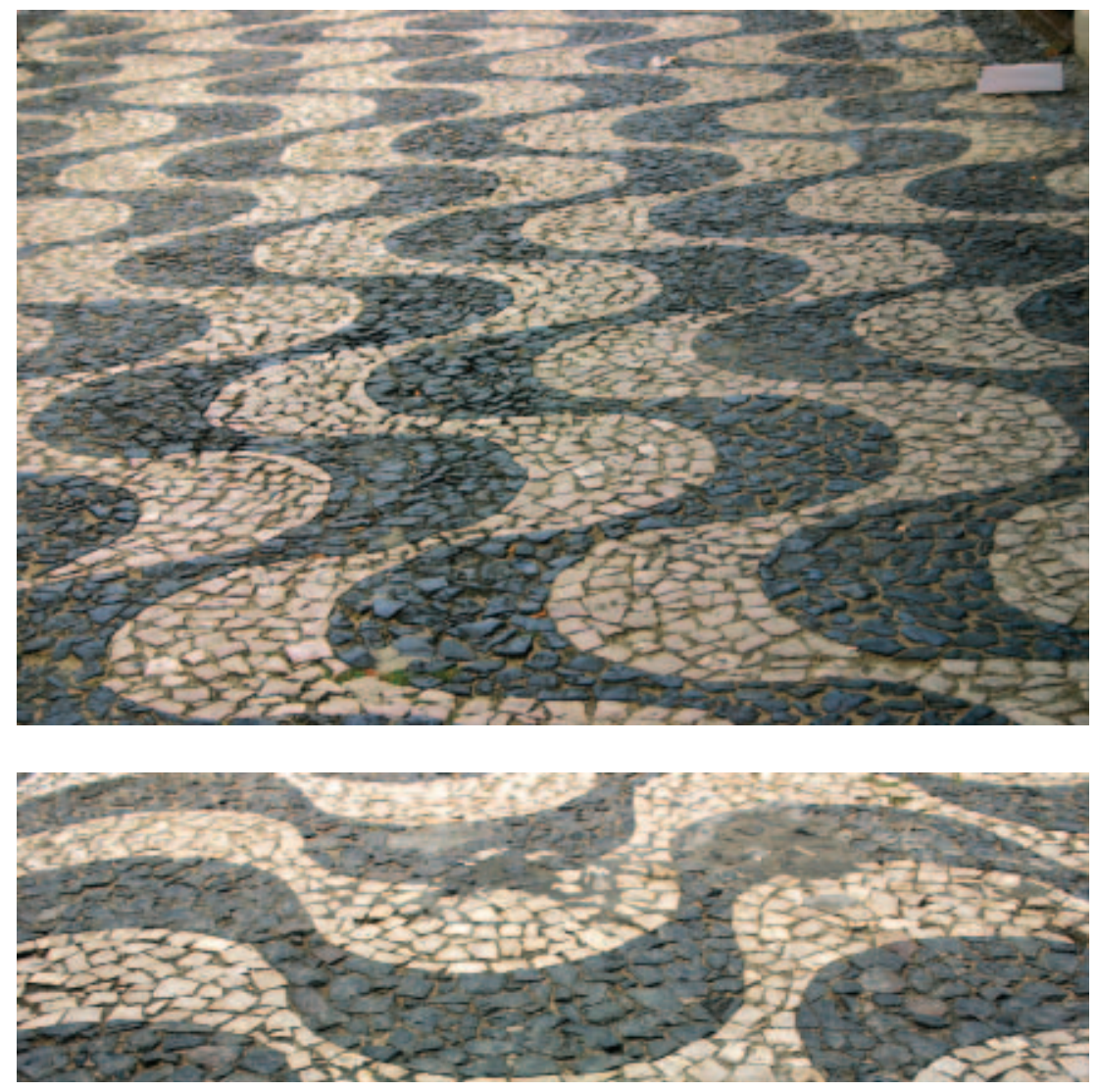


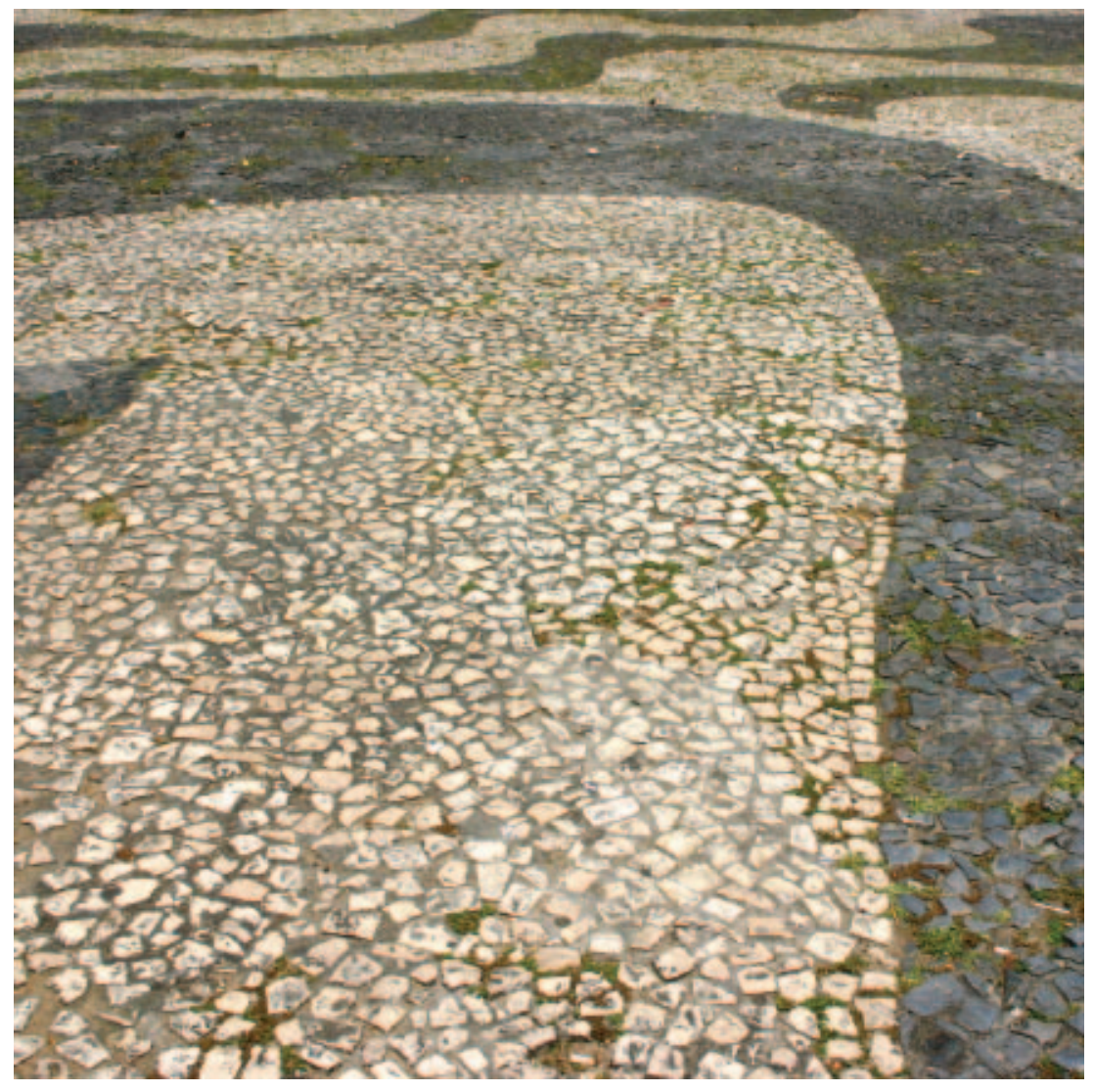




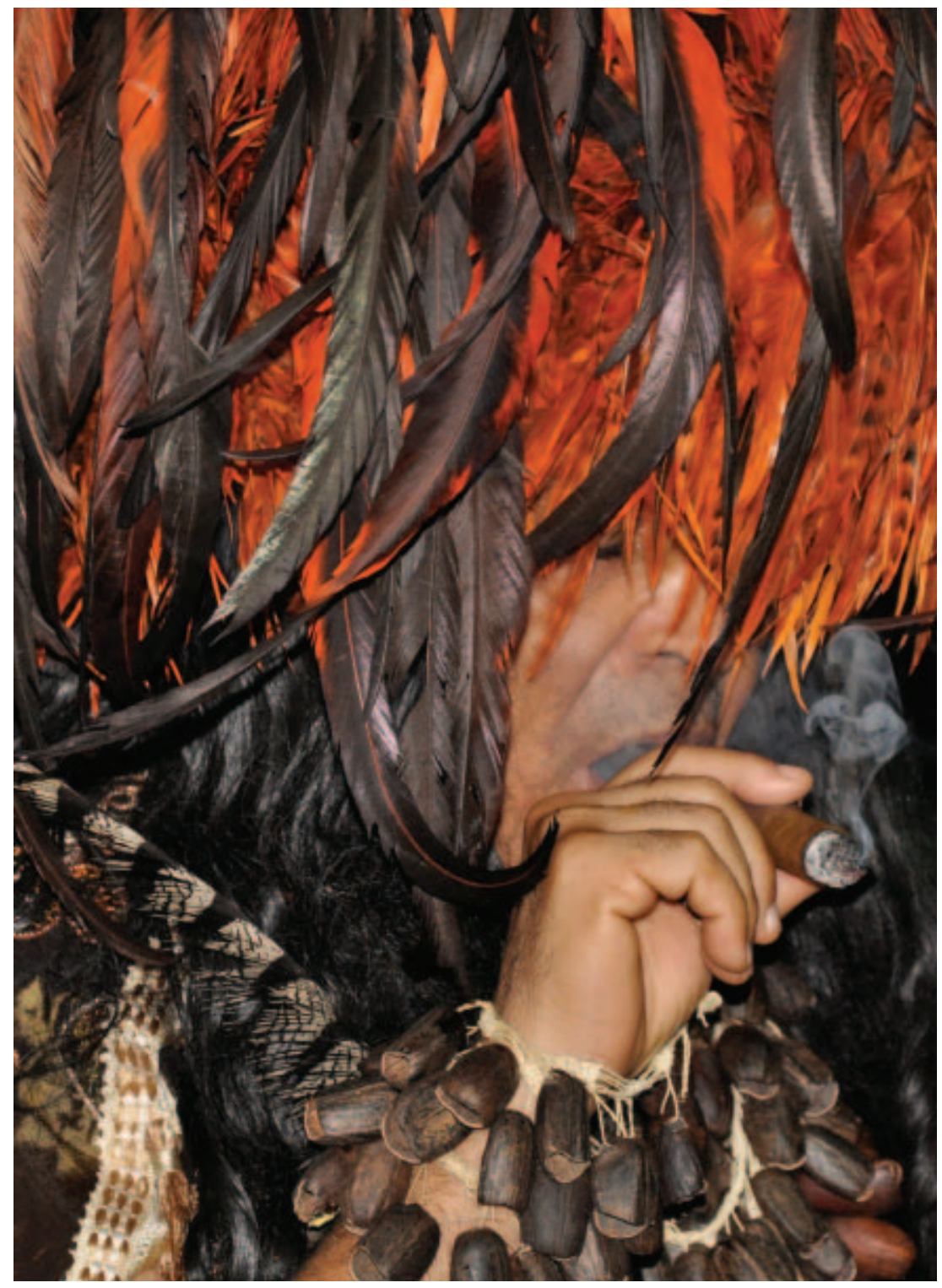

Ecstatic religion: spirit mediums in a state of possession.

Photographs by Kostana Banovic 

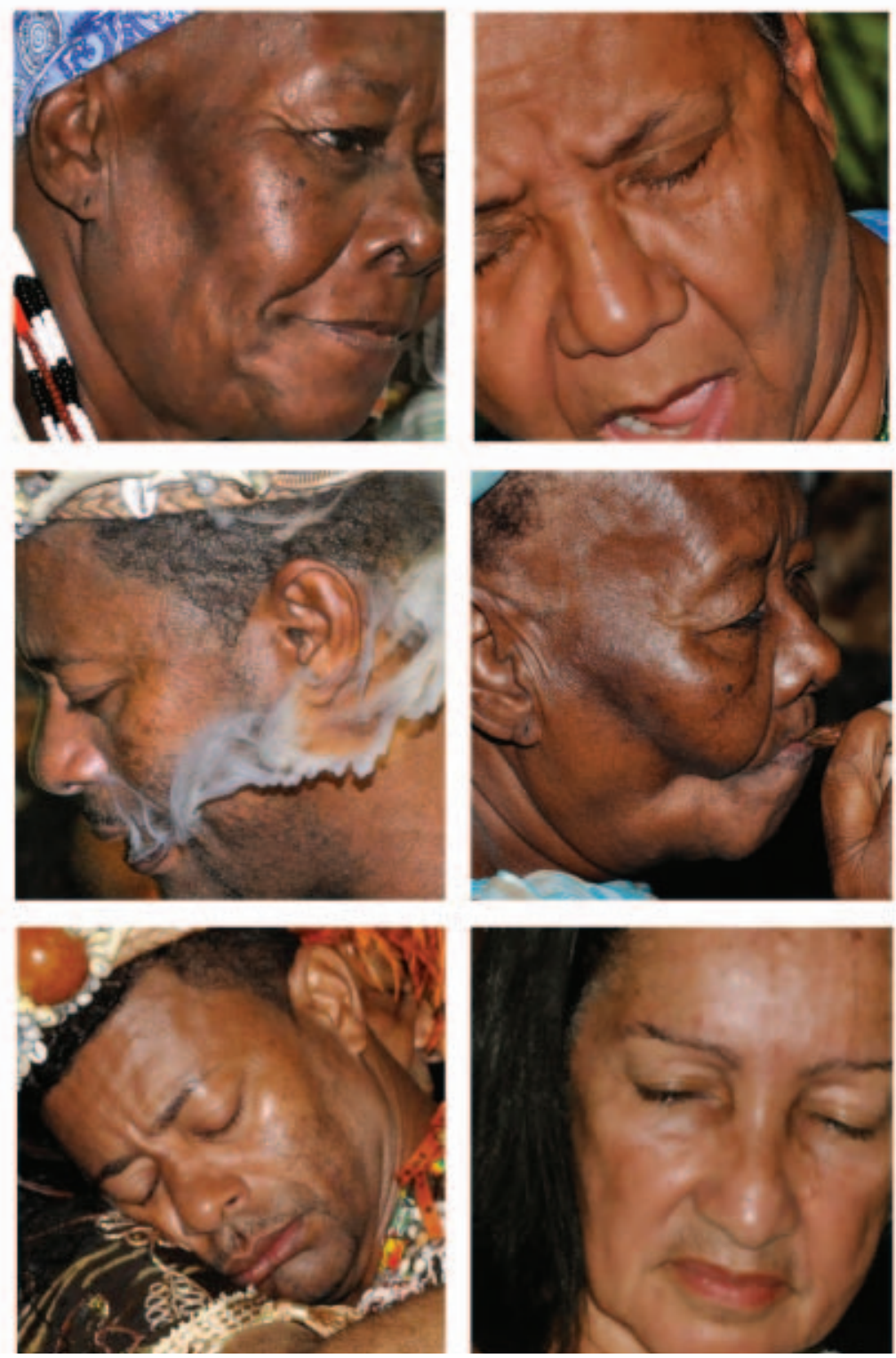

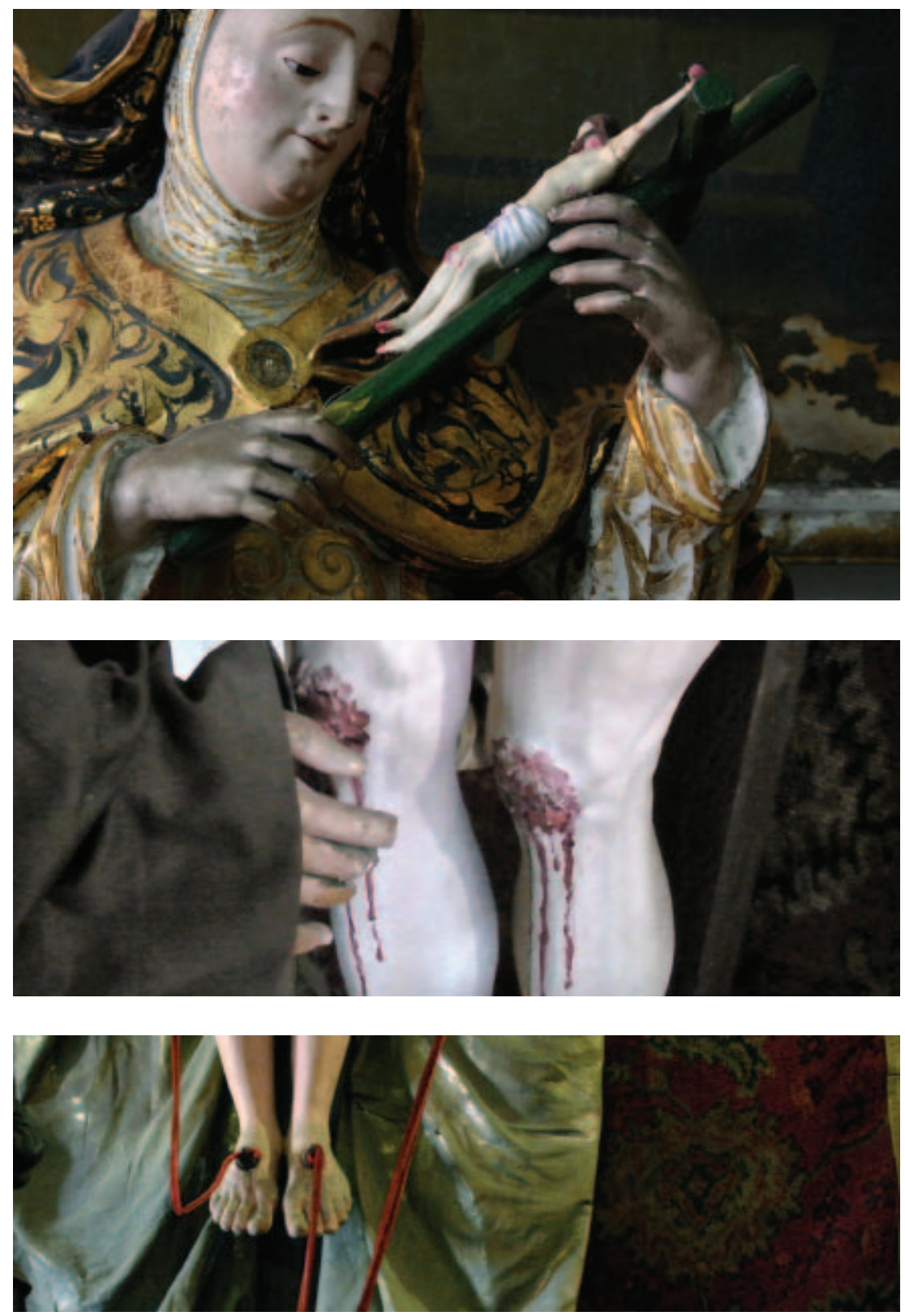


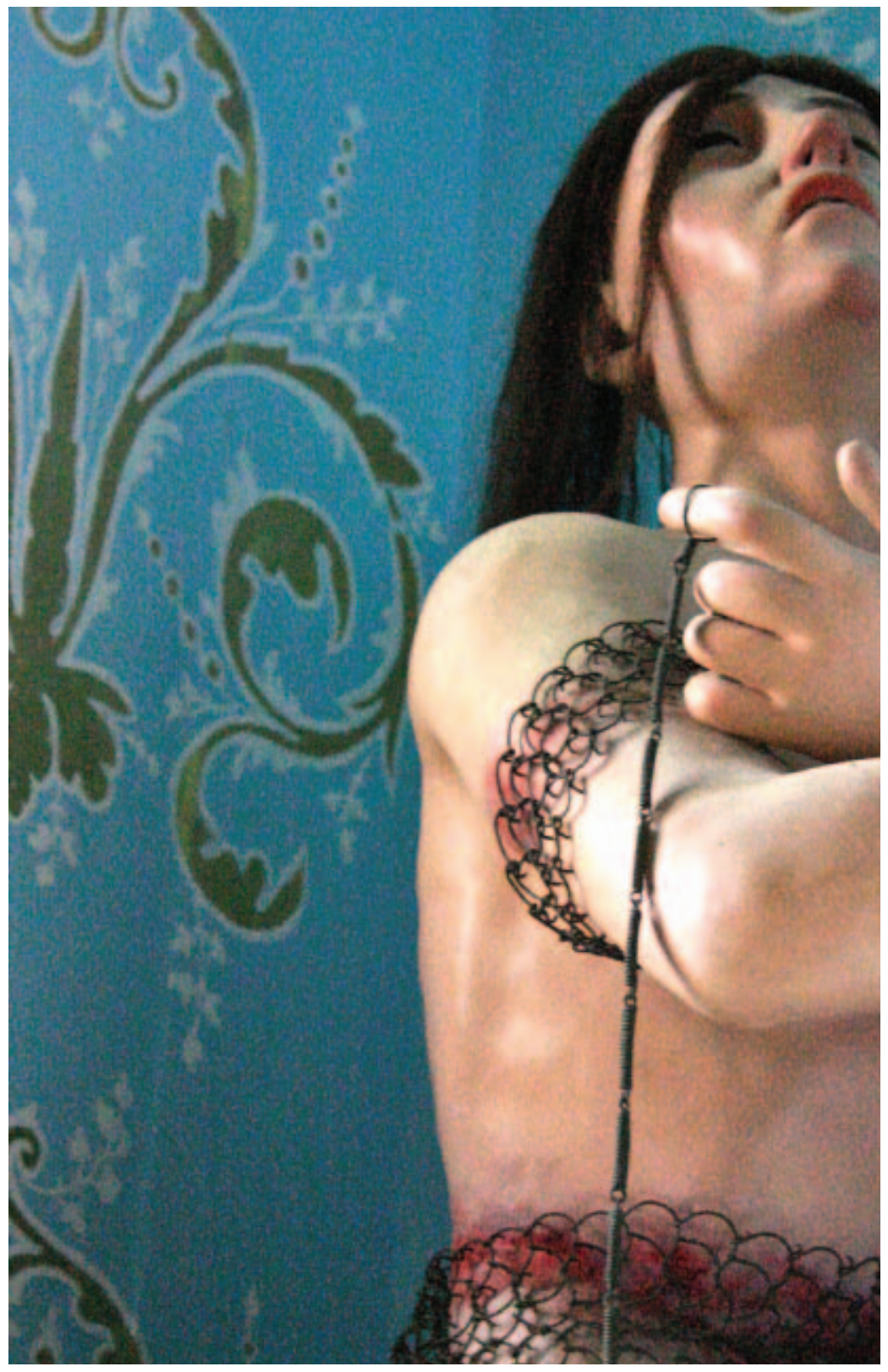




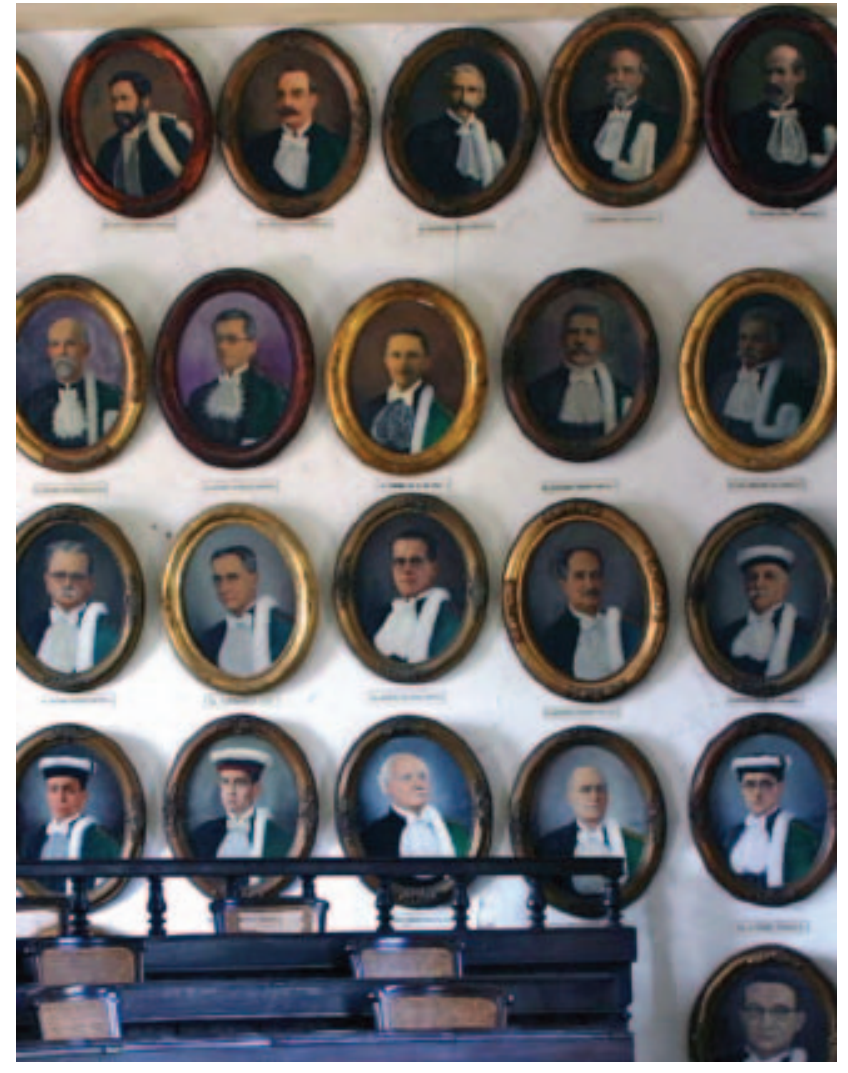

Professors of the Faculdade de Medicina.

The third portrait in the upper row is Dr. Nina 


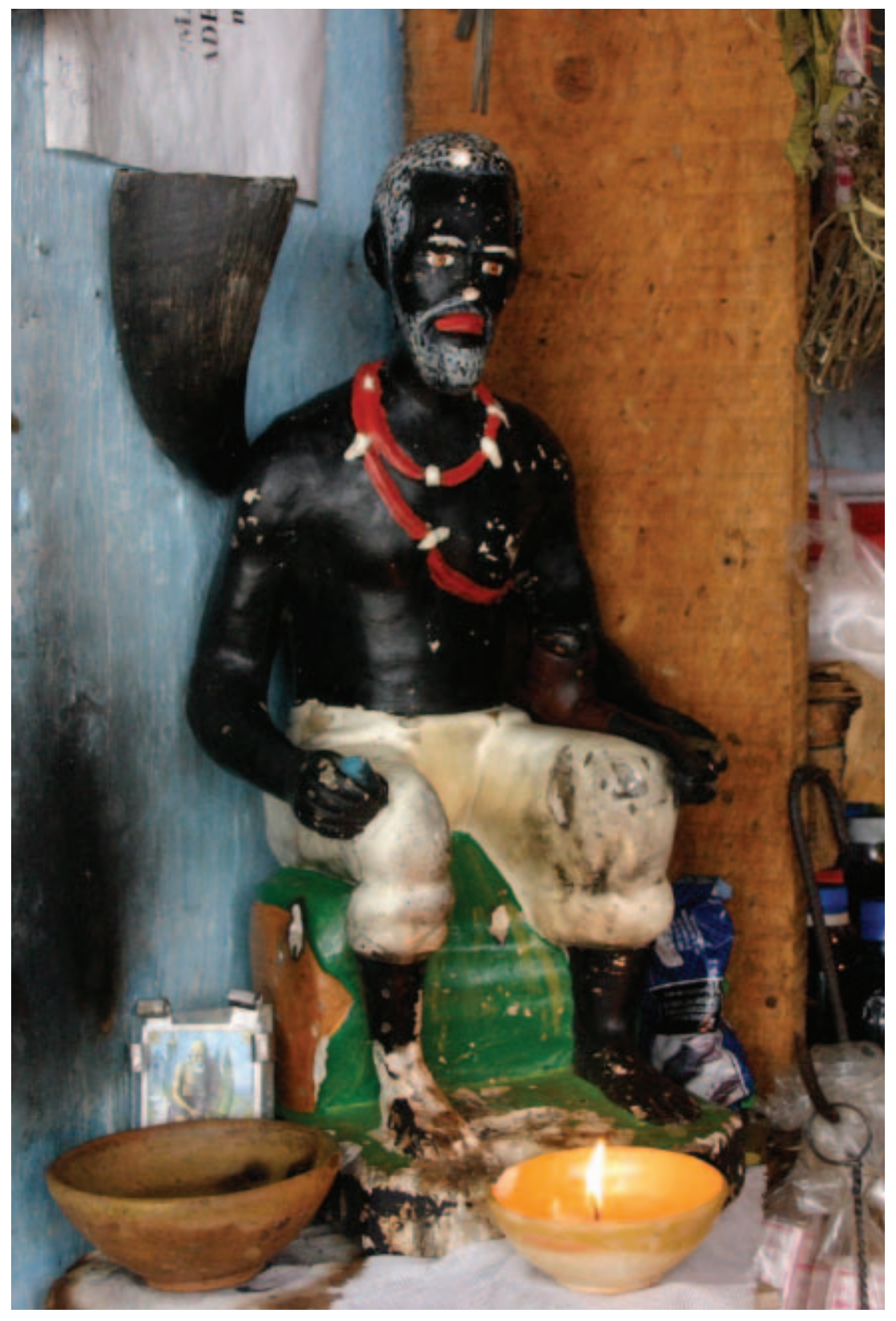

Preto Velho. The old slave spirit 

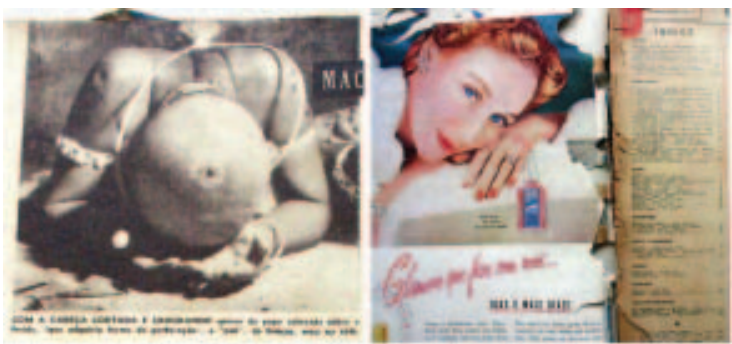

IS IOIIIS DOS NRLSES SIIIHIIIIRIOS
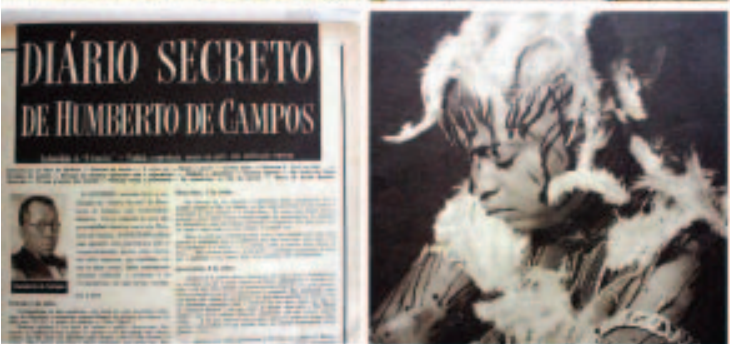

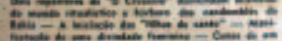

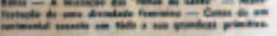
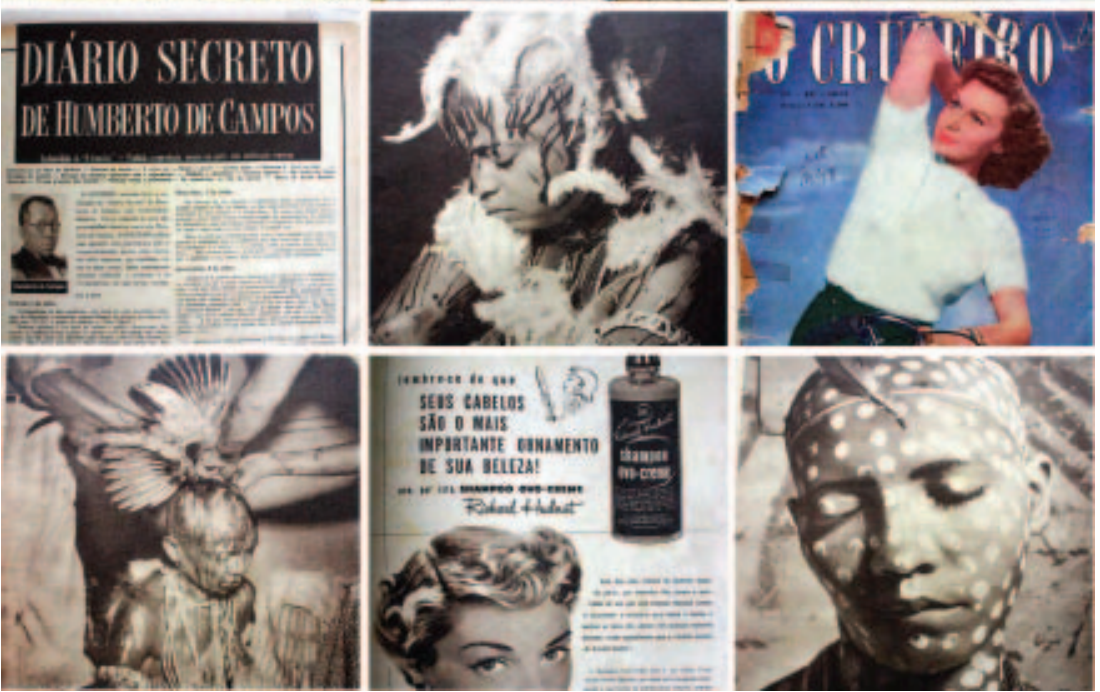

Candomble and other issues in the family weekly O Cruzeiro, 1951. From top left to bottom right: 1. 'With her head cut and bleeding, notwithstanding the poultice pasted over the wound (which is like a perforation), the "yaô", face down, prays in her cell'; 2. 'Glamour that stays with you', advertizing nail polish; 3. 'The fiancées of the bloodthirsty gods. Two reporters from "O Cruzeiro" show the mysteries of the ritualistic and barbarous world of the Candomblés in Bahia - the initiation of the 'daughters-of-the-saint' - the manifestation of a female divinity 


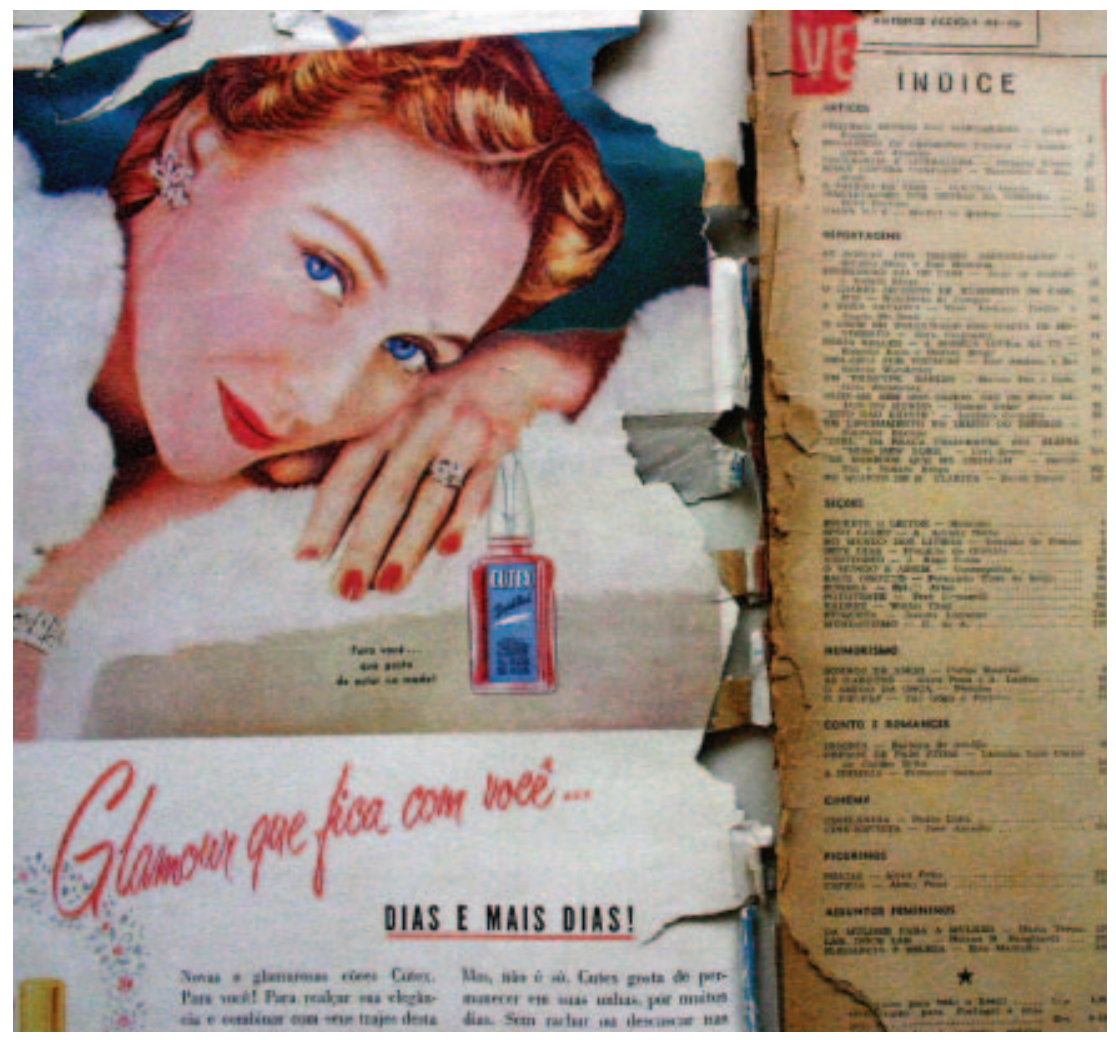

- scenes from a secret ceremony in all of its primitive grandeur'; 4. The 'secret diary' of the writer Humberto de Campo, announced as an exclusive, posthumous publication; 5. Photograph of an initiate, covered in blood and chicken feathers; 6. Front cover of o Cruzeiro with typical blue-eyed lady; 6. Blood bath; 7. 'Your hair is the most important ornament of your beauty', advertizing egg-shampoo; 8. Shaven and painted initiate. 

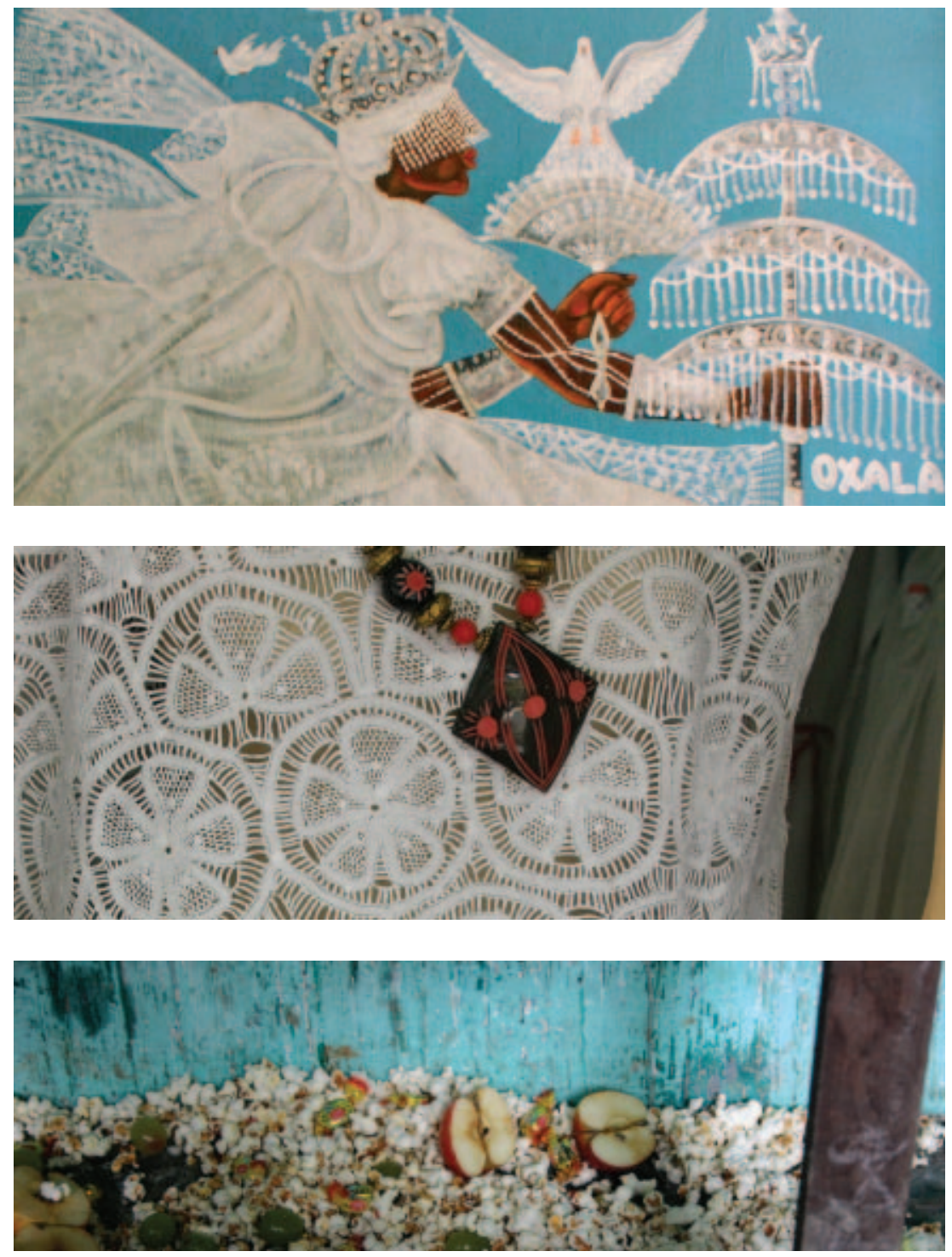


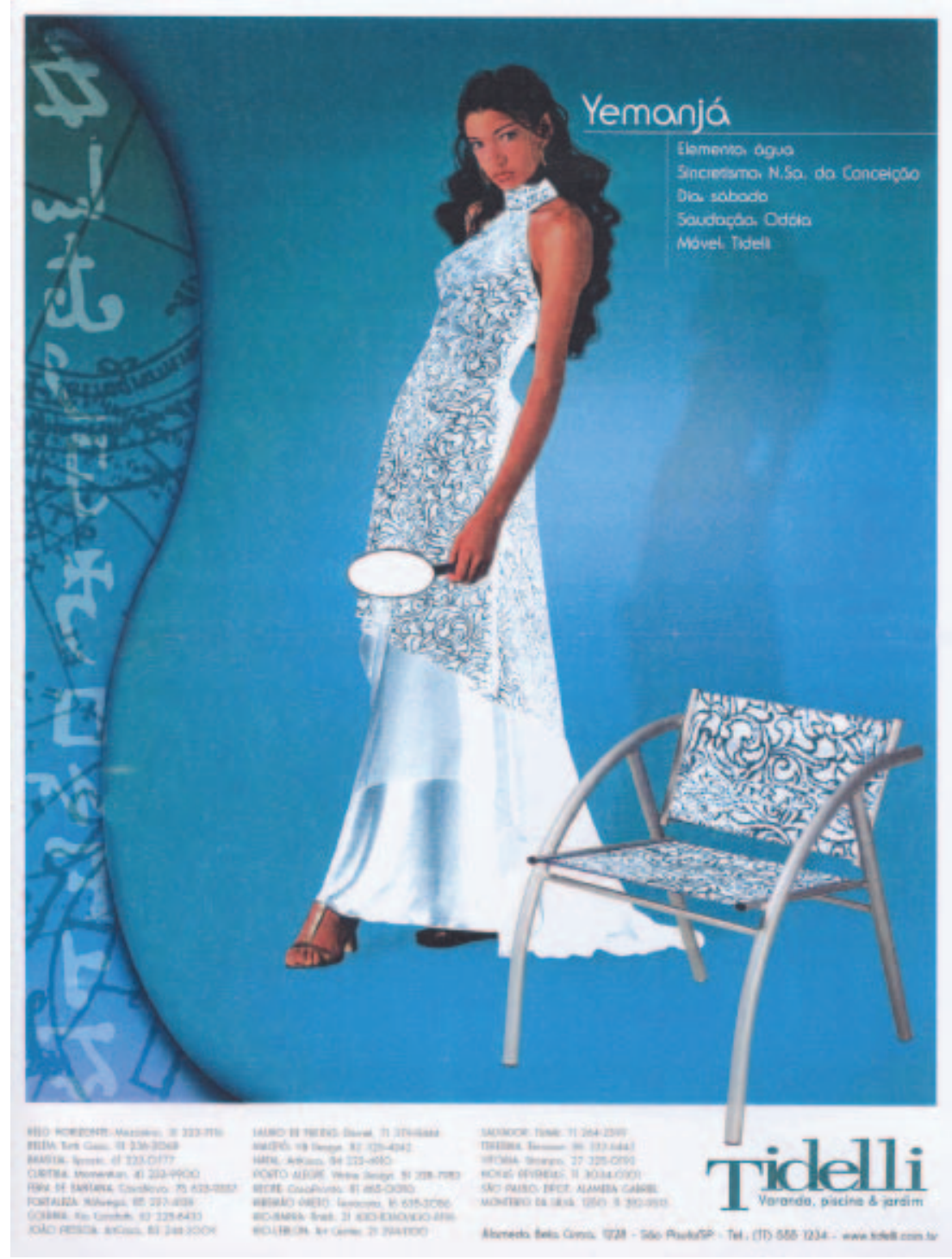




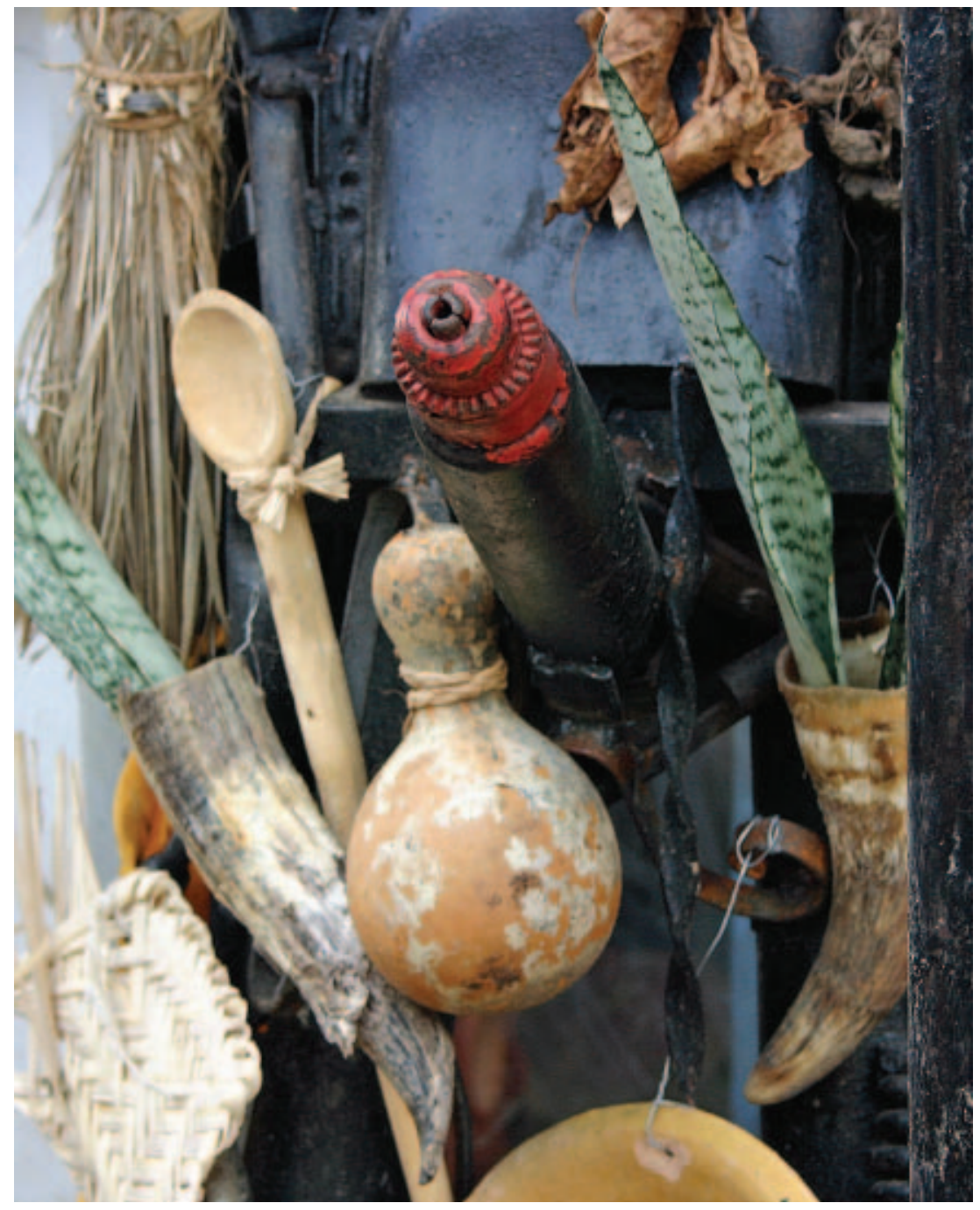

Candomblé as risk, danger and seduction 

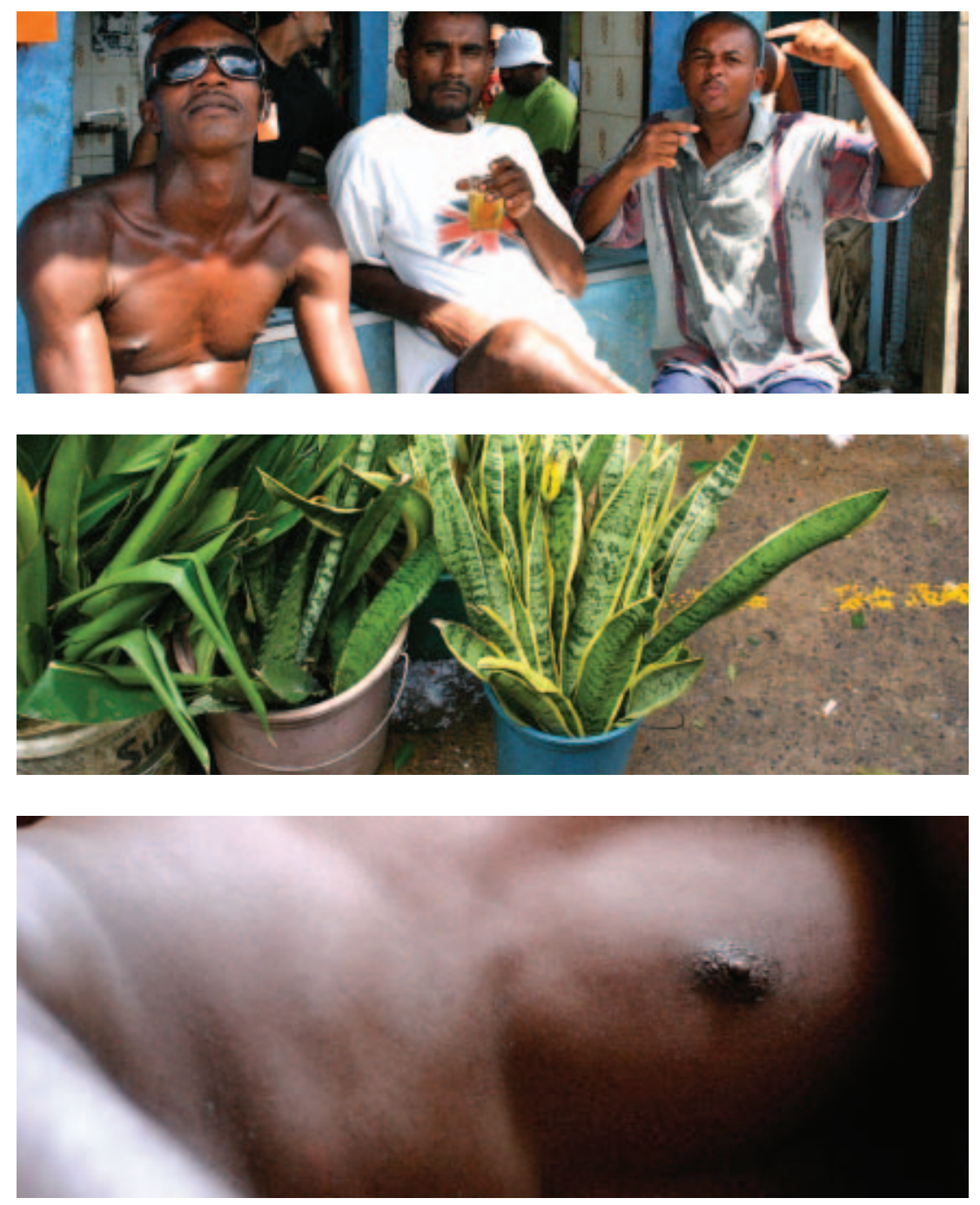

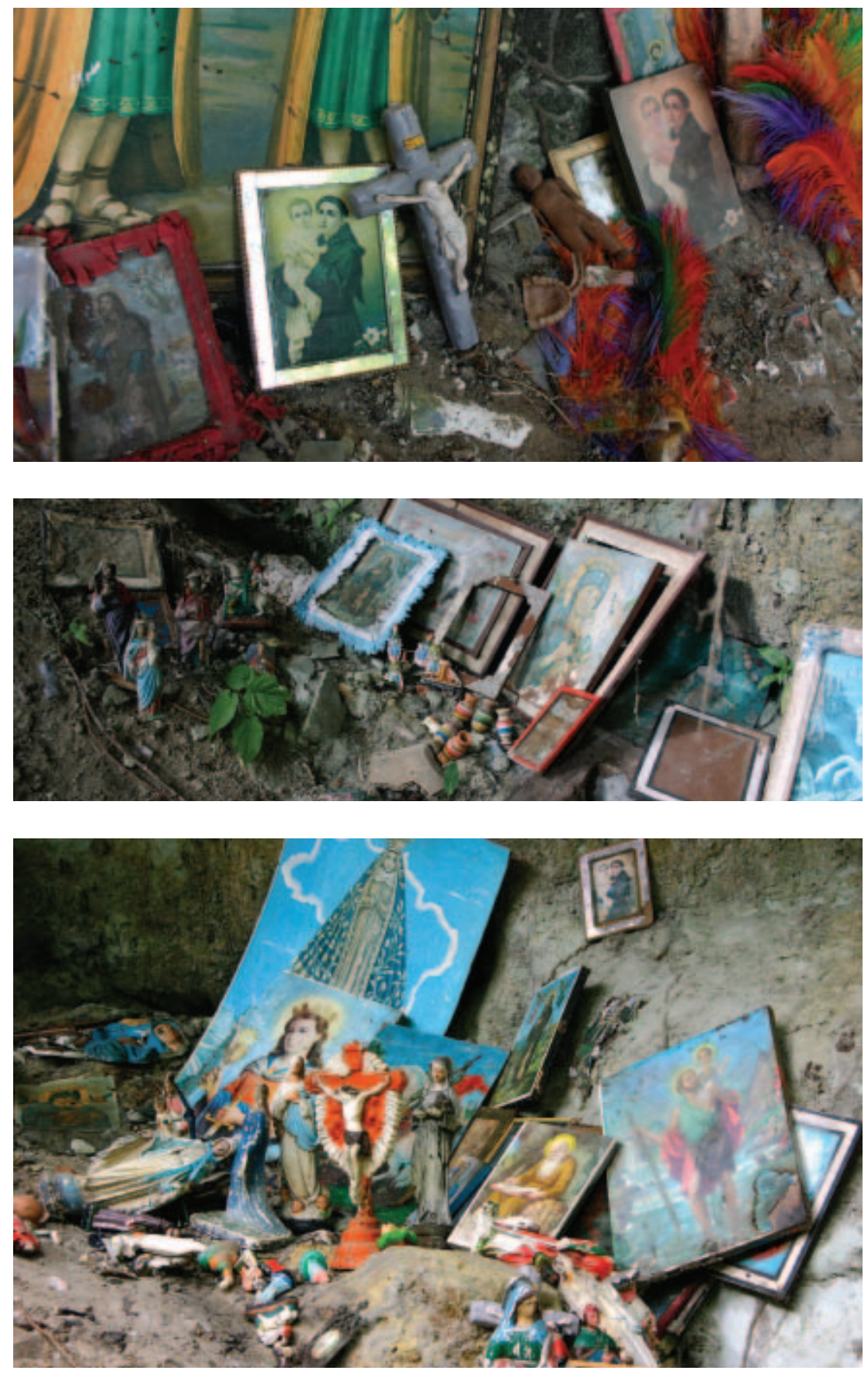

Milagre de São Roque 


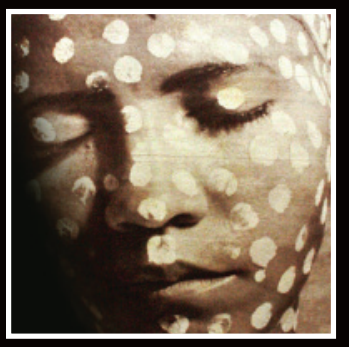

realITY DOES NOT COMPLY WITH OUI NarraTIONS OF IT. And that is most certainly

the case with the narrations produced in academia. An anthropologist in Bahia, Brazil, fears to become possessed by the spirits he had come to study; falls madly in love with an 'informant'; finds himself baffled by the sayings of a clairvoyant; and has to come to grips with the murder of one of his best friends. Unsettling events that do not belong to the orderly world of scientific research, yet leave their imprint on the way the anthropologist comes to understand the world.

Reflecting on his long research experience with the spirit possession cult Candomblé, the author shows, in a probing manner, how definitions of reality always require the exclusion of certain perceptions, experiences and insights. And yet, this 'rest-of-what-is' turns out to be an inexhaustible source of amazement, seduction and renewal.

Mattijs van de Port is an anthropologist and works at the University of Amsterdam and the VU University Amsterdam.

Thriving in the gap between the sensuous fullness of life and the impossibility of its cultural representation, Ecstatic Encounters opens mind-blowing vistas for 'writing culture' in anthropology today.

Birgit Meyer, Professor of Cultural Anthropology, VU University Amsterdam

The book's charm is that it shows how an anthropologist can bring Lacanian notions of the Real to life.

Peter Geschiere, author of The Modernity of Witchcraft, Politics and the Occult in Postcolonial Africa

Showing great sensibility, the author portrays a life-world in which the forces of the occult - as well as those of occultation - are omnipresent.

Patricia Birman, Professor of Anthropology,

Universidade do Estado do Rio de Janeiro

ISBN 9789089642981

AMSTERDAM UNIVERSITY PRESS www.aup.nl

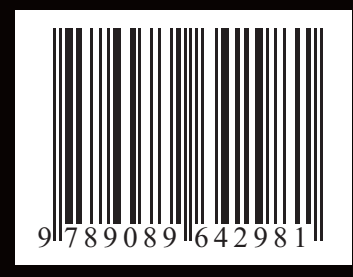

